\title{
p-Multigrid explícito para um método de volumes finitos de alta-ordem não estruturado
}

\author{
Juan Eduardo Casavilca Silva
}

TESE APRESENTADA

$\mathrm{AO}$

Instituto De Matemática e Estatística

DA

Universidade DE SÃO PAUlo

PARA

OBTENÇÃO DO TÍTULO

$\mathrm{DE}$

DOUTOR EM CIÊNCIAS

Programa: Matemática Aplicada

Orientador: Prof. Dr. Luis Carlos de Castro Santos

Durante o desenvolvimento deste trabalho o autor recebeu auxílio financeiro da CAPES

São Paulo, Junho de 2016 


\section{p-Multigrid explícito \\ para um método de volumes finitos \\ de alta-ordem não estruturado}

Esta versão da tese contém as correções e alterações sugeridas pela Comissão Julgadora durante a defesa da versão original do trabalho, realizada em 02/06/2016. Uma cópia da versão original está disponível no

Instituto de Matemática e Estatística da Universidade de São Paulo.

Comissão Julgadora:

- Prof. Dr. Luis Carlos de Castro Santos (orientador) - IME-USP

- Prof. Dr. Nelson Mugayar Kuhl - IME-USP

- Prof. Dr. Ernani Volpe - POLI-USP

- Prof. Dr. Antonio Castelo Filho - ICMC-USP

- Prof ${ }^{\mathrm{a}}$. Dr ${ }^{\mathrm{a}}$. Claudia Regina de Andrade - ITA 


\section{Agradecimentos}

A Deus pela graça concedida, em virtude da Sua misericórdia.

A meus pais, Hilda e Eduardo, por serem exemplo de amoroso e indescriptível sacrifício. A meus antepassados, em especial a dona Luisa (in memoriam), a dom José (in memoriam), a dona Blanca e a dom Daniel pela vida de meus pais, pelas inesquecíveis palavras e pelas suas constantes orações. A toda minha família peruana: irmãos, primos, tios e amigos da infância por manter-se comunicados e atentos comigo, apesar da distância. Um agradecimento mais do que especial a todos e cada um dos amigos que conheci no Brasil (brasileiros e de outras nacionalidades); eles me acolheram nas suas vidas como a um irmão. Muito obrigado a esta minha nova e numerosa família.

Ao meu orientador, Prof. Dr. Luis Santos, engenheiro entendidíssimo da mecânica dos fluidos computacional, pela continua supervisão, gentileza e compreensão em todos os momentos da elaboração desta tese. À Dra. Olga Saito e ao Dr. Alessandro Santana, ex-orientandos do Dr. Santos, por compartilhar comigo o código desenvolvido por eles. Ao Prof. Dr. Alexandre Roma, Chefe do Laboratório de Matemática Aplicada do IME-USP, por permitir-me utilizar as máquinas do laboratório. Aos membros da Comissão Julgadora, por aceitar e revisar o presente trabalho.

À Faculdade Pitágoras de Londrina, especialmente à Prof. Ma. Ísis Geraldini e ao Prof. Me. Daniel Geraldini, prestativos e corajosos amigos, por dar-me a oportunidade de trabalhar como professor para financiar a última etapa do doutorado, e também por auxiliar-me na instalação na cidade de Londrina (PR).

Finalmente, à Coordenação de Aperfeiçoamento de Pessoal de Nível Superior (CAPES) pela bolsa concedida na primeira etapa desta pesquisa. 


\section{Resumo}

CASAVILCA SILVA, J. E. p-Multigrid explícito para um método de volumes finitos de alta-ordem não estruturado. 2016. 151 f. Tese (Doutorado) - Instituto de Matemática e Estatística, Universidade de São Paulo, São Paulo, 2016.

Desde o importante trabalho de Barth e Frederickson (1990), um certo número de pesquisadores têm estudado o método de Volumes Finitos de alta-ordem k-exato, por exemplo o grupo do Prof. Ollivier-Gooch: Ollivier-Gooch e van Altena (2002), Nejat (2007), Michalak (2009), etc. Outras discretizações espaciais de alta-ordem bastante populares são o método Galerkin Descontínuo e o método de Diferença Espectral; processos iterativos que involucram estes esquemas tem sido acelerados, nos últimos anos, por métodos p-multigrid. Porém, esta aceleração não tem sido aplicada no contexto do método de Volumes Finitos de alta-odem, pelo menos para conhecimento do autor desta tese. Por isso, o objetivo desta pesquisa é adaptar o p-multigrid desenvolvido por Liang et al. (2009b) no contexto da Diferença Espectral, para o ambiente dos Volumes Finitos estudado pelo Prof. Ollivier-Gooch. A pesquisa começa implementando o solver VF-RK, de Volumes Finitos com avanço Runge-Kutta, para resolver as equações de advecção-difusão e de Euler aplicados a problemas estacionários, por exemplo, o escoamento transônico ao redor do NACA 0012. Depois, estuda-se o método p-multigrid no contexto da Diferença Espectral; o p-multigrid acelera o processo iterativo comutando níveis polinomiais de alta e de baixa-ordem. Após esse estudo, a adaptação ao âmbito dos Volumes Finitos é realizada resultando num p-multigrid relativamente mais simples porque, em contraposição com o p-multigrid para Diferença Espectral, não precisa de operadores de restrição e prolongação para a comunicação entre diferentes níveis polinomiais. A pesquisa conclui com uma comparação com o método de Volumes Finitos de 4a ordem sem p-multigrid (solver VF-RK). Nesse sentido, implementa-se o solver pMG, baseado no p-multigrid proposto, para resolver os problemas estacionários considerados na primeira parte do trabalho; o smoother do p-multigrid é o esquema Runge-Kutta do código VF-RK, e cada problema estacionário é resolvido utilizando diferentes Vciclos procurando sempre soluções de $4 \mathrm{a}$ ordem. Os resultados indicam que o método p-multigrid proposto é mais eficiente que o método de Volumes Finitos de 4a ordem sem p-multigrid, isto é, os dois métodos oferecem a mesma precisão mas o primeiro pode levar menos de $50 \%$ do tempo de CPU do segundo.

Palavras-chave: p-multigrid, volumes finitos, alta-ordem, advecção-difusão, Euler. 


\section{Abstract}

\section{CASAVILCA SILVA, J. E. Explicit p-multigrid for an unstructured high-order finite vo-}

lume method. 2016. 151 f. Tese (Doutorado) - Instituto de Matemática e Estatística, Universidade de São Paulo, São Paulo, 2016.

Since Barth and Frederickson's important work (Barth e Frederickson, 1990), a number of researchers have studied high-order k-exact Finite Volume method, for example Prof. Ollivier-Gooch's group: Ollivier-Gooch e van Altena (2002), Nejat (2007), Michalak (2009), etc. Other quite popular high-order spatial discretizations are the Discontinuous Galerkin methods and the Spectral Difference methods; the iterative processes involving these schemes have been accelerated in recent years by p-multigrid methods. However, this acceleration has not been applied in the context of the high-order Finite Volume method, at least for the knowledge of the author of this thesis. Therefore, the objective of this research is to adapt the p-multigrid developed by Liang et al. (2009b) in the context of Spectral Difference methods, to the environment of Finite Volume studied by Prof. Ollivier-Gooch. This research begins by implementing the solver VF-RK, Finite Volume solver with Runge-Kutta advance, to compute the advection-diffusion equation and Euler equations applied to steady state problems, for example, the transonic flow around NACA 0012. Then, it is studied the p-multigrid method in the context of Spectral Difference schemes; p-multigrid accelerate the iterative process by switching polynomial levels of high- and low-order. After this study, the adaptation to the context of the Finite Volume scheme is performed resulting in a relatively simple p-multigrid because, in contrast to the p-multigrid for Spectral Difference schemes, it doesn't need restriction and prolongation operators for communication between different polynomial levels. The research concludes with a comparison with 4th order Finite Volume method without p-multigrid (solver VFRK). Accordingly, the solver pMG, based on the proposed p-multigrid, is implemented to resolve the steady state problems considered in the first part of the work; the p-multigrid smoother is the Runge-Kutta scheme from VF-RK code, and each steady state problem is solved using different Vcycles, looking for 4th order solutions ever. The results indicate that the proposed p-multigrid method is more efficient than the 4th order Finite Volume method without p-multigrid: the two methods give the same accuracy but the first one can take less than $50 \%$ of second one's CPU time.

Keywords: p-multigrid, finite volume, high-order, advection-diffusion, Euler. 


\section{Sumário}

$\begin{array}{ll}\text { Lista de Abreviaturas } & \text { ix }\end{array}$

Lista de Símbolos $\quad$ xi

Lista de Figuras $\quad$ xiii

Lista de Tabelas $\quad$ xvii

1 Introdução $\quad 1$

1.1 Necessidade de Alta-Ordem . . . . . . . . . . . . . . . . . . . . . . 1

1.2 Breve Revisão sobre Alta-Ordem . . . . . . . . . . . . . . . . . . . . 2

1.3 Dificuldades Práticas . . . . . . . . . . . . . . . . . . . . 3

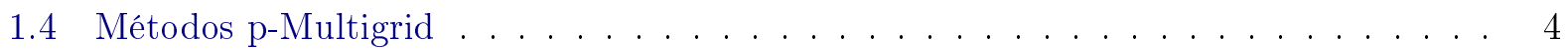

1.5 Proposta do Trabalho . . . . . . . . . . . . . . . . . . . 5

2 Método de Volumes Finitos para a Equação de Advecção-Difusão $\quad 7$

2.1 Forma Integral da Equação de Advecção-Difusão $\ldots \ldots$. . . . . . . . . . . . . 7

2.2 Método de Volumes Finitos . . . . . . . . . . . . . . . . . . 8

2.3 Reconstrução . . . . . . . . . . . . . . . . . . . . . . . 9

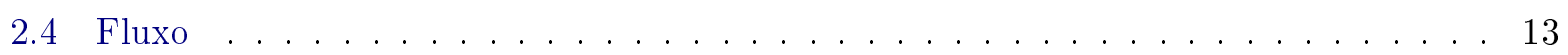

2.5 Tratamento das Fronteiras Curvas . . . . . . . . . . . . . . . . . . 14

2.6 Casos de Validação . . . . . . . . . . . . . . . . . . . . . . . 16

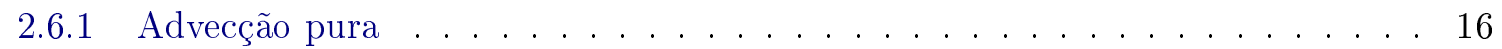

2.6.2 Adveç̧ão-difusão em um canal retangular . . . . . . . . . . . . . . . . . . . . . . 22

2.6.3 Advecção-difusão em um segmento anular . . . . . . . . . . . . . . . . . . . . 31

2.7 Conclusão . . . . . . . . . . . . . . . . . . . . . . . . . . 39

3 Método de Volumes Finitos para as Equações de Euler $\quad 41$

3.1 Forma Integral das Equações de Euler 2D . . . . . . . . . . . . . . . . . . . 41

3.2 Método de Volumes Finitos . . . . . . . . . . . . . . . . . . . . 42

3.3 Reconstrução . . . . . . . . . . . . . . . . . . . . . . . . 44

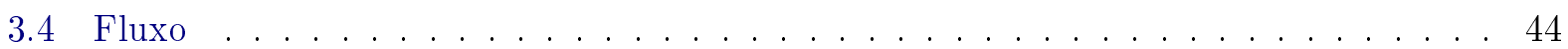

3.5 Implementação das Condições de Fronteira . . . . . . . . . . . . . . . . . . . . . . 45

3.6 Tratamento das Fronteiras Curvas . . . . . . . . . . . . . . . . . . . . 45

3.7 Limitadores de Alta-Ordem . . . . . . . . . . . . . . . . . . . . . 46

3.8 Simulações . . . . . . . . . . . . . . . . . . . . . . . 47 
3.8.1 NACA 0012 Subsônico, $M_{\infty}=0,4, \alpha=0^{\circ} \ldots \ldots \ldots \ldots \ldots$

3.8.2 NACA 0012 Subsônico, $M_{\infty}=0,5, \alpha=2^{\circ} \ldots \ldots \ldots \ldots \ldots$

3.8.3 NACA 0012 Transônico, $M_{\infty}=0,8, \alpha=1,25^{\circ} \ldots \ldots \ldots$. . . . . 69

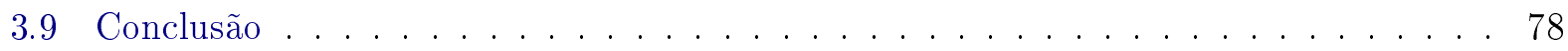

4 Método p-Multigrid para Volumes Finitos de Alta-Ordem $\quad 83$

4.1 Método de Diferença Espectral . . . . . . . . . . . . . . . . . . 83

4.2 p-Multigrid Explícito para o Método de Diferença Espectral . . . . . . . . . . . . . 85

4.3 Adaptação ao Método de Volumes Finitos . . . . . . . . . . . . . . . . . . . 88

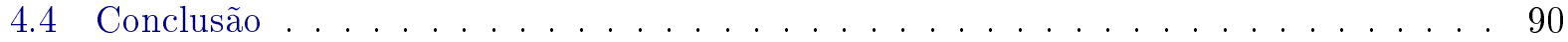

$\begin{array}{lll}5 & \text { Resultados } & \mathbf{9 1}\end{array}$

5.1 Advecção-difusão no canal retangular . . . . . . . . . . . . . . . . . . . . . 91

5.2 Advecção-difusão no segmento anular . . . . . . . . . . . . . . . . . . . 97

5.3 NACA 0012 Subsônico, $M_{\infty}=0,4, \alpha=0^{\circ} \ldots \ldots \ldots \ldots \ldots$. . . . . . . . . . . .

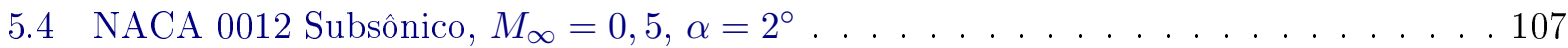

$5.5 \quad$ NACA 0012 Transônico, $M_{\infty}=0,8, \alpha=1,25^{\circ} \ldots \ldots \ldots \ldots \ldots \ldots \ldots$

6 Conclusões e Futuros Trabalhos 119

6.1 Conclusões . . . . . . . . . . . . . . . . . . . . . . . . 119

6.2 Sugestões para Pesquisas Futuras . . . . . . . . . . . . . . . . . . 119

6.3 Consideração Final . . . . . . . . . . . . . . . . . . . . . . . . . . 121

A $\quad$ Tempo de CPU (\%) 123

A.1 Definições relacionadas ao Tempo de CPU . . . . . . . . . . . . . . . . . . . . 123

A.2 Objetivo do Apêndice . . . . . . . . . . . . . . . . . . . . . 123

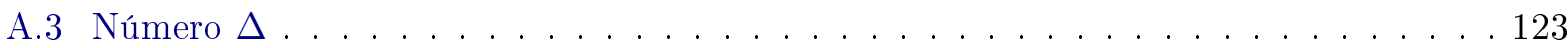

A.4 Recurso computacional utilizado . . . . . . . . . . . . . . . . . 125

$\begin{array}{ll}\text { Referências Bibliográficas } & 127\end{array}$ 


\section{Lista de Abreviaturas}

CFD Dinâmica de Fluidos Computacional (Computational Fluid Dynamics)

CFL Número de Courant-Friedrichs-Lewy

CPU Unidade Central de Processamento (Central Processing Unit)

DE Método de Diferença Espectral

EDP Equação Diferencial Parcial

EF Método de Elementos Finitos

GD Método Galerkin Descontínuo

RK Método Runge-Kutta

VC Volume(s) de controle

VF Método de Volumes Finitos 


\section{Lista de Símbolos}

\section{Romanos}

a velocidade do som

c comprimento da corda do aerofólio

$D \quad$ domínio espacial (subconjunto de $\mathbb{R}^{2}$ ) das equações de movimento do fluido

$F_{\text {Num } i, k} \quad$ fluxo numérico no ponto $r_{i, k}$

$\widehat{i_{n} i_{n+1}}$ face de fronteira limitada pelos vértices $i_{n}$ e $i_{n+1}$

$\hat{n}_{i, k} \quad$ normal unitária exterior a $\Omega_{i}$ em $r_{i, k}$

$P \quad$ pressão estática

$R_{i}^{p} \quad$ resíduo no volume de controle $\Omega_{i}$, calculado pelo método VF de ordem $p$

$r_{i, k} \quad k$-ésimo ponto de Gauss associado ao volume de controle $\Omega_{i}$

$T$ temperatura estática

$V \quad$ vetor velocidade, com componentes $u$ e $v$

$w_{i, j} \quad$ peso geométrico associado ao volume de controle $\Omega_{i, j}$

$w r_{i, k} \quad$ peso geométrico associado ao ponto $r_{i, k}$

$\left(x_{i}, y_{i}\right) \quad$ coordenadas do vértice $i$

$\overline{x^{m} y^{n}}{ }_{i} \quad$ momentos do volume de controle $\Omega_{i}$

${\widehat{x^{m} y^{n}}}_{i j} \quad$ momentos do volume de controle $\Omega_{i, j}$ em relação ao vértice $i$

\section{Gregos}

$\alpha \quad$ coeficiente de difusão

$\alpha_{k} \quad$ coeficiente do $k$-ésimo estágio RK

$\phi(x, y, t)$ solução exata da equação de advecção-difusão

$\phi_{i}(x, y)$ polinômio de reconstrução para o volume de controle $\Omega_{i}$

$\phi_{\mathrm{Num} i, k} \quad$ solução numérica no ponto $r_{i, k}$

$\bar{\phi}_{i}^{\text {exata }}$ solução média exata no volume de controle $\Omega_{i}$

$\bar{\phi}_{i} \quad$ solução média aproximada no volume de controle $\Omega_{i}$

$\bar{\phi}_{i, j} \quad$ solução média aproximada no volume de controle $\Omega_{i, j}$

$\widehat{\Phi}_{i} \quad$ limitadores de alta-ordem para o volume de controle $\Omega_{i}$

$\Omega_{i} \quad$ volume de controle (subconjunto de $\mathbb{R}^{2}$ ) associado ao vértice $i$

$\Omega_{i, j} \quad j$-ésima célula do estêncil do volume de controle $\Omega_{i}$ 


\section{Outros}

$\nabla \phi_{\mathrm{Num}_{i, k}} \quad$ gradiente numérico no ponto $r_{i, k}$ $\infty$ condições de corrente livre 


\section{Lista de Figuras}

1.1 (a) Ilustração de um lado interior cortando a fronteira curva. (b) Esse corte é evitado usando um modelo de mecânica de sólidos para curvar o lado interior (Persson e Peraire , 2009). Fonte: Wang (2014) _ . . . . . . . . . . . . . . . 4

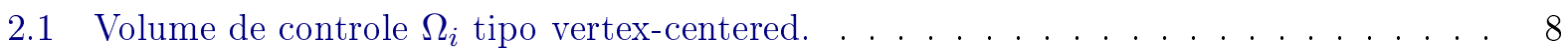

2.2 Estêncil do volume de controle $\Omega_{i}$. Observe-se que, nesta figura, o estêncil para $p=3$ também serve para $p=4 \ldots \ldots \ldots \ldots \ldots \ldots$

2.3 Localização dos pontos de integração de Gauss e suas normais associadas na interface de células, para o método VF de alta-ordem. . . . . . . . . . . . . . . . . . . . . 14

2.4 Tratamento das fronteiras curvas. . . . . . . . . . . . . . . . . . . . 14

2.5 Localização dos pontos de Gauss $r_{i, k}$ para o cálculo da integral de fluxo para $\Omega_{i}$. . 15

2.6 Campo de velocidades no caso de advecção pura. Fonte: Saito (2008). . . . . . . . . 17

2.7 Função $\phi$ sendo transportada pelo escoamento com uma velocidade angular de $2 \pi$

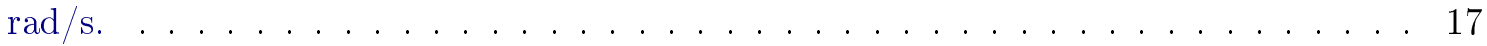

2.8 Malhas computacionais para o caso advecção pura . . . . . . . . . . . . . 18

2.9 Erro na solução numérica para $t=1 \mathrm{~s}$, no caso advecção pura. . . . . . . . . . . 20

2.10 Erro máximo versus Número de VC e Tempo de CPU, no caso advecção pura. . . . . 21

2.11 Combinações Ordem-Malha que resultam num erro máximo de $5,5 \times 10^{-3}$, no caso advecção pura. . . . . . . . . . . . . . . . . . . . . . 22

2.12 Solução estacionária da equação de advecção-difusão no canal retangular. . . . . . . 23

2.13 Malhas computacionais para o caso advecção-difusão no canal retangular. . . . . . . 23

2.14 Erro na solução numérica, no caso advecção-difusão no canal retangular. . . . . . . . 26

2.15 Comparação deste trabalho com o artigo de Ollivier-Gooch e van Altena (2002), no caso advecção-difusão no canal retangular. . . . . . . . . . . . . . . . . . 27

2.16 Erro máximo versus Número de VC e Tempo de CPU, no caso advecção-difusão no canal retangular. As combinações 2a Ordem-Malha 1 e 2a Ordem-Malha 2 levam um tempo de CPU menor a 1s e não são mostrados em $(b) . \quad \ldots \ldots$. . . . . . . . . . . 28

2.17 Combinações Ordem-Malha que resultam num erro máximo de $2 \times 10^{-3}$, no caso advecção-difusão no canal retangular. . . . . . . . . . . . . . . . . . . . . 29

2.18 Combinações Ordem-Malha que resultam num erro máximo de $5 \times 10^{-4}$, no caso advecção-difusão no canal retangular. . . . . . . . . . . . . . . . . . . . . 30

2.19 Solução estacionária da equação de advecção-difusão no segmento anular. . . . . . . 32

2.20 Malhas computacionais para o caso advecção-difusão no segmento anular. . . . . . . 33

2.21 Erro na solução numérica, no caso advecção-difusão no segmento anular. . . . . . . . 35 
2.22 Comparação deste trabalho com o artigo de Ollivier-Gooch e van Altena (2002), no caso advecção-difusão no segmento anular. . . . . . . . . . . . . . . . . . . . . 36

2.23 Erro máximo versus Número de VC e Tempo de CPU, no caso advecção-difusão no segmento anular. As combinações: 2a Ordem-Malha 1, 2a Ordem-Malha 2, 3a Ordem-Malha 1 e 4a Ordem-Malha 1 levam um tempo de CPU menor a 1s e não são mostrados em (b).

2.24 Combinações Ordem-Malha que resultam num erro máximo de $2 \times 10^{-3}$, no caso advecção-difusão no segmento anular. . . . . . . . . . . . . . . . . . . . .

2.25 Combinações Ordem-Malha que resultam num erro máximo de $7 \times 10^{-4}$, no caso advecção-difusão no segmento anular. . . . . . . . . . . . . . . . . . .

3.1 Localização dos pontos de integração de Gauss e suas normais associadas na interface de células, para o método VF de alta-ordem. . . . . . . . . . . . . . . . . . . 45

3.2 Localização dos pontos de Gauss $r_{i, k}$ para o cálculo da integral de fluxo para $\Omega_{i}$. . . 46

3.3 Domínio físico para o caso subsônico e $\alpha=0^{\circ}$. . . . . . . . . . . . . . . . . . . . . . 48

3.4 Malhas computacionais para o caso subsônico e $\alpha=0^{\circ}$. . . . . . . . . . . . . . 50

3.5 Influência do número CFL no Coeficiente de pressão $\left(C_{p}\right)$ ao longo do aerofólio, no caso subsônico e $\alpha=0^{\circ}$. . . . . . . . . . . . . . . . . . . . . . . . . . . 55

3.6 Coeficientes de sustentação $\left(C_{l}\right)$ e de arrasto $\left(C_{d}\right)$, no caso subsônico e $\alpha=0^{\circ}$. . . . 57

3.7 Malhas computacionais para o caso subsônico e $\alpha=2^{\circ}$. . . . . . . . . . . . . . . . 59

3.8 Influência do número CFL no Coeficiente de pressão $\left(C_{p}\right)$ ao longo do aerofólio, no caso subsônico e $\alpha=2^{\circ}$. . . . . . . . . . . . . . . . . . . . . . . . . . . . . . . . . 64

3.9 Erros nos coeficientes de sustentação $\left(C_{l}\right)$ e de arrasto $\left(C_{d}\right)$, no caso subsônico e $\alpha=2^{\circ}$. 66

3.10 Coeficiente de pressão $C_{p}$ ao longo do aerofólio, no caso subsônico e $\alpha=2^{\circ}$. . . . . 67

3.11 Pressão do escoamento $P\left(\mathrm{~N} / \mathrm{m}^{2}\right)$, no caso subsônico e $\alpha=2^{\circ}$. . . . . . . . . . . . . . 68

3.12 Malhas computacionais para o caso transônico. . . . . . . . . . . . . . . . 70

3.13 Influência do número CFL no Coeficiente de pressão $\left(C_{p}\right)$ ao longo do aerofólio, no caso transônico. . . . . . . . . . . . . . . . . . . . . . . . . . . . 74

3.14 Erros nos coeficientes de sustentação $\left(C_{l}\right)$ e de arrasto $\left(C_{d}\right)$, no caso transônico. . . . 76

3.15 Coeficiente de pressão $C_{p}$ ao longo do aerofólio, no caso transônico. . . . . . . . . . . 77

3.16 Pressão do escoamento $P\left(\mathrm{~N} / \mathrm{m}^{2}\right)$, no caso transônico. . . . . . . . . . . . . . . . . . 79

3.17 Limitador da pressão $\widehat{\Phi}_{i}$ para cada célula $\Omega_{i}$, no caso transônico. Eles são ativados $\left(\widehat{\Phi}_{i}<1\right)$, principalmente, quando são esperados extremos locais. . . . . . . . . . . . . 80

3.18 Número de Mach do escoamento, no caso transônico. . . . . . . . . . . . . . . . . 81

4.1 Pontos de solução $r_{j, i}(\bullet)$ e pontos de fluxo $r_{k, i}(\boldsymbol{\bullet})$ da célula $i$ triangular. . . . . . . 84

4.2 Percurso das iterações (passos) do smoother RK-SSP pelos níveis polinomiais $p, p-1$ e $p-2$. Em particular, esta figura representa um Vciclo de três níveis. . . . . . . . . 86

4.3 Vciclo de três níveis no contexto do método de Diferença Espectral. . . . . . . . . . . 87

4.4 Vciclo de três níveis no contexto do método de Volumes Finitos. . . . . . . . . . . . . 89

5.1 Erro máximo versus Número de VC e Tempo de CPU, no caso advecção-difusão no canal retangular. As combinações 2a Ordem-Malha 1 e 2a Ordem-Malha 2 levam um tempo de CPU menor a 1s e não são mostrados em (b). 
5.2 Número de Iterações (\%) e Tempo de CPU (\%) consumido nos testes com p-multigrid, no caso advecção-difusão no canal retangular. . . . . . . . . . . . . . . . 95

5.3 Comparação do esquema p-multigrid MG 1-1-8-1-1 com duas ordens do método VF, utilizando a Malha 6 (8079 VC), no caso advecção-difusão no canal retangular. . . 96

5.4 Comparação do esquema p-multigrid Full-MG 1-1-8-1-1 com duas ordens do método VF, utilizando a Malha 6 (8079 VC), no caso advecção-difusão no canal retangular. . 96

5.5 Erro máximo versus Número de VC e Tempo de CPU, no caso advecção-difusão no segmento anular. As combinações com a Malha 1 e a combinação 2a Ordem-Malha 2 levam um tempo de CPU menor a 1s e não são mostrados em (b). . . . . . . . . . 97

5.6 Número de Iterações (\%) e Tempo de CPU (\%) consumido nos testes com p-multigrid, no caso advecção-difusão no segmento anular. ～. . . . . . . . . . . . . . . 100

5.7 Comparação do esquema p-multigrid MG 1-1-8-1-1 com duas ordens do método VF, utilizando a Malha 7 (8144 VC), no caso advecção-difusão no segmento anular. . . . 101

5.8 Comparação do esquema p-multigrid Full-MG 1-1-8-1-1 com duas ordens do método VF, utilizando a Malha 7 (8144 VC), no caso advecção-difusão no segmento anular. . 101

5.9 Coeficientes de sustentação $\left(C_{l}\right)$ e de arrasto $\left(C_{d}\right)$, no caso subsônico e $\alpha=0^{\circ} \ldots \ldots 104$

5.10 Número de Iterações (\%) e Tempo de CPU (\%) consumido nos testes com p-multigrid, no caso subsônico e $\alpha=0^{\circ}$. . . . . . . . . . . . . . . . . 105

5.11 Comparação do esquema p-multigrid 1-1-8-1-1 com duas ordens do método VF, utilizando a Malha 1 (779 VC), no caso subsônico e $\alpha=0^{\circ}$. . . . . . . . . . . . 106

5.12 Comparação do esquema p-multigrid 1-1-8-1-1 com duas ordens do método VF, utilizando a Malha $3(3156 \mathrm{VC})$, no caso subsônico e $\alpha=0^{\circ}$. . . . . . . . . . 106

5.13 Erros nos coeficientes de sustentação $\left(C_{l}\right)$ e de arrasto $\left(C_{d}\right)$, no caso subsônico e $\alpha=2^{\circ} .109$

5.14 Número de Iterações (\%) e Tempo de CPU (\%) consumido nos testes com p-multigrid,

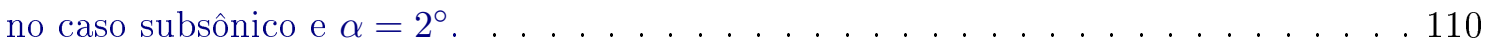

5.15 Comparação do esquema p-multigrid 1-1-8-1-1 com duas ordens do método VF, utilizando a Malha 1 (2261 VC), no caso subsônico e $\alpha=2^{\circ}$. . . . . . . . . . . 111

5.16 Comparação do esquema p-multigrid 1-1-8-1-1 com duas ordens do método VF, utilizando a Malha $3(9328 \mathrm{VC})$, no caso subsônico e $\alpha=2^{\circ}$. . . . . . . . . . . 111

5.17 Erros nos coeficientes de sustentação $\left(C_{l}\right)$ e de arrasto $\left(C_{d}\right)$, no caso transônico. . . . 114

5.18 Número de Iterações (\%) e Tempo de CPU (\%) consumido nos testes com p-multigrid, no caso transônico. . . . . . . . . . . . . . . . . . . . 115

5.19 Comparação do esquema p-multigrid 1-3-1 com duas ordens do método VF, utilizando a Malha $3(9328 \mathrm{VC})$, no caso transônico. . . . . . . . . . . . . . . . . 116

5.20 Comparação do esquema p-multigrid 1-1-3-1-1 com a 4a ordem do método VF, utilizando a Malha $3(9328 \mathrm{VC})$, no caso transônico. . . . . . . . . . . . . . 116

5.21 Pressão do escoamento $P\left(\mathrm{~N} / \mathrm{m}^{2}\right)$, no caso transônico. . . . . . . . . . . . . 117

5.22 Número de Mach do escoamento, no caso transônico. . . . . . . . . . . . . . . . 118 


\section{Lista de Tabelas}

1.1 Resumo do desenvolvimento dos métodos GD, DE, e VF, de alta-ordem não estru-

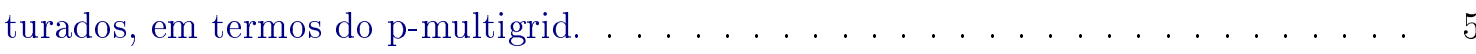

2.1 Valores mínimos para $N_{s}$ (número de células do estêncil) em função da ordem polinomial. . . . . . . . . . . . . . . . . . . . . . 12

2.2 Número de VC das malhas computacionais para o caso advecção pura. . . . . . . . . 18

2.3 Ordem nominal vs. Ordem obtida, no caso advecção pura. . . . . . . . . . . . . . . 20

2.4 Número de VC das malhas computacionais para o caso advecção-difusão no canal

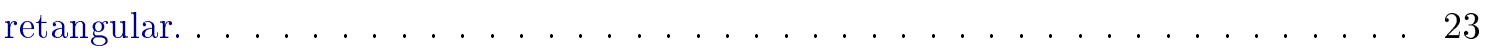

2.5 Ordem nominal vs. Ordem obtida, no caso advecção-difusão no canal retangular. 26

2.6 Comparação de ordens obtidas no caso advecção-difusão no canal retangular. . . . . 27

2.7 Número de VC das malhas computacionais para o caso advecção-difusão no segmento anular. . . . . . . . . . . . . . . . . . . . . 32

2.8 Ordem nominal vs. Ordem obtida, no caso advecção-difusão no segmento anular. . 35

2.9 Comparação de ordens obtidas no caso advecção-difusão no segmento anular. . . . . 36

3.1 Condições de corrente livre, no caso subsônico e $\alpha=0^{\circ} \ldots \ldots \ldots \ldots \ldots$

3.2 Características das malhas computacionais para o caso subsônico e $\alpha=0^{\circ} \ldots \ldots$. . . 50

3.3 Busca do CFL máximo para cada ordem do método de VF, no caso subsônico e $\alpha=0^{\circ}$. 51

3.4 Resultados obtidos com cada combinação Ordem-Malha-CFL, no caso subsônico e

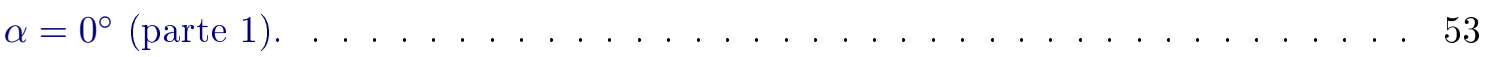

3.5 Resultados obtidos com cada combinação Ordem-Malha-CFL, no caso subsônico e

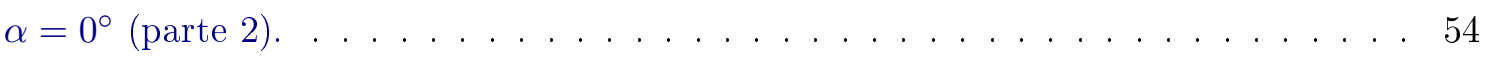

3.6 Dois exemplos da razão $\frac{\text { Tempo de CPU medido (\%) }}{\text { Tempo de CPU teórico (\%) }}$, no caso subsônico e $\alpha=0^{\circ} . \quad \ldots 56$

3.7 Comparação de coeficientes de arrasto $C_{d}$ obtidos no caso subsônico e $\alpha=0^{\circ}$. . . . 57

3.8 Condições de corrente livre, no caso subsônico e $\alpha=2^{\circ} \ldots \ldots \ldots \ldots \ldots$

3.9 Características das malhas computacionais para o caso subsônico e $\alpha=2^{\circ} \ldots \ldots$. . . 59

3.10 Busca do CFL máximo para cada ordem do método de VF, no caso subsônico e $\alpha=2^{\circ}$. 60

3.11 Resultados obtidos com cada combinação Ordem-Malha-CFL, no caso subsônico e

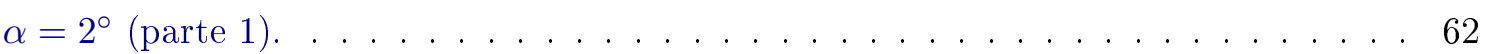

3.12 Resultados obtidos com cada combinação Ordem-Malha-CFL, no caso subsônico e

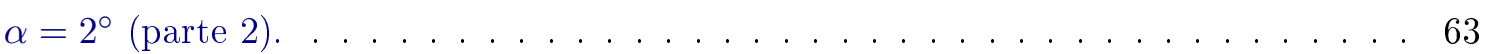

3.13 Exemplos da razão $\frac{\text { Tempo de CPU medido (\%) }}{\text { Tempo de CPU teórico (\%) }}$, no caso subsônico e $\alpha=2^{\circ} \ldots \ldots \ldots$

3.14 Condições de corrente livre, no caso transônico. . . . . . . . . . . . . . . . . . 69

3.15 Características das malhas computacionais para o caso transônico. . . . . . . . . . 70 
3.16 Busca do CFL máximo para cada ordem do método de VF, no caso transônico. . . . 71

3.17 Resultados obtidos com cada combinação Ordem-Malha-CFL, no caso transônico. . . 73

3.18 Exemplos da razão $\frac{\text { Tempo de CPU medido }(\%)}{\text { Tempo de CPU teórico }(\%)}$, no caso transônico. . . . . . . . . . . . 75

3.19 Comparação dos coeficientes de sustentação $C_{l}$ e de arrasto $C_{d}$ obtidos no caso transônico. . . . . . . . . . . . . . . . . . . . . . 76

5.1 Acrônimos dos esquemas p-multigrid utilizados no caso advecção-difusão no canal retangular. . . . . . . . . . . . . . . . . . . . . . 91

5.2 Resultados obtidos com cada combinação Malha-p-Multigrid, no caso advecção-difusão no canal retangular $($ parte 1$) \ldots \ldots \ldots$. . . . . . . . . . . . 92

5.3 Resultados obtidos com cada combinação Malha-p-Multigrid, no caso advecção-difusão no canal retangular $($ parte 2$) \ldots \ldots \ldots \ldots$. . . . . . . . . . . . 93

5.4 Resultados obtidos com cada combinação Malha-p-Multigrid, no caso advecção-difusão

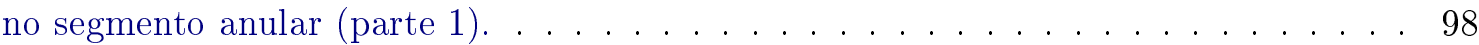

5.5 Resultados obtidos com cada combinação Malha-p-Multigrid, no caso advecção-difusão no segmento anular $($ parte 2$) \ldots \ldots \ldots \ldots$. . . . . . . . . . 99

5.6 Acrônimos dos esquemas p-multigrid utilizados no caso subsônico e $\alpha=0^{\circ}$. . . . . 102

5.7 Resultados obtidos com cada combinação Malha-p-Multigrid, no caso subsônico e

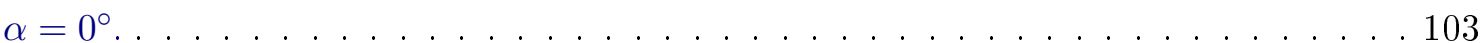

5.8 Resultados obtidos com cada combinação Malha-p-Multigrid, no caso subsônico e

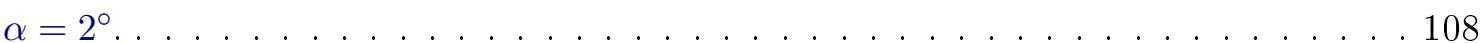

5.9 Acrônimos dos esquemas p-multigrid utilizados no caso transônico. . . . . . . . . . 112

5.10 Resultados obtidos com cada combinação Malha-p-Multigrid, no caso transônico. . 113

6.1 Resultados de alguns testes com p-multigrid. O símbolo (\%) indica quantidades relativas às que resultam com o método VF de 4a ordem (sem p-multigrid). . . . . . . 120 


\section{Capítulo 1}

\section{Introdução}

\subsection{Necessidade de Alta-Ordem}

As equações do escoamento de fluidos podem ser resolvidas numericamente usando uma ampla variedade de técnicas, que geralmente implicam na discretização independente do espaço e do tempo. Segundo Vincent e Jameson (2011), para a discretização espacial é utilizado frequentemente:

- um método de diferenças finitas (Strikwerda, 2004) que discretiza a forma diferencial das equações de escoamento de fluidos; ou

- um método de volumes finitos (Leveque, 2002) que discretiza uma forma integral das equações de escoamento de fluidos; ou

- um método de elementos finitos (Zienkiewicz et al., 2005) que discretiza alguma formulação variacional das equações de escoamento de fluidos.

Todos esses métodos de discretização espacial foram desenvolvidos nos últimos 50 anos e tipicamente oferecem, na melhor das hipóteses, uma precisão espacial de ordem dois (Vincent e Jameson, 2011). Para os propósitos deste trabalho tais esquemas serão designados como esquemas de baixaordem. Esquemas de baixa-ordem são em geral intuitivos, geometricamente flexíveis e adequadamente precisos para muitos problemas de escoamento. Dentre os esquemas de baixa-ordem pode-se destacar os chamados esquemas de captura de choques de alta resolução que são não oscilatórios e ao mesmo tempo mantém segunda ordem de precisão em todo o domínio exceto na vizinhança dos pontos extremos (de máximo e de mínimo).

Como resultado das suas favoráveis propriedades, esquemas de baixa-ordem formam a base de quase todos os solvers de escoamento de fluido comercialmente disponíveis (Wang, 2014) (Wang , 2015). No entanto, apesar desses sucessos, existe um conjunto de importantes problemas de escoamento (que requerem muito baixa dissipação numérica) para os quais esses métodos não são adequados. Esses problemas incluem escoamentos dominados por vórtices (e.g. o escoamento ao redor de pás de helicópteros ou de asas oscilantes) bem como problemas em aeroacústica. Para resolver tais problemas poderia ser vantajoso o uso de uma discretização espacial de alta-ordem (definida neste trabalho como um esquema que tem uma precisão espacial de ordem três ou maior). Quando comparados com esquemas de baixa-ordem, os métodos de alta-ordem teoricamente oferecem maior precisão por um custo computacional similar. Os métodos espectrais clássicos (Canuto et al., 2006) são um exemplo de uma discretização espacial de alta-ordem. Estes métodos implicam uma decomposição da solução em modos (no espaço da frequência) que são definidos globalmente no domínio de interesse. Porém, métodos espectrais carecem da flexibilidade geométrica de esquemas de baixa-ordem porque muitas vezes é impossível definir globalmente modos contínuos dentro de uma geometria complexa. Como tal, o seu uso é limitado. Para superar estas limitações, têm sido desenvolvidos uma variedade de assim chamados métodos de alta-ordem não estruturados que podem, teoricamente, estender a precisão de métodos espectrais para malhas não estruturadas. 


\subsection{Breve Revisão sobre Alta-Ordem}

O objetivo dos métodos de alta-ordem não estruturados é combinar a flexibilidade geométrica de esquemas de baixa-ordem com as boas propriedades de convergência de métodos espectrais de alta-ordem (que não podem ser usados em geometrias complexas). Vários métodos têm sido desenvolvidos para atingir este objetivo. De um modo geral, tais métodos podem ser classificados como esquemas de volumes finitos (VF) de alta-ordem ou esquemas de elementos finitos (EF) de alta-ordem (Wang, 2007) (Vincent e Jameson, 2011). Entretanto, deve-se notar que alguns métodos recentes não se ajustam (pelo menos naturalmente) nessas duas categorias.

Os esquemas de VF de alta-ordem mais populares incluem métodos k-exatos, métodos essencialmente não oscilatórios (ENO) de tipo VF, e métodos ENO ponderados (WENO) de tipo VF. Os métodos de EF de alta-ordem mais populares incluem métodos Galerkin Contínuo de alta-ordem e métodos Galerkin Descontínuo de alta-ordem. Outros esquemas de alta-ordem recentemente desenvolvidos incluem métodos de Volume Espectral que adaptam ideias dos métodos k-exato e Galerkin Descontínuo, e métodos de Diferença Espectral que são semelhantes aos métodos Galerkin Descontínuo mas estão baseados na forma diferencial das equações de movimento do fluido.

Uma revisão completa de todos os métodos acima mencionados é apresentada por Wang (2007). A seguir apresenta-se apenas uma visão global da essência de três desses esquemas: métodos kexatos, métodos Galerkin Descontínuo e métodos de Diferença Espectral.

\section{Métodos k-Exatos}

Métodos k-exatos de alta-ordem foram desenvolvidos primeiro por Barth e Frederickson (1990). Esses esquemas podem ser considerados como uma extensão direta dos métodos de VF do tipo Godunov de baixa-ordem, os quais resolvem uma forma integral das equações de escoamento dentro de cada célula do domínio computacional. Como tal, esquemas k-exatos trabalham somente com as médias da solução dentro de cada célula. Sua natureza de alta-ordem é atingida pela construção de uma representação polinomial da solução dentro de cada célula do domínio (baseada nas soluções médias de um estêncil de células circundantes). Descontinuidades entre essas representações são logo utilizadas como dados de entrada de Riemann solvers em cada interface de células. Tipicamente, os problemas de Riemann são resolvidos numa distribuição adequada de pontos de quadratura em cada interface de células tal que a integração numérica do total de fluxo da interface possa ser calculada de maneira precisa. Note que tal integração de alta-ordem do fluxo é crítica na preservação da precisão de alta-ordem. Uma vez obtidos, os fluxos integrados por cada face de célula são utilizados para atualizar as soluções médias das células no tempo. Observe que a extensão à alta-ordem é alcançada através de um estêncil expandido e portanto os esquemas são em geral espacialmente não compactos. Vale destacar ainda que, por definição, um esquema k-exato de grau k reconstruirá de maneira exata a solução verdadeira, se ela for um polinômio de grau k. O leitor encontrará exemplos de como métodos k-exatos são aplicados em malhas não estruturadas na publicação de Barth e Frederickson (1990) assim como nos trabalhos de Ollivier-Gooch e van Altena (2002), Nejat (2007) e Michalak (2009).

\section{Métodos Galerkin Descontínuo}

Os métodos Galerkin Descontínuo (GD) de alta-ordem constituem provavelmente o tipo de esquemas de alta-ordem não estruturados mais amplamente utilizado nas aplicações da dinâmica dos fluidos computacional. Estes métodos implicam a resolução de uma forma variacional das equações de movimento do fluido. Uma aproximação polinomial de alta-ordem é utilizada dentro de cada elemento do domínio. Como o nome sugere, os métodos Galerkin Descontínuo não exigem a continuidade da solução aproximada na interface dos elementos. Em vez disso, os elementos são acoplados via o cálculo do fluxo comum na interface (obtido, por exemplo, por um Riemann solver). Vale destacar que métodos GD de alta-ordem não estruturados são de natureza compacta porque as aproximações polinomiais estão contidas dentro de elementos independentes (em contraposição 
com os esquemas k-exatos, que precisam um estêncil expandido de elementos circundantes para alcançar a alta-ordem). O leitor encontrará mais informações sobre esquemas Galerkin Descontínuo no livro de texto de Cockburn et al. (2000). Avanços deste método de alta-ordem são apresentados por Fidkowski e Darmofal (2011); mais especificamente, resultados sobre adaptação de malha e estimativa do erro no output (p. ex. na força de sustentação num aerofolio) no contexto de problemas de Reynolds-averaged Navier-Stokes. Estes resultados incluem os publicados por Lu (2005).

\section{Métodos de Diferença Espectral}

As bases para os esquemas de Diferença Espectral (DE) foram apresentadas pela primeira vez por Kopriva e Kolias (1996). Alguns anos mais tarde, Liu et al. (2006) apresentaram uma extensão a elementos triangulares e quadrilaterais, que eles chamaram de método de Diferença Espectral (um nome que é mantido até a atualidade). Tais métodos são semelhantes a alguns esquemas GD: àqueles que empregam funções base de tipo nodal (por exemplo, polinômios de Lagrange). No entanto, os métodos DE baseiam-se na forma diferencial das equações de movimento do fluido. Dois conjuntos de pontos de grade, isto é os pontos de solução e os pontos de fluxo, são definidos dentro de cada elemento do domínio computacional (alguns dos pontos de fluxo são situados no contorno do elemento). Valores da solução são armazenados em cada ponto de solução, e são usados para construir uma representação polinomial da solução, descontínua elemento a elemento, via interpolação de Lagrange dentro de cada elemento. Esta representação da solução é, então, avaliada em cada ponto de fluxo. Logo, valores de fluxo em pontos de fluxo internos são obtidos diretamente a partir destes valores de solução, e os valores do fluxo em pontos de fluxo de contorno são obtidos usando uma fórmula de fluxo de interface, tal como um Riemann solver (que toma valores da solução de ambos os elementos que partilham a interface). Depois, uma interpolação de Lagrange é novamente utilizada, desta vez para reconstruir uma representação polinomial do fluxo (a partir de valores de fluxo nos pontos de fluxo) que supere por um grau ao polinômio da solução. A divergência deste fluxo é então avaliada nos pontos de solução, e usada para atualizar os valores da solução no tempo através de uma discretização de tempo adequada. Como os esquemas Galerkin Descontínuo (e pelas mesmas razões), os esquemas de Diferença Espectral são de natureza compacta. Após, o método DE experimentar problemas de estabilidade numa malha triangular (van den Abeele et al. , 2008), Balan et al. (2012a) introduziram uma nova função base para o fluxo, e isto parece ter resolvido o problema. Os trabalhos de Liang et al. (2009a) e Ou et al. (2009) apresentam aplicações do método DE em escoamentos compressíveis e viscosos; os problemas em (Ou et al., 2009) são não estacionários.

\subsection{Dificuldades Práticas}

Embora métodos de alta-ordem não estruturados oferecem potencialmente grandes vantagens, seu uso na indústria permanece limitado. Há várias razões para isto. Vincent e Jameson (2011) identificam e examinam 4 assuntos que inibem a adoção de tais métodos. Especificamente, esses assuntos são:

- ausência de softwares robustos para a geração de malhas de alta-ordem,

- ausência de esquemas eficientes de integração de tempo (adequados para discretizações espaciais de alta-ordem),

- ausência de algoritmos robustos e precisos para a captura de choques, e

- complexidade dos métodos de alta-ordem não estruturados (por exemplo, a formulação matemática é frequentemente mais complicada que aquela dos esquemas de baixa-ordem).

Os métodos de alta-ordem não estruturados de natureza compacta (por exemplo GD, DE) precisam de múltiplos graus de liberdade em cada elemento. Consequentemente, as malhas para 


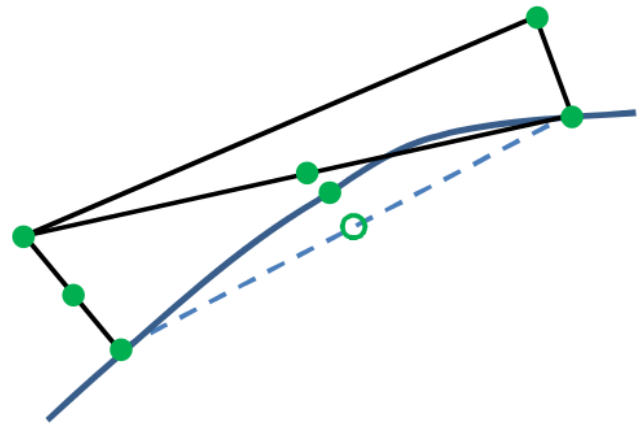

(a)

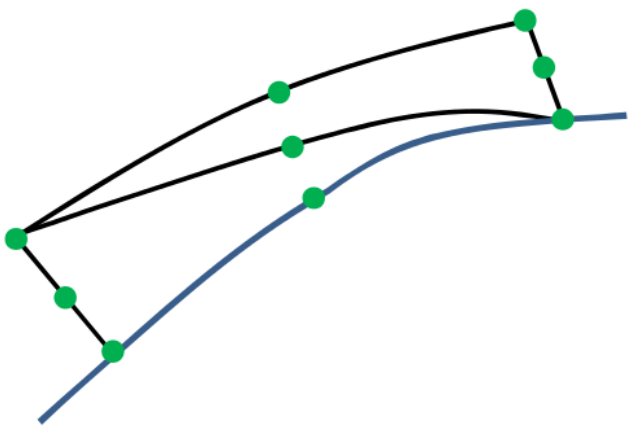

(b)

Figura 1.1: (a) Ilustração de um lado interior cortando a fronteira curva. (b) Esse corte é evitado usando um modelo de mecânica de sólidos para curvar o lado interior (Persson e Peraire, 2009). Fonte: Wang (2014)

esquemas de alta-ordem compactos são comumente mais grossas do que aquelas para esquemas de baixa-ordem ou para esquemas VF k-exatos (não compactos), considerando o mesmo número total de graus de liberdade. A exigência de elementos relativamente maiores, e a existência de múltiplos graus de liberdade por elemento, conduz a alguns problemas na geração de malhas. Por exemplo, uma tarefa não trivial é o uso de elementos com lados curvos nas fronteiras complexas: Persson e Peraire (2009) sugerem modelar a malha de lados retos (lineares) como um sólido não linearmente elástico (vide Figura 1.1). Apesar de existir avanços nesta área, atualmente todos os geradores de malha comerciais no âmbito CFD produzem malhas para métodos de baixa-ordem (Wang, 2015).

Em relação aos esquemas de integração de tempo, Vincent e Jameson (2011) afirmam que há dois grandes problemas. Para a integração explícita das discretizações espaciais de alta-ordem, o passo de tempo permitido (baseado em considerações de estabilidade) é tipicamente proporcional à inversa da ordem ao quadrado. E para a integração implícita das discretizações espaciais de altaordem, tem-se grandes requerimentos de memória quando os problemas são 3D e de grande escala. No entanto, também há progressos nesta área: na seguinte seção, apresentam-se alguns resultados dos esquemas p-multigrid.

\subsection{Métodos p-Multigrid}

A finalidade dos métodos p-multigrid é acelerar o processo iterativo. O p-multigrid pode ser considerado como uma extensão natural do método multigrid geométrico, e é adequado para o uso com discretizações espaciais de alta-ordem não estruturadas. A maior diferença é que, num método p-multigrid, são empregados espaços de polinômios de ordem cada vez mais baixa na mesma malha (em vez de malhas cada vez mais grossas). Em todos os outros aspectos, o p-multigrid é similar ao método multigrid geométrico. Em particular, um smoother (esquema de avanço no tempo) eficiente e devidamente sintonizado é requerido em cada nível p-multigrid para o avanço da solução. Tal como acontece com o multigrid geométrico, podem ser usados smoothers explícitos ou implícitos.

Nos últimos anos tem havido um interesse significativo no método p-multigrid e sua aplicação a esquemas de alta-ordem não estruturados (Tabela 1.1). Por exemplo, no contexto GD, Fidkowski et al. (2005) apresentam um algoritmo p-multigrid para resolver as equações de NavierStokes utilizando um smoother implícito. O trabalho de Nastase e Mavriplis (2006) é interessante porque desenvolveram um hp-multigrid; mais especificamente, eles empregam um esquema multigrid geométrico após o algoritmo atingir o nível p-multigrid mais baixo. No mesmo ano, Luo et al. (2006) investigam uma mistura de um smoother explícito RK (para o nível multigrid de alta-ordem) com um smoother implícito (para níveis multigrid de baixa-ordem); assim, o smoother explícito limita o requerimento de memória e o smoother implícito acelera o processo iterativo. No âmbito DE, 


\begin{tabular}{lcccc}
\hline \hline & \multicolumn{2}{c}{ Integração de tempo } & & \\
\cline { 2 - 3 } & Explícito & Implícito & p-Multigrid & Equação resolvida \\
\hline Galerkin Descontínuo (GD) & & & & \\
Fidkowski et al. (2005) & & $\checkmark$ & $\checkmark$ & Navier-Stokes \\
Nastase e Mavriplis (2006) & & $\checkmark$ & $\checkmark$ & Euler \\
Luo et al. (2006) & $\checkmark$ & $\checkmark$ & $\checkmark$ & Euler \\
\hline Diferença Espectral (DE) & & & & Navier-Stokes \\
Premasuthan et al. (2009) & $\checkmark$ & $\checkmark$ & $\checkmark$ & Euler \\
Liang et al. (2009b) & $\checkmark$ & & & Euler \\
\hline Volumes Finitos (VF) & & $\checkmark$ & & Navier-Stokes \\
Nejat (2007) & & $\checkmark$ & & \\
Michalak (2009) &
\end{tabular}

Tabela 1.1: Resumo do desenvolvimento dos métodos GD, DE, e VF, de alta-ordem não estruturados, em termos do p-multigrid.

Premasuthan et al. (2009) investigam o uso de um algoritmo p-multigrid com smoother explícito RK. Devido ao menor armazenamento de memória, este trabalho sugere que o smoother explícito poderia ser bastante adequado para simulações 3D de grande escala. Finalmente, Liang et al. (2009b) apresentam alguns esquemas p-multigrid no contexto da DE para resolver as equações de Euler. Um desses esquemas utiliza uma mistura de smoothers implícito e explícito em diferentes níveis multigrid (esquema similar ao algoritmo de Luo et al. (2006)).

\subsection{Proposta do Trabalho}

A ausência de geradores de malha de alta-ordem comerciais - dificuldade não superada até a presente data (Wang, 2015) - indica que um caminho para a utilização de discretizações espaciais de alta-ordem em maior escala passa pela utilização da estrutura convencional dos métodos de baixa-ordem; de fato, o método VF de alta-ordem, de natureza não compacta, aproveita as malhas de baixa-ordem em combinação com um tratamento nas fronteiras curvas. Além disso, a Tabela 1.1 resume a aplicação dos métodos p-multigrid a discretizações espaciais de alta-ordem; para conhecimento do autor deste trabalho, o método VF de alta-ordem ainda não inclui o acelerador p-multigrid.

Nesse sentido, a proposta deste trabalho é adaptar o método p-multigrid desenvolvido por Liang et al. (2009b) no contexto DE, para o âmbito do esquema VF k-exato, estudado e analisado por Michalak (2009). O p-multigrid resultante será testado para resolver diversos problemas de referência da literatura, envolvendo advecção pura, advecção-difusão e a equações de Euler. Esses testes permitem afirmar que o método proposto, neste trabalho de forma original, possui um desempenho diferenciado em relação aos resultados da literatura.

Os Capítulos 2 e 3 apresentam o método VF de alta-ordem aplicado na resolução da equação de advecção-difusão e das equações de Euler, respectivamente. Um solver de Volumes Finitos com avanço Runge-Kutta é desenvolvido e validado. Os resultados são comparados com os valores reportados na literatura. O Capítulo 4 apresenta o p-multigrid proposto. Esse p-multigrid é implementado, no Capítulo 5, utilizando o smoother explícito (Runge-Kutta) dos Capítulos 2 e 3. Os resultados destes dois capítulos são agora comparados com os obtidos pelo p-multigrid proposto. E por fim, uma visão global dos resultados permite, no Capítulo 6, dar conclusões assim como sugerir algumas pesquisas a futuro. 


\section{Capítulo 2}

\section{Método de Volumes Finitos para a Equação de Advecção-Difusão}

Neste capítulo é apresentado o método VF de alta-ordem tomando como base a equação de advecção-difusão por facilidade didática. Nos capítulos seguintes, detalhes específicos são introduzidos tomando como referência a descrição metodológica deste capítulo.

\subsection{Forma Integral da Equação de Advecção-Difusão}

A equação de advecção-difusão é um exemplo de uma EDP parabólica, e tem a seguinte forma:

$$
\frac{\partial \phi}{\partial t}+\frac{\partial(u \phi)}{\partial x}+\frac{\partial(v \phi)}{\partial y}=\alpha\left(\frac{\partial^{2} \phi}{\partial x^{2}}+\frac{\partial^{2} \phi}{\partial y^{2}}\right)
$$

onde $\phi(x, y, t)$ é a solução da EDP. O coeficiente de difusão $\alpha$ e a velocidade de advecção $V \equiv(u, v)$ são conhecidos; a velocidade $V$ não necessariamente é constante, e o coeficiente de difusão $\alpha$, sim. O método de VF baseia-se na forma integral das equações de movimento do fluido; assim, nesta seção, re-escreve-se a equação de advecção-difusão (2.1) começando pela integração dessa equação num volume de controle $\Omega_{i} \subset \mathbb{R}^{2}$ :

$$
\iint_{\Omega_{i}} \frac{\partial \phi}{\partial t} d x d y+\oint_{\partial \Omega_{i}}\left(\begin{array}{c}
u \phi \\
v \phi
\end{array}\right) \cdot \hat{n} d l=\oint_{\partial \Omega_{i}}\left(\begin{array}{c}
\alpha \phi_{x} \\
\alpha \phi_{y}
\end{array}\right) \cdot \hat{n} d l
$$

depois, comuta-se a derivada no tempo com a integral dupla $\left(\Omega_{i}\right.$ é um compacto e permanece fixo ao longo do tempo):

$$
\frac{d}{d t} \iint_{\Omega_{i}} \phi d x d y+\oint_{\partial \Omega_{i}}\left(\begin{array}{c}
u \phi \\
v \phi
\end{array}\right) \cdot \hat{n} d l=\oint_{\partial \Omega_{i}}\left(\begin{array}{c}
\alpha \phi_{x} \\
\alpha \phi_{y}
\end{array}\right) \cdot \hat{n} d l
$$

e finalmente, divide-se esta equação pela área da célula $\Omega_{i}$ :

$$
\frac{d}{d t} \bar{\phi}_{i}^{\text {exata }}+\frac{1}{\operatorname{area}\left(\Omega_{i}\right)} \oint_{\partial \Omega_{i}}\left(\begin{array}{c}
u \phi-\alpha \phi_{x} \\
v \phi-\alpha \phi_{y}
\end{array}\right) \cdot \hat{n} d l=0,
$$

onde

$$
\bar{\phi}_{i}^{\text {exata }} \equiv \frac{1}{\operatorname{area}\left(\Omega_{i}\right)} \iint_{\Omega_{i}} \phi d x d y
$$

é a média da solução exata $\phi$ da equação de advecção-difusão no volume de controle $\Omega_{i}$. 


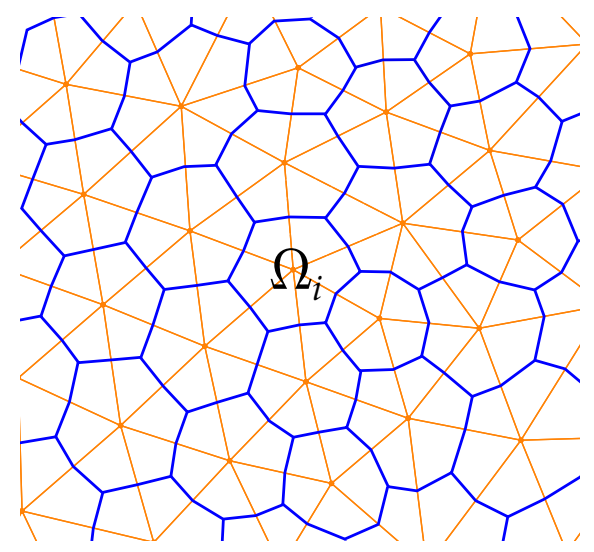

Figura 2.1: Volume de controle $\Omega_{i}$ tipo vertex-centered.

\subsection{Método de Volumes Finitos}

O método de VF permite aproximar a equação integral de advecção-difusão (2.4) por um sistema de EDOs do tipo

$$
\frac{d}{d t} \bar{\phi}_{i}=-R_{i}^{p}(\bar{\phi})
$$

A notação usada nessas EDOs é dada a seguir. No presente trabalho, o domínio (espacial) do problema de advecção-difusão, $D \subset \mathbb{R}^{2}$, é dividido em volumes de controle $\Omega_{i}$ tipo vertex-centered (vide Figura 2.1). Cada célula $\Omega_{i}$ está associada à função $\bar{\phi}_{i}(t)$; estas resolvem o sistema de EDOs (2.6). Vale destacar que $\bar{\phi}_{i}(t)$ é uma aproximação da solução média $\bar{\phi}_{i}^{\text {exata }}(t)$ da equação de advecçãodifusão (2.4). Além disso, cada célula $\Omega_{i}$ possui um estêncil de células $\Omega_{i, j}$ circundantes e pontos de Gauss $r_{i, k} \in \partial \Omega_{i}$; as seguintes seções apresentam a escolha do estêncil e dos pontos de Gauss. A seguir, apresenta-se, de maneira resumida, o processo de definição do resíduo $R_{i}^{p}(\bar{\phi})$ (Ollivier-Gooch e van Altena, 2002) (Michalak, 2009):

Passo 1: A partir das soluções médias aproximadas $\bar{\phi}_{i}$ e $\bar{\phi}_{i, j}$, constrói-se um polinômio de ordem $p$, $\phi_{i}(x, y)$, em cada célula $i$. Este polinômio é contínuo dentro da célula de controle, e descontínuo nas interfaces da célula. Os detalhes desta construção são apresentados na Seção 2.3.

Passo 2: Com o polinômio e suas derivadas avaliados num ponto de Gauss $r_{i, k}$ (ou seja $\phi_{i}\left(r_{i, k}\right)$, $\phi_{i x}\left(r_{i, k}\right)$ e $\left.\phi_{i y}\left(r_{i, k}\right)\right)$, poderia-se calcular o fluxo nesse ponto $\left(\begin{array}{c}u \phi_{i}-\alpha \phi_{i x} \\ v \phi_{i}-\alpha \phi_{i y}\end{array}\right) . \hat{n}$. Mas, em $r_{i, k}$ localizado numa interface de células, o fluxo não estaria unicamente determinado e portanto, deve-se impor um único fluxo numérico $F_{\mathrm{Num} i, k}$. Este fluxo numérico é descrito na Seção 2.4. Ora, a integral do fluxo numérico é aproximada utilizando uma quadratura de Gauss, ou seja,

$$
\oint_{\partial \Omega_{i}} F_{\text {Num }} d l \approx \sum_{k=1}^{N_{\text {Gauss }}^{p}} F_{\text {Num } i, k} W_{\text {Gauss } i, k},
$$

onde $N_{\text {Gauss }}^{p}$ é a quantidade de pontos de Gauss suficiente para que a integral seja exata em caso do integrando ser um polinômio de ordem $p$, e $W_{\text {Gauss } i, k}$ são os pesos deste método de quadratura (Stoer e Bulirsch, 2002).

Passo 3: Por fim, define-se o resíduo em cada volume de controle $\Omega_{i}$ como

$$
R_{i}^{p}(\bar{\phi}) \equiv \frac{1}{\operatorname{area}\left(\Omega_{i}\right)} \sum_{k=1}^{N_{\text {Gauss }}^{p}} F_{\text {Num } i, k} W_{\text {Gauss } i, k},
$$

onde $\bar{\phi}$, argumento do resíduo, representa o conjunto de todas as soluções médias aproximadas; ou seja, não basta a solução média aproximada $\bar{\phi}_{i}$ para definir o resíduo na célula $\Omega_{i}$. 
Para resolver a equação de advecção-difusão semi-discretizada (2.6), utiliza-se algum esquema de integração de tempo (explícito ou implícito). A seguir, apresenta-se um esquema Runge-Kutta (RK) explícito de 5 estágios (van Leer et al., 1989) com resíduo VF de ordem $p$ :

$$
\begin{aligned}
\bar{\phi}_{i}^{(0)} & =\bar{\phi}_{i}^{n} \\
\bar{\phi}_{i}^{(k)} & =\bar{\phi}_{i}^{(0)}-\alpha_{k} \Delta t R_{i}^{p}\left(\bar{\phi}^{(k-1)}\right), k=1, . ., 5 \\
\bar{\phi}_{i}^{n+1} & =\bar{\phi}_{i}^{(5)}
\end{aligned}
$$

onde $\alpha_{1}=0,0695, \alpha_{2}=0,1602, \alpha_{3}=0,2898, \alpha_{4}=0,5060$ e $\alpha_{5}=1$. A estabilidade deste esquema depende de uma restrição ao passo de tempo $\Delta t_{i}$ em cada volume de controle $\Omega_{i}$. O valor limite devido à advecção (Ii et al., 2005) (Ahmad e Boybeyi, 2005) (Saito, 2008) e o devido à difusão (Ahmad e Boybeyi, 2005) são:

$$
\begin{aligned}
\Delta t_{i}(\operatorname{advecção~}) & =\operatorname{CFL} \frac{\Delta x_{i}}{\left\|V_{i}\right\|} \\
\Delta t_{i}(\text { difusão }) & =\frac{\left(\Delta x_{i}\right)^{2}}{4 \alpha},
\end{aligned}
$$

onde

$$
\begin{aligned}
\Delta x_{i} & =\sqrt{\frac{\text { área }\left(\Omega_{i}\right)}{6}} \\
V_{i} & =\text { vetor velocidade no vértice } i \\
\alpha & =\text { coeficiente de difusão. }
\end{aligned}
$$

Portanto, o passo de tempo $\Delta t_{i}$ em cada célula é o mínimo desses dois valores limites. Ora, o passo de tempo $\Delta t$ em (2.9) depende do tipo de problema resolvido no presente trabalho. Para problemas não estacionários é necessário um passo de tempo global, ou seja,

$$
\Delta t=\operatorname{Min}_{i}\left\{\Delta t_{i}\right\}
$$

E para problemas estacionários utiliza-se o passo de tempo local (Blazek, 2001), ou seja, $\Delta t=\Delta t_{i}$; isto significa que cada célula da malha avança com seu próprio passo de tempo ótimo. Por fim, o critério de parada dos passos (2.9) também depende do tipo de problema. Os problemas não estacionários são interrompidos quando o tempo $t$ da física do problema atinge o valor desejado. Já os problemas estacionários são interrompidos quando $\operatorname{Res}_{L_{2}}<10^{-10}$, onde (Wang et al., 2013)

$$
\operatorname{Res}_{L_{2}} \equiv \sqrt{\frac{1}{N} \sum_{i=1}^{N}\left[R_{i}^{p}\left(\bar{\phi}^{n}\right)\right]^{2}}
$$

é a norma $L_{2}$ do resíduo (para alguma iteração $n$ ), e $N$ é o número de volumes de controle.

\subsection{Reconstrução}

O objetivo nesta seção é definir, em cada célula $\Omega_{i}$, um polinômio de ordem $p$ (ou grau $p-1$ ) da forma

$$
\phi_{i}(x, y) \equiv \sum_{0 \leq m+n<p} c_{m, n}\left(x-x_{i}\right)^{m}\left(y-y_{i}\right)^{n}, \forall(x, y) \in \Omega_{i}
$$

a partir da estimativa da solução para a célula $i\left(\bar{\phi}_{i}\right)$ e das estimativas para as células do estêncil $\left(\bar{\phi}_{i, j}\right)$; as coordenadas $\left(x_{i}, y_{i}\right)$ são as coordenadas do vértice $i$. O polinômio $\phi_{i}(x, y)$ deve satisfazer 
a propriedade da conservação da média (Barth e Frederickson, 1990), isto é,

$$
\begin{aligned}
\frac{1}{\operatorname{area}\left(\Omega_{i}\right)} \iint_{\Omega_{i}} \phi_{i} d x d y & =\bar{\phi}_{i}, \text { ou } \\
\sum_{0 \leq m+n<p} c_{m, n} \overline{x^{m} y^{n}} & =\bar{\phi}_{i}
\end{aligned}
$$

onde

$$
\overline{x^{m} y^{n}}{ }_{i} \equiv \frac{1}{\operatorname{area}\left(\Omega_{i}\right)} \iint_{\Omega_{i}}\left(x-x_{i}\right)^{m}\left(y-y_{i}\right)^{n} d x d y
$$

são os momentos do volume de controle $\Omega_{i}$. Ou seja, os coeficientes $c_{m, n}$ devem satisfazer a equação (2.16). Ora, além da conservação da média, deve-se minimizar o erro na predição do valor médio $\bar{\phi}_{i, j}$ na célula $\Omega_{i, j}$ do estêncil. Isto é, considere-se a seguinte aproximação

$$
\begin{aligned}
\frac{1}{\operatorname{area}\left(\Omega_{i, j}\right)} \iint_{\Omega_{i, j}} \phi_{i} d x d y & \approx \bar{\phi}_{i, j}, \text { ou } \\
\sum_{0 \leq m+n<p} c_{m, n} \widehat{x}^{m} y^{n} & \approx \bar{\phi}_{i, j},
\end{aligned}
$$

onde

$$
{\widehat{x^{m} y^{n}}}_{i j} \equiv \frac{1}{\operatorname{area}\left(\Omega_{i, j}\right)} \iint_{\Omega_{i, j}}\left(x-x_{i}\right)^{m}\left(y-y_{i}\right)^{n} d x d y
$$

são os momentos do volume de controle $\Omega_{i, j}$ em relação ao vértice $i$; a aproximação (2.18) é multiplicada pelo peso geométrico $w_{i j}$ (Ollivier-Gooch e van Altena, 2002) (Michalak, 2009),

$$
w_{i j} \equiv \frac{1}{\left|\vec{x}_{i, j}-\vec{x}_{i}\right|^{\beta}}
$$

onde $\left|\vec{x}_{i, j}-\vec{x}_{i}\right|$ é a distância entre os vértices associados às células $\Omega_{i, j}$ e $\Omega_{i}$, e $\beta$ é uma constante (1 para a resolução de problemas de advecção pura e 2 para problemas de advecção com difusão); os coeficientes $c_{m, n}$ devem satisfazer aproximações desse tipo para cada célula do estêncil de $\Omega_{i}$, minimizando a soma dos quadrados dos erros de cada aproximação. Ao escrever a conservação da média (2.16) junto a estas aproximações obtem-se o sistema (2.20) que é resolvido da seguinte maneira:

- Primeiro, a restrição da média é eliminada analiticamente: utiliza-se eliminação gaussiana para zerar a primeira coluna da matriz em (2.20) exceto o primeiro termo (o número 1).

- Segundo, o problema de mínimos quadrados não restrito restante é resolvido: calcula-se a decomposição em valores singulares (Golub e van Loan, 1996) da matriz deste problema e encontra-se a pseudo-inversa dessa matriz. Vale destacar que esta decomposição é utilizada por Michalak (2009) e o presente trabalho segue essa metodologia; a decomposição e a pseudoinversa são calculadas pelas funções GNU gsl_linalg_SV (Galassi et al., 2015).

- Por fim, a restrição da média (2.16) é utilizada para encontrar o termo constante $c_{0,0}$ do polinômio $\phi_{i}(x, y)$.

O número $N_{s}$, que estabelece o número de equações do problema de mínimos quadrados restrito (2.20), é o número de células do estêncil de $\Omega_{i}$. A definição deste número é dada no final desta Seção. 


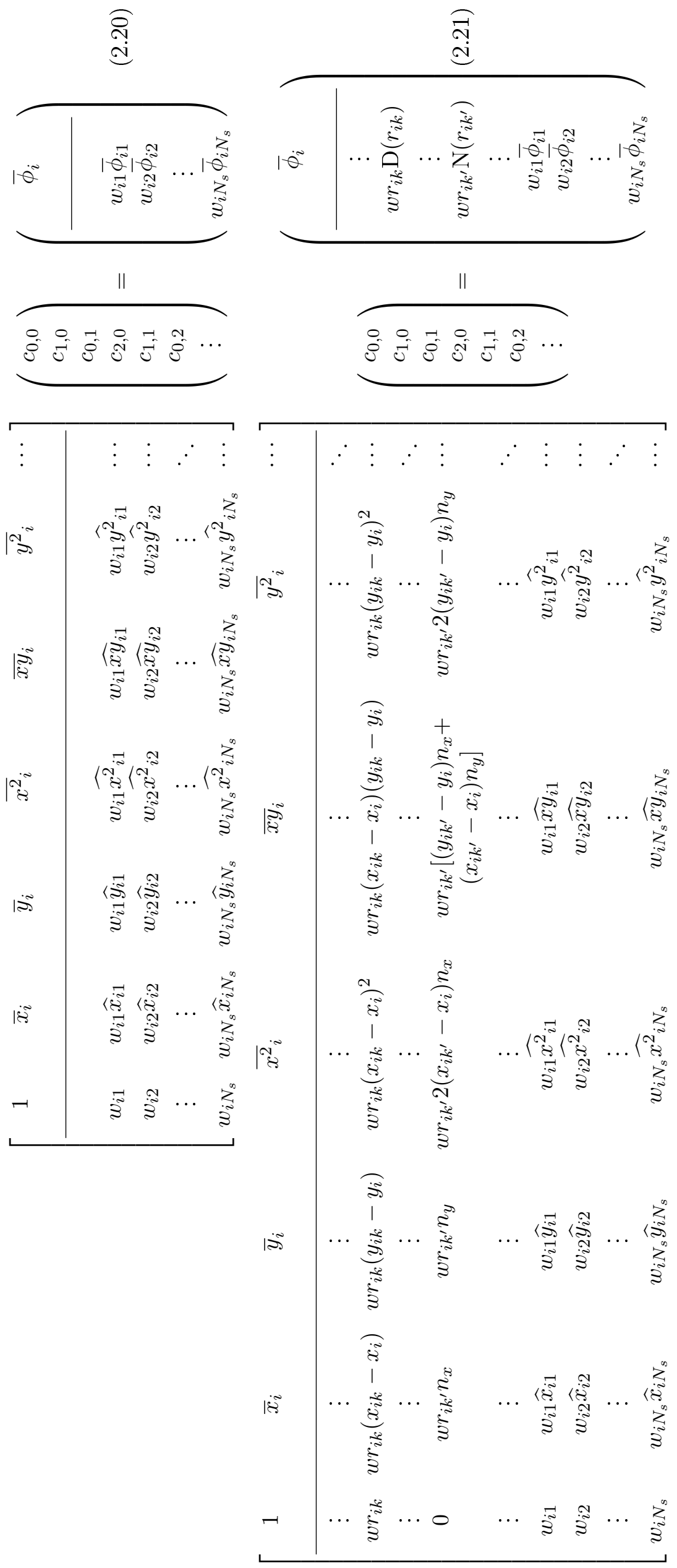




\section{Implementação das Condições de Fronteira}

É importante observar que, numa malha, existem volumes de controle adjacentes à fronteira do domínio $\partial D$ (volumes de fronteira) e outros volumes que não (volumes do interior). Nestes volumes do interior, o polinômio é construído resolvendo o problema (2.20); já, nos volumes de fronteira, se resolve o problema (2.21) que está baseado na proposta de Michalak (2009) ${ }^{1}$ : são incluídas as condições de fronteira na construção do polinômio. Neste capítulo, a fronteira do domínio $\partial D$ está dividida: uma parte sob condição de Dirichlet D e outra sob condição de Neumann N, ou seja,

$$
\begin{aligned}
& \phi(x, y)=\mathrm{D}(x, y), \text { se }(x, y) \text { está numa fronteira Dirichlet, } \\
& \nabla \phi \cdot \hat{n}=\mathrm{N}(x, y), \text { se }(x, y) \text { está numa fronteira Neumann. }
\end{aligned}
$$

A montagem do problema (2.21), específico para células de fronteira, é descrita a seguir. Dada uma célula de fronteira $\Omega_{i}$, o polinômio associado a ela, $\phi_{i}(x, y)$, deve satisfazer aproximadamente a condição de fronteira nos pontos da quadratura gaussiana $r_{i, k}$ (vide Seção 2.4) localizados em $\partial D \cap \partial \Omega_{i}$, isto é,

$$
\begin{aligned}
\phi_{i}\left(r_{i, k}\right) & \approx \mathrm{D}\left(r_{i, k}\right), \text { se } r_{i, k} \text { está numa fronteira Dirichlet, } \\
\nabla \phi_{i}\left(r_{i, k}\right) \cdot \hat{n}_{i, k} & \approx \mathrm{N}\left(r_{i, k}\right), \text { se } r_{i, k} \text { está numa fronteira Neumann, }
\end{aligned}
$$

onde $\hat{n}_{i, k}$ é a normal exterior avaliada em $r_{i, k}$. A aproximação associada ao ponto de Gauss $r_{i, k}$, seja (2.24) ou (2.25), é multiplicada pelo peso geométrico $w r_{i k}$ (Michalak, 2009),

$$
w r_{i k} \equiv c_{b} \frac{1}{\left|r_{i, k}-\vec{x}_{i}\right|^{\beta}}
$$

onde $\left|r_{i, k}-\vec{x}_{i}\right|$ é a distância entre o ponto de Gauss $r_{i, k}$ e o vértice da célula $\Omega_{i}, \beta$ é a mesma constante utilizada na equação (2.19), e $c_{b}=6$. Assim, o polinômio da célula de fronteira $\Omega_{i}$ deve satisfazer aproximações desse tipo para cada ponto de Gauss $r_{i, k} \in \partial D \cap \partial \Omega_{i}$. Ao incluir estas aproximações ao problema de mínimos quadrados (2.20) obtem-se o sistema (2.21).

Observe-se que a matriz do problema (2.21), associado ao volume de fronteira $\Omega_{i}$, considera que uma parte de $\partial D \cap \partial \Omega_{i}$ está sob condição de Dirichlet e outra parte sob condição de Neumann. Isto não sempre acontece no presente trabalho: a maioria de volumes de fronteira é adjacente apenas a uma fronteira Dirichlet ou a uma fronteira Neumann.

\section{Estêncil}

O mínimo valor para $N_{s}$ (número de células do estêncil) depende da ordem do polinômio: Ollivier-Gooch et al. (2009) sugerem os valores da Tabela 2.1. Uma outra característica do estêncil é sua simetria: vão-se adicionando sucessivamente camadas inteiras de vizinhos até superar o mínimo (vide Figura 2.2). Para o caso particular de esta figura, observa-se que a ordem $p=3$ precisa uma camada mais do que a ordem $p=2$ necessita; e também que, para a ordem $p=4$ é suficiente o estêncil da ordem $p=3$.

\begin{tabular}{ccc}
\hline \hline Ordem & Quantidade & \\
$p$ & de coeficientes $c_{m, n}$ & $N_{s} \geq$ \\
\hline 2 & 3 & 3 \\
3 & 6 & 8 \\
4 & 10 & 14 \\
\hline \hline
\end{tabular}

Tabela 2.1: Valores minimos para $N_{s}$ (número de células do estêncil) em função da ordem polinomial.

\footnotetext{
${ }^{1}$ A proposta de Michalak (2009), para a construção de polinômios na fronteira, é aquela do Capítulo 4, Extension to Viscous Flows, específica para as equações de Navier-Stokes.
} 


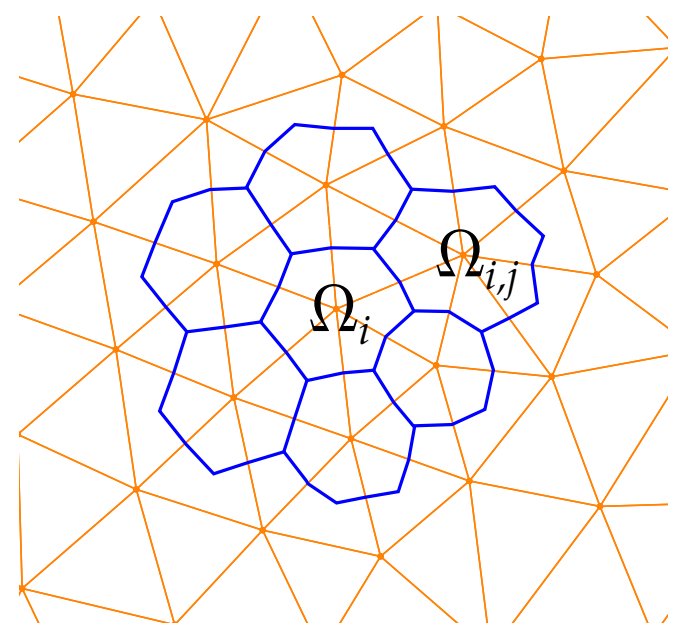

(a) $p=2$

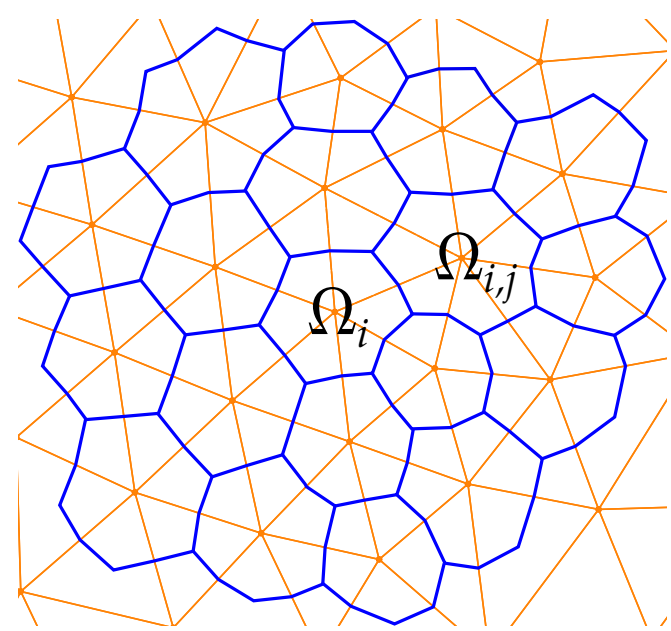

(b) $p=3$

Figura 2.2: Estêncil do volume de controle $\Omega_{i}$. Observe-se que, nesta figura, o estêncil para p $=3$ também serve para $p=4$.

Finalmente vale destacar que a matriz do problema de mínimos quadrados restrito, (2.20) ou (2.21), associado a $\Omega_{i}$, depende unicamente da geometria da malha e esta não muda com o tempo. Por isso, a pseudo-inversa da matriz do problema de mínimos quadrados não restrito é calculada e armazenada antes do processo iterativo que resolve a equação de advecção-difusão semi-discretizada (2.6).

\subsection{Fluxo}

O fluxo (exato) é o integrando da equação (2.4), isto é,

$$
\phi V \cdot \hat{n}-\alpha \nabla \phi \cdot \hat{n}
$$

avaliado em $(x, y) \in \partial \Omega_{i}$. No presente trabalho, esse fluxo é estimado a partir dos valores dos polinômios de reconstrução. Ainda mais, para o cálculo da integral no contorno $\partial \Omega_{i}$, o fluxo numérico é definido apenas nos pontos de Gauss $r_{i, k} \in \partial \Omega_{i}$. Se $r_{i, k}$ está localizado na interface das células $\Omega_{i}$ e $\Omega_{i, j}$ (vide Figura 2.3), o fluxo numérico é definido assim (van Altena, 1999) (Ollivier-Gooch e van Altena, 2002):

$$
F_{\mathrm{Num} i, k} \equiv \phi_{\mathrm{Num} i, k} V_{i, k} \cdot \hat{n}_{i, k}-\alpha \nabla \phi_{\mathrm{Num} i, k} \cdot \hat{n}_{i, k}
$$

onde $V_{i, k}$ e $\hat{n}_{i, k}$ são, respectivamente, o vetor velocidade e a normal (exterior a $\Omega_{i}$ ) avaliados em $r_{i, k}, \mathrm{e}$

$$
\begin{aligned}
\phi_{\mathrm{Num}_{i, k}} & \equiv \begin{cases}\phi_{i}\left(r_{i, k}\right) & \text { se } V_{i, k} \cdot \hat{n}_{i, k} \geq 0 \\
\phi_{i, j}\left(r_{i, k}\right) & \text { se } V_{i, k} \cdot \hat{n}_{i, k}<0\end{cases} \\
\nabla \phi_{\mathrm{Num}_{i, k}} & \equiv \frac{\operatorname{área}\left(\Omega_{i}\right) \nabla \phi_{i}\left(r_{i, k}\right)+\operatorname{área}\left(\Omega_{i, j}\right) \nabla \phi_{i, j}\left(r_{i, k}\right)}{\operatorname{área}\left(\Omega_{i}\right)+\operatorname{area}\left(\Omega_{i, j}\right)}
\end{aligned}
$$

Ora, os pontos de Gauss $r_{i, k}$ também poder estar localizados na fronteira do domínio $\partial D$ (vide Figura 2.5). O fluxo numérico para estes pontos é definido a seguir.

\section{Implementação das Condições de Fronteira}

Se o ponto de integração de Gauss $r_{i, k}$ está sobre uma fronteira Dirichlet, então o fluxo $F_{\mathrm{Num} i, k}$ tem a forma da equação (2.27) substituindo $\phi_{\mathrm{Num}_{i, k}}$ pela condição de fronteira e o gradiente é 


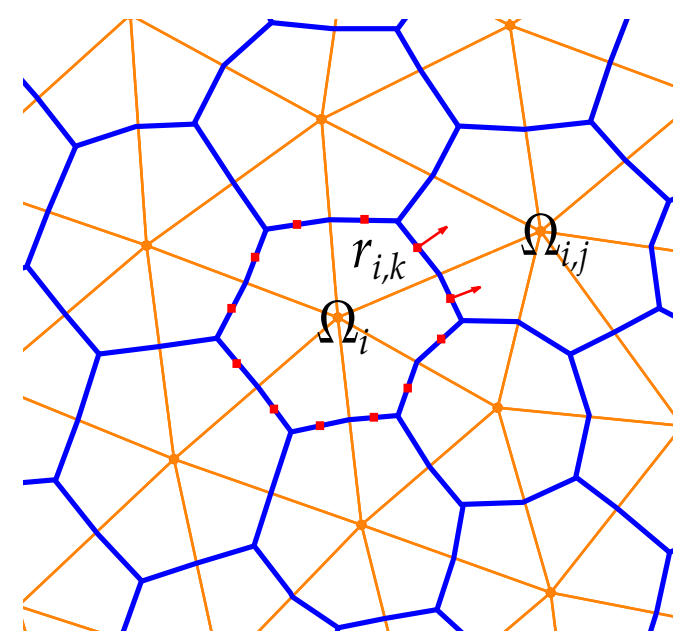

(a) $2 \mathrm{a}$ ordem

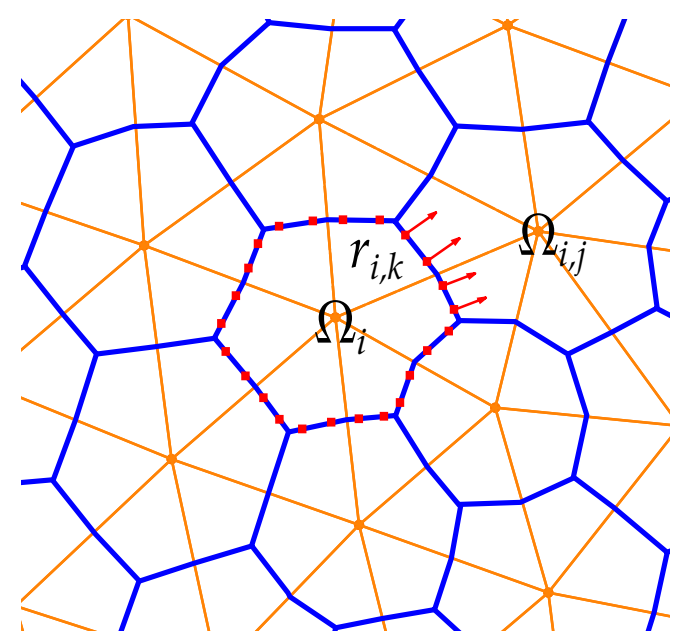

(b) 3a e 4a ordem

Figura 2.3: Localização dos pontos de integração de Gauss e suas normais associadas na interface de células, para o método VF de alta-ordem.

calculado pela reconstrução. Ora, se $r_{i, k}$ está sobre uma fronteira Neumann, então o fluxo $F_{\text {Num } i, k}$ também tem a forma da equação $(2.27)$ mas substituindo $\nabla \phi_{\mathrm{Num} i, k} \cdot \hat{n}_{i, k}$ pela condição de fronteira e o que sobra é calculado pela reconstrução da solução $\phi_{i}$.

\subsection{Tratamento das Fronteiras Curvas}

O método de VF considerado no presente trabalho utiliza uma malha de baixa-ordem (ela é definida no trabalho de Wang (2015) como uma malha que tem todas suas faces retas), junto com um tratamento nas fronteiras curvas para obter uma precisão espacial de alta-ordem (Ollivier-Gooch et al. , 2009). Uma fronteira curva refere-se, em geral, a um segmento da fronteira do domínio. O tratamento da malha de baixa-ordem começa assinando um raio de curvatura $R_{i}$ a cada vértice $i$ localizado na fronteira curva (vide Figura 2.4(a)). Para isso, a fronteira curva é representada por um spline cúbico natural (Stoer e Bulirsch, 2002): o spline interpola os vértices localizados na fronteira curva. A construção do spline é realizada pelas funções GNU gsl_spline (Galassi et al., 2015) tendo como dados de entrada às coordenadas $\left(x_{i}, y_{i}\right)$ dos vértices $i$ de fronteira. Depois, é calculado

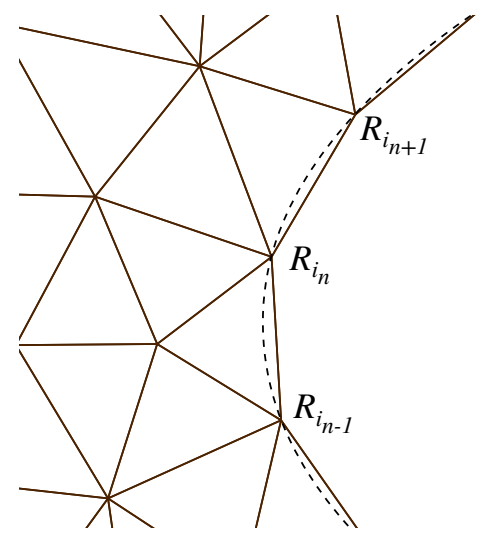

(a) Vértices (sobre a fronteira curva) e seus Raios de curvatura.

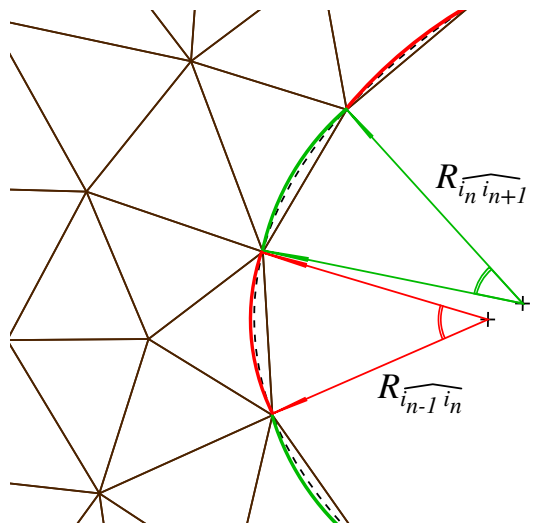

(b) Faces de fronteira $\widehat{i_{n-1} i_{n}}$ e $\widehat{i_{n} i_{n+1}}$.

Figura 2.4: Tratamento das fronteiras curvas. 


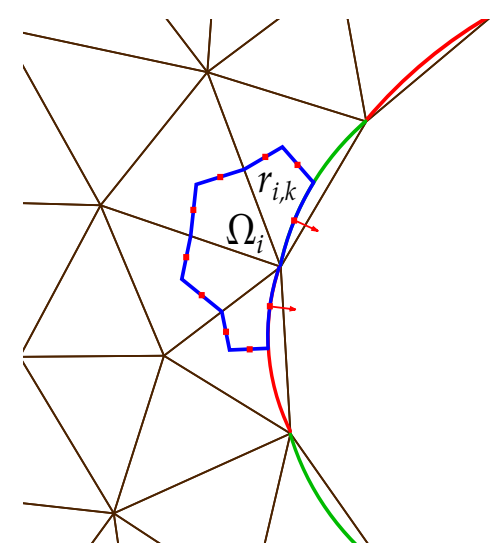

(a) 2a Ordem.

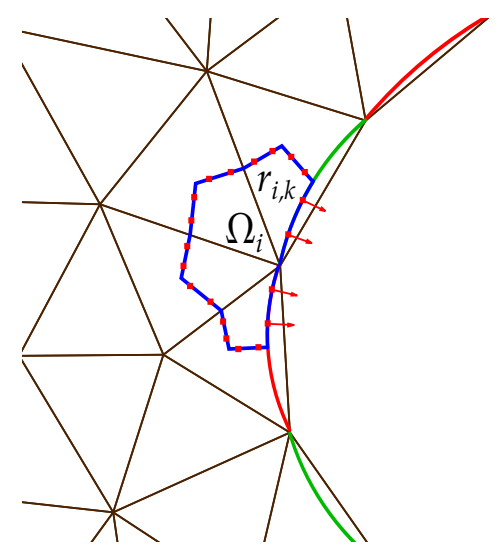

(b) 3a e 4a Ordem.

Figura 2.5: Localização dos pontos de Gauss $r_{i, k}$ para o cálculo da integral de fluxo para $\Omega_{i}$.

o raio de curvatura do spline em cada vértice:

$$
R_{i} \equiv \frac{\left(x_{i}^{\prime 2}+y_{i}^{\prime 2}\right)^{3 / 2}}{\left|x_{i}^{\prime} y_{i}^{\prime \prime}-y_{i}^{\prime} x_{i}^{\prime \prime}\right|}
$$

onde $x_{i}^{\prime}, y_{i}^{\prime}, x_{i}^{\prime \prime}$ e $y_{i}^{\prime \prime}$ são as derivadas do spline no vértice $i$ de fronteira. Se conhecer a equação que define a fronteira, pode-se usar essa equação para o cálculo do raio de curvatura (sem interpolação por splines). Embora o presente trabalho utilizar um spline cúbico (uma aproximação da curva real), ele permite encontrar soluções numéricas de até 4a ordem de precisão. De fato, sob certas condições de diferenciabilidade, a diferença entre a fronteira curva real e a interpolação spline é $O\left(\Delta^{4}\right)$, onde $\Delta$ é um comprimento característico da partição da fronteira (Stoer e Bulirsch, 2002). Uma última observação desta primeira parte do tratamento é a seguinte: os raios $R_{i}$ para os vértices inicial e final do spline são, respectivamente, infinito devido ao tipo de spline (natural).

O segundo (e último) passo no tratamento das fronteiras curvas consiste em parametrizar cada face de fronteira. Dada uma fronteira curva, define-se a face de fronteira $\widehat{i_{n} i_{n+1}}$ como um arco de circunferência limitado por dois vértices consecutivos $i_{n}$ e $i_{n+1}$ da fronteira curva (vide Figura 2.4(b)); esta face de fronteira modela localmente à fronteira curva (ou ao spline). O raio de $\widehat{i_{n} i_{n+1}}$ é definido, no presente trabalho, assim:

$$
R_{\widehat{i_{n} i_{n+1}}} \equiv \frac{R_{i_{n}}+R_{i_{n+1}}}{2}
$$

Este raio determina completamente a face $\widehat{i_{n} i_{n+1}}$ (pode-se, por exemplo, localizar o centro da circunferência). Assim, a face $\widehat{i_{n} i_{n+1}}$ é parametrizada pelo ângulo subtendido pelo arco, visto pelo centro da circunferência. Uma observação importante é a seguinte: dado que, no presente trabalho, os raios $R_{i}$ associados aos vértices inicial e final da fronteira curva são indeterminados, as respectivas faces de fronteira desconsideram esses raios $R_{i}$ na definição do raio de face. Mais especificamente, a face inicial $\widehat{i_{0} i_{1}}$ tem como raio $R_{\widehat{i_{0} i_{1}}} \equiv R_{i_{1}}$; e de maneira análoga, define-se o raio da face final.

Com a fronteira curva localmente parametrizada, a malha agora tem faces curvas: a malha deixa de ser de baixa-ordem. No entanto, dado que o método VF de alta-ordem é não compacto, a malha do presente trabalho não precisa de graus de liberdade adicionais, ao interior das células (como sim acontece nas malhas dos métodos GD e DE de alta-ordem compactos). Ora, os cálculos geométricos da malha, em comparação com uma malha de baixa-ordem, devem ser feitos com atenção. Nesse sentido, para cada um dos seguintes parâmetros, apresenta-se de maneira resumida os aspectos a ter em conta no cálculo deles. Vale destacar que, a base desse cálculo está na correta localização dos pontos de Gauss (Ollivier-Gooch et al., 2009).

- centroides de triângulos adjacentes a fronteiras curvas: eles são necessários para limitar cada 
célula vertex-centered, e para calcular o centroide é preciso localizar três pontos de Gauss em cada lado curvo do triângulo.

- momentos de volumes de controle ao longo das fronteiras curvas: os momentos dos volumes de controle são utilizados na reconstrução dos polinômios. Deve-se localizar três pontos de Gauss em cada segmento curvo de $\partial \Omega_{i}$ para calcular, de maneira precisa, os momentos.

- integral de fluxo ao longo das fronteiras curvas: para isto é necessário localizar os pontos de Gauss sobre os segmentos curvos de $\partial \Omega_{i}$ (vide Figura 2.5). A quantidade é a mesma que nas interfaces de células (vide Figura 2.3).

\subsection{Casos de Validação}

São resolvidos três problemas de advecção-difusão:

- Advecção pura (Ii et al., 2005),

- Advecção-difusão em um canal retangular (Ollivier-Gooch e van Altena, 2002),

- Advecção-difusão em um segmento anular (Ollivier-Gooch e van Altena, 2002).

Para este propósito foi implementado um solver de VF de alta-ordem não estruturado com avanço no tempo RK. A discretização espacial de VF está descrita nas seções anteriores. Isto implica que a reconstrução polinomial de Michalak (2009) e o cálculo dos fluxos invíscidos e viscosos (Ollivier-Gooch e van Altena, 2002) fazem parte do código. O método RK de van Leer et al. (1989), descrito em (2.9), é utilizado pelo código para atualizar a solução numérica. Para dar inicio a um teste, o código VF-RK precisa de alguns dados de entrada como: os dados da física do problema, a malha computacional, a ordem (nominal) do método de VF, e o número CFL do método RK. Os dados de saída incluem o tempo de CPU e o erro cometido; este é medido segundo três normas (Wang et al., 2013):

$$
\begin{aligned}
\operatorname{Erro}_{L_{1}} & \equiv \frac{\sum_{i}\left|\bar{\phi}_{i}^{\text {exata }}-\bar{\phi}_{i}\right| \cdot \operatorname{área}\left(\Omega_{i}\right)}{\sum_{i} \operatorname{área}\left(\Omega_{i}\right)} \\
\operatorname{Erro}_{L_{2}} & \equiv \sqrt{\frac{\sum_{i}\left|\bar{\phi}_{i}^{\text {exata }}-\bar{\phi}_{i}\right|^{2} \cdot \operatorname{área}\left(\Omega_{i}\right)}{\sum_{i} \text { área }\left(\Omega_{i}\right)}} \\
\operatorname{Erro}_{L_{\infty}} & \equiv \max _{i}\left\{\left|\bar{\phi}_{i}^{\text {exata }}-\bar{\phi}_{i}\right|\right\} .
\end{aligned}
$$

\subsubsection{Advecção pura}

Este primeiro caso corresponde a um problema do artigo do Ii et al. (2005), cujos dados (domínio, campo de velocidades e condição inicial) são reproduzidos a seguir. Considere a equação de advecção bidimensional sem difusão,

$$
\frac{\partial \phi}{\partial t}+\frac{\partial(u \phi)}{\partial x}+\frac{\partial(v \phi)}{\partial y}=0
$$

definida no quadrado $[0,2] \times[0,2]$; nessa equação, a velocidade horizontal $u$ e a velocidade vertical $v$ são conhecidas:

$$
\begin{aligned}
& u(x, y) \equiv-2 \pi(y-1) \\
& v(x, y) \equiv 2 \pi(x-1)
\end{aligned}
$$

A Figura 2.6 mostra o campo de velocidades ${ }^{2}$. O escoamento é rotacional com velocidade angular $2 \pi \mathrm{rad} / \mathrm{s}$ e com centro de rotação no ponto $(1,1)$. Partes do contorno do quadrado são a entrada do

\footnotetext{
${ }^{2}$ Este campo de velocidades corresponde ao problema de Rotação de um Corpo Rígido (Leveque, 2002).
} 
escoamento e outras partes são a saída. A condição nula $\phi=0$ é imposta na fronteira de entrada. Não é imposta nenhuma condição na saída. A condição inicial, Figura 2.7(a), é a seguinte:

$$
\phi(x, y, t=0 \mathrm{~s})= \begin{cases}\cos ^{2}(2 \pi r) & \text { se } r \equiv \sqrt{(x-0.5)^{2}+(y-1)^{2}} \leq 0.25 \\ 0 & \text { caso contrario. }\end{cases}
$$

Com esses dados, a função $\phi$ é transportada pelo escoamento com uma velocidade angular de $2 \pi$ $\mathrm{rad} / \mathrm{s}$. Ou seja, no tempo $t=1 \mathrm{~s}$ a função $\phi$ chega de novo ao ponto de partida,

$$
\phi(x, y, t=1 \mathrm{~s})=\phi(x, y, t=0 \mathrm{~s})= \begin{cases}\cos ^{2}(2 \pi r) & \text { se } r \equiv \sqrt{(x-0.5)^{2}+(y-1)^{2}} \leq 0.25 \\ 0 & \text { caso contrario }\end{cases}
$$

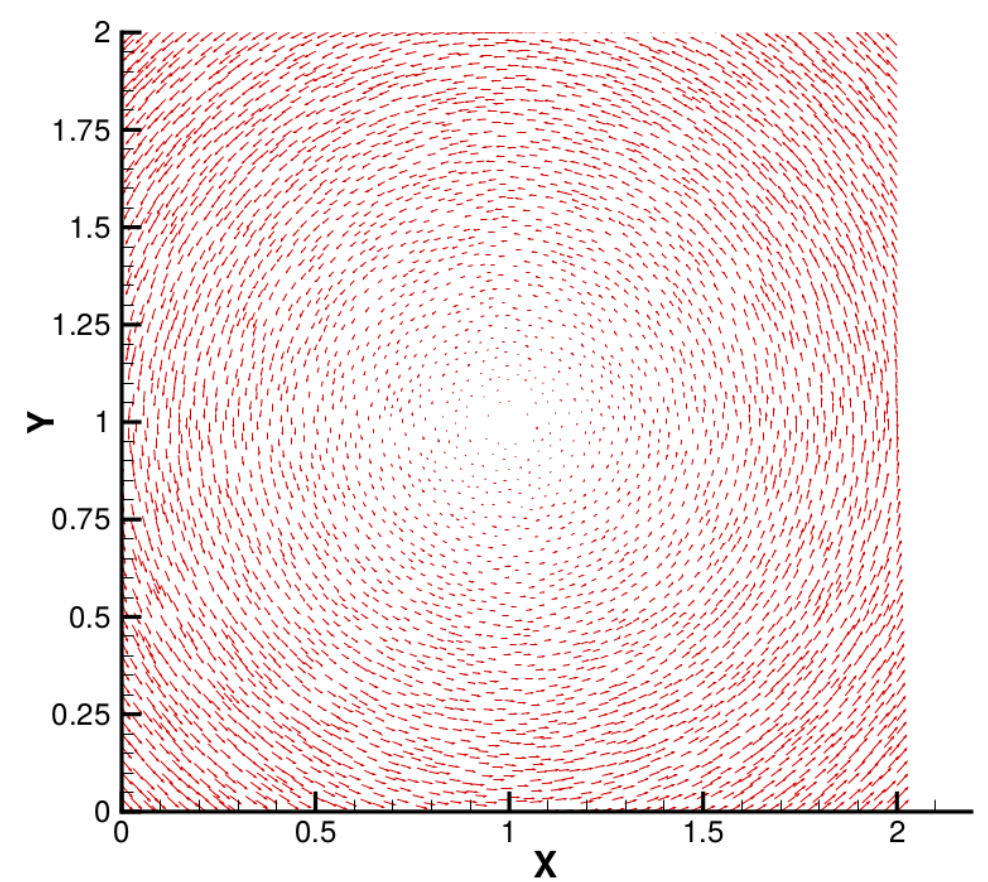

Figura 2.6: Campo de velocidades no caso de advecção pura. Fonte: Saito (2008).

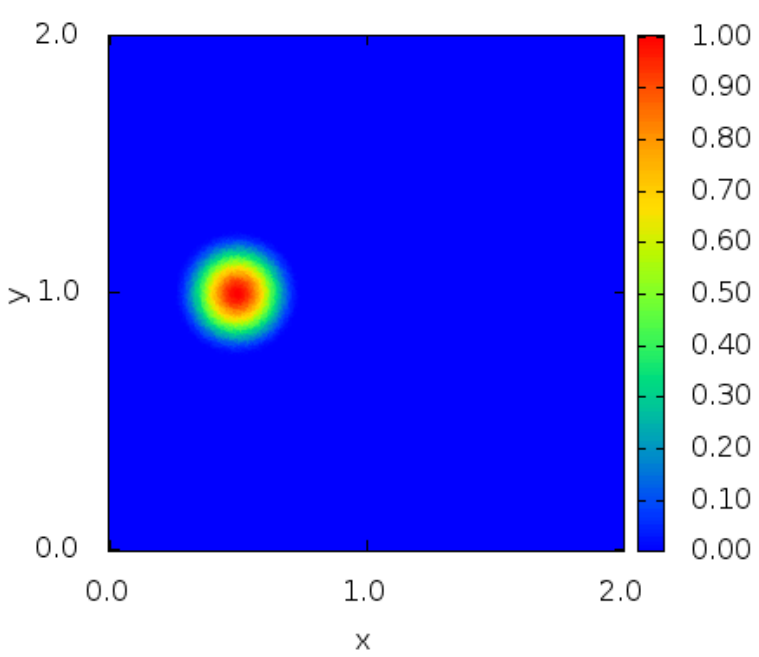

(a) $t=0 \mathrm{~s}$

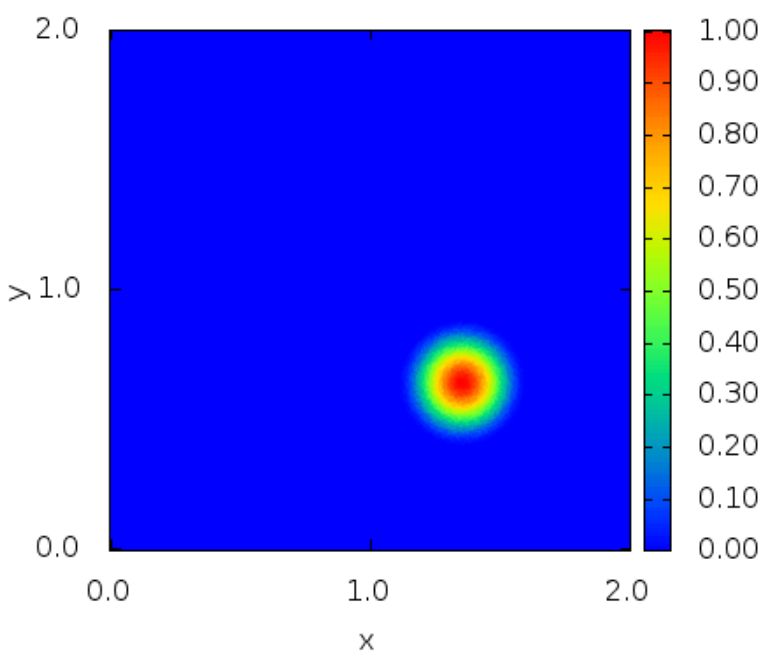

(b) $t=0.375 \mathrm{~s}$

Figura 2.7: Função $\phi$ sendo transportada pelo escoamento com uma velocidade angular de $2 \pi \mathrm{rad} / \mathrm{s}$. 


\section{Descrição dos testes}

De todos os casos apresentados neste trabalho, a advecção pura foi o primeiro em ser implementado. Nesse sentido, foi utilizada uma versão preliminar do solver VF-RK. Duas são as diferenças em relação à versão atual do código VF-RK. A primeira está relacionada à reconstrução no método de VF: utiliza-se a fatoração QR do tipo Householder (Golub e van Loan, 1996) e não é calculada a pseudo-inversa da matriz antes de começar com as iterações. A segunda diferença está relacionada ao esquema de avanço no tempo RK: o esquema utilizado é o Runge-Kutta de 4 estágios clássico (Jameson et al., 1981).

Este caso de advecção pura é resolvido numericamente pelo código mencionado acima. Considerase $\mathrm{CFL}=0,9$ na definição do passo de tempo global (equação (2.12)). A equação (2.33) é utilizada na definição da solução inicial do processo iterativo: $\bar{\phi}_{i}$ para cada $\mathrm{VC}_{i}$. Essas iterações são interrompidas quando o tempo $t$ alcança $1 \mathrm{~s}$. Para dar início a um teste, o código precisa de dois dados de entrada: a malha computacional e a ordem (nominal) do método de VF.

Com o Gmsh (Geuzaine e Remacle, 2009) criam-se sete malhas computacionais. A Tabela 2.2 mostra o número de VC dessas malhas. A Malha 1 possui 5520 vértices (ou VC). Eles são distribuídos equitativamente em todo o quadrado: não há zonas com maior ou menor concentração de vértices (Figura 2.8(a)). As seguintes malhas são geradas uma a partir da anterior: dividindo-se todos os comprimentos característicos $h$ por aproximadamente $\sqrt{2}$. Por isso, o número de $\mathrm{VC}$ de uma malha é aproximadamente o dobro da malha anterior. Por outro lado, esse refinamento uniforme permite manter a distribuição equitativa dos vértices em todo o quadrado (Figura 2.8). O Gmsh permite salvar os dados das malhas em arquivos de texto. O código do presente trabalho consegue ler o arquivo da malha computacional selecionada e dar início a um teste.

No. de VC \begin{tabular}{rccccccc|}
\cline { 2 - 7 } & Malha 1 & Malha 2 & Malha 3 & Malha 4 & Malha 5 & Malha 6 & Malha 7 \\
\cline { 2 - 8 } & 5520 & 11400 & 21889 & 42969 & 87365 & 175712 & 347433 \\
\hline
\end{tabular}

Tabela 2.2: Número de VC das malhas computacionais para o caso advecção pura.

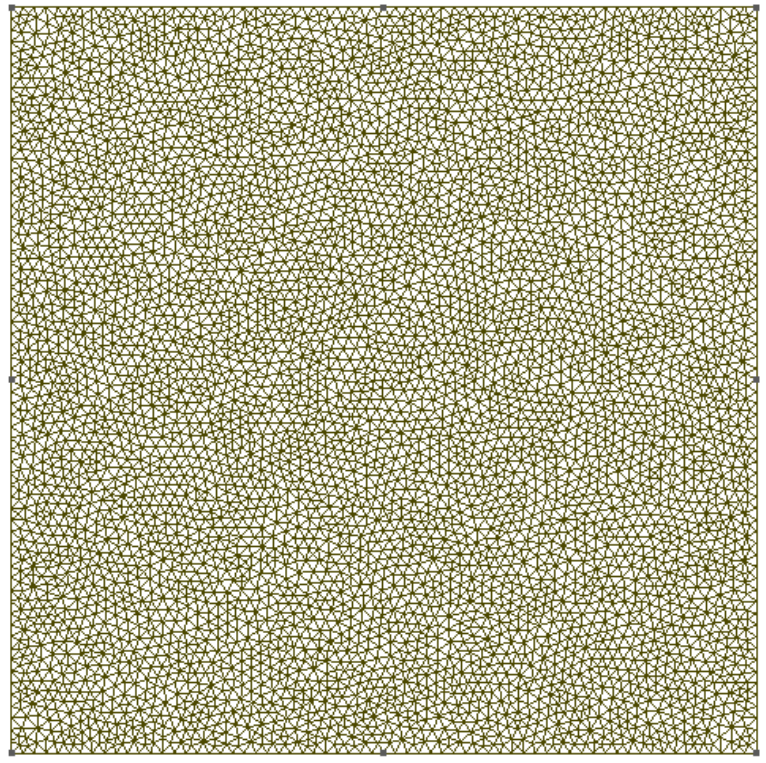

(a) Malha 1 (5520 vértices).

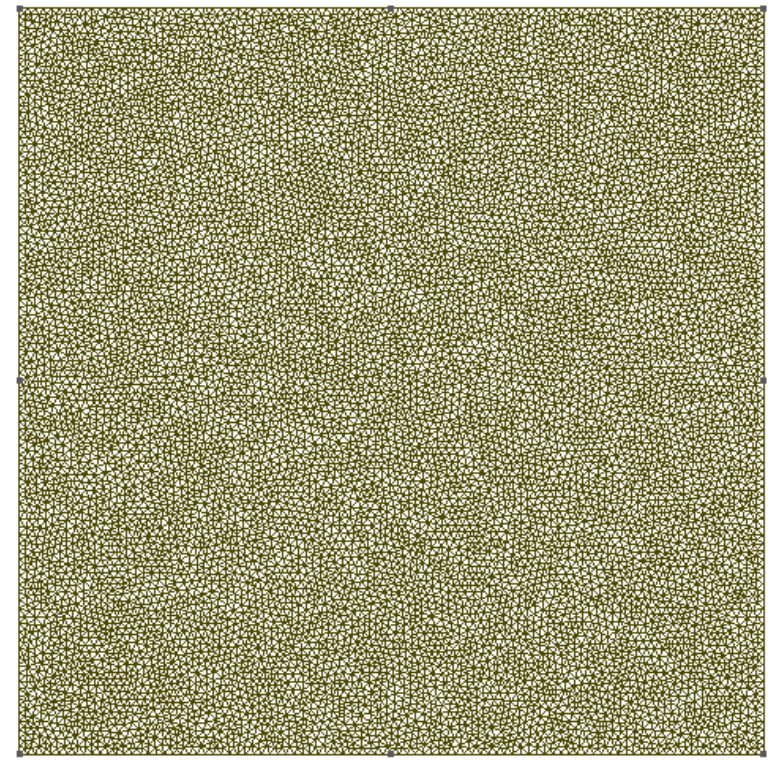

(b) Malha 2 (11400 vértices).

Figura 2.8: Malhas computacionais para o caso advecção pura. 


\section{Ordem obtida nos testes}

São consideradas sete malhas computacionais e três ordens do método de VF (2a, 3a e 4a ordem). Para cada combinação Ordem-Malha obtem-se uma solução numérica $\bar{\phi}_{i}$ para o tempo $t=1 \mathrm{~s}$. Essa solução numérica é comparada com a solução exata $\bar{\phi}_{i}^{\text {exata }}$ (baseada na equação (2.34)). O erro (equações (2.30), (2.31) e (2.32)) serve para quantificar essa diferença. O erro medido na norma $L_{1}, L_{2}$ e $L_{\infty}$ é mostrado nas Figuras 2.9(a), 2.9(b) e 2.9(c) respectivamente. Os eixos dessas figuras estão em escala logarítmica e os resultados estão classificados segundo a ordem (nominal) do método de VF. Observa-se que os testes com alta-ordem possuem resultados mais precisos. Por exemplo, na norma $L_{1}$, o erro obtido com 4 a ordem é de 3 a 12 vezes menor que o erro obtido com 2a ordem. E na norma $L_{\infty}$, o erro obtido com 4 a ordem é de 4 a 8 vezes menor que o erro obtido com 2a ordem. Agora, é importante lembrar que este caso de advecção pura é um problema não estacionário. Portanto,

$$
\text { Norma do Erro } \propto(\Delta x)^{m} \cdot(\Delta t)^{n},
$$

onde $\Delta x$ é o comprimento característico de uma malha e $\Delta t$ é o passo de tempo global (equação (2.12)). Ora, dadas as características dos testes, tem-se que $\Delta t$ e $\Delta x$ são proporcionais. Por isso, a equação (2.35) é re-escrita como

$$
\text { Norma do Erro } \propto(\Delta x)^{m+n}=(\Delta x)^{k},
$$

onde $k$ é a ordem espaço-tempo, isto é, a ordem conjunta da discretização espacial (VF) e temporal (RK). A discretização espacial de Diferença Espectral de alta-ordem com o esquema RK de 4 estágios do tipo Jameson atinge ordem 2 (Premasuthan, 2010). No presente trabalho, também obtem-se 2a ordem (Tabela 2.3): o erro médio (norma $L_{1}$ ) obtido com o método de VF de 4 a ordem atinge uma ordem efetiva de 2,34 e com 2a ordem alcança uma ordem de 1,83; o erro máximo (norma $L_{\infty}$ ) obtido com o método de VF de 4 a ordem atinge uma ordem efetiva de 1,71 e com $2 \mathrm{a}$ ordem alcança uma ordem de 1,82. Na literatura, encontra-se uma classe de métodos de integração no tempo que preservam propriedades de estabilidade e que alcançam uma precisão espaço-tempo de alta-ordem. Por exemplo, Shu (1988) apresenta um esquema Runge-Kutta do tipo SSP (Strong Stability Preserving) de 2a e 3a ordem. E Spiteri e Ruuth (2002) apresentam um esquema SSP-RK de 4a ordem de precisão. Estes esquemas de alta-ordem não são considerados no presente trabalho. A seguir, apresenta-se a maneira como são encontradas as ordens da Tabela 2.3. Da equação (2.36) tem-se que

$$
\text { Norma do Erro } \propto\left(\frac{1}{\sqrt{N}}\right)^{k}
$$

onde $N$ é o número de volumes de controle da malha com comprimento característico $\Delta x$. Reescrevendo esta última equação em termos logarítmicos tem-se a expressão

$$
\log (\text { Norma do Erro })=\log (C)-\frac{k}{2} \log (N) .
$$

Nesse sentido, as ordens $k$ da Tabela 2.3 são encontradas utilizando o ajuste dos mínimos quadrados (Burden e Faires, 2004) da forma

$$
\log (\text { Norma do Erro })=\log (b)+a \log (N),
$$

aos resultados do método de VF de ordem (nominal) $p$. Assim, a ordem efetiva $k$ dos testes com o método de VF de ordem $p$ é $-2 a$. 

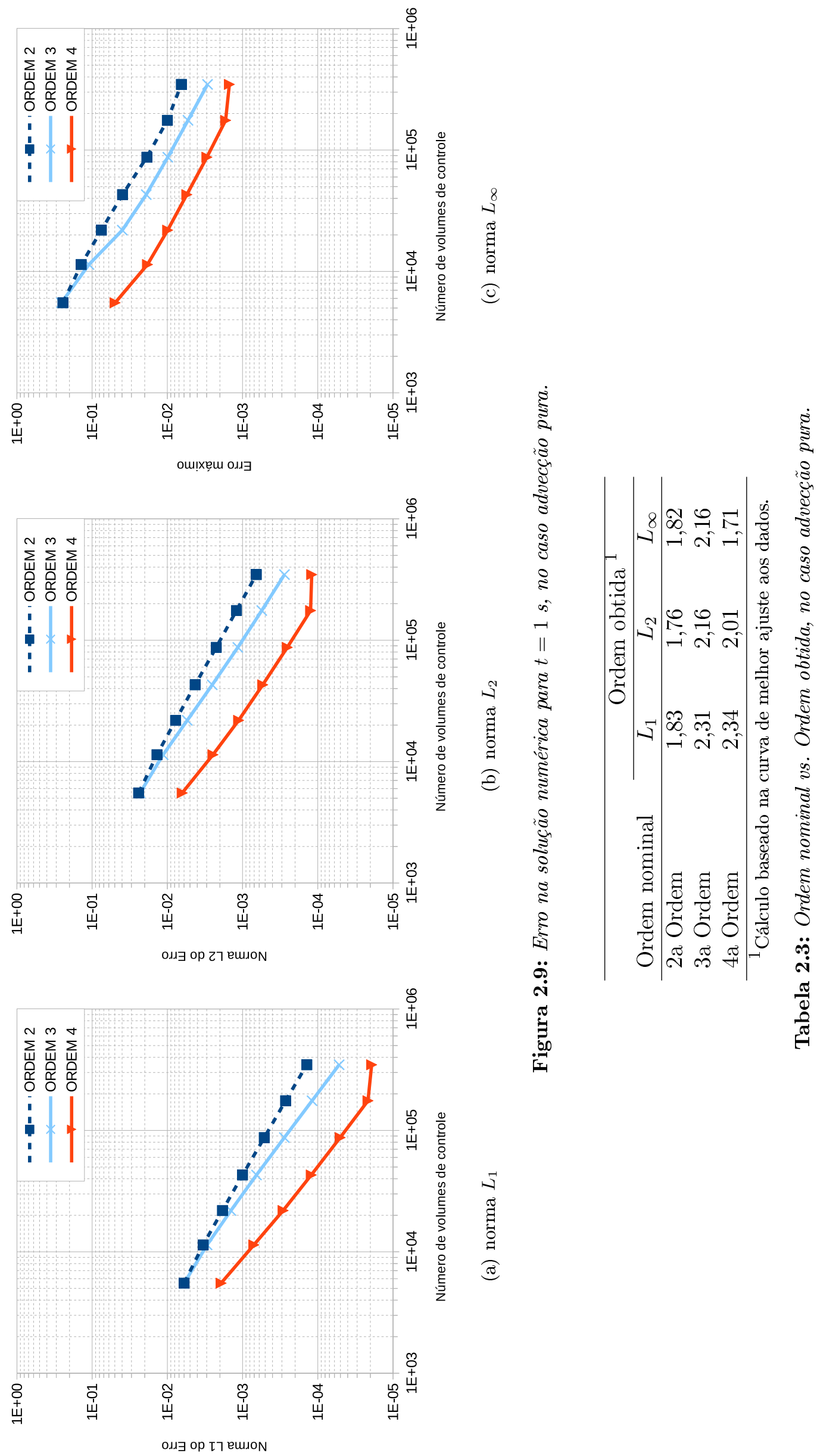


\section{Desempenho dos testes}

Neste trabalho o custo computacional é estimado com o tempo que a CPU demora em rodar um teste. Todos os testes foram executados sob as mesmas condições (o mesmo computador, a mesma solução inicial, o mesmo critério de parada, etc). O esquema de integração no tempo utilizado neste caso (advecção pura) é o esquema RK de 4 estágios clássico (Jameson et al., 1981). Nesse artigo se deduz que, o esquema RK junto a um método de VF de ordem 2 é estável para valores CFL de até $2 \sqrt{2}$, na resolução de um problema advectivo modelo. No presente trabalho, considera-se $\mathrm{CFL}=0,9$. Assim, os tempos de CPU mostrados neste caso não são, necessariamente, os melhores. Mas é possível dar uma interpretação qualitativa aos testes.

As Figuras 2.10(a) e 2.10(b) mostram o erro máximo versus o número de VC e o tempo de CPU. Por exemplo, a combinação 4a ordem-Malha $2(11400 \mathrm{VC})$ resulta num erro máximo de $2 \times 10^{-2} \mathrm{e}$ leva um tempo de $1550 \mathrm{~s}$. Ora, a combinação 2a ordem-Malha 5 (87365 VC) também resulta num erro máximo de $2 \times 10^{-2}$ mas leva um tempo de $5720 \mathrm{~s}$. Comparando esses dois testes, tem-se que a 4 a ordem leva 3,7 vezes menos tempo que a 2 a ordem para obter o mesmo erro $\left(2 \times 10^{-2}\right)$. Também há combinações Ordem-Malha que resultam em erros máximos de $10^{-2}$. Nesses testes a $4 \mathrm{a}$ ordem leva $4100 \mathrm{~s}$ e a $2 \mathrm{a}$ ordem leva $21700 \mathrm{~s}$ ( 5,3 vezes o tempo da $4 \mathrm{a}$ ordem). Por fim, a Figura 2.11 mostra três combinações Ordem-Malha que resultam em erros máximos de 5,5 $\times 10^{-3}$ : uma de 4 a ordem, outra de $3 \mathrm{a}$ ordem e a última de $2 \mathrm{a}$ ordem. Nesta figura apresentam-se os erros medidos na norma $L_{\infty}$ e $L_{2}$ assim como o tempo de CPU dessas três combinações. Os erros são comparáveis (eles são da mesma ordem de magnitude) mas a maior diferença está nos tempos de CPU: a combinação de ordem 4 é 10 vezes mais rápida que a de ordem 2. Vale destacar de novo que, esses tempos de CPU não são os ótimos mas dão indícios da superioridade da 4a ordem. Nos seguintes casos (advecção-difusão), sim se conclui que a alta-ordem é mais eficiente.

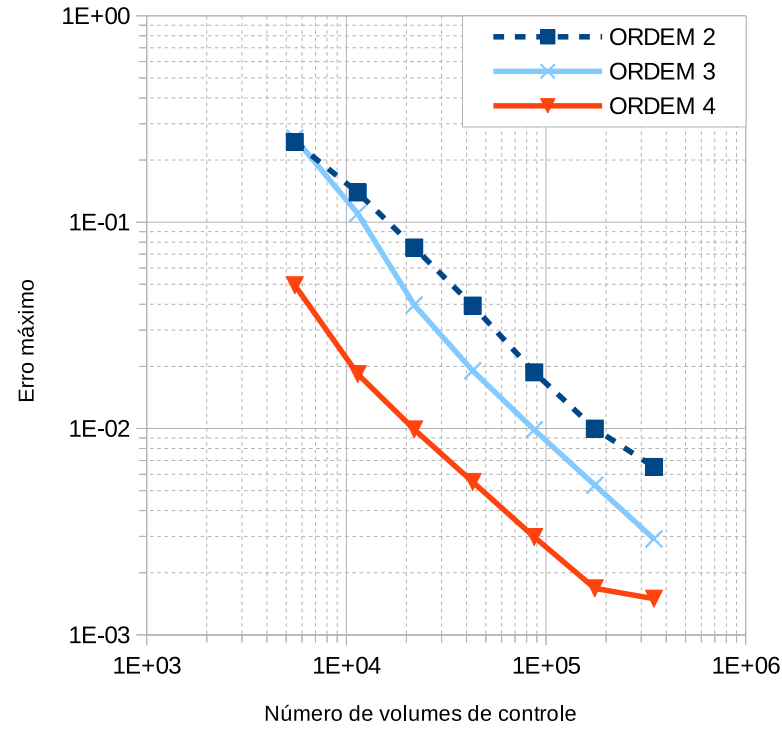

(a)

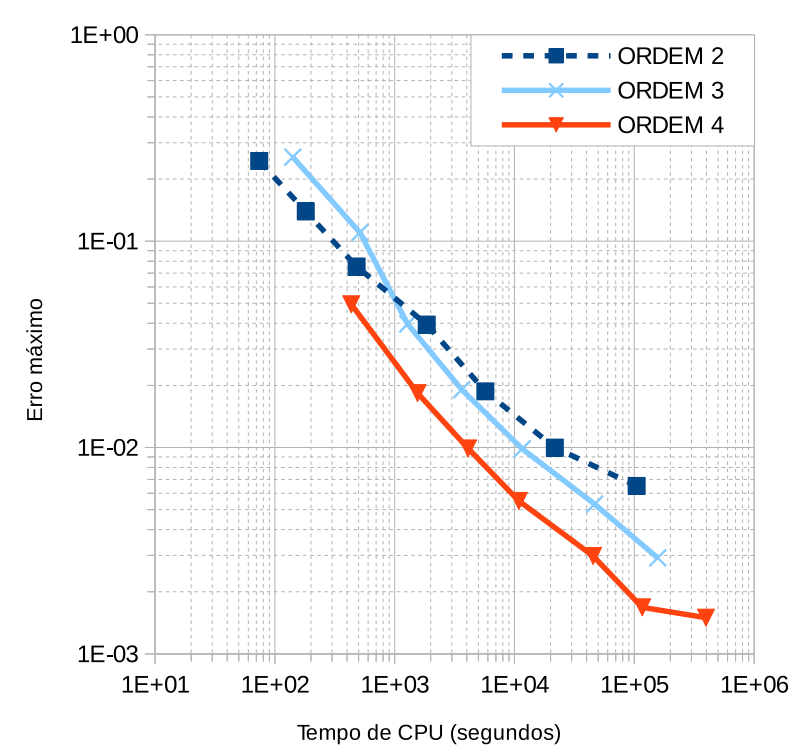

(b)

Figura 2.10: Erro máximo versus Número de VC e Tempo de CPU, no caso advecção pura. 


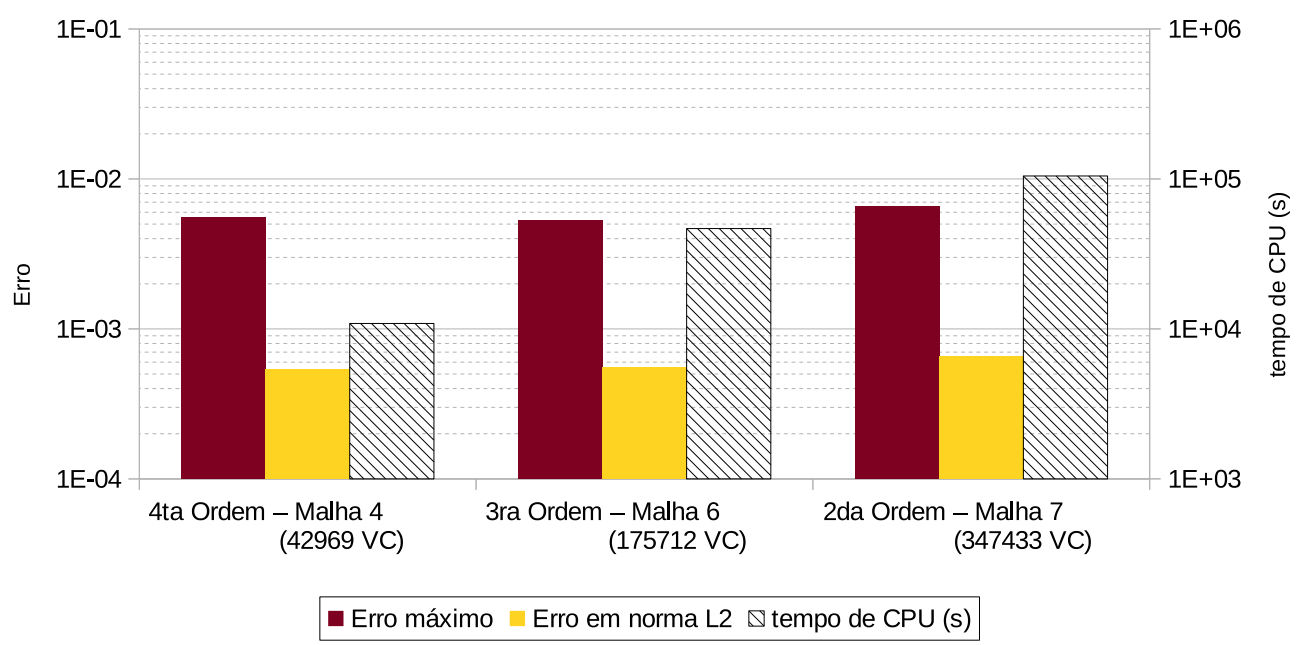

Figura 2.11: Combinações Ordem-Malha que resultam num erro máximo de $5,5 \times 10^{-3}$, no caso advecção pura.

\subsubsection{Advecção-difusão em um canal retangular}

Considere a equação de advecção-difusão bidimensional,

$$
\frac{\partial \phi}{\partial t}+\frac{\partial \phi}{\partial x}=\alpha\left(\frac{\partial^{2} \phi}{\partial x^{2}}+\frac{\partial^{2} \phi}{\partial y^{2}}\right)
$$

com $\alpha \equiv 0,01$ (coeficiente de difusão); observe-se que a velocidade de advecção tem componentes $u \equiv 1$ e $v \equiv 0$. O domínio deste problema é o retângulo $[0,3] \times[0,1]$. As condições de fronteira são iguais a:

$$
\begin{aligned}
\phi(x, 0)=\phi(x, 1) & =0 \\
\phi(0, y) & =\operatorname{sen}(\pi y) \\
\frac{\partial \phi}{\partial x}(3, y) & =0 .
\end{aligned}
$$

Com esses dados, a solução $\phi$ da equação de advecção-difusão alcança o estado estacionário (Figura 2.12). A expressão da solução estacionária é a seguinte (Ollivier-Gooch e van Altena, 2002):

$$
\phi(x, y)=\operatorname{sen}(\pi y)\left[\frac{e^{s_{2} \cdot x}-\frac{s_{2}}{s_{1}} e^{\left(s_{2}-s_{1}\right) L+s_{1} \cdot x}}{1-\frac{s_{2}}{s_{1}} e^{\left(s_{2}-s_{1}\right) L}}\right],
$$

onde $L$ é o comprimento do canal, ou seja, 3 e

$$
s_{1,2}=\frac{1 \pm \sqrt{1^{2}+(2 \pi \cdot 0,01)^{2}}}{2 \cdot 0,01} .
$$

\section{Descrição dos testes}

Soluções estacionárias numéricas são obtidas pelo código VF-RK com passo local de tempo (Seção 2.2). Considera-se $\mathrm{CFL}=1,0$ na definição desse passo local de tempo. A solução nula é utilizada como solução inicial do processo iterativo: $\bar{\phi}_{i}=0$ para cada $\mathrm{VC}_{i}$. O critério de parada está baseado no resíduo: $O$ processo iterativo é interrompido quando a norma $L_{2}$ do resíduo converge a $10^{-10}$. Para dar início a um teste, o código VF-RK precisa de dois dados de entrada: a malha computacional e a ordem (nominal) do método de VF. 


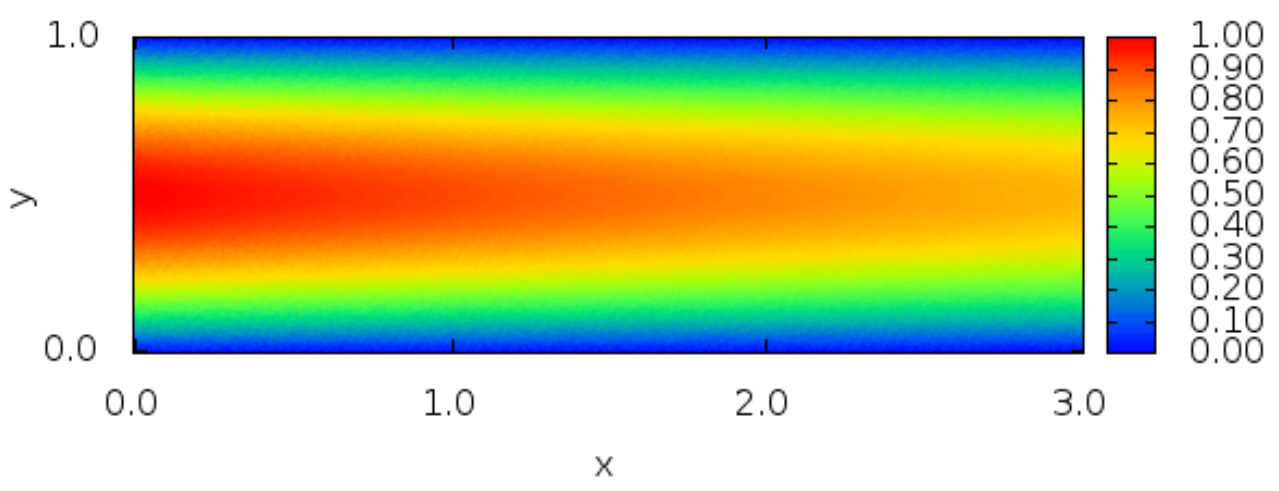

Figura 2.12: Solução estacionária da equação de advecção-difusão no canal retangular.

Com o Gmsh (Geuzaine e Remacle, 2009) criam-se seis malhas computacionais. Os vértices das malhas são distribuídos equitativamente em todo o retângulo. A Figura 2.13 mostra quatro das seis malhas computacionais. Começando pela Malha 1, as seguintes malhas são geradas uma a partir da anterior, seguindo a metodologia descrita no caso de Adveç̧ão Pura (Seção 2.6.1). A Tabela 2.4 mostra o número de $\mathrm{VC}$ dessas malhas. O Gmsh permite salvar os dados das malhas em arquivos de texto. O código VF-RK consegue ler o arquivo da malha computacional selecionada e dar início a um teste.

\begin{tabular}{|c|c|c|c|c|c|c|}
\hline \multirow{2}{*}{ No. de $V C$} & Malha 1 & Malha & Malha 3 & Malha 4 & Malha & Malha 6 \\
\hline & 260 & 548 & 1021 & 2016 & 4006 & 8079 \\
\hline
\end{tabular}

Tabela 2.4: Número de VC das malhas computacionais para o caso advecção-difusão no canal retangular.

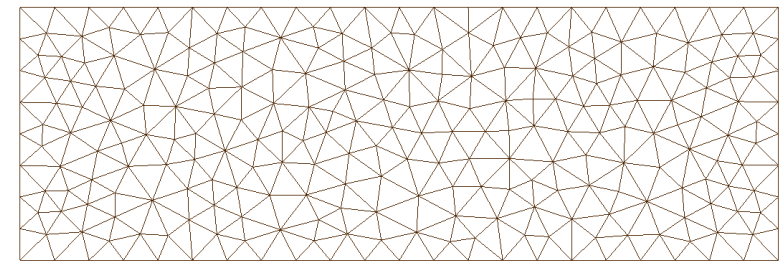

(a) Malha 1 (260 vértices).

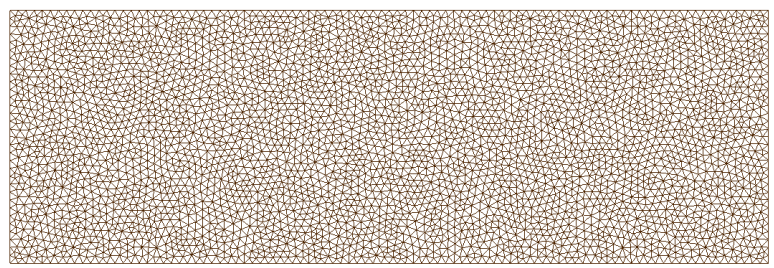

(c) Malha 5 (4006 vértices).

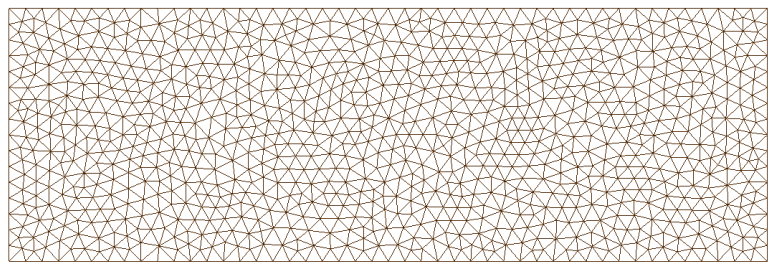

(b) Malha 3 (1021 vértices).

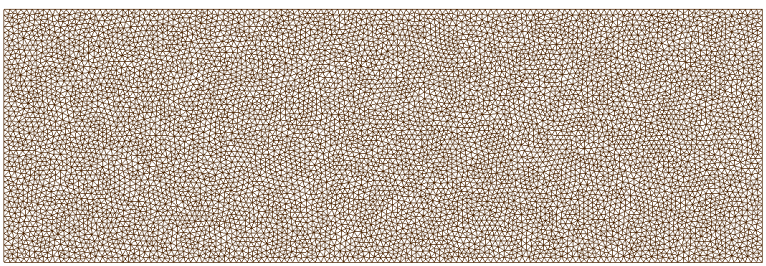

(d) Malha 6 (8079 vértices).

Figura 2.13: Malhas computacionais para o caso advecção-difusão no canal retangular.

\section{Ordem obtida nos testes}

São consideradas seis malhas computacionais e três ordens do método de VF (2a, 3a e 4a ordem). Para cada combinação Ordem-Malha obtem-se uma solução estacionária numérica $\bar{\phi}_{i}$, que 
é comparada com a solução estacionária exata $\bar{\phi}_{i}^{\text {exata }}$ (baseada na equação (2.40)). O erro (equações (2.30), (2.31) e (2.32)) serve para quantificar essa diferença. O erro medido na norma $L_{1}, L_{2}$ e $L_{\infty}$ é mostrado nas Figuras 2.14(a), 2.14(b) e 2.14(c) respectivamente. Os eixos dessas figuras estão em escala logarítmica e os resultados estão classificados segundo a ordem (nominal) do método de VF. Como é de esperar, os testes com alta-ordem possuem resultados mais precisos. Por exemplo, na norma $L_{1}$, o erro obtido com 4 a ordem é de 10 a 1000 vezes menor que o erro obtido com 2 a ordem. E na norma $L_{\infty}$, o erro obtido com 4 a ordem é de 8 a 28 vezes menor que o erro obtido com 2 a ordem. Note que a superioridade do método de 4 a ordem é mais evidente na norma $L_{1}$ do que na norma $L_{\infty}$. Isto também se verifica na Tabela 2.5: o erro médio (norma $L_{1}$ ) obtido com 4 a ordem atinge uma ordem efetiva de 4,25 e com 2a ordem alcança uma ordem de 1,64; já o erro máximo (norma $L_{\infty}$ ) obtido com 4 a ordem atinge uma ordem efetiva de 2,29 (menor à nominal) e com 2a ordem alcança uma ordem de 1,60. Da Figura 2.14, observa-se que a combinação do método de 3a ordem com as malhas mas finas resulta no mesmo erro (medido na norma $L_{2}$ ). Ora, considerando as seis malhas, a ordem efetiva do esquema de 3a ordem é de 3,36 (para o erro médio) e 3,18 (para o erro máximo). A seguir, apresenta-se a maneira como são encontradas as ordens da Tabela 2.5. Se o método de VF é de ordem (nominal) $p$ então é de esperar que:

$$
\text { Norma do Erro } \propto h^{p} \propto\left(\frac{1}{\sqrt{N}}\right)^{p},
$$

onde $h$ é o comprimento característico de uma malha e $N$ é o número de volumes de controle dessa malha. Re-escrevendo a equação (2.41) em termos logarítmicos tem-se a expressão

$$
\log (\text { Norma do Erro })=\log (C)-\frac{p}{2} \log (N) .
$$

Nesse sentido, as ordens $\hat{p}$ da Tabela 2.5 são encontradas utilizando o ajuste dos mínimos quadrados (Burden e Faires, 2004) da forma

$$
\log (\text { Norma do Erro })=\log (b)+a \log (N)
$$

aos resultados com ordem nominal $p$. Assim, a ordem efetiva $\hat{p}$ do método de VF de ordem $p$ é $-2 a$.

Para finalizar a validação, compara-se este trabalho com o artigo de Ollivier-Gooch e van Altena (2002). Nesse artigo são utilizadas quatro malhas computacionais. As duas malhas mais finas tem 511 e 1965 volumes de controle vertex-centered. Essas malhas correspondem as malhas 2 (548 VC) e 4 (2016 VC) do presente trabalho. Consequentemente, apenas essas malhas são utilizadas para a comparação de ambos os trabalhos. A Figura 2.15 mostra o erro medido em norma $L_{1}$ obtido pelas combinações Ordem-Malha. Observa-se que, ambos os trabalhos conseguem resultados similares. Por exemplo, com o método de 4a ordem, o erro obtido por Ollivier-Gooch e van Altena (2002) cai de $8 \times 10^{-5}$ para $6 \times 10^{-6}$, e o erro obtido no presente trabalho cai de $4,5 \times 10^{-5}$ para $2,5 \times 10^{-6}$. As magnitudes são similares, mas também é visível uma ligeira diferença na ordem obtida com o método de $4 \mathrm{a}$ ordem. Isto se verifica na Tabela 2.6: Com o método de $4 \mathrm{a}$ ordem (nominal), a ordem obtida por Ollivier-Gooch e van Altena (2002) é de 3,93 (para a norma $L_{1}$ ) e 2,13 (para a norma $L_{\infty}$ ), e a ordem obtida no presente trabalho é de 4,39 (para a norma $L_{1}$ ) e 1,80 (para a norma $L_{\infty}$ ). Na norma $L_{1}$, então, os dois trabalhos alcançam a ordem nominal. Já, na norma $L_{\infty}$, ambos os trabalhos não atingem a ordem nominal. Com o método de 3 a ordem, ambos os trabalhos atingem a ordem nominal, porém o presente trabalho tem ordens efetivas maiores $\left(3,45\right.$ na norma $\left.L_{\infty}\right)$. E por fim, com o método de 2 a ordem, ambos trabalhos tem ordens efetivas um pouco abaixo da nominal. O presente trabalho obtêm uma ordem de 1,50 na norma $L_{\infty}$. Vale destacar ainda que, o cálculo da ordem efetiva no artigo de Ollivier-Gooch e van Altena (2002) está baseado nas duas malhas mais finas, isto é, as malhas de 511 e $1965 \mathrm{VC}$ mencionadas acima. Por isso, as ordens do presente trabalho mostradas na Tabela 2.6 também estão baseadas em duas malhas (de 548 e 2016 VC). Para o cálculo dessas ordens utiliza-se a seguinte expressão que é uma consequência da equação 
(2.41):

$\frac{\text { Norma do Erro - Malha A }}{\text { Norma do Erro - Malha B }}=\left(\frac{\text { No. volumes de controle da Malha A }}{\text { No. volumes de controle da Malha B }}\right)^{-\frac{p}{2}}$. 


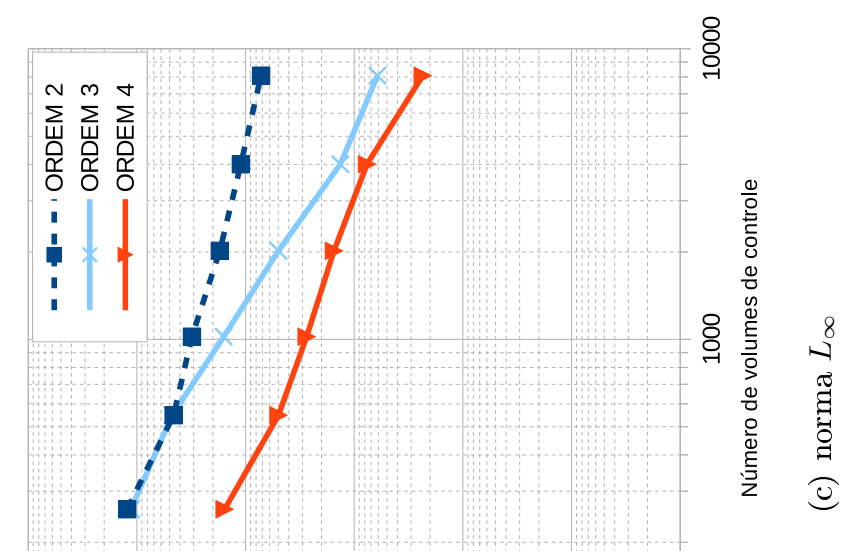

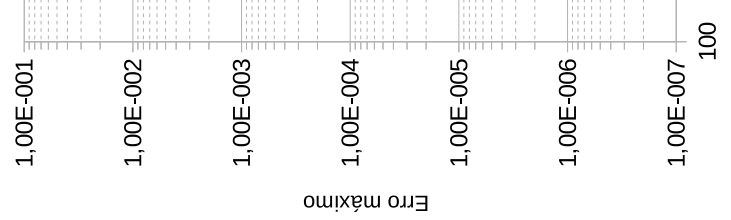
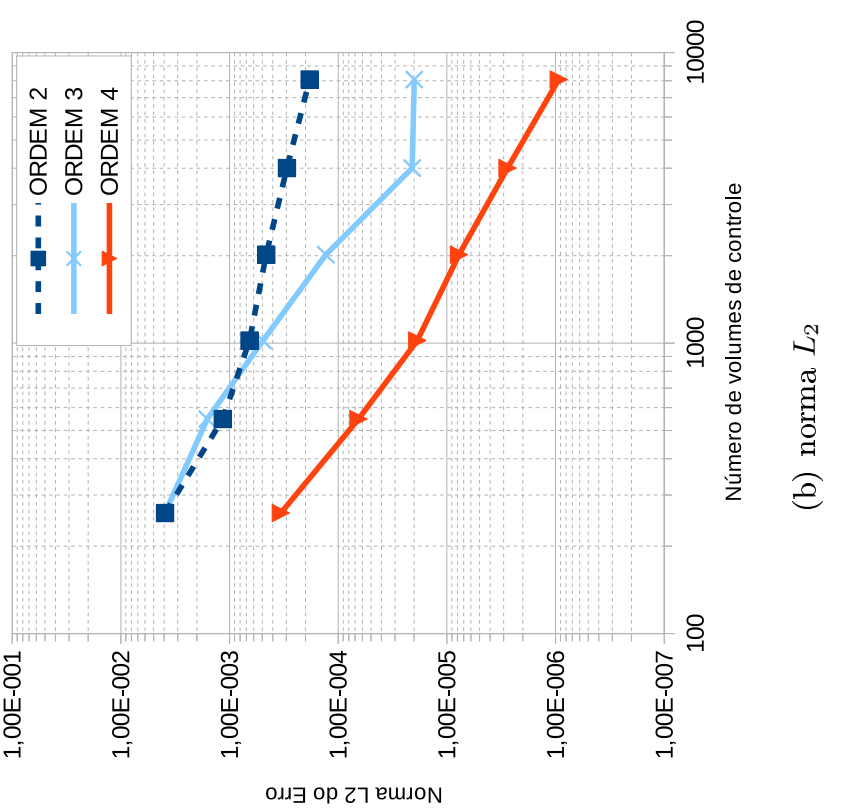

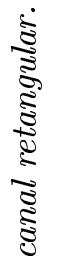

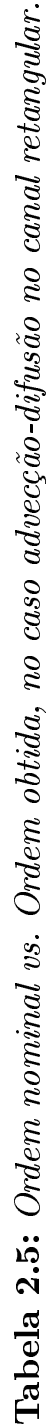

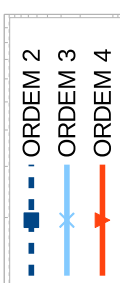

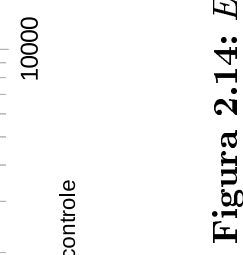

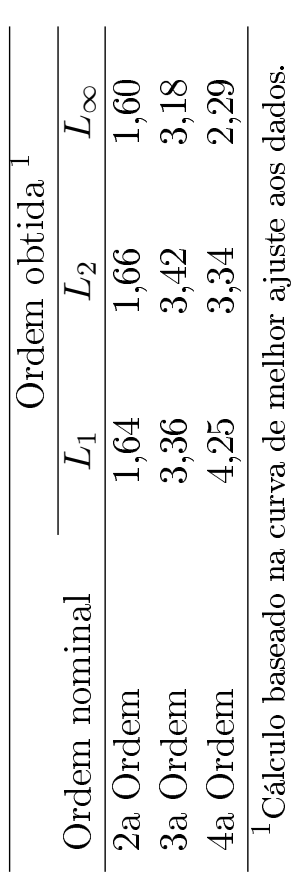

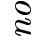

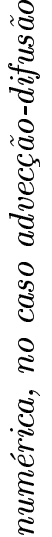

离

움

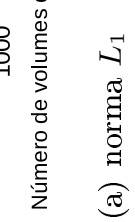

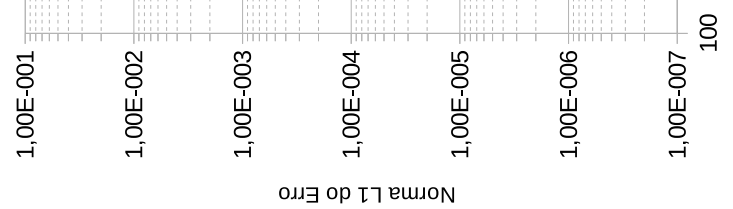




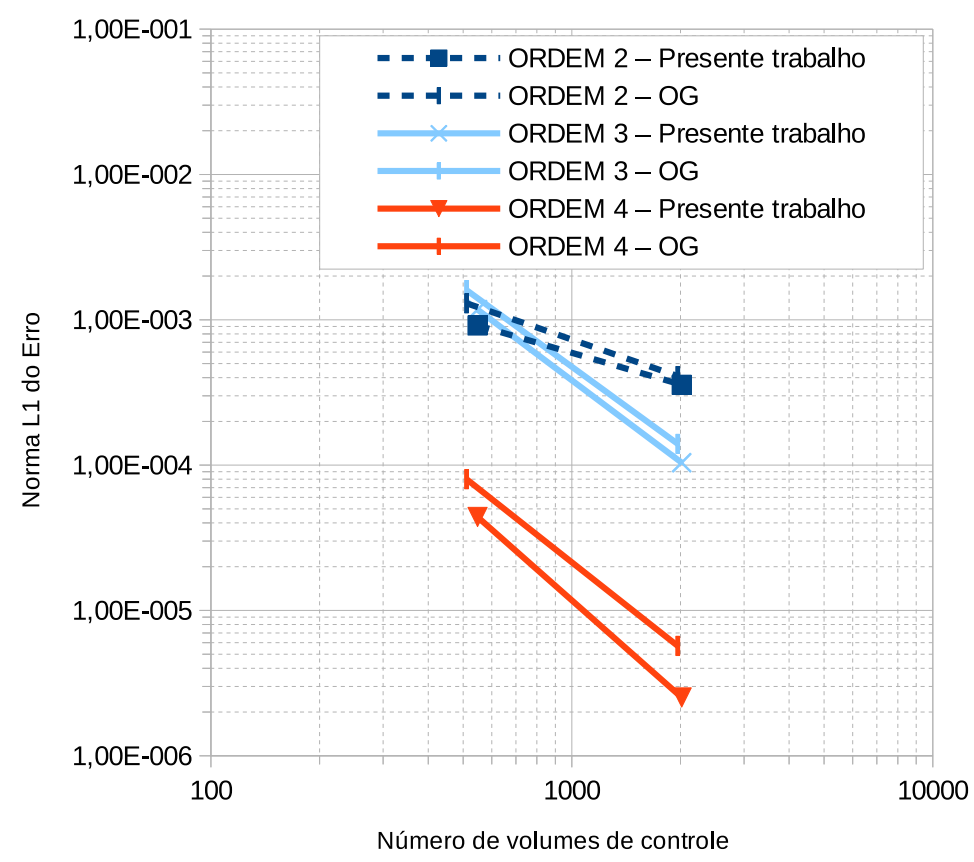

Figura 2.15: Comparação deste trabalho com o artigo de Ollivier-Gooch e van Altena (2002), no caso advecção-difusão no canal retangular.

\begin{tabular}{lccc}
\hline \multirow{2}{*}{ Ordem nominal } & \multicolumn{4}{c}{$L_{1}$ Ordem obtida } \\
\cline { 2 - 4 } & Presente trabalho ${ }_{2}$ & $L_{\infty}$ \\
2a Ordem & 1,44 & 1,41 & 1,50 \\
3a Ordem & 3,73 & 3,86 & 3,45 \\
4a Ordem & 4,39 & 3,27 & 1,80 \\
Ollivier-Gooch e van Altena (2002) & \\
2a Ordem & 1,70 & 1,65 & 1,66 \\
3a Ordem & 3,62 & 3,57 & 3,08 \\
4a Ordem & 3,93 & 3,09 & 2,13
\end{tabular}

${ }^{1}$ Cálculo baseado nas Malhas de 548 e 2016 VC deste trabalho.

${ }^{2}$ Cálculo baseado nas Malhas de 511 e 1965 VC de Ollivier-Gooch e van Altena (2002).

Tabela 2.6: Comparação de ordens obtidas no caso advecção-difusão no canal retangular.

\section{Desempenho dos testes}

Neste trabalho o custo computacional é estimado com o tempo que a CPU demora em rodar um teste. Todos os testes são executados sob as mesmas condições (o mesmo computador, o mesmo chute inicial, o mesmo critério de parada, etc). Utiliza-se $\mathrm{CFL}=1,0$ para o esquema RK; este valor não necessariamente é o valor máximo (valor limite do esquema explícito RK), portanto, os tempos de CPU registrados não são os ótimos. Contudo, cada tempo registrado não deve ser maior a 10 vezes o tempo ótimo porque, muito provavelmente, o CFL máximo é menor do que 10.

As Figuras 2.16(a) e 2.16(b) mostram o erro máximo versus o número de VC e o tempo de CPU. Por exemplo, a combinação 4a ordem-Malha 1 (260 VC) resulta num erro máximo de $1,5 \times 10^{-3} \mathrm{e}$ leva um tempo de 1 s. Ora, a combinação 2a ordem-Malha 4 (2016 VC) resulta num erro máximo aproximado de $2 \times 10^{-3}$ e leva um tempo de $9 \mathrm{~s}$. Comparando esses dois testes, tem-se que a $4 \mathrm{a}$ ordem leva 9 vezes menos tempo que a 2 a ordem para obter, aproximadamente, o mesmo erro $\left(2 \times 10^{-3}\right)$. Se o processo iterativo RK for otimizado, a diferença desses dois tempos poderia ser menor. Mas, 
como foi dito acima, o número CFL limita o tempo ótimo. Assim, esses dois testes dão um indício da superioridade da 4a ordem. Essas duas combinações Ordem-Malha podem ser comparadas ainda com a combinação 3a ordem-Malha $3(1021 \mathrm{VC})$ pois esta resulta num erro máximo de $1,5 \times 10^{-3}$. As três combinações são mostradas na Figura 2.17(a). Ali apresenta-se os erros medidos na norma $L_{\infty}$ e $L_{2}$ assim como o tempo de CPU dessas três combinações. Os erros são comparáveis (eles são da mesma ordem de magnitude) mas a maior diferença está nos tempos de CPU. As Figuras 2.17(b) e 2.17(c) mostram a distribuição do erro no canal retangular para os testes de 4a e 2a ordem, respectivamente. Ambas as figuras utilizam a mesma escala e os erros estão associados aos vértices. No teste de $4 \mathrm{a}$ ordem, percebe-se que os erros de magnitude $10^{-3}$ estão concentrados na região central do canal e próxima à saída (com condição de Neumann). No teste de 2 a ordem, os erros de magnitude $10^{-3}$ estão espalhados em toda a região central e estão misturados com erros de magnitude $10^{-5}$.

Analogamente, a Figura 2.18(a) mostra uma comparação entre combinações que resultam num erro máximo de $5 \times 10^{-4}$. A combinação 4 a ordem-Malha $2(548 \mathrm{VC})$ leva $3 \mathrm{~s}$, enquanto que a combinação 2a ordem-Malha 6 ( $8079 \mathrm{VC}$ ) leva $150 \mathrm{~s}$ (50 vezes mais). Mesmo que esses tempos não são os ótimos, a maior eficiência da 4a ordem está garantida: a relação entre os tempos é de 50 . As Figuras 2.18(b) e 2.18(c) mostram a distribuição do erro no canal retangular para esses testes de 4a e 2a ordem, respectivamente. Na região central do canal e próxima à saída, há erros de magnitude maior a $10^{-4}$, nos dois testes. E nas proximidades das fronteiras Dirichlet, há erros de magnitude menor a $10^{-5}$ nos dois testes porém, no teste de 2 a ordem, existem ainda erros de magnitude $10^{-4}$.

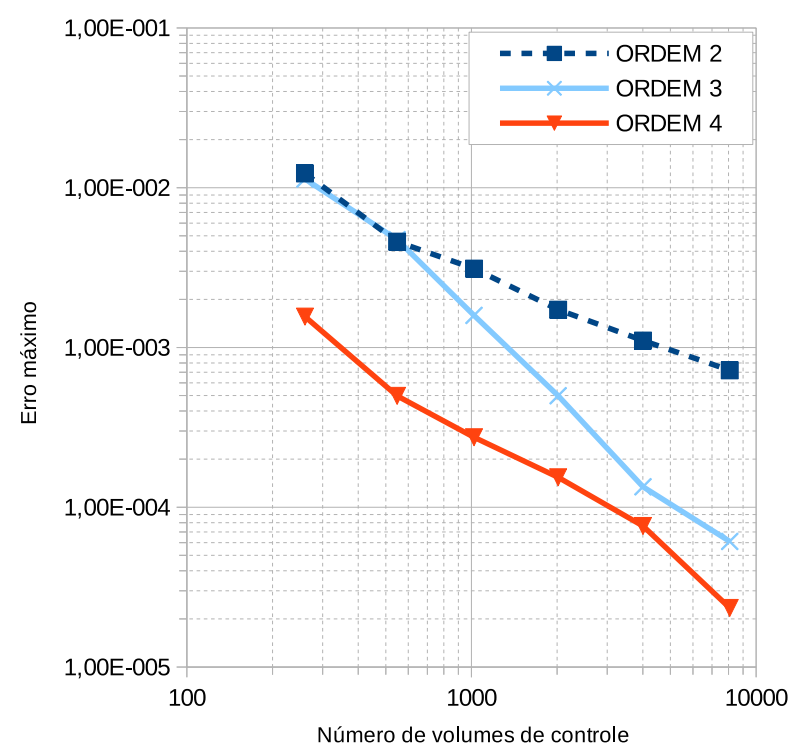

(a)

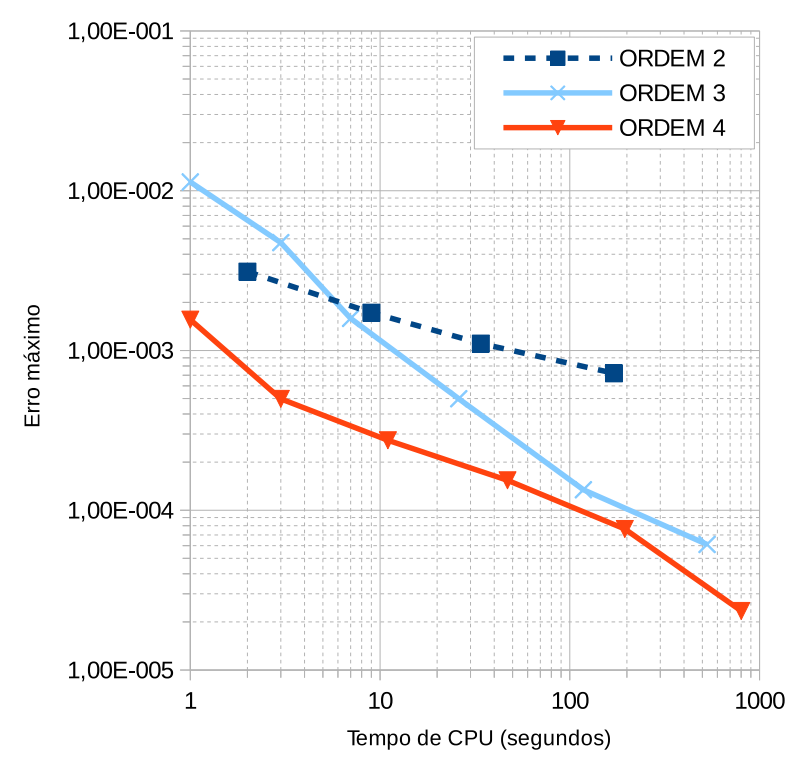

(b)

Figura 2.16: Erro máximo versus Número de VC e Tempo de CPU, no caso advecção-difusão no canal retangular. As combinações $2 a$ Ordem-Malha 1 e 2 a Ordem-Malha 2 levam um tempo de CPU menor a $1 s$ e não são mostrados em (b). 


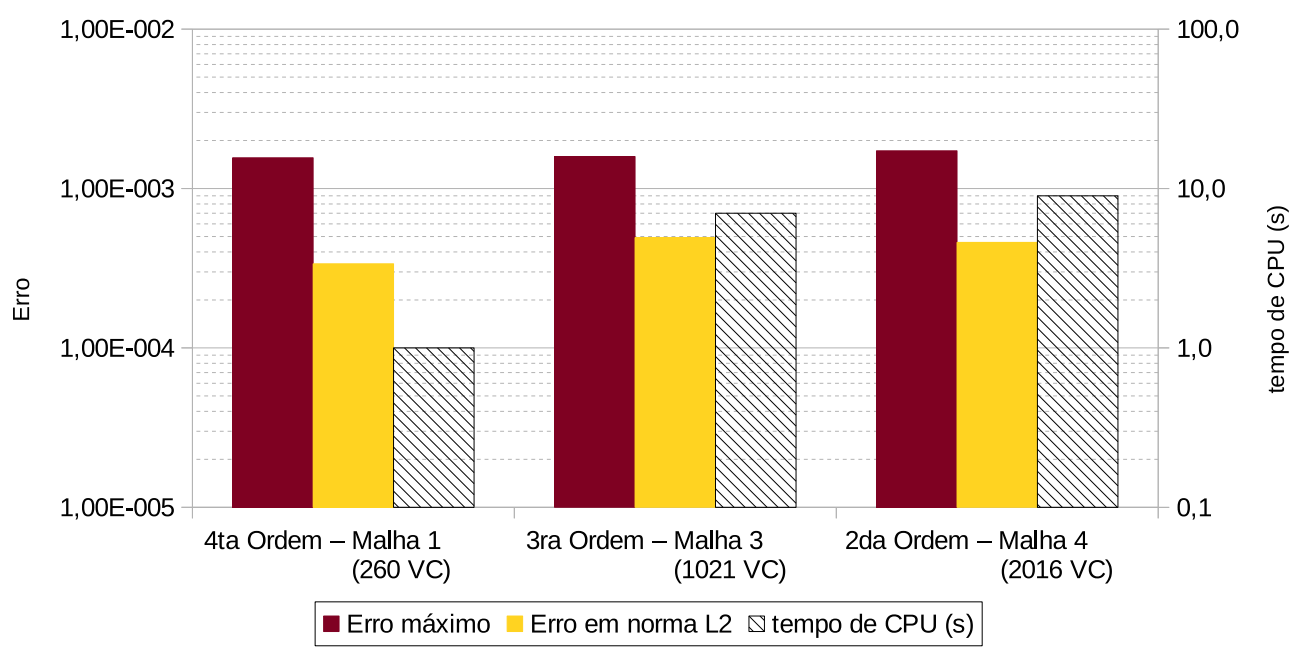

(a)
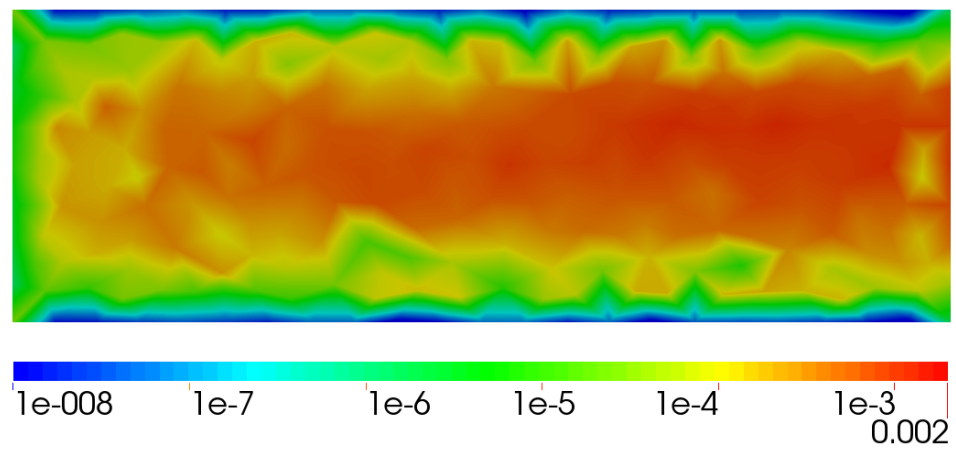

(b) Erro no teste de 4a Ordem com Malha 1 (260 VC)

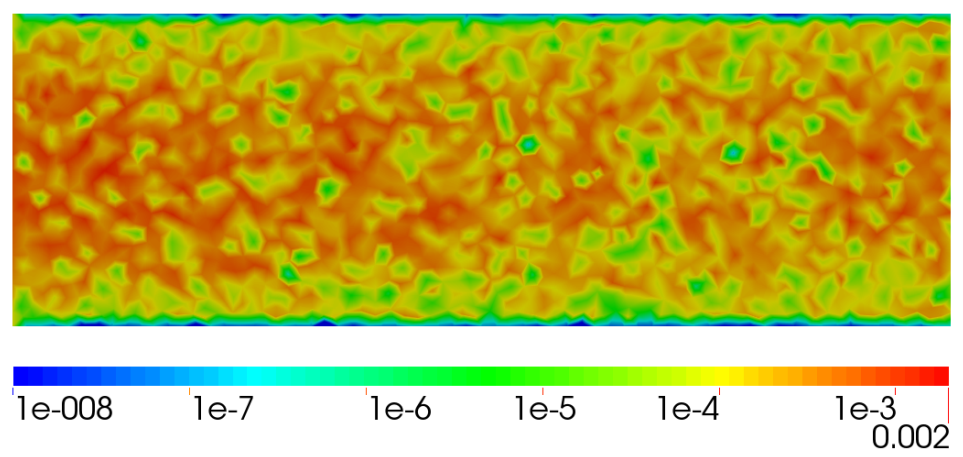

(c) Erro no teste de 2a Ordem com Malha 4 (2016 VC)

Figura 2.17: Combinações Ordem-Malha que resultam num erro máximo de $2 \times 10^{-3}$, no caso advecçãodifusão no canal retangular. 


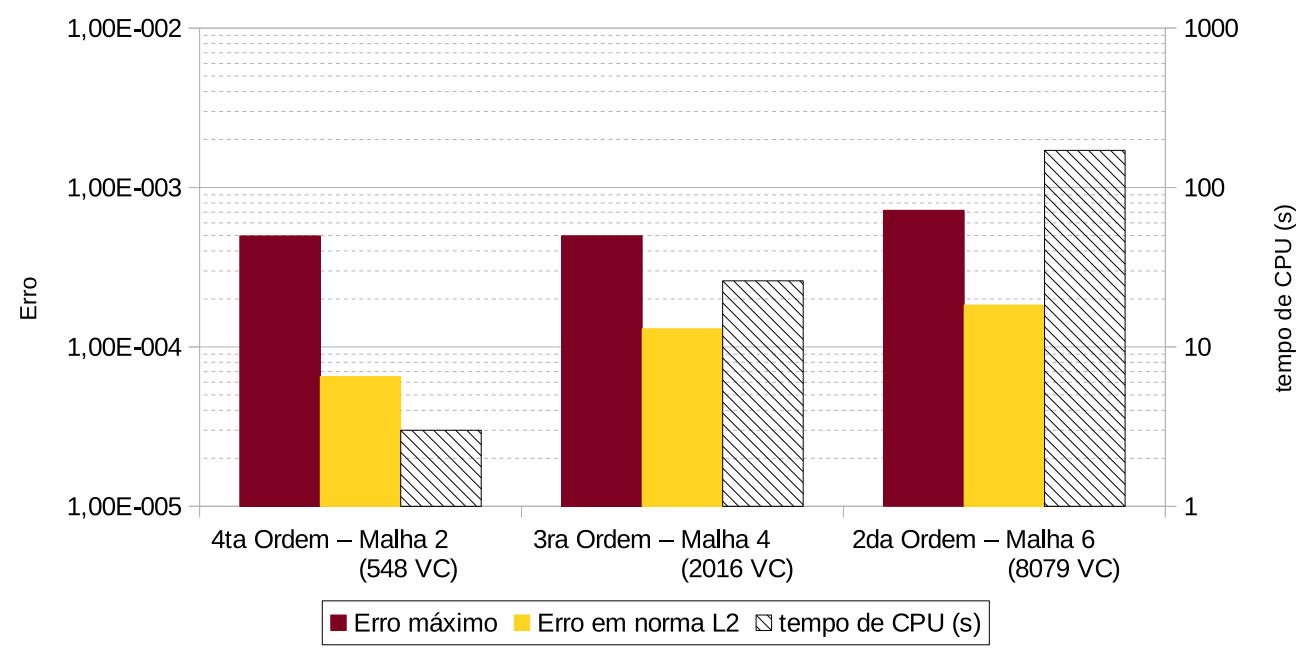

(a)
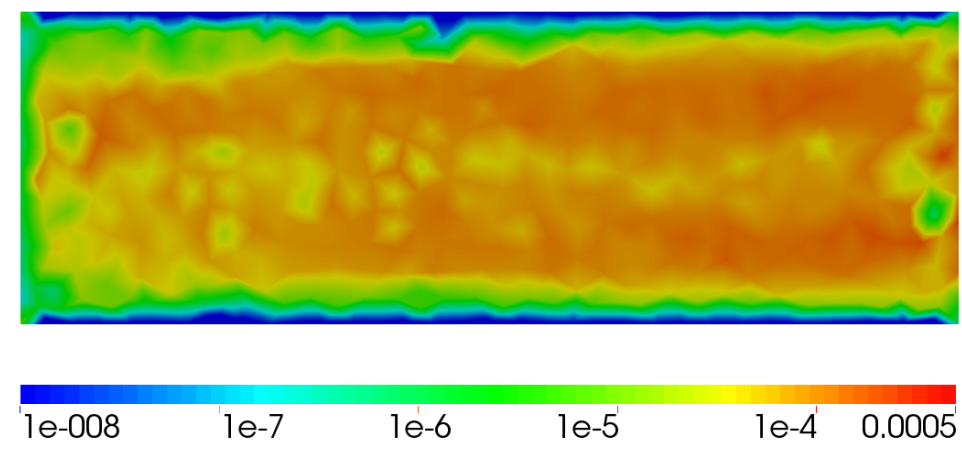

(b) Erro no teste de 4a Ordem com Malha 2 (548 VC)

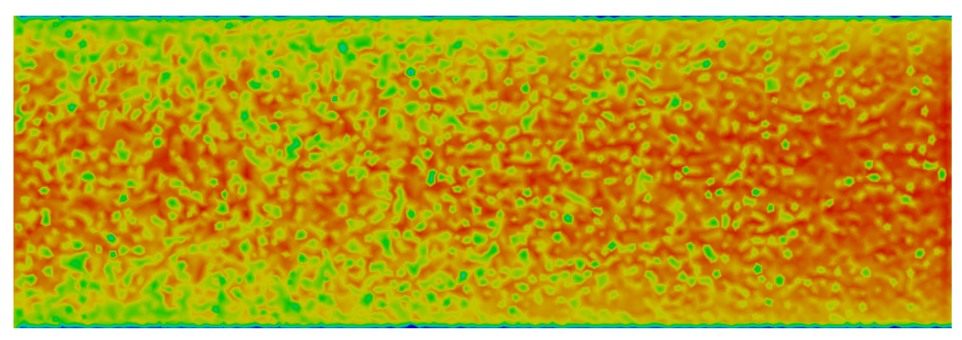

1e-008 le-7 le-6 le-5

(c) Erro no teste de 2a Ordem com Malha 6 (8079 VC)

Figura 2.18: Combinações Ordem-Malha que resultam num erro máximo de $5 \times 10^{-4}$, no caso advecçãodifusão no canal retangular. 


\subsubsection{Advecção-difusão em um segmento anular}

Considere a equação de advecção-difusão bidimensional,

$$
\frac{\partial \phi}{\partial t}+\frac{\partial(u \phi)}{\partial x}+\frac{\partial(v \phi)}{\partial y}=\alpha\left(\frac{\partial^{2} \phi}{\partial x^{2}}+\frac{\partial^{2} \phi}{\partial y^{2}}\right)
$$

com

$$
\begin{aligned}
\alpha & \equiv 0,01 \\
u(x, y) & \equiv \frac{-y}{x^{2}+y^{2}} \\
v(x, y) & \equiv \frac{x}{x^{2}+y^{2}} .
\end{aligned}
$$

O domínio deste problema é o segmento anular mostrado na Figura 2.19. As condições de fronteira são iguais a:

$$
\begin{aligned}
\phi & =0 \text { nas fronteiras curvas, } \\
\phi(x, 0) & =\operatorname{sen}\left(\frac{\pi \ln x}{\ln 2}\right) \text { na fronteira horizontal e, } \\
\frac{\partial \phi}{\partial x}(0, y) & =0 \text { na fronteira vertical. }
\end{aligned}
$$

Com esses dados, a solução $\phi$ da equação de advecção-difusão alcança o estado estacionário (Figura 2.19). A expressão da solução estacionária é a seguinte (Ollivier-Gooch e van Altena, 2002):

$$
\phi(x, y)=\operatorname{sen}\left(\frac{\pi \ln r}{\ln 2}\right)\left[\frac{e^{s_{2} \cdot \theta}-\frac{s_{2}}{s_{1}} e^{\left(s_{2}-s_{1}\right) \pi / 2+s_{1} \cdot \theta}}{1-\frac{s_{2}}{s_{1}} e^{\left(s_{2}-s_{1}\right) \pi / 2}}\right],
$$

onde $(r, \theta)$ são as coordenadas polares do ponto $(x, y) \mathrm{e}$

$$
s_{1,2}=\frac{1 \pm \sqrt{1^{2}+\left(\frac{2 \pi \alpha}{\ln 2}\right)^{2}}}{2 \alpha} .
$$

\section{Descrição dos testes}

Soluções estacionárias numéricas são obtidas pelo código VF-RK com passo local de tempo (Seção 2.2). Considera-se $\mathrm{CFL}=1,0$ na definição desse passo local de tempo. A solução nula é utilizada como solução inicial do processo iterativo: $\bar{\phi}_{i}=0$ para cada $\mathrm{VC}_{i}$. O critério de parada está baseado no resíduo: $O$ processo iterativo é interrompido quando a norma $L_{2}$ do resíduo converge a $10^{-10}$. Para dar início a um teste, o código VF-RK precisa de dois dados de entrada: a malha computacional e a ordem (nominal) do método de VF.

Com o Gmsh (Geuzaine e Remacle, 2009) criam-se sete malhas computacionais. Os vértices das malhas são distribuídos equitativamente em todo o segmento anular. A Figura 2.20 mostra quatro das sete malhas computacionais. Começando pela Malha 1, as seguintes malhas são geradas uma a partir da anterior, seguindo a metodologia descrita no caso de Advecção Pura (Seção 2.6.1). A Tabela 2.7 mostra o número de VC dessas malhas. O Gmsh permite salvar os dados das malhas em arquivos de texto. O código VF-RK consegue ler o arquivo da malha computacional selecionada e dar início a um teste. 


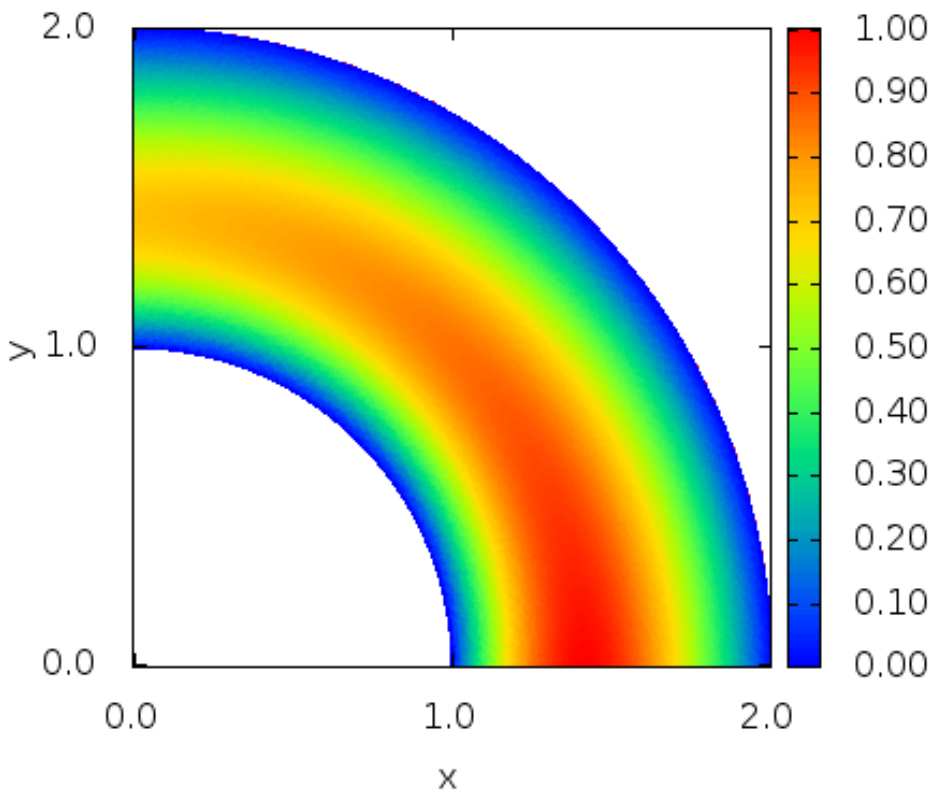

Figura 2.19: Solução estacionária da equação de advecção-difusão no segmento anular.

\begin{tabular}{|cccccccc|}
\cline { 2 - 8 } No. de VC & Malha 1 & Malha 2 & Malha 3 & Malha 4 & Malha 5 & Malha 6 & Malha 7 \\
\cline { 2 - 8 } & 137 & 252 & 532 & 1074 & 2081 & 4075 & 8144 \\
\hline
\end{tabular}

Tabela 2.7: Número de VC das malhas computacionais para o caso advecção-difusão no segmento anular.

\section{Ordem obtida nos testes}

São consideradas sete malhas computacionais e três ordens do método de VF (2a, 3a e 4a ordem). Para cada combinação Ordem-Malha obtem-se uma solução estacionária numérica $\bar{\phi}_{i}$, que é comparada com a solução estacionária exata $\bar{\phi}_{i}^{\text {exata }}$ (baseada na equação (2.45)). O erro (equações (2.30), (2.31) e (2.32)) serve para quantificar essa diferença. O erro medido na norma $L_{1}, L_{2}$ e $L_{\infty}$ é mostrado nas Figuras 2.21(a), 2.21(b) e 2.21(c) respectivamente. Os eixos dessas figuras estão em escala logarítmica e os resultados estão classificados segundo a ordem (nominal) do método de VF. Como é de esperar, os testes com alta-ordem possuem resultados mais precisos. Por exemplo, na norma $L_{1}$, o erro obtido com 4 a ordem é de 5 a 1000 vezes menor que o erro obtido com 2a ordem. E na norma $L_{\infty}$, o erro obtido com 4 a ordem é de 4 a 25 vezes menor que o erro obtido com 2 a ordem. Note que a superioridade do método de 4 a ordem é mais evidente na norma $L_{1}$ do que na norma $L_{\infty}$. Isto também se verifica na Tabela 2.8: o erro médio (norma $L_{1}$ ) obtido com 4 a ordem atinge uma ordem efetiva de 3,94 e com 2a ordem alcança uma ordem de 1,42; já o erro máximo (norma $L_{\infty}$ ) obtido com 4a ordem atinge uma ordem efetiva de 2,57 (menor à nominal) e com 2a ordem alcança uma ordem de 1,52. Da Figura 2.21, observa-se que a combinação do método de 3a ordem com as malhas mas finas não consegue diminuir o erro na mesma taxa que com as malhas mais grossas. Ora, considerando as sete malhas, a ordem efetiva do esquema de 3 a ordem é de 2,75 (para o erro médio) e 2,77 (para o erro máximo). As ordens da Tabela 2.8 são encontradas da mesma maneira que no caso do canal retangular, isto é, utilizando o ajuste dos mínimos quadrados (Burden e Faires, 2004) da forma

$$
\log (\text { Norma do Erro })=\log (b)+a \log (N),
$$

aos resultados com ordem nominal $p$. Assim, a ordem efetiva $\hat{p}$ do método de VF de ordem $p$ é $-2 a$.

Para finalizar a validação, compara-se este trabalho com o artigo de Ollivier-Gooch e van Altena (2002). Nesse artigo são utilizadas três malhas computacionais. As duas malhas mais finas tem 145 e 537 volumes de controle vertex-centered. Essas malhas correspondem as malhas 1 (137 VC) e 


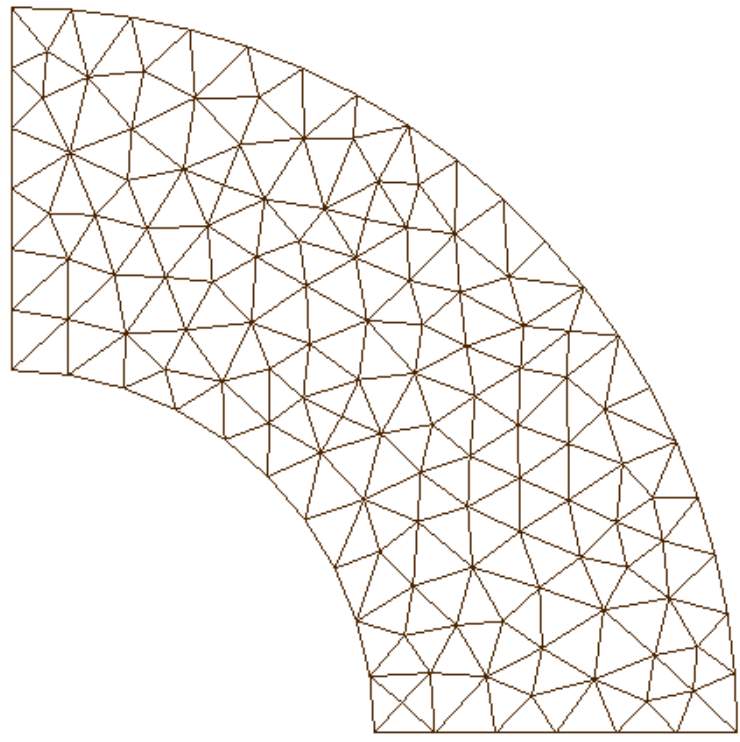

(a) Malha 1 (137 vértices).

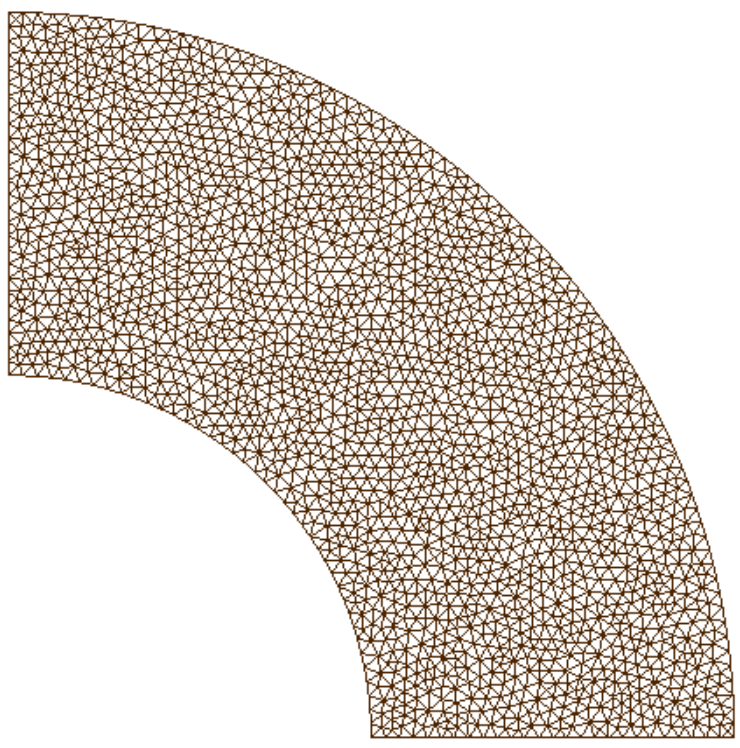

(c) Malha 5 (2081 vértices).

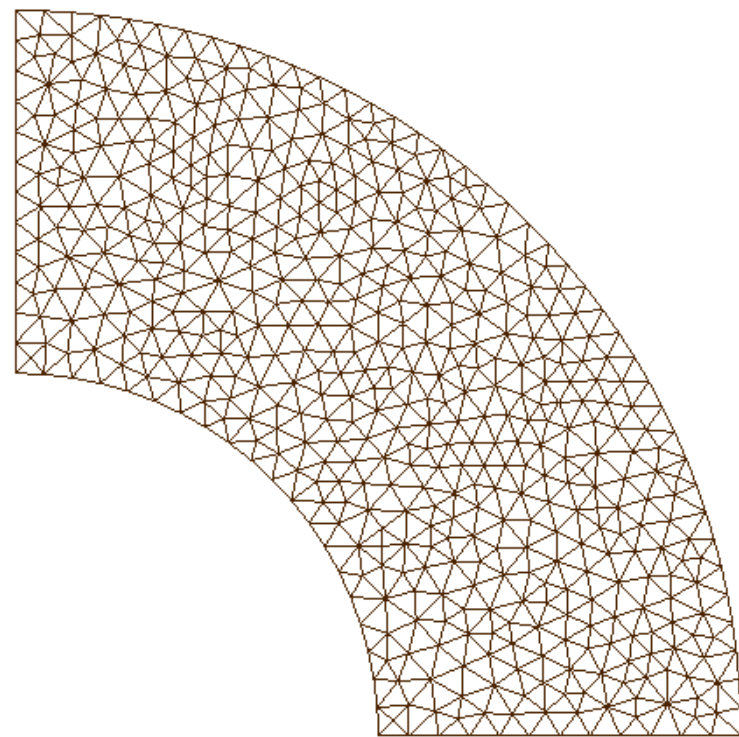

(b) Malha 3 (532 vértices).

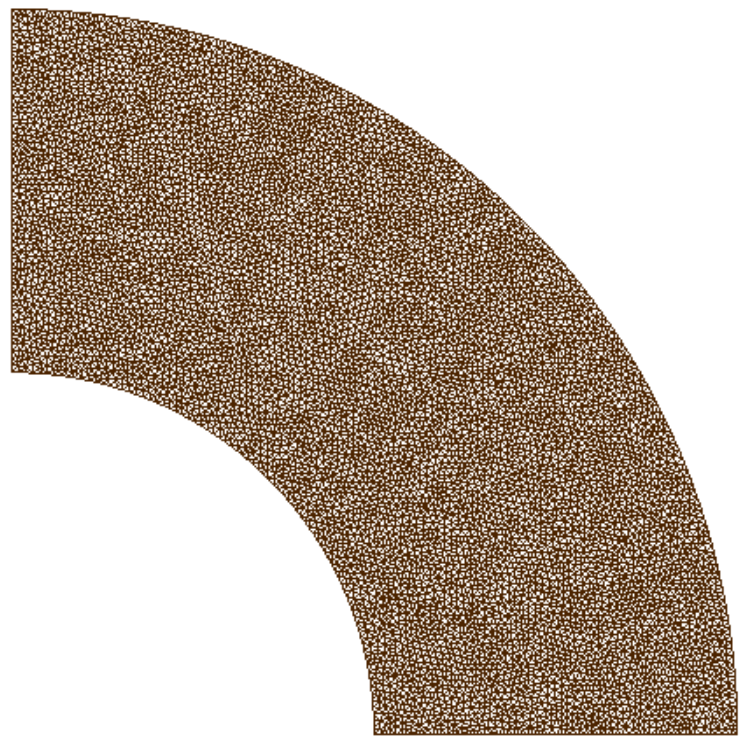

(d) Malha 7 (8144 vértices).

Figura 2.20: Malhas computacionais para o caso advecção-difusão no segmento anular.

3 (532 VC) do presente trabalho. Consequentemente, apenas essas malhas são utilizadas para a comparação de ambos os trabalhos. A Figura 2.22 mostra o erro medido em norma $L_{1}$ obtido pelas combinações Ordem-Malha. Observa-se que, ambos os trabalhos conseguem resultados similares. Por exemplo, com o método de 4a ordem, o erro obtido por Ollivier-Gooch e van Altena (2002) cai de $5 \times 10^{-4}$ para $3,5 \times 10^{-5}$, e o erro obtido no presente trabalho cai de $6,5 \times 10^{-4}$ para $5 \times 10^{-5}$. As magnitudes são similares, mas também é visível uma ligeira diferença na ordem obtida com o método de 4a ordem. Isto se verifica na Tabela 2.9: Com o método de 4a ordem (nominal), a ordem obtida por Ollivier-Gooch e van Altena (2002) é de 4,14 (para a norma $L_{1}$ ) e 2,63 (para a norma $L_{\infty}$ ), e a ordem obtida no presente trabalho é de 3,81 (para a norma $L_{1}$ ) e 2,91 (para a norma $L_{\infty}$ ). Na norma $L_{1}$, então, o presente trabalho leva uma ligeira desvantagem, porém, alcança a ordem nominal. Na norma $L_{\infty}$, ambos os trabalhos não atingem a ordem nominal. Com o método de 3a ordem, ambos os trabalhos atingem a ordem nominal, porém o presente trabalho 
tem ordens efetivas menores $\left(2,55\right.$ na norma $\left.L_{\infty}\right)$. E por fim, com o método de 2 a ordem, ambos trabalhos atingem a ordem nominal. Vale destacar ainda que, o cálculo da ordem efetiva no artigo de Ollivier-Gooch e van Altena (2002) está baseado nas duas malhas mais finas, isto é, as malhas de 145 e 537 VC mencionadas acima. Por isso, as ordens do presente trabalho mostradas na Tabela 2.9 também estão baseadas em duas malhas (de 137 e 532 VC). Como no caso do canal retangular, utiliza-se a seguinte expressão para o cálculo dessas ordens:

$$
\frac{\text { Norma do Erro - Malha A }}{\text { Norma do Erro - Malha B }}=\left(\frac{\text { No. volumes de controle da Malha A }}{\text { No. volumes de controle da Malha B }}\right)^{-\frac{p}{2}} \text {. }
$$




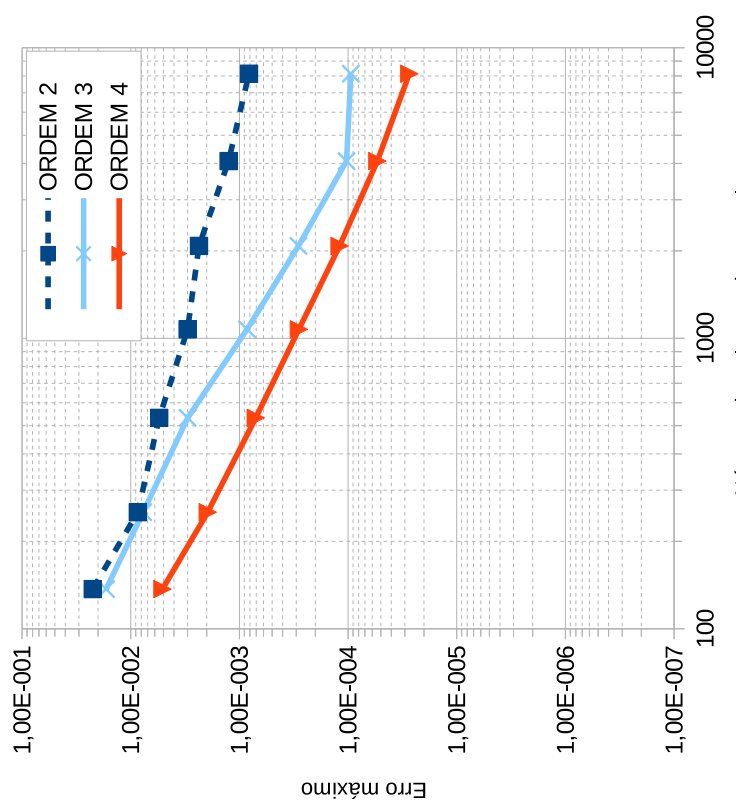

ᄋ్త

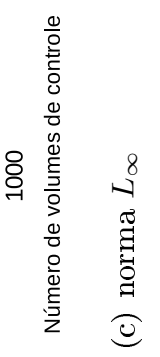

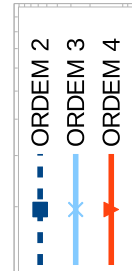

웅

:
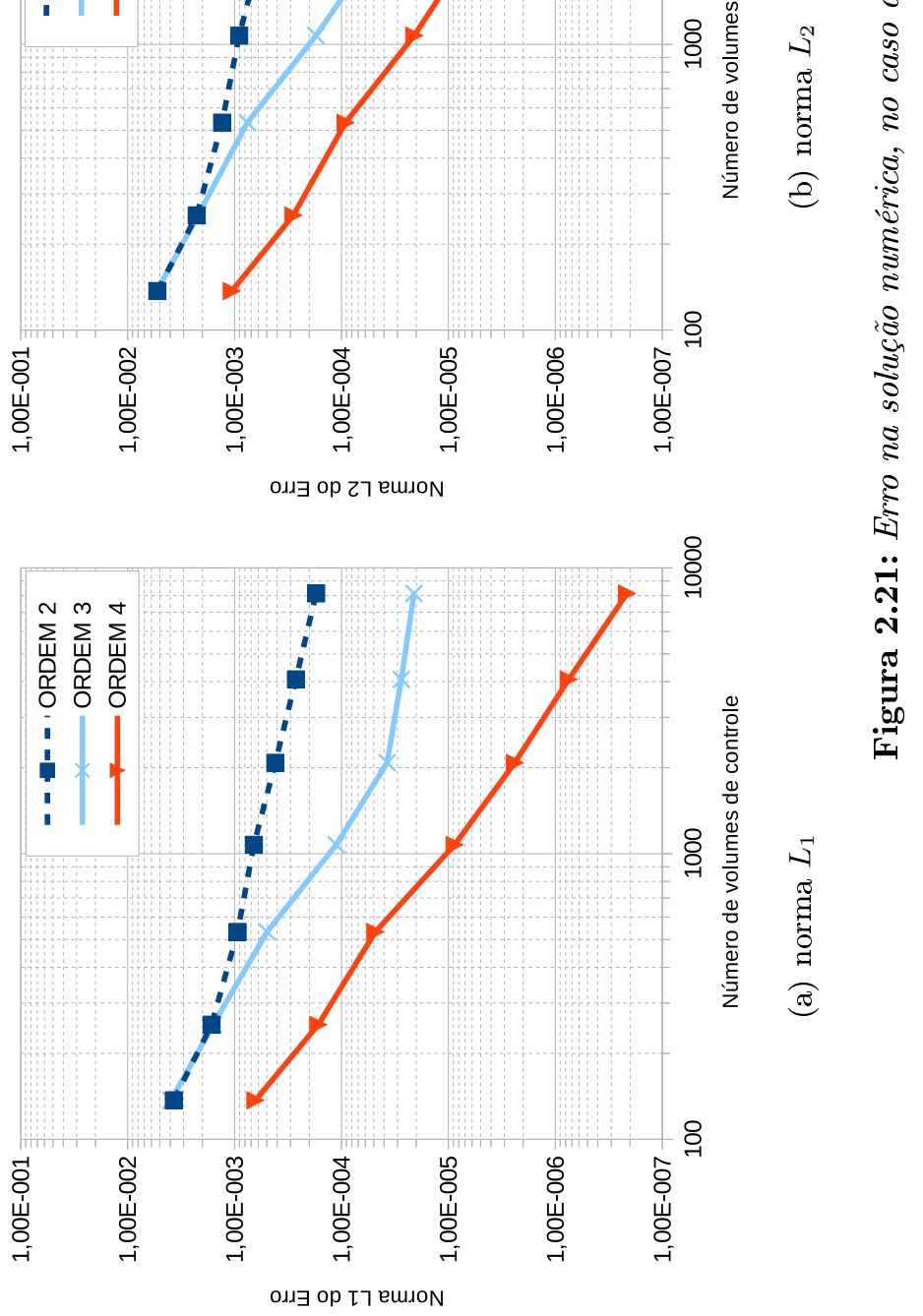


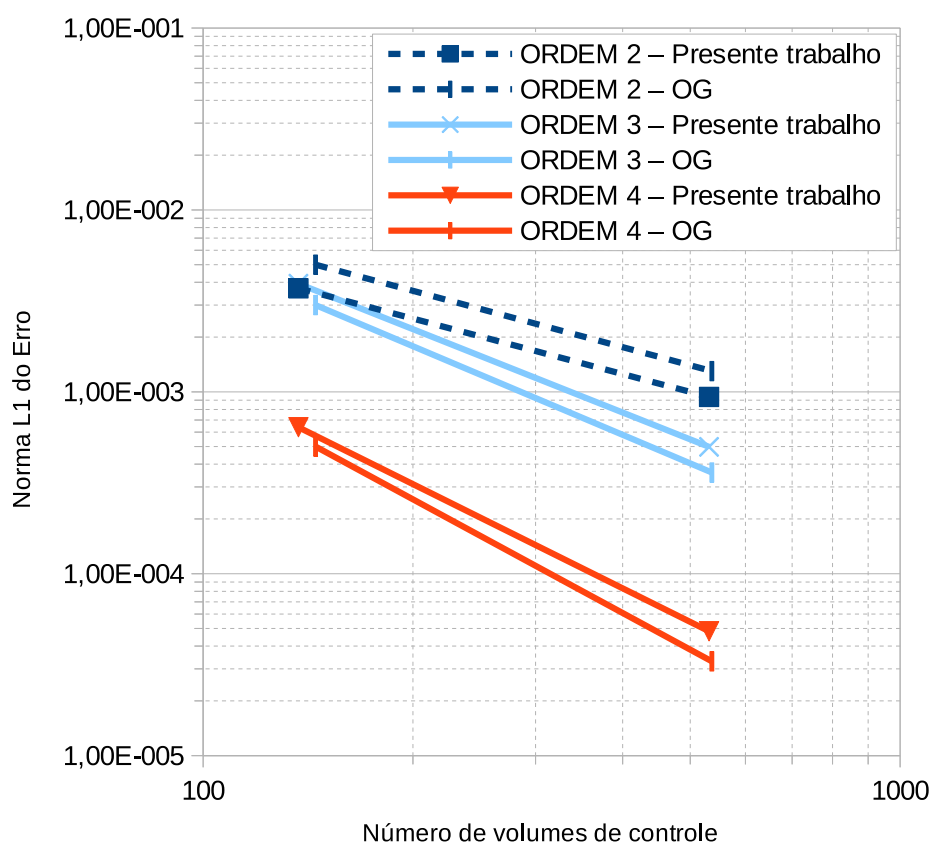

Figura 2.22: Comparação deste trabalho com o artigo de Ollivier-Gooch e van Altena (2002), no caso advecção-difusão no segmento anular.

\begin{tabular}{|c|c|c|c|}
\hline \multirow[b]{2}{*}{ Ordem nominal } & \multicolumn{3}{|c|}{ Ordem obtida } \\
\hline & $L_{1}$ & $L_{2}$ & $L_{\infty}$ \\
\hline \multicolumn{4}{|c|}{ Presente trabalho ${ }^{1}$} \\
\hline 2a Ordem & 2,03 & 2,05 & 2,08 \\
\hline 3a Ordem & 3,05 & 2,87 & 2,55 \\
\hline 4a Ordem & 3,81 & 3,61 & 2,91 \\
\hline \multicolumn{4}{|c|}{ Ollivier-Gooch e van Altena (2002) ${ }^{2}$} \\
\hline 2a Ordem & 1,98 & 2,08 & 2,10 \\
\hline 3a Ordem & 3,25 & 3,27 & 3,06 \\
\hline 4a Ordem & 4,14 & 4,17 & 2,63 \\
\hline
\end{tabular}

${ }^{1}$ Cálculo baseado nas Malhas de 137 e $532 \mathrm{VC}$ deste trabalho.

${ }^{2}$ Cálculo baseado nas Malhas de 145 e 537 VC de Ollivier-Gooch e van Altena (2002).

Tabela 2.9: Comparação de ordens obtidas no caso advecção-difusão no segmento anular.

\section{Desempenho dos testes}

Neste trabalho o custo computacional é estimado com o tempo que a CPU demora em rodar um teste. Todos os testes são executados sob as mesmas condições (o mesmo computador, o mesmo chute inicial, o mesmo critério de parada, etc). E, assim como no caso do canal retangular (Seção 2.6.2), utiliza-se $\mathrm{CFL}=1,0$ para o esquema $\mathrm{RK}$ (um valor que não necessariamente é o valor máximo); portanto, os tempos de CPU registrados não são os ótimos. Contudo, cada tempo registrado não deve ser maior a 10 vezes o tempo ótimo porque, muito provavelmente, o CFL máximo é menor do que 10.

As Figuras 2.23(a) e 2.23(b) mostram o erro máximo versus o número de VC e o tempo de CPU. Por exemplo, a combinação 4 a ordem-Malha $2(252 \mathrm{VC})$ resulta num erro máximo de $2 \times 10^{-3}$ e leva um tempo de $1 \mathrm{~s}$. Ora, a combinação 2a ordem-Malha 5 (2081 VC) resulta num erro máximo aproximado de $2,5 \times 10^{-3}$ e leva um tempo de $25 \mathrm{~s}$. Comparando esses dois testes, pode-se concluir que a 4 a ordem é mais eficiente que a 2 a ordem porque leva 25 vezes menos tempo para obter, 
aproximadamente, o mesmo erro $\left(2 \times 10^{-3}\right)$. Se o processo iterativo RK for otimizado, a diferença desses dois tempos poderia ser menor. Mas, como foi dito acima, o número CFL limita o tempo ótimo e a diferença de 25 vezes no tempo garante a superioridade da alta-ordem. Essas duas combinações Ordem-Malha podem ser comparadas ainda com a combinação 3a ordem-Malha 3 (532 VC) pois esta resulta num erro máximo de $3 \times 10^{-3}$. As três combinações são mostradas na Figura 2.24(a). Ali apresenta-se os erros medidos na norma $L_{\infty}$ e $L_{2}$ assim como o tempo de CPU dessas três combinações. Os erros são comparáveis (eles são da mesma ordem de magnitude) mas a maior diferença está nos tempos de CPU. As Figuras 2.24(b) e 2.24(c) mostram a distribuição do erro no segmento anular para os testes de $4 \mathrm{a}$ e $2 \mathrm{a}$ ordem, respectivamente. Ambas as figuras utilizam a mesma escala e os erros estão associados aos vértices. No teste de 4 a ordem, percebe-se que os erros de magnitude $10^{-3}$ estão concentrados numa região próxima ao arco de menor raio e à fronteira vertical (com condição de Neumann). No teste de $2 \mathrm{a}$ ordem, também há erros de magnitude $10^{-3}$ na mesma região, porém estão misturados com erros de magnitude $10^{-5}$.

Analogamente, a Figura 2.25(a) mostra uma comparação entre combinações que resultam num erro máximo de $7 \times 10^{-4}$. De novo, pode-se concluir que a 4 a ordem é mais eficiente que a $2 \mathrm{a}$ ordem. A combinação 4a ordem-Malha $3(532 \mathrm{VC})$ leva $7 \mathrm{~s}$, enquanto que a combinação $2 \mathrm{a}$ ordem-Malha 7 ( $8144 \mathrm{VC}$ ) leva $400 \mathrm{~s}$ (57 vezes mais). As Figuras 2.25(b) e 2.25(c) mostram a distribuição do erro no segmento anular para esses testes de 4 a e 2a ordem, respectivamente. Na região próxima ao arco de menor raio e à fronteira vertical, há erros de magnitude maior a $10^{-4}$, nos dois testes. Fora desta região, há erros de magnitude menor a $10^{-5}$ nos dois testes porém, no teste de 2 a ordem, existe ainda erros de magnitude $10^{-4}$.

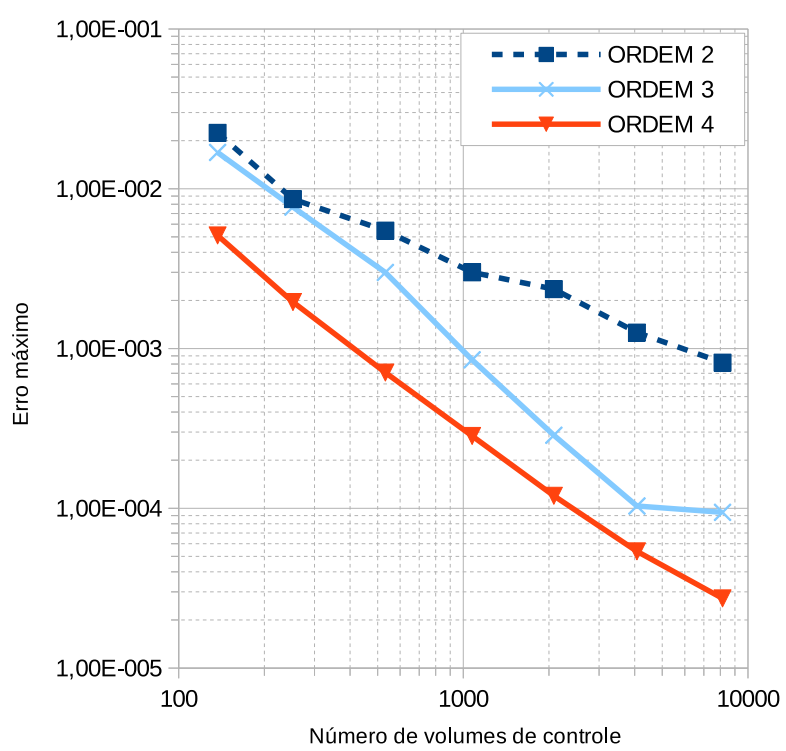

(a)

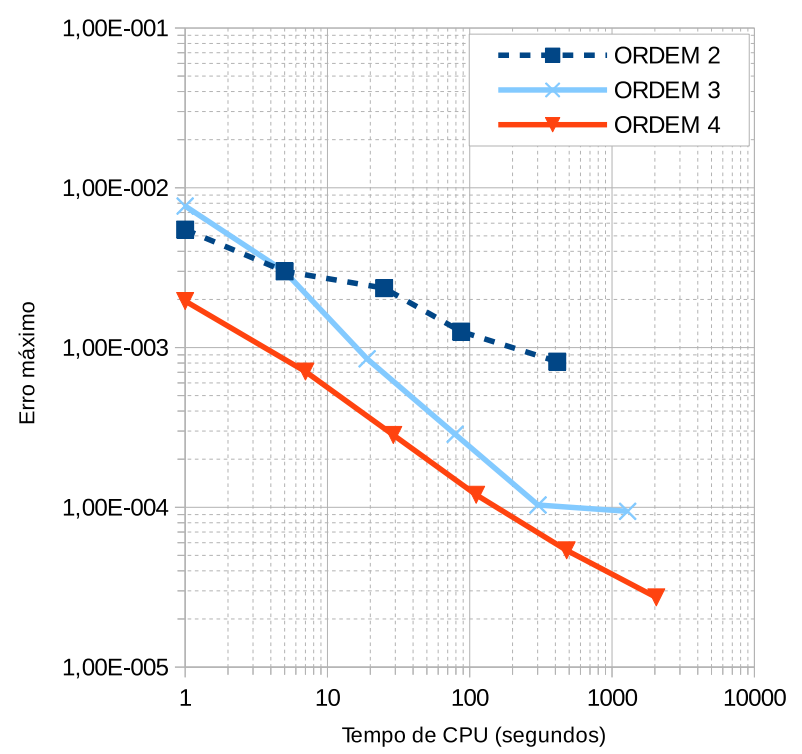

(b)

Figura 2.23: Erro máximo versus Número de VC e Tempo de CPU, no caso advecção-difusão no segmento anular. As combinações: 2a Ordem-Malha 1, 2a Ordem-Malha 2, 3a Ordem-Malha 1 e 4a Ordem-Malha 1 levam um tempo de CPU menor a 1 s e não são mostrados em (b). 


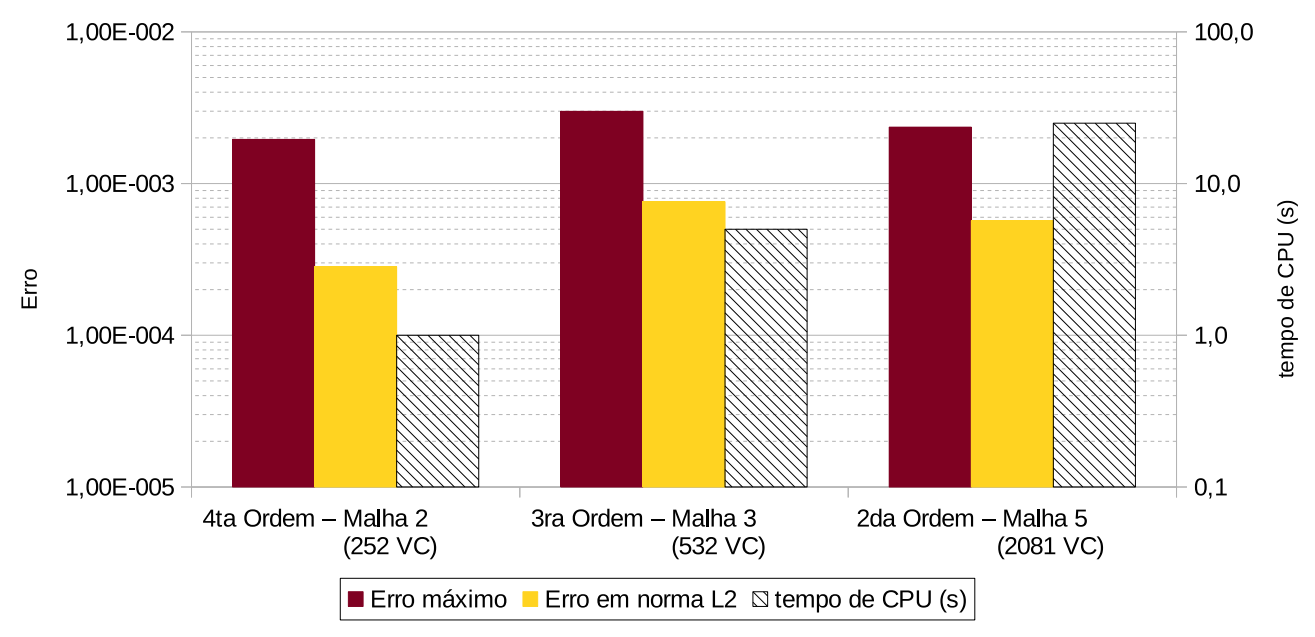

(a)
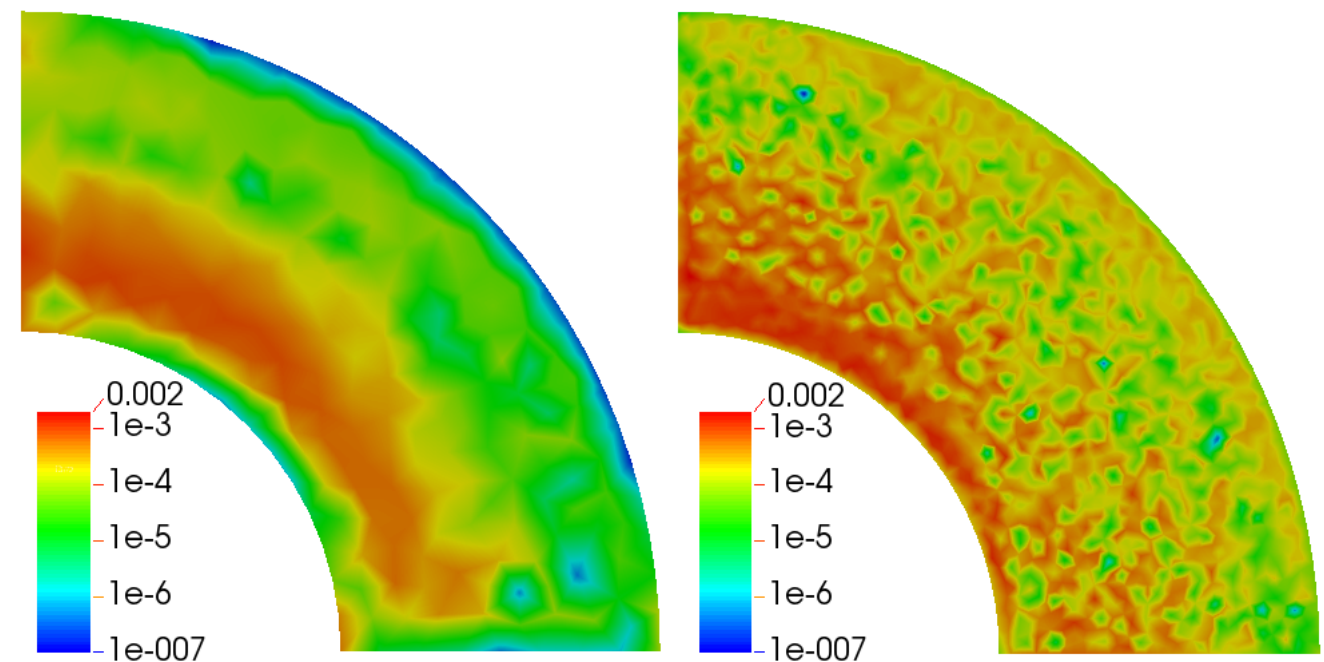

(b) Erro no teste de 4a Ordem com Malha 2 (c) Erro no teste de 2a Ordem com Malha 5 $(252 \mathrm{VC})$ (2081 VC)

Figura 2.24: Combinações Ordem-Malha que resultam num erro máximo de $2 \times 10^{-3}$, no caso advecçãodifusão no segmento anular. 


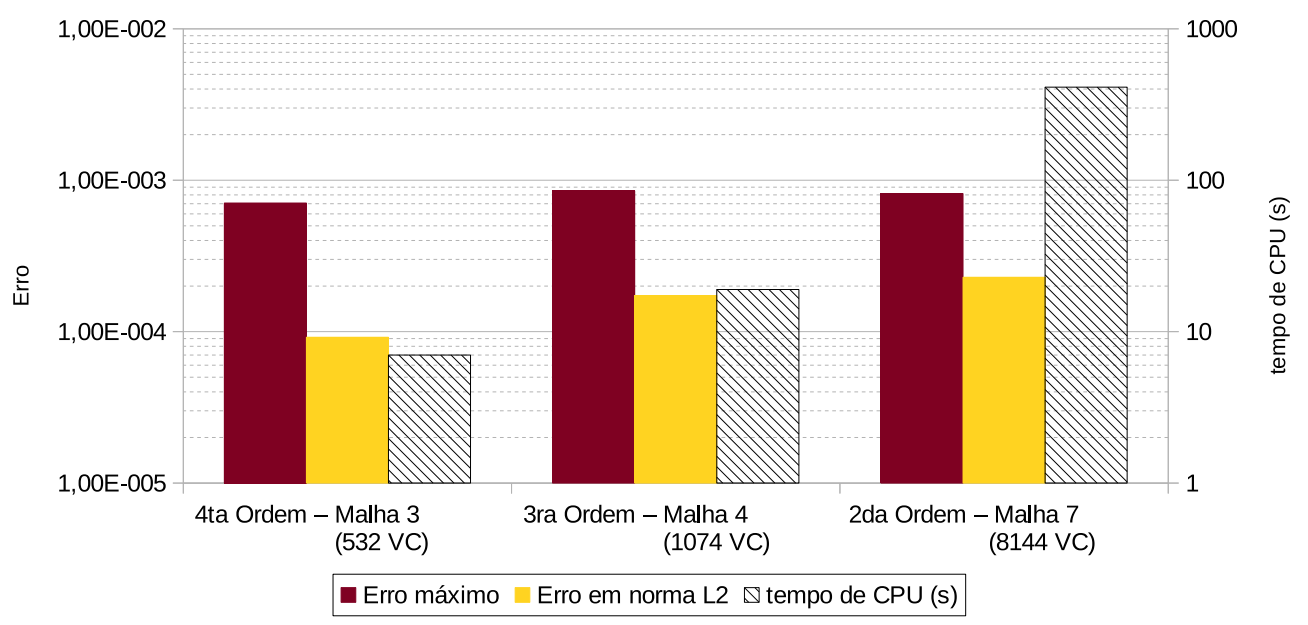

(a)
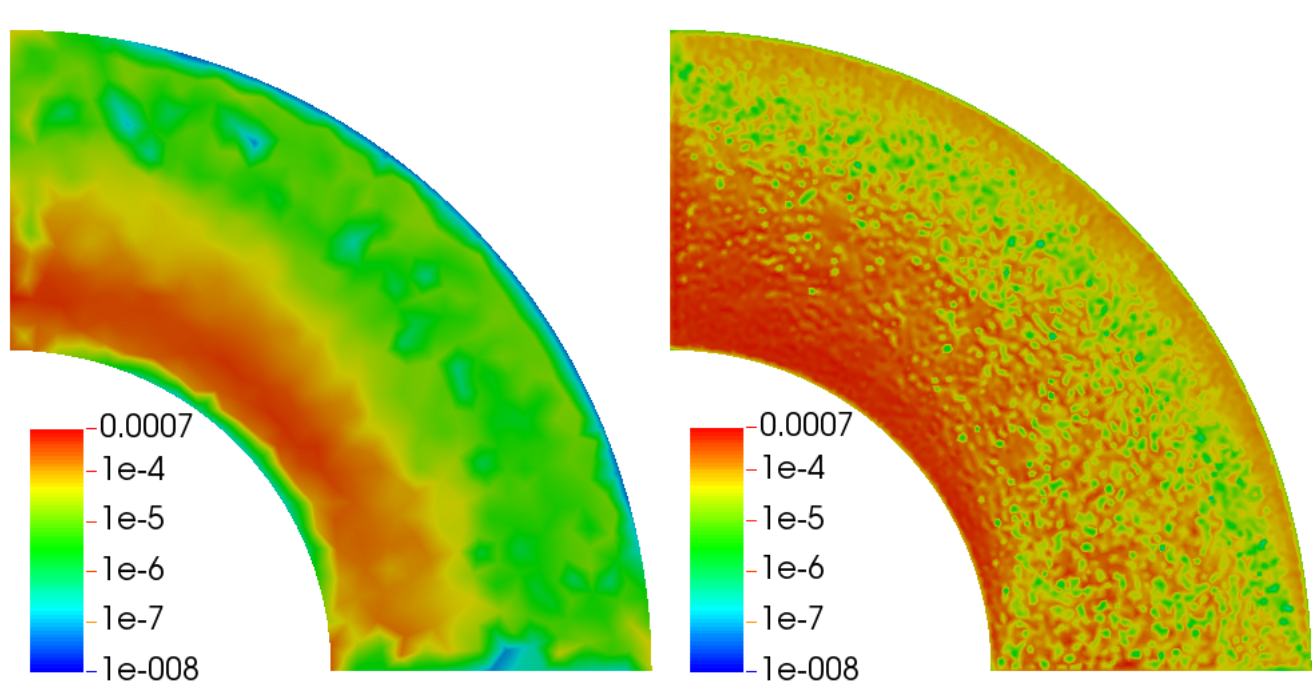

(b) Erro no teste de 4a Ordem com Malha 3 (c) Erro no teste de 2a Ordem com Malha 7 $(532 \mathrm{VC})$

$(8144 \mathrm{VC})$

Figura 2.25: Combinações Ordem-Malha que resultam num erro máximo de $7 \times 10^{-4}$, no caso advecçãodifusão no segmento anular.

\subsection{Conclusão}

Refazendo problemas da literatura (Ii et al., 2005)(Ollivier-Gooch e van Altena, 2002), demonstrase que o solver VF-RK, desenvolvido neste trabalho, recupera soluções com a ordem esperada para o método VF de alta-ordem. Embora a combinação deste método com o avanço RK não foi otimizada para atingir tempos de CPU ótimos, verifica-se que a 4 a ordem é mais eficiente que a 2a ordem: se ambas ordens resultam em erros de igual magnitude, a 4a ordem atinge esse resultado num tempo de CPU dezenas de vezes menor. Vale lembrar que, no problema não estacionário, obtêm-se indícios dessa superioridade mas para confirmar-la será necessário, no futuro, utilizar esquemas RK do tipo SSP (Shu, 1988)(Spiteri e Ruuth, 2002). Nos seguintes capítulos, a estrutura do código é expandida para incorporar a solução das equações de Euler (Capítulo 3), assim como o método p-multigrid (Capítulos 4 e 5). 


\section{Capítulo 3}

\section{Método de Volumes Finitos para as Equações de Euler}

Neste capítulo apresenta-se a extensão do método VF para a solução do sistema de equações de Euler. Dois aspectos fundamentais, a serem considerados nesta extensão, são o cálculo do fluxo e o tratamento dos choques. Este último, implica no uso de um limitador de alta-ordem que controle as oscilações da solução próxima aos choques (descontinuidades). Este tratamento é utilizado em uma das três simulações deste capítulo, mais especificamente, na simulação do escoamento transônico ao redor do aerofólio NACA 0012.

\subsection{Forma Integral das Equações de Euler 2D}

As equações de Euler são um sistema de leis de conservação hiperbólicas não lineares que governam a dinâmica de um fluido (gás ou líquido), sobre o qual os efeitos de forças gravitacionais, de esforços viscosos e de fluxo de calor são insignificantes. A dedução das equações de Euler está baseada em equações integrais sobre volumes de controle e suas fronteiras (Chorin e Marsden, 2000). A forma integral dessas equações admite descontinuidade nas variáveis do escoamento (em contraposição com a forma diferencial que precisa da diferenciabilidade). Do ponto de vista computacional, há uma outra boa razão para utilizar a forma integral das equações de Euler. Domínios discretizados resultam naturalmente em volumes de controle finitos ou células computacionais. A aplicação das equações fundamentais nesses volumes conduzem aos métodos numéricos de volumes finitos. Considere-se, então, a forma integral das equações de Euler bi-dimensionais sobre um volume de controle $\Omega_{i} \subset \mathbb{R}^{2}$ :

$$
\begin{gathered}
\frac{d}{d t} \iint_{\Omega_{i}} U d x d y+\oint_{\partial \Omega_{i}} F(U) d l=0, \\
U \equiv\left[\begin{array}{c}
\rho \\
\rho u \\
\rho v \\
E
\end{array}\right] \quad F(U) \equiv\left[\begin{array}{c}
\rho V_{n} \\
\rho u V_{n}+P n_{x} \\
\rho v V_{n}+P n_{y} \\
(E+P) V_{n}
\end{array}\right] .
\end{gathered}
$$

Nesta equação, $U$ é o vetor das variáveis conservadas: a densidade $(\rho)$, duas componentes do momentum ( $\rho u$ e $\rho v$ ) e a energia total por unidade de volume $(E)$; o vetor $F(U)$ é o fluxo projetado na normal exterior $\left(n_{x}, n_{y}\right)$ no contorno $\partial \Omega_{i}$; e $V_{n}$ é a projeção escalar do vetor velocidade $(u, v)$ na direção da normal exterior, i.e. $V_{n}=u n_{x}+v n_{y}$. O fluido a ser estudado é o ar (compressível). Ele é modelado como gás ideal (constante de gás específico $R=287,05 \mathrm{~J} /(\mathrm{kg} \mathrm{K})$ e taxa de calores específicos $\gamma=1,4)$. Assim, a energia $E$ pode ser escrita em termos das variáveis primitivas ( $\rho, u$, $v$ e pressão $P$ ) pela expressão (Toro, 2009):

$$
E=\frac{P}{\gamma-1}+\frac{1}{2} \rho\left(u^{2}+v^{2}\right) .
$$


Ora, as equações de Euler 2D (3.1) podem ser re-escritas assim:

$$
\frac{d}{d t} \bar{U}_{i}^{\text {exata }}+\frac{1}{\operatorname{area}\left(\Omega_{i}\right)} \oint_{\partial \Omega_{i}} F(U) d l=0
$$

onde

$$
\bar{U}_{i}^{\text {exata }} \equiv \frac{1}{\operatorname{area}\left(\Omega_{i}\right)} \iint_{\Omega_{i}} U d x d y
$$

é a média da solução exata $U$ das equações de Euler no volume de controle $\Omega_{i}$.

\subsection{Método de Volumes Finitos}

No caso das equações de Euler, o método VF resulta numa extensão do método apresentado no Capítulo 2. O método VF aproxima as equações integrais (3.4) por um sistema de EDOs do tipo

$$
\frac{d}{d t} \bar{U}_{i}=-R_{i}^{p}(\bar{U})
$$

A notação usada nessas EDOs é dada a seguir. O domínio (espacial) é dividido em volumes de controle $\Omega_{i}$ tipo vertex-centered. Cada célula $\Omega_{i}$ está associada à função $\bar{U}_{i}(t)$; estas resolvem o sistema de EDOs (3.6). Vale destacar que $\bar{U}_{i}(t)$ é uma aproximação da solução média $\bar{U}_{i}^{\text {exata }}(t)$ das equações de Euler (3.4). Além disso, cada célula $\Omega_{i}$ possui um estêncil de células $\Omega_{i, j}$ circundantes e pontos de Gauss $r_{i, k} \in \partial \Omega_{i}$; as seguintes seções apresentam a escolha do estêncil e dos pontos de Gauss. A seguir, apresenta-se, de maneira resumida, o processo de definição do resíduo $R_{i}^{p}(\bar{U})$ (Michalak, 2009):

Passo 1: Vale ressaltar que em cada célula $i$, a solução média aproximada $\bar{U}_{i}$ é um vetor que contem as soluções médias aproximadas das variáveis conservadas $\left(\bar{\rho}_{i}, \overline{\rho u}_{i}, \overline{\rho v}_{i}\right.$ e $\left.\bar{E}_{i}\right)$. Estas soluções médias são transformadas de variáveis conservadas para variáveis primitivas (densidade $\bar{\rho}_{i}$, velocidades $\bar{u}_{i}$ e $\bar{v}_{i}$, e pressão $\bar{P}_{i}$ ).

Passo 2: Para cada célula $i$ e para cada variável primitiva, constrói-se um polinômio de ordem $p$ a partir das soluções médias na célula $\Omega_{i}$ e nas células $\Omega_{i, j}$ do estêncil. Por exemplo, o polinômio $P_{i}(x, y)$, para a pressão, está baseado nas soluções médias $\bar{P}_{i}$ e $\bar{P}_{i, j}$. Cada polinômio é contínuo dentro da célula de controle, e descontínuo nas interfaces da célula. Os detalhes desta construção são apresentados na Seção 3.3.

Passo 3: Com os polinômios avaliados num ponto de Gauss (ou seja $\rho_{i}\left(r_{i, k}\right), u_{i}\left(r_{i, k}\right), v_{i}\left(r_{i, k}\right)$ e $P_{i}\left(r_{i, k}\right)$ ), pode-se calcular o fluxo $F$ nesse ponto (equação (3.2)). Mas, em $r_{i, k}$, o fluxo não está unicamente determinado e portanto, deve-se impor um único fluxo numérico $F_{\mathrm{Num} i, k}$. Este fluxo numérico é descrito na Seção 3.4. Ora, a integral do fluxo numérico é aproximada utilizando uma quadratura de Gauss, ou seja,

$$
\oint_{\partial \Omega_{i}} F_{\mathrm{Num}} d l \approx \sum_{k=1}^{N_{\text {Gauss }}^{p}} F_{\mathrm{Num} i, k} W_{\mathrm{Gauss} i, k},
$$

onde $N_{\text {Gauss }}^{p}$ é a quantidade de pontos de Gauss suficiente para que a integral seja exata em caso de que cada componente do vetor integrando seja um polinômio de ordem $p$, e $W_{\text {Gauss } i, k}$ são os pesos deste método de quadratura (Stoer e Bulirsch, 2002).

Passo 4: Por fim, define-se o resíduo em cada volume de controle $\Omega_{i}$ como

$$
R_{i}^{p}(\bar{U}) \equiv \frac{1}{\operatorname{area}\left(\Omega_{i}\right)} \sum_{k=1}^{N_{\text {Gauss }}^{p}} F_{\mathrm{Num} i, k} W_{\mathrm{Gauss} i, k}
$$


onde $\bar{U}$, argumento do resíduo, representa o conjunto de todas as soluções médias aproximadas; ou seja, não basta a solução média aproximada $\bar{U}_{i}$ para definir o resíduo na célula $\Omega_{i}$.

Para resolver as equações de Euler semi-discretizadas (3.6), utiliza-se, como no Capítulo 2, o esquema explícito RK de van Leer et al. (1989). Assim, a combinação deste com o método VF de ordem $p$ resulta no seguinte algoritmo:

$$
\begin{aligned}
\bar{U}_{i}^{(0)} & =\bar{U}_{i}^{n} \\
\bar{U}_{i}^{(k)} & =\bar{U}_{i}^{(0)}-\alpha_{k} \Delta t R_{i}^{p}\left(\bar{U}^{(k-1)}\right), k=1, . ., 5 \\
\bar{U}_{i}^{n+1} & =\bar{U}_{i}^{(5)}
\end{aligned}
$$

onde $\alpha_{1}=0,0695, \alpha_{2}=0,1602, \alpha_{3}=0,2898, \alpha_{4}=0,5060$ e $\alpha_{5}=1$. A estabilidade deste esquema depende de uma restrição ao passo de tempo $\Delta t_{i}$ em cada volume de controle $\Omega_{i}$ (Vijayan e Kallinderis , 1994) (Blazek, 2001):

$$
\Delta t_{i}=\mathrm{CFL} \cdot \frac{\operatorname{área}\left(\Omega_{i}\right)}{\left(\left|\bar{u}_{i}\right|+\bar{a}_{i}\right) \Delta \hat{S}^{x}+\left(\left|\bar{v}_{i}\right|+\bar{a}_{i}\right) \Delta \hat{S}^{y}}
$$

onde

$$
\begin{aligned}
\bar{a}_{i} & =\sqrt{\frac{\gamma \bar{P}_{i}}{\bar{\rho}_{i}}}, \text { velocidade do som associada à célula } i \\
\Delta \hat{S}^{x} & =\frac{1}{2} \sum_{j}\left|\Delta S_{j} n_{x j}\right| \\
\Delta \hat{S}^{y} & =\frac{1}{2} \sum_{j}\left|\Delta S_{j} n_{y_{j}}\right| \\
\Delta S_{j} & =\text { comprimento da interface reta } j, \subset \partial \Omega_{i} \\
\left(n_{x}, n_{y}\right)_{j} & =\text { vetor normal exterior à interface reta } j .
\end{aligned}
$$

Ora, o passo de tempo $\Delta t$ em (3.9) depende do tipo de problema a ser resolvido. No presente trabalho, são considerados problemas estacionários, e portanto utiliza-se o passo de tempo local (Blazek, 2001), ou seja, $\Delta t=\Delta t_{i}$. Observe-se que $\Delta t_{i}$ depende da solução numérica, então esse passo de tempo varia com o avanço do processo iterativo; no presente trabalho, $\Delta t_{i}$ é redefinido no início de cada passo RK (3.9). Por fim, o processo iterativo é interrompido, no presente trabalho, quando Res-dens $L_{2}<10^{-10}$, onde (Wang et al., 2013)

$$
\operatorname{Res-dens}_{L_{2}} \equiv \sqrt{\frac{1}{N} \sum_{i=1}^{N}\left[R_{i}^{p}\left(\bar{U}^{n}\right)_{(\mathbf{1})}\right]^{2}}
$$

é a norma $L_{2}$ do resíduo associado à densidade (para alguma iteração $n$ ), e $N$ é o número de volumes de controle; vale destacar que o subíndice (1) na equação (3.11) refere-se à primeira componente do resíduo, isto é, à componente associada à densidade. 


\subsection{Reconstrução}

A partir das soluções médias aproximadas das variáveis conservadas $\left(\bar{\rho}_{i}, \overline{\rho u}_{i}, \overline{\rho v}_{i}\right.$ e $\left.\bar{E}_{i}\right)$ definemse as soluções médias estimadas das variáveis primitivas:

$$
\begin{aligned}
\bar{u}_{i} & =\frac{\overline{\rho u}_{i}}{\bar{\rho}_{i}} \\
\bar{v}_{i} & =\frac{\overline{\rho v}_{i}}{\bar{\rho}_{i}} \\
\bar{P}_{i} & =(\gamma-1) \cdot\left[\bar{E}_{i}-\frac{1}{2} \bar{\rho}_{i}\left(\bar{u}_{i}^{2}+\bar{v}_{i}^{2}\right)\right] .
\end{aligned}
$$

Para cada célula $\Omega_{i}$, se constroem quatro polinômios de ordem $p$ (ou grau $p-1$ ), uma para cada variável primitiva. A seguir apresenta-se a construção do polinômio associado à pressão; para as outras variáveis o procedimento é análogo. A partir da estimativa para a célula $i\left(\bar{P}_{i}\right)$ e das estimativas para as células do estêncil $\left(\bar{P}_{i, j}\right)$ define-se o polinômio

$$
P_{i}(x, y) \equiv \sum_{0 \leq m+n<p} c_{m, n}\left(x-x_{i}\right)^{m}\left(y-y_{i}\right)^{n}, \forall(x, y) \in \Omega_{i}
$$

expandido ao redor do vértice $\left(x_{i}, y_{i}\right)$. Este polinômio debe satisfazer as condições (entre elas a conservação da média) detalhadas na Seção 2.3. Assim, os coeficientes do polinômio são a solução do problema (3.16), onde $\beta=1$ é o valor sugerido por Michalak (2009) para os pesos geométricos $w_{i j}$ na resolução das equações de Euler. O método de resolução do problema (3.16) assim como o número $N_{s}$, que é o número de vizinhos da célula $\Omega_{i}$, também estão descritos na Seção 2.3. Vale lembrar, que para cada célula $\Omega_{i}$, se constroem quatro polinômios (uma para cada variável primitiva).

Finalmente, vale destacar que Michalak (2009), no contexto das equações de Euler, não impõe as condições de fronteira na reconstrução polinomial, e sim no cálculo do fluxo.

$\left[\begin{array}{ccccccc}1 & \bar{x}_{i} & \bar{y}_{i} & \bar{x}^{2}{ }_{i} & \overline{x y}_{i} & \bar{y}^{2}{ }_{i} & \cdots \\ \hline w_{i 1} & w_{i 1} \widehat{x}_{i 1} & w_{i 1} \widehat{y}_{i 1} & w_{i 1} \widehat{x}^{2}{ }_{i 1} & w_{i 1} \widehat{x y}_{i 1} & w_{i 1} \widehat{y}^{2}{ }_{i 1} & \cdots \\ w_{i 2} & w_{i 2} \widehat{x}_{i 2} & w_{i 2} \widehat{y}_{i 2} & w_{i 2} \widehat{x}^{2}{ }_{i 2} & w_{i 2} \widehat{x y}_{i 2} & w_{i 2} \widehat{y}^{2}{ }_{i 2} & \cdots \\ \vdots & \vdots & \vdots & \vdots & \vdots & \vdots & \ddots \\ w_{i N_{s}} & w_{i N_{s} \widehat{x}_{i N_{s}}} & w_{i N_{s}} \widehat{y}_{i N_{s}} & w_{i N_{s} \widehat{x}^{2}}{ }_{i N_{s}} & w_{i N_{s}} \widehat{x y}_{i N_{s}} & w_{i N_{s}}{\widehat{y^{2}}}_{i N_{s}} & \cdots\end{array}\right]\left(\begin{array}{c}c_{0,0} \\ c_{1,0} \\ c_{0,1} \\ c_{2,0} \\ c_{1,1} \\ c_{0,2} \\ \vdots\end{array}\right)=\left(\begin{array}{c}\bar{P}_{i} \\ -w_{i 1} \bar{P}_{i 1} \\ w_{i 2} \bar{P}_{i 2} \\ \vdots \\ w_{i N_{s}} \bar{P}_{i N_{s}}\end{array}\right)$

\subsection{Fluxo}

$\mathrm{Na}$ interface das células $\Omega_{i}$ e $\Omega_{i, j}$, tem-se descontinuidades entre os polinômios construídos para essas duas células. Essas descontinuidades são agora utilizadas como dados de entrada do método de Roe (1981) para calcular o fluxo numérico $F_{\text {Num }}$ na interface. Especificamente, o fluxo numérico é calculado numa distribuição adequada de pontos de quadratura $r_{i, k}$ sobre a interface tal que a integração numérica do total de fluxo da interface possa ser calculada de maneira precisa. Michalak (2009) sugere os pontos de Gauss amostrados na Figura 3.1. O fluxo numérico de Roe (1981), $F_{\mathrm{Num} i, k}$, nesses pontos de integração é calculado a partir dos polinômios associados à célula $\Omega_{i}$ (ou seja $\rho_{i}, u_{i}, v_{i}$ e $P_{i}$ ), e dos polinômios análogos associados à célula $\Omega_{i, j}$, assim como da normal exterior à célula $\Omega_{i}$. O leitor encontrará maior informação no artigo de Roe (1981), no livro de Blazek (2001), entre outras publicações de Riemann solvers. 


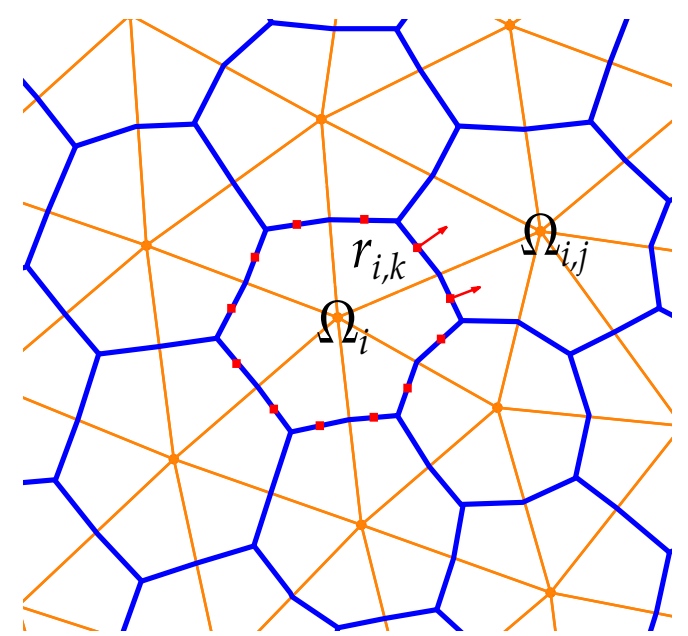

(a) $2 \mathrm{a}$ ordem

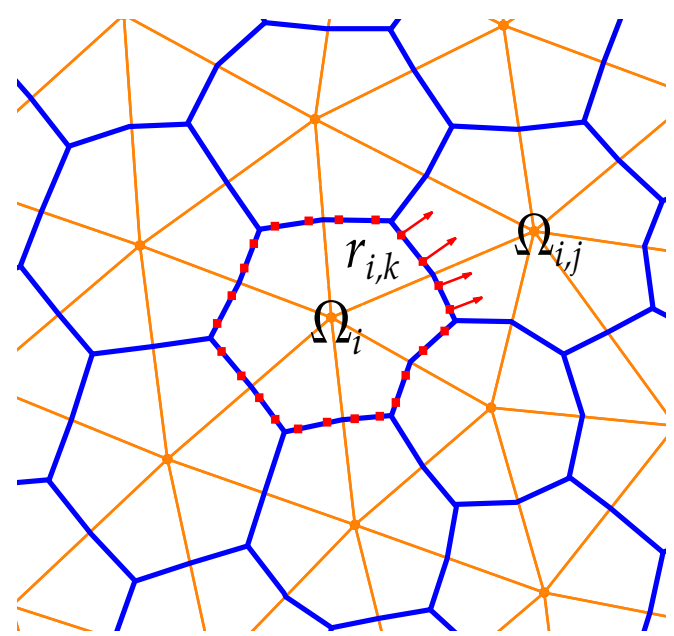

(b) 3a e 4a ordem

Figura 3.1: Localização dos pontos de integração de Gauss e suas normais associadas na interface de células, para o método VF de alta-ordem.

\subsection{Implementação das Condições de Fronteira}

Considere as seguintes condições de fronteira:

- Condição de parede,

- Condição de entrada subsônica,

- Condição de saída subsônica,

- Condição de entrada supersônica, e

- Condição de saída supersônica.

Michalak (2009) sugere impor estas condições no cálculo do fluxo (não na reconstrução polinomial). O presente trabalho segue essa ideia, ou seja, é definido o fluxo numérico $F_{\mathrm{Num} i, k}$ nos pontos de Gauss $r_{i, k} \in \partial D \cap \partial \Omega_{i}$. Em geral, $F_{\mathrm{Num} i, k}$ é definido como na equação (3.2) tomando alguma informação da reconstrução para a célula de fronteira $i$ e outra informação da condição de fronteira (Fidkowski et al., 2005). Especificamente, para parede utiliza-se o valor reconstruído $\rho_{i}$ e $P_{i}$, assim como uma velocidade normal (na parede) nula. Para as condições de entrada e saída, o fluxo numérico está baseado num análise de autovalores. Isto é, para entrada supersônica todos os valores são tomados da condição de fronteira. Para a entrada subsônica o valor reconstruído da pressão $P_{i}$ é utilizado junto com a pressão total, a temperatura total, e a direção do escoamento das condições de corrente livre. Analogamente, para saída supersônica, o fluxo está baseado nos quatro valores reconstruídos; para saída subsônica, a pressão é definida pela condição de fronteira e as outras variáveis são obtidas da reconstrução (Michalak, 2009) (Fidkowski et al., 2005).

Finalmente, Blazek (2001) sugere uma correção de vórtice 2D em problemas de escoamento externo com sustentação, cuja distancia far-field influi na solução. O presente trabalho não inclui esta correção e sim utiliza a distância far-field reportada nas referências desse tipo de escoamento.

\subsection{Tratamento das Fronteiras Curvas}

Assim como na resolução da equação de advecção-difusão (Capítulo 2), a malha de baixa-ordem (malha com todas suas faces retas) deve ser tratada para obter uma precisão espacial de alta-ordem. A Seção 2.5 dá os detalhes desse tratamento, que é também aplicado na resolução das equações de Euler porque o tratamento envolve apenas à geometria da malha (Ollivier-Gooch et al., 2009). 


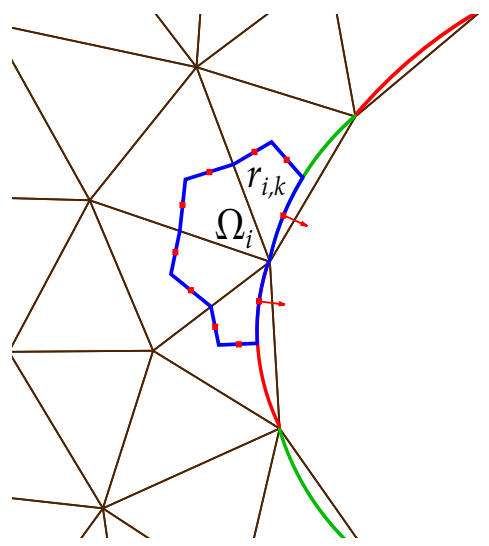

(a) 2a Ordem.

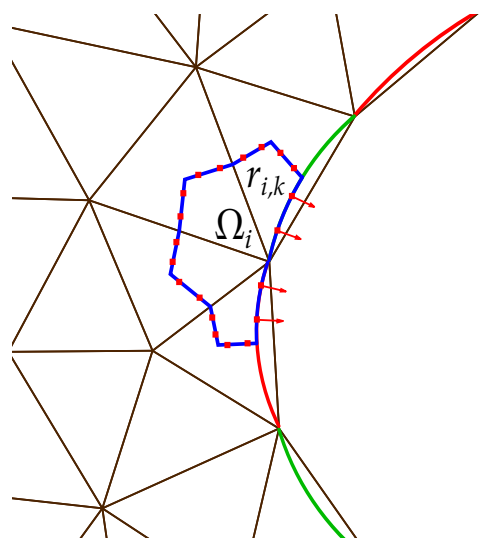

(b) 3a e 4a Ordem.

Figura 3.2: Localização dos pontos de Gauss $r_{i, k}$ para o cálculo da integral de fluxo para $\Omega_{i}$.

Isto é, primeiro dota-se um raio de curvatura $R_{i}$ a cada vértice $i$ localizado numa fronteira curva; e segundo, se parametriza cada face de fronteira $\widehat{i_{n} i_{n+1}}$, limitado por dois vértices consecutivos $i_{n}$ e $i_{n+1}$ da fronteira curva. Lembre-se que esta parametrização é utilizada na correta localização dos pontos de quadratura de Gauss para encontrar três parâmetros, entre eles a integral de fluxo ao longo das fronteiras curvas (vide Figura 3.2).

\subsection{Limitadores de Alta-Ordem}

Na resolução dos choques, é necessário limitar as oscilações da solução de alta-ordem ao redor dessas descontinuidades. No contexto dos Volumes Finitos, há esforços bastante bem sucedidos neste controle: os trabalhos de Michalak e Ollivier-Gooch (2008), Michalak (2009) e Michalak e Ollivier-Gooch (2009) fornecem limitadores para o método VF de alta-ordem utilizado no presente trabalho.

Para cada célula $\Omega_{i}$, constroem-se quatro limitadores, um para cada variável primitiva. A seguir apresenta-se a definição do limitador para a pressão $P_{i}(x, y)$; para as outras variáveis o procedimento é análogo. Considera-se, inicialmente, o polinômio de reconstrução escrito em termos do valor médio na célula $\Omega_{i}$, isto é (Michalak, 2009),

$$
P_{i}(x, y)=\bar{P}_{i}+\sum_{1 \leq m+n<p} c_{m, n}\left(\left(x-x_{i}\right)^{m}\left(y-y_{i}\right)^{n}-{\overline{x^{m} y^{n}}}_{i}\right)
$$

O limitador $\widehat{\Phi}_{i} \in[0,1]$ evita extremos locais nos pontos de integração de Gauss, para isto multiplica o segundo termo do polinômio, ou seja,

$$
P_{i}^{l i m}(x, y)=\bar{P}_{i}+\widehat{\Phi}_{i} \cdot\left[\sum_{1 \leq m+n<p} c_{m, n}\left(\left(x-x_{i}\right)^{m}\left(y-y_{i}\right)^{n}-\overline{x^{m} y^{n}}{ }_{i}\right)\right] .
$$

Esta é a forma limitada do polinômio reconstruído. O algoritmo completo para a definição do limitador $\widehat{\Phi}_{i}$ é apresentado no trabalho de Michalak (2009); a seguir apresenta-se apenas um resumo desse algoritmo:

Passo 1: Encontre o máximo número de Mach no estêncil da célula $i$ e avalie o valor $\widehat{\sigma}_{i} \in[0,1]$ (Michalak, 2009) a partir deste Mach máximo e de uma função $s:[0,1] \rightarrow[0,1], s(y)=$ $2 y^{3}-3 y^{2}+1$. Se o estêncil da célula $i$ está numa região subsônica, $\widehat{\sigma}_{i}$ resulta ser igual a 1 . Neste caso, define-se $\widehat{\Phi}_{i} \equiv 1$, isto é, o limitador é desabilitado e o algoritmo acaba.

Passo 2: Encontre a maior diferença negativa $\left(\delta P_{i}^{\min } \equiv\left|\min _{j} \min \left\{\overline{P_{j}}-\overline{P_{i}}, 0\right\}\right|\right)$ e positiva $\left(\delta P_{i}^{\text {max }} \equiv\right.$ 
$\left.\max \max \left\{\overline{P_{j}}-\overline{P_{i}}, 0\right\}\right)$ entre a solução nos vizinhos mais próximos $j$ e na célula $i$. Se algum de aqueles vizinhos ou a célula $i$ são adjacentes à fronteira com condição de parede, inclua os valores ghost (Michalak, 2009).

Passo 3: Calcule $\widetilde{\sigma}_{i} \in[0,1]$ a partir de $\delta P_{i} \equiv \delta P_{i}^{\max }-\delta P_{i}^{\min }$ e o parâmetro $K=0,25$ (Michalak , 2009). Se a diferença $\delta P_{i}$ é suficientemente pequena, $\widetilde{\sigma}_{i}$ resulta ser igual a 1 . Neste caso, define-se $\widehat{\Phi}_{i} \equiv \widetilde{\Phi}_{i} \equiv 1$, isto é, o limitador é desabilitado e o algoritmo acaba.

Passo 4: Calcule $P_{i, k} \equiv P_{i}\left(r_{i, k}\right)$, o valor do polinômio reconstruído (sem limitar) nos pontos de integração de Gauss $r_{i, k}$.

Passo 5: Em cada ponto de Gauss, calcule $\Phi_{i, k} \in[0,1]$ (Michalak, 2009) a partir do quociente $\frac{\delta P_{i}^{\max }}{P_{i, k}-\overline{P_{i}}}$ se $P_{i, k}-\overline{P_{i}}>0$, ou a partir de $\frac{\delta P_{i}^{\min }}{\left|P_{i, k}-\overline{P_{i}}\right|}$ se $P_{i, k}-\overline{P_{i}}<0$. E se o ponto de Gauss é tal que $P_{i, k}-\overline{P_{i}}=0$ então $\Phi_{i, k} \equiv 1$.

Passo 6: Defina $\Phi_{i} \equiv \min _{k}\left\{\Phi_{i, k}\right\}$.

Passo 7: Defina $\widetilde{\Phi}_{i} \equiv \widetilde{\sigma}_{i}+\left(1-\widetilde{\sigma}_{i}\right) \Phi_{i}$.

Passo 8: Defina $\widehat{\Phi}_{i} \equiv \widehat{\sigma}_{i}+\left(1-\widehat{\sigma}_{i}\right) \widetilde{\Phi}_{i}$.

Vale lembrar que por cada célula $i$ há quatro limitadores (um por cada variável primitiva). No presente trabalho, o cálculo destes limitadores é requerido apenas em uma das simulações da Seção 3.8 (escoamento transônico). Nesta simulação, o algoritmo de definição dos limitadores é colocado entre a construção polinomial e o cálculo do fluxo (vide Seçao 3.2), porque o fluxo nos pontos de quadratura gaussiana deve ser calculado a partir dos polinômios limitados $\rho_{i}^{\text {lim }}, u_{i}^{\text {lim }}, v_{i}^{\text {lim }}$ e $P_{i}^{\text {lim }}$.

\subsection{Simulações}

São simuladas três condições do escoamento invíscido e estacionário ao redor do aerofólio NACA 0012:

- Escoamento subsônico $M_{\infty}=0,4$ e $\alpha=0^{\circ}$,

- Escoamento subsônico $M_{\infty}=0,5$ e $\alpha=2^{\circ}$,

- Escoamento transônico $M_{\infty}=0,8$ e $\alpha=1,25^{\circ}$.

Para este propósito foi implementado um solver de VF de alta-ordem não estruturado com avanço no tempo RK. A discretização espacial de VF está descrita nas seções anteriores. Isto implica que a reconstrução polinomial de Michalak (2009) e o Riemann solver aproximado de Roe (1981) fazem parte do código. O método RK de van Leer et al. (1989), descrito em (3.9), é utilizado pelo código para atualizar a solução numérica. Para dar inicio a um teste, o código VF-RK precisa de alguns dados de entrada como: as condições de corrente livre do fluido, a malha computacional, a ordem (nominal) do método de VF, e o número CFL do método RK. Vale lembrar que os limitadores de alta-ordem (Michalak e Ollivier-Gooch, 2008) (Michalak e Ollivier-Gooch, 2009) são utilizados apenas no caso do escoamento transônico.

\subsubsection{NACA 0012 Subsônico, $M_{\infty}=0,4, \alpha=0^{\circ}$}

Este caso refere-se ao escoamento invíscido e estacionário ao redor do aerofólio NACA 0012 sob as condições mostradas na Tabela $3.1^{1}$. Em condições de corrente livre, o ar escoa horizontalmente $\left(\alpha=0^{\circ}\right) \operatorname{com}$ Mach 0,4 , a uma pressão estática de $25000 \mathrm{~N} / \mathrm{m}^{2}$ e a uma temperatura estática

\footnotetext{
${ }^{1}$ Este caso é simulado também por Liang et al. (2009b). Já, Ollivier-Gooch (1995) e Premasuthan (2010) (entre outros) simulam este caso com $M_{\infty}=0,5$.
} 
de $233 \mathrm{~K}$. Com esses dados encontra-se a pressão total e a temperatura total de corrente livre (Anderson, 2001): $P_{\text {total }, \infty}=27913,8 \mathrm{~N} / \mathrm{m}^{2}$ e $T_{\text {total }, \infty}=240,456 \mathrm{~K}$. Estes valores são necessários para especificar a condição de entrada subsônica (Seção 3.5). A condição de parede é imposta na superfície do aerofólio porque ali a velocidade do ar (invíscido) é tangencial à superfície.

$\begin{array}{ccc}\alpha & = & 0^{\circ} \\ M_{\infty} & = & 0,4 \\ P_{\infty} & = & 25000 \mathrm{~N} / \mathrm{m}^{2} \\ T_{\infty} & = & 233 \mathrm{~K}\end{array}$

Tabela 3.1: Condições de corrente livre, no caso subsônico e $\alpha=0^{\circ}$.

O aerofólio NACA0012 é modificado para fechar o bordo de fuga. Assim, a expressão analítica para a superfície do aerofólio é

$$
y= \pm 0,6\left(0,2969 \sqrt{x}-0,1260 x-0,3516 x^{2}+0,2843 x^{3}-0,1036 x^{4}\right)
$$

com $x \in[0,1]$. Isto é, a corda do aerofólio mede um metro $(c=1 \mathrm{~m})$. O domínio de interesse (Figura 3.3) é a região em volta do NACA0012 e que está limitada por uma circunferência de raio $20 c$ centrada no ponto $0,3 c$ da corda do aerofólio.

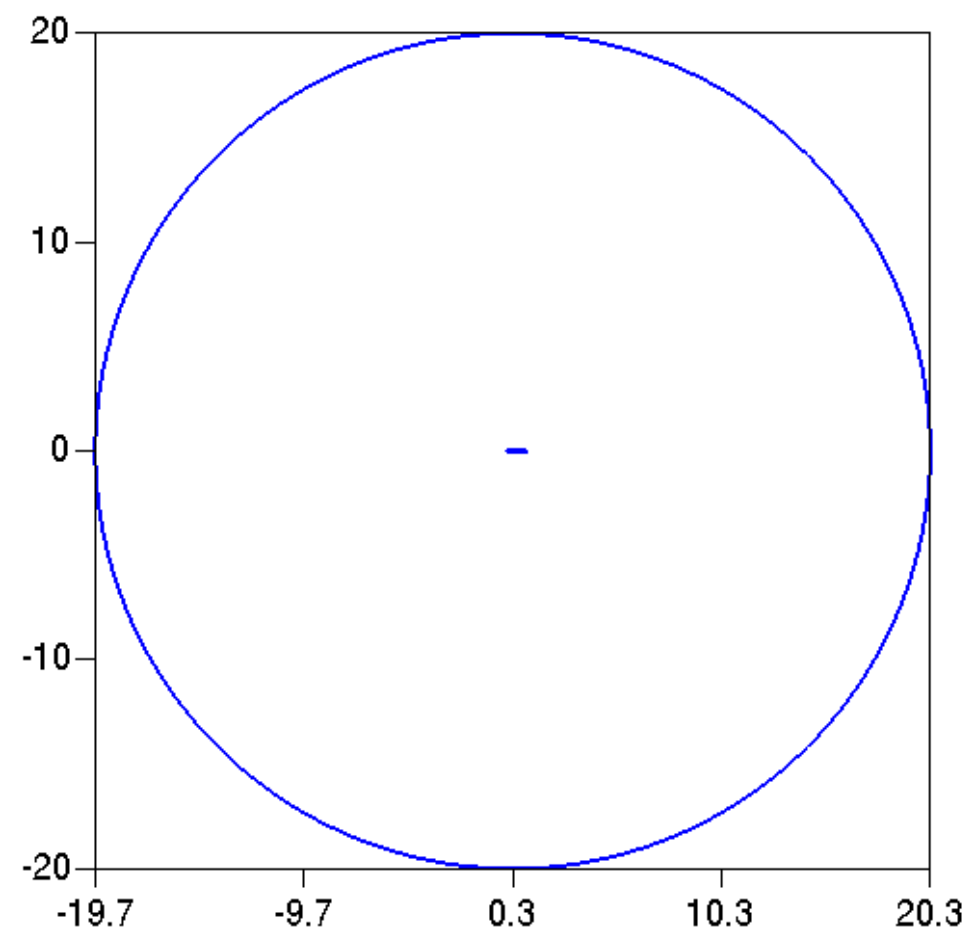

Figura 3.3: Domínio físico para o caso subsônico e $\alpha=0^{\circ}$.

Com o domínio já definido, criam-se três malhas utilizando o Gmsh (Geuzaine e Remacle, 2009). Na Tabela 3.2 tem-se algumas características dessas malhas computacionais. A Malha 1 possui 66 vértices (ou VC) sobre a superfície do aerofólio. Eles não são distribuídos igualmente: há uma maior concentração de vértices no bordo de ataque e no bordo de fuga (Figura 3.4(a)). Assim os VC ao redor de ambos os bordos tem comprimentos característicos $h$ menores do que dos VC no resto da superfície do aerofólio (e no resto da malha). No total, a Malha 1 possui 779 vértices (ou VC). As seguintes malhas são geradas uma a partir da anterior: dividindo-se todos os comprimentos característicos $h$ por aproximadamente $\sqrt{2}$. Por isso, o número de VC sobre a superfície do aerofólio vai aumentando a uma taxa aproximada de $\sqrt{2}$. E também, o número total de VC de uma malha é aproximadamente o dobro da malha anterior. No entanto, as três malhas mantêm o mesmo padrão 
de distribuição de vértices dado que o refinamento foi uniforme (Figura 3.4). O Gmsh permite salvar os dados das malhas em arquivos de texto. O código VF-RK consegue ler o arquivo da malha computacional selecionada e dar início a um teste. Nos testes desta subseção são consideradas as mesmas condições iniciais e o mesmo critério de parada. A condição inicial utilizada é a condição de corrente livre: Impõe-se os valores da Tabela 3.1 em cada VC. O critério de parada está descrito na Seção 3.2: O processo iterativo é interrompido quando a norma $L_{2}$ do resíduo converge a $10^{-10}$. 


\begin{tabular}{|c|c|c|}
\hline Malha & No. de VC na superfície do aerofólio & No. total de VC \\
\hline \hline Malha 1 & 66 & 779 \\
Malha 2 & 98 & 1610 \\
Malha 3 & 138 & 3156 \\
\hline
\end{tabular}

Tabela 3.2: Características das malhas computacionais para o caso subsônico e $\alpha=0^{\circ}$.

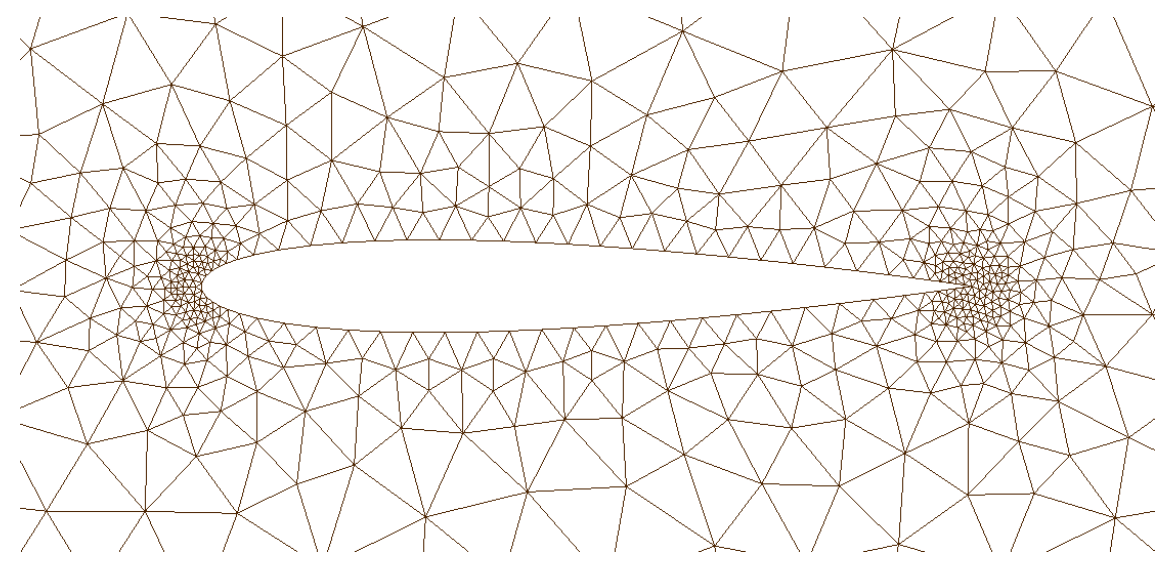

(a) Malha 1 (66 vértices na superfície do aerofólio).

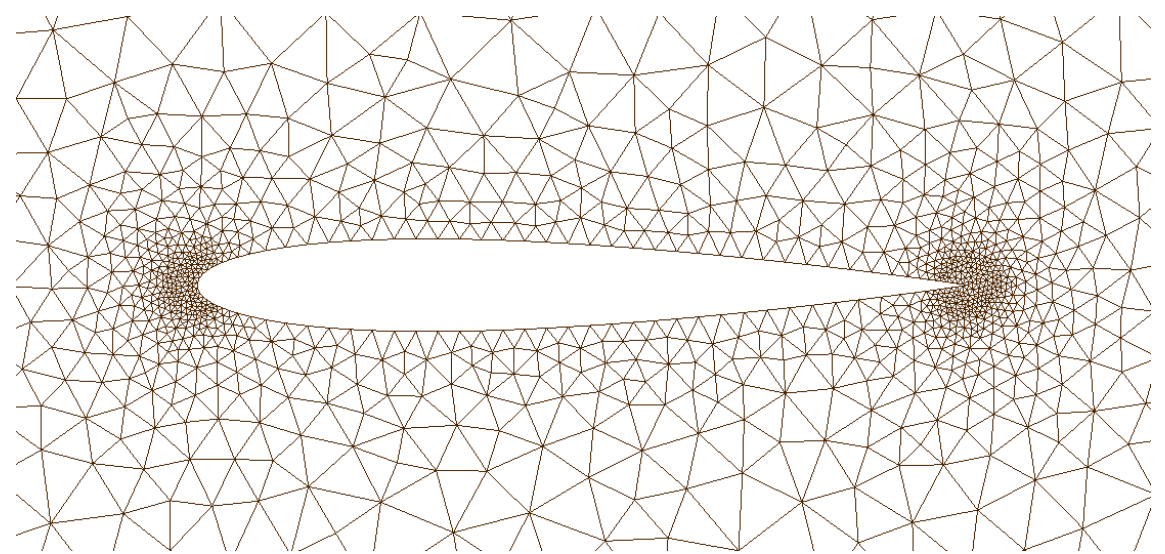

(b) Malha 2 (98 vértices na superfície do aerofólio).

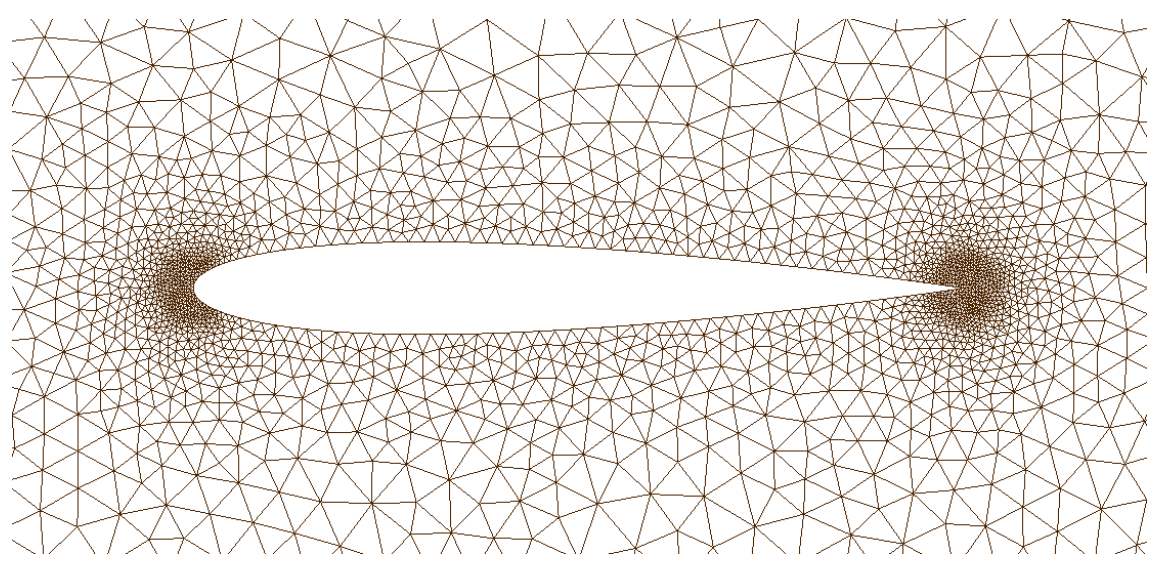

(c) Malha 3 (138 vértices na superfície do aerofólio).

Figura 3.4: Malhas computacionais para o caso subsônico e $\alpha=0^{\circ}$. 


\section{Busca experimental do CFL máximo}

O passo de tempo no solver VF-RK é limitado pelo número CFL. Nesse sentido, procura-se o CFL máximo para cada ordem do método VF. A Tabela 3.3 mostra que o método de VF de 2a ordem combina bem (consegue-se convergência) com valores de CFL menores ou iguais a 3,0. Já os métodos de VF de alta-ordem se ajustam a valores de CFL menores ou iguais a 2,5. Vale destacar que a Tabela 3.3 refere-se à discretização espacial e temporal deste trabalho e ao caso subsônico desta subseção. Também é importante enfatizar que a busca desses valores máximos de CFL foi empírica (utilizou-se o código). Os testes convergentes da Tabela 3.3 se dão para todas as malhas da Tabela 3.2. Ora, os testes não convergentes são peculiares e merecem ser detalhados. Com 2a ordem e $\mathrm{CFL}=3,5$ não se consegue convergência com nenhuma das três malhas. Com 3 a ordem e $\mathrm{CFL}=3,0$ não se consegue convergência com as Malhas 2 e 3, e sim com a Malha 1. Mas, para uniformizar, considera-se que a $3 \mathrm{a}$ ordem combina bem com números CFL menores ou iguais a 2,5. E por fim, com 4 a ordem e $\mathrm{CFL}=3,0$ não se consegue convergência com nenhuma das três malhas.

\begin{tabular}{|c|ccc|}
\hline Ordem & $\mathrm{CFL}=2,5$ & $\mathrm{CFL}=3,0$ & $\mathrm{CFL}=3,5$ \\
\hline \hline 2a Ordem & converge & converge & não converge \\
3a Ordem & converge & não converge & não converge \\
4a Ordem & converge & não converge & não converge \\
\hline
\end{tabular}

Tabela 3.3: Busca do CFL máximo para cada ordem do método de VF, no caso subsônico e $\alpha=0^{\circ}$.

\section{Influência do CFL nos testes}

As Tabelas 3.4 e 3.5 mostram os resultados dos testes para este caso subsônico. Para dar início a um teste, o código VF-RK precisa de três dados de entrada: a ordem (nominal) do método VF, a malha computacional e o número CFL do esquema RK. As combinações Ordem-Malha-CFL consideradas estão listadas na coluna "Dados de entrada do solver" das Tabelas acima mencionadas. Percebe-se que, dada uma ordem do método VF e dada uma malha, são utilizados três valores para o CFL. Por exemplo, ao combinar 2a Ordem com a Malha 1 utilizam-se os números CFL: 0,75, 1,5 e 3. A coluna "Norma $L_{2}$ do resíduo" mostra que todos os testes resultam em soluções numéricas estacionárias. A partir dessas soluções estacionárias, calculam-se os coeficientes de sustentação e de arrasto (colunas " $C_{l}$ " e " $C_{d}$ ", respectivamente). Observa-se que, esses valores são independentes do número CFL. Por exemplo, cada combinação 2a Ordem-Malha 1 resulta em valores de $C_{l}=$ $-5,15 \times 10^{-3}$ e de $C_{d}=5,03 \times 10^{-3}$, mesmo utilizando diferentes valores CFL do esquema RK. Outro exemplo é dado pelas combinações 3a Ordem-Malha 3: elas fornecem valores de $C_{l}=1,99 \times 10^{-3}$ e de $C_{d}=1,28 \times 10^{-3}$, independentemente do número CFL utilizado. De fato, a precisão no tempo não influi nas soluções estacionárias. Pela mesma razão, o coeficiente de pressão $C_{p}$ ao longo do aerofólio também é independente do número CFL. Por exemplo, a Figura 3.5(a) mostra o $C_{p}$ ao longo do aerofólio obtido pela combinação Ordem2-Malha1-CFL $=3,0$ e pela combinação Ordem2-Malha1-CFL $=0,75$. A diferença entre ambas soluções estacionárias não é maior do que $5 \times 10^{-12}$ (Figura 3.5(c)). Similarmente, a Figura 3.5(b) mostra o $C_{p}$ ao longo do aerofólio obtido pela combinação Ordem3-Malha3-CFL $=2,5$ e pela combinação Ordem3-Malha3- $C F L=0,625$. Aqui, a variação no coeficiente de pressão $C_{p}$ devida ao CFL é menor do que $10^{-13}$ (Figura 3.5(d)).

O aumento do número CFL não diminui (nem aumenta) a precisão da solução estacionária, mas é importante para otimizar os tempos de CPU. As colunas "Iterações" e "Tempo de CPU" 2 das Tabelas 3.4 e 3.5 apresentam, respectivamente, o número de iterações e o tempo necessários para alcançar a solução estacionária. Percebe-se que, dada uma ordem do método VF e dada uma malha, o número de iterações diminui ao aumentar o número CFL. Por exemplo, o número de iterações que resulta da combinação Ordem2-Malha1-CFL=3,0 é 7835, ou seja, um 24\% do número

\footnotetext{
${ }^{2} \mathrm{O}$ tempo de CPU inclui, ademais do tempo do processo iterativo, o tempo pre-processo iterativo. O pre-processo iterativo demora, na maioria dos testes desta subseção, menos de $1 \mathrm{~s}$. Esses tempos são quase insignificantes quando comparados com os tempos do processo iterativo.
} 
de iterações da combinação Ordem2-Malha1-CFL $=0,75$. De maneira similar, a combinação Ordem2Malha3-CFL $=3,0$ resulta em 65723 iterações, que representa um $23 \%$ do número de iterações da combinação Ordem2-Malha3-CFL $=0,75$. Esta queda no número de iterações também é observada no tempo de CPU. De fato,

$$
\text { Tempo de CPU teórico }=t_{1 \text { iter }} \times \text { No. de Iterações, }
$$

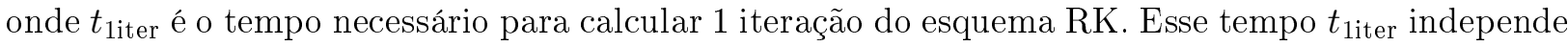
do número CFL (Seção 3.2). Ora, dada uma ordem do método VF e dada uma malha, tem-se que o número de iterações muda com o CFL. Logo, o tempo de CPU teórico também varia e na mesma proporção, isto é,

$$
\text { Tempo de CPU teórico (\%) = No. de Iterações (\%), }
$$

onde o símbolo (\%) indica quantidades relativas às que resultam com o CFL mais baixo. Assim, a coluna "Iterações (\%)" das Tabelas 3.4 e 3.5 mostra também o tempo de CPU teórico (\%). Comparese com a coluna "Tempo de CPU (\%)". Por exemplo, o tempo de CPU teórico (\%) da combinação Ordem2-Malha3-CFL=3,0 é 23\%. Já o tempo de CPU medido (\%) dessa combinação é de $25 \%$. A diferença entre o tempo teórico e o medido é devida, principalmente, à performance do computador ${ }^{3}$. Dado que o mesmo computador é utilizado nos testes dos próximos capítulos, acredita-se

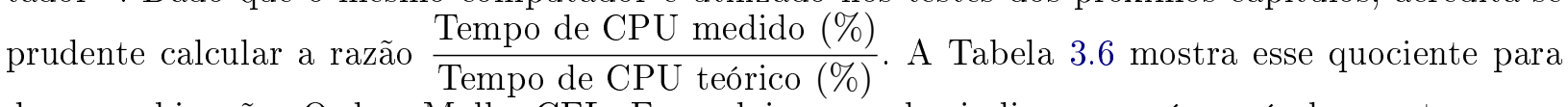
duas combinações Ordem-Malha-CFL. Esses dois exemplos indicam que é possível encontrar uma relação de 1,10 entre o tempo de CPU medido (\%) e o tempo de CPU teórico (\%).

\footnotetext{
${ }^{3}$ Vide Apêndice A
} 


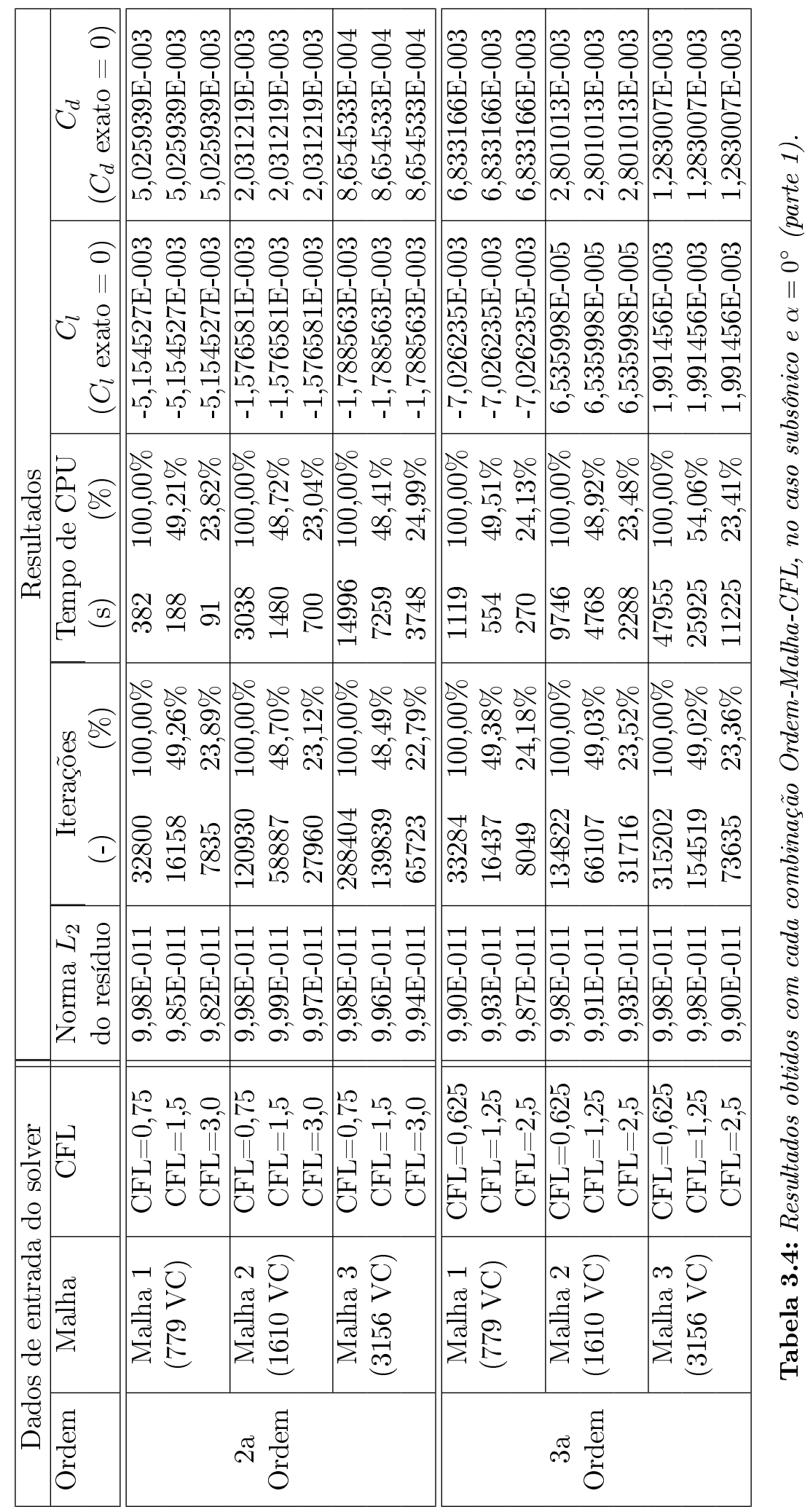




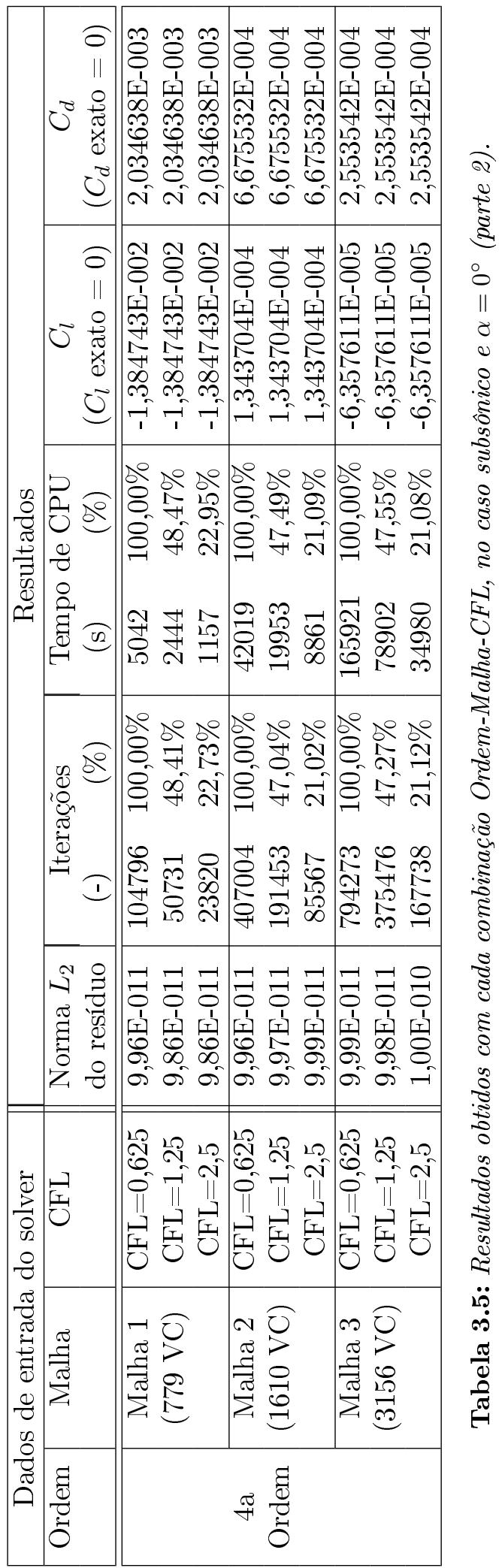



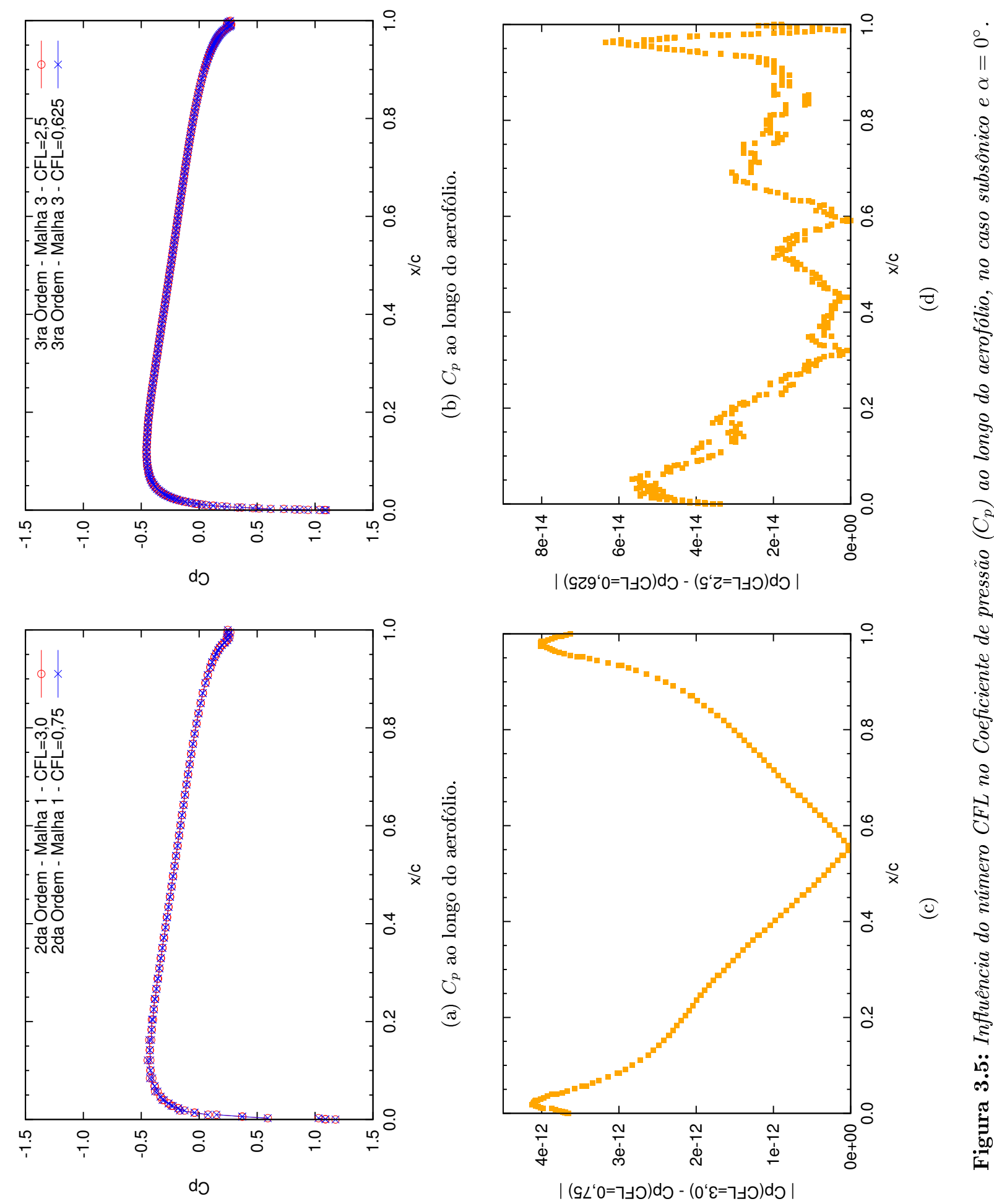


\begin{tabular}{|lccc|}
\hline Combinação & $\begin{array}{c}\text { Tempo de } \\
\text { CPU teórico } \\
(\%)\end{array}$ & $\begin{array}{c}\text { Tempo de } \\
\text { CPU medido } \\
(\%)\end{array}$ & $\begin{array}{c}\text { Tempo de CPU medido (\%) } \\
\text { Tempo de CPU teórico (\%) }\end{array}$ \\
\hline \hline Ordem2-Malha3-CFL $=3,0$ & $22,79 \%$ & $24,99 \%$ & 1,10 \\
Ordem3-Malha3-CFL $=1,25$ & $49,02 \%$ & $54,06 \%$ & 1,10 \\
\hline
\end{tabular}

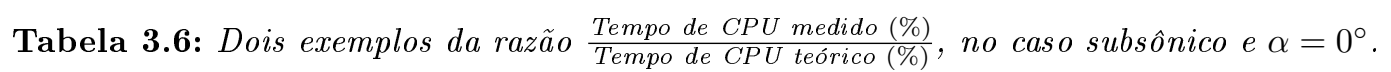

\section{Coeficientes $C_{l}$ e $C_{d}$}

Neste caso subsônico, o coeficiente de sustentação $\left(C_{l}\right)$ deveria ser nulo porque o aerofólio NACA 0012 é simétrico e o escoamento não forma um ângulo com ele. Também, o coeficiente de arrasto $\left(C_{d}\right)$ deveria ser nulo porque este escoamento subsônico é irrotacional (Jameson e Mavriplis, 1985). Para avaliar a precisão e o desempenho dos testes são plotadas as Figuras 3.6(a) - 3.6(d) a partir das Tabelas 3.4 e 3.5. Os coeficientes $C_{l}$ e $C_{d}$ obtidos por cada combinação Ordem-Malha ${ }^{4}$ são mostrados nas Figuras 3.6(a) e 3.6(c). Estas dão indícios da convergência (em malha) de cada ordem do método VF. Isto é, os coeficientes obtidos seriam mais próximos do valor exato (zero) se continuar aumentando o número de volumes de controle das malhas. Em relação ao $C_{l}$, observa-se que a 4 a ordem consegue uma rápida convergência (em malha). Já a 2a ordem precisará de malhas mais finas para alcançar a boa precisão da 4a ordem. E a 3a ordem apresenta flutuações na convergência. Vale lembrar que as malhas utilizadas não são simétricas em relação ao eixo $X$ e que na literatura encontram-se simulações deste caso com malhas simétricas, o que resulta em valores $C_{l}$ de nível zero de máquina. Em relação ao $C_{d}$, todas as ordens do método VF estão convergindo (em malha) sem oscilações. Vale destacar que a 4 a ordem apresenta os resultados mais precisos.

A seguir, estudam-se os coeficientes $C_{d}$ obtidos com a malha mais fina (3156 VC) e os valores obtidos em outras pesquisas com malhas equivalentes (Tabela 3.7). Ollivier-Gooch (1995) reporta um valor $C_{d}=0,00022$ obtido com o método de VF de 2a ordem sobre uma malha quadrada de $40 \mathrm{c}$ por lado e $3084 \mathrm{VC}$. Esta simulação é, em termos de ordem, malha e tamanho do domínio, comparável à combinação 2a Ordem-Malha 3 (3156 VC). Perceba-se, porém, que o presente trabalho consegue um valor próximo ao obtido por Ollivier-Gooch (1995) utilizando somente 4a ordem $\left(C_{d}=\right.$ 0,000255). Isto poderia explicar-se pelo fato de que Ollivier-Gooch (1995) utiliza um limitador para garantir a monotonicidade e o presente trabalho utiliza-o apenas para o caso transônico. Premasuthan (2010) encontra um valor $C_{d}=0,000158$ utilizando o método de Diferença Espectral de 3a ordem sobre uma malha circular de raio $25 c$ e 2880 graus de liberdade. Esta simulação é, em termos de ordem, malha e tamanho do domínio, comparável à combinação 3a Ordem-Malha 3 (3156 VC). Porém, esta combinação não alcança a boa precisão reportada pelo Premasuthan (2010) talvez porque este considera uma malha simétrica em relação ao eixo $X$. Vassberg e Jameson (2010) utilizam uma malha simétrica e de raio maior $(150 \mathrm{c})$, mas esta malha possui 128 células sobre o aerofólio, o que é comparável com a malha de $3156 \mathrm{VC}$ do presente trabalho. De novo, somente com 4a ordem, este trabalho consegue um valor próximo ao obtido por Vassberg e Jameson (2010).

Ao aplicar métodos de alta e de baixa-ordem no cálculo do coeficiente de arrasto $C_{d}$ deste caso subsônico, Andren et al. (2011) encontram que as discretizações de alta-ordem não são tão eficientes para $C_{d}>10^{-4}$; o favoritismo sobre os métodos de baixa-ordem é mais claro ao procurar maior precisão $\left(C_{d}<10^{-4}\right)$. Os testes do presente trabalho não chegam neste nível de precisão. Mesmo assim, analisa-se a eficiência das ordens do método VF. As Figuras 3.6(b) e 3.6(d) apresentam os coeficientes de sustentação $\left(C_{l}\right)$ e de arrasto $\left(C_{d}\right)$ versus o tempo de CPU ${ }^{5}$. Por exemplo, a combinação 2a Ordem-Malha $2(1610 \mathrm{VC})$ resulta num valor de $\left|C_{l}\right|=1,6 \times 10^{-3}$ e demora 700 s. A 4a ordem levaria hipoteticamente 7000 s para alcançar a mesma precisão. Ora, a mesma

\footnotetext{
${ }^{4}$ Lembre-se que, dada uma ordem do método VF e uma malha computacional, obtem-se uma solução estacionária independente do número CFL do esquema RK.

${ }^{5}$ Esses tempos de CPU são os ótimos, isto é, são calculados com o CFL máximo para cada ordem do método VF: $\mathrm{CFL}=3,0$ para o método de $2 \mathrm{a}$ ordem e $\mathrm{CFL}=2,5$ para os métodos de alta-ordem.
} 


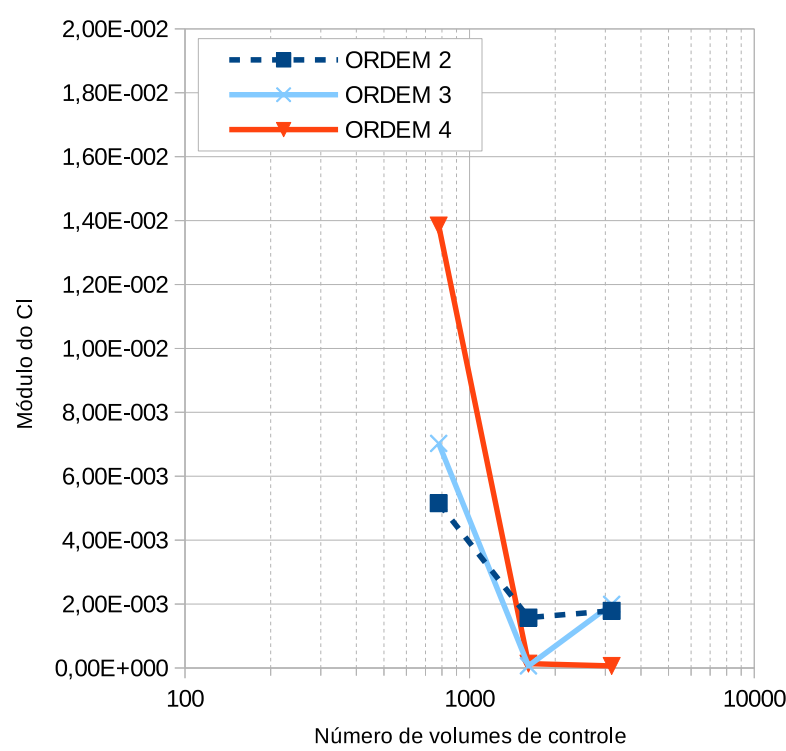

(a)

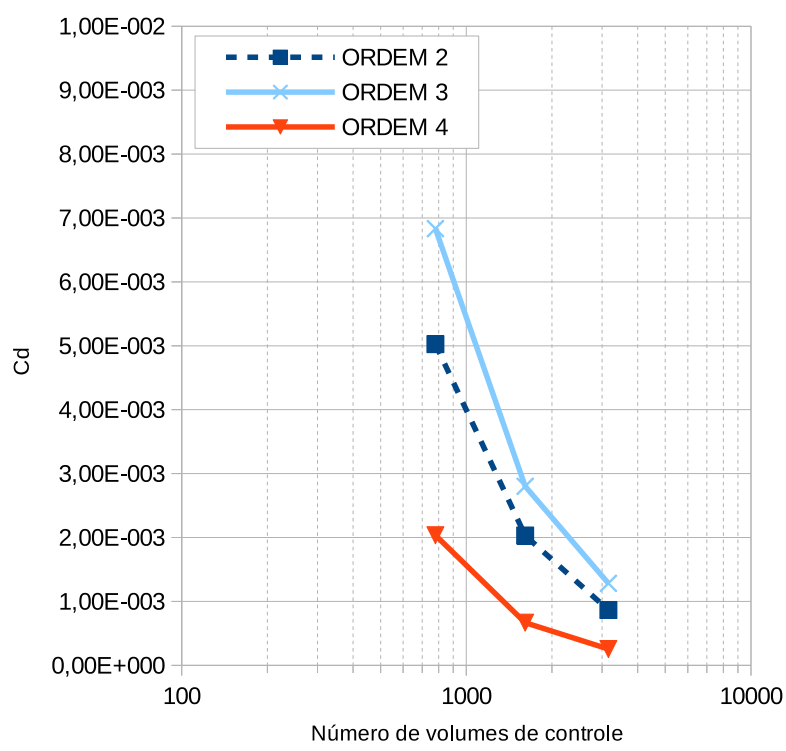

(c)

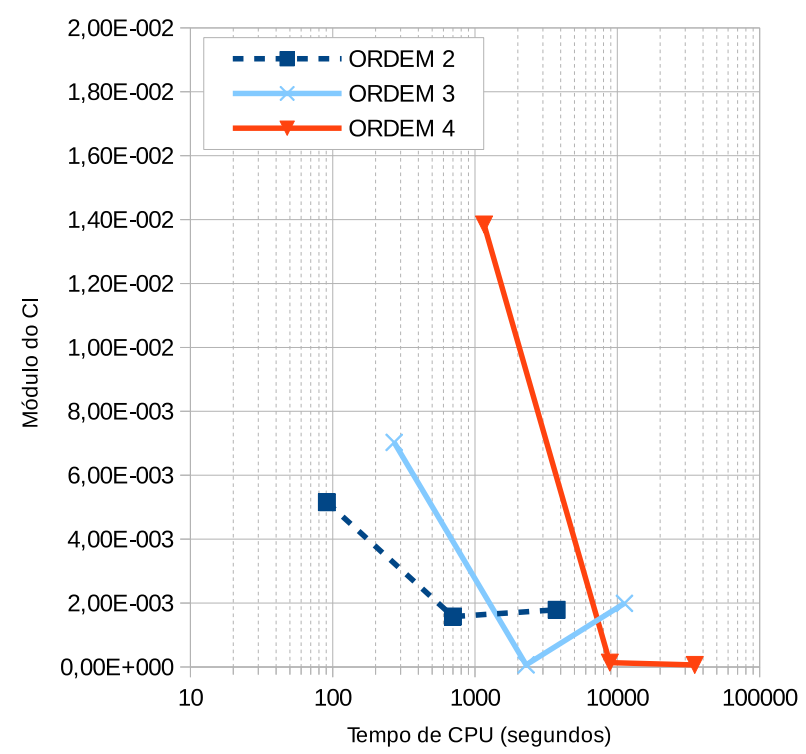

(b)

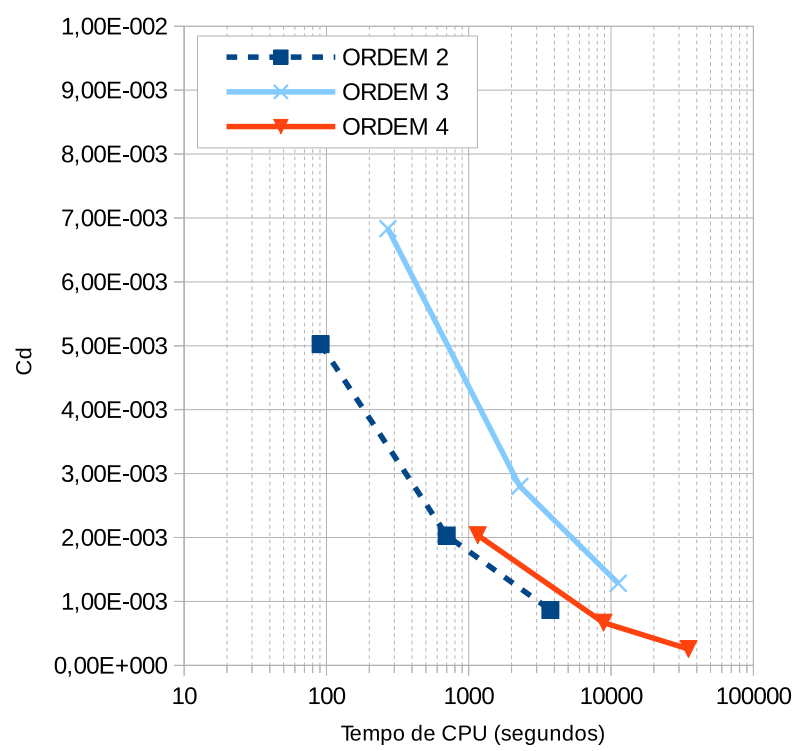

(d)

Figura 3.6: Coeficientes de sustentação $\left(C_{l}\right)$ e de arrasto $\left(C_{d}\right)$, no caso subsônico e $\alpha=0^{\circ}$.

Presente trabalho - 2a Ordem, 3156 VC

$$
\begin{array}{lc} 
& C_{d} \\
\text { Presente trabalho - 2a Ordem, 3156 VC } & 0,000865 \\
\text { Presente trabalho - 3a Ordem, 3156 VC } & 0,001283 \\
\text { Presente trabalho - 4a Ordem, 3156 VC } & 0,000255 \\
\text { Ollivier-Gooch (1995) - 2a Ordem, 3084 VC } & 0,000220 \\
\text { Premasuthan (2010) - 3a Ordem, 2880 graus de liberdade } & 0,000158 \\
\text { Vassberg e Jameson (2010) - 2a Ordem, 128 células sobre o aerofólio } & 0,000308
\end{array}
$$$$
\text { Presente trabalho - 4a Ordem, } 3156 \text { VC }
$$$$
\text { Ollivier-Gooch (1995) - 2a Ordem, } 3084 \text { VC }
$$

Tabela 3.7: Comparação de coeficientes de arrasto $C_{d}$ obtidos no caso subsônico e $\alpha=0^{\circ}$.

combinação, 2a Ordem-Malha 2, resulta num valor de $C_{d}=2 \times 10^{-3}(700 \mathrm{~s})$ e a 4 a ordem leva mais de $1000 \mathrm{~s}$ para conseguir a mesma precisão. Assim, se verifica que para $C_{d}>10^{-4}$ a $4 \mathrm{a}$ ordem não supera a eficiência da 2a ordem. Um conjunto de malhas mais finas (e domínios de raio maior) 
será necessário para obter menores valores de $C_{d}$ e para analisar a eficiência das ordens do método VF nesses níveis de precisão (Andren et al., 2011). Já, para os propósitos deste trabalho, as três malhas desta subseção continuam sendo consideradas nos testes com p-multigrid (Capítulo 5).

\subsubsection{NACA 0012 Subsônico, $M_{\infty}=0,5, \alpha=2^{\circ}$}

Este caso refere-se ao escoamento invíscido e estacionário ao redor do aerofólio NACA 0012 sob as condições mostradas na Tabela 3.8. Em condições de corrente livre, a velocidade do ar forma um ângulo $\left(\alpha=2^{\circ}\right)$ com a horizontal, o número Mach do ar é 0,5 , a pressão estática é de $25000 \mathrm{~N} / \mathrm{m}^{2}$ e a temperatura estática é de $233 \mathrm{~K}$. Com esses dados encontra-se a pressão total e a temperatura total de corrente livre (Anderson, 2001): $P_{\text {total }, \infty}=29655,3 \mathrm{~N} / \mathrm{m}^{2}$ e $T_{\text {total }, \infty}=244,65 \mathrm{~K}$. Estes valores são necessários para especificar a condição de entrada subsônica (Seção 3.5). A condição de parede é imposta na superfície do aerofólio porque ali a velocidade do ar (invíscido) é tangencial à superfície.

$\begin{array}{ccc}\alpha & = & 2^{\circ} \\ M_{\infty} & = & 0,5 \\ P_{\infty} & = & 25000 \mathrm{~N} / \mathrm{m}^{2} \\ T_{\infty} & = & 233 \mathrm{~K}\end{array}$

Tabela 3.8: Condições de corrente livre, no caso subsônico e $\alpha=2^{\circ}$.

A equação (3.19) é a expressão analítica para a superfície do NACA0012 com comprimento de corda $c$ igual a $1 \mathrm{~m}$. O domínio de interesse é a região em volta do NACA0012 e que está limitada por uma circunferência de raio $50 c$ centrada no ponto $0,3 c$ da corda do aerofólio. Com o domínio já definido, criam-se três malhas utilizando o Gmsh (Geuzaine e Remacle, 2009). As malhas (Figura 3.7) são diferentes às utilizadas no caso subsônico e $\alpha=0^{\circ}$ (Seção 3.8.1): a maior concentração de vértices está localizada numa vizinhança do aerofólio inteiro e não apenas ao redor dos bordos de ataque e fuga. Começando pela Malha 1, as seguintes malhas são geradas uma a partir da anterior, seguindo a metodologia descrita no caso subsônico e $\alpha=0^{\circ}$. Na Tabela 3.9 tem-se algumas características dessas malhas computacionais. O código VF-RK consegue ler o arquivo da malha computacional selecionada e dar início a um teste. Nos testes desta subseção são consideradas as mesmas condições iniciais e o mesmo critério de parada. A condição inicial utilizada é a condição de corrente livre: Impõe-se os valores da Tabela 3.8 em cada VC. O critério de parada está descrito na Seção 3.2: O processo iterativo é interrompido quando a norma $L_{2}$ do resíduo converge a $10^{-10}$. 


\begin{tabular}{|c|c|c|}
\hline Malha & No. de VC na superfície do aerofólio & No. total de VC \\
\hline \hline Malha 1 & 142 & 2261 \\
Malha 2 & 204 & 4630 \\
Malha 3 & 296 & 9328 \\
\hline
\end{tabular}

Tabela 3.9: Características das malhas computacionais para o caso subsônico e $\alpha=2^{\circ}$.

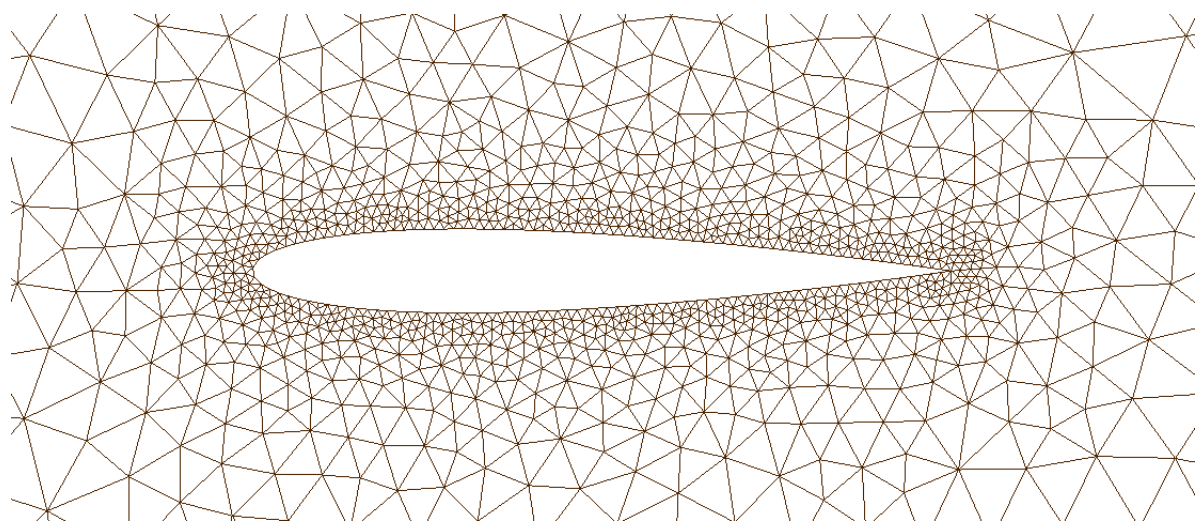

(a) Malha 1 (142 vértices na superfície do aerofólio).

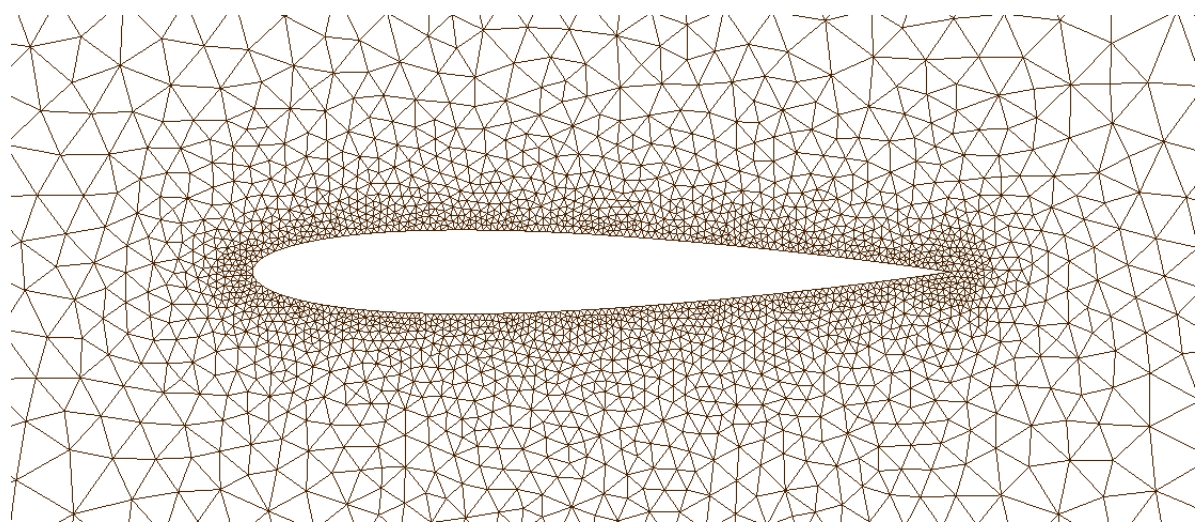

(b) Malha 2 (204 vértices na superfície do aerofólio).

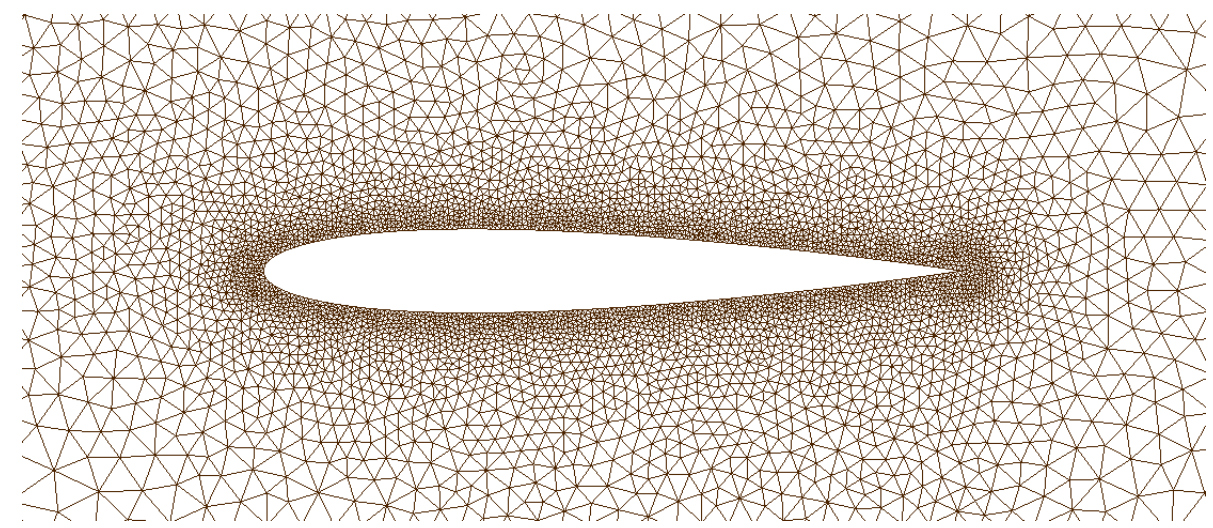

(c) Malha 3 (296 vértices na superfície do aerofólio).

Figura 3.7: Malhas computacionais para o caso subsônico e $\alpha=2^{\circ}$. 


\section{Busca experimental do CFL máximo}

De maneira análoga ao caso subsônico e $\alpha=0^{\circ}$ (Seção 3.8.1), procura-se o CFL máximo para cada ordem do método VF. Apesar de utilizar a mesma discretização espacial e temporal, os resultados desta busca são diferentes aos obtidos no caso subsônico e $\alpha=0^{\circ}$. A Tabela 3.10 mostra que o método de VF de 2a ordem combina bem (consegue-se convergência) com valores de CFL menores ou iguais a 4,0. E os métodos de VF de alta-ordem se ajustam a valores de CFL menores ou iguais a 3,5. Vale destacar que a busca desses valores máximos de CFL foi empírica (utilizou-se o código). Os testes convergentes da Tabela 3.10 se dão para todas as malhas da Tabela 3.9. Ora, os testes não convergentes são peculiares e merecem ser detalhados. Com $2 \mathrm{a}$ ordem e $\mathrm{CFL}=4,5$ não se consegue convergência com nenhuma das três malhas. Com 3a ordem e $\mathrm{CFL}=4,0$ não se consegue convergência com a Malha 3, e sim com as Malha 1 e 2. Mas, para uniformizar, considera-se que a 3a ordem combina bem com números CFL menores ou iguais a 3,5. E por fim, com 4a ordem e $\mathrm{CFL}=4,0$ não se consegue convergência com nenhuma das três malhas.

\begin{tabular}{|c|ccc|}
\hline Ordem & $\mathrm{CFL}=3,5$ & $\mathrm{CFL}=4,0$ & $\mathrm{CFL}=4,5$ \\
\hline \hline 2a Ordem & converge & converge & não converge \\
3a Ordem & converge & não converge & não converge \\
4a Ordem & converge & não converge & não converge \\
\hline
\end{tabular}

Tabela 3.10: Busca do CFL máximo para cada ordem do método de $V F$, no caso subsônico e $\alpha=2^{\circ}$.

\section{Influência do CFL nos testes}

As Tabelas 3.11 e 3.12 mostram os resultados dos testes para este caso subsônico. Consideramse, assim como no caso subsônico e $\alpha=0^{\circ}$, combinações Ordem-Malha-CFL (coluna "Dados de entrada do solver" das Tabelas acima mencionadas). A coluna "Norma $L_{2}$ do resíduo" mostra que todos os testes resultam em soluções numéricas estacionárias. A partir dessas soluções estacionárias, calculam-se os coeficientes de sustentação e de arrasto (colunas " $C_{l}$ " e " $C_{d}$ ", respectivamente). E, da mesma maneira que no caso subsônico e $\alpha=0^{\circ}$, comprova-se que o aumento do número CFL não diminui (nem aumenta) a precisão da solução estacionária. Por exemplo, cada combinação 2a Ordem-Malha 1 resulta em valores de $C_{l}=0,26647$ e de $C_{d}=0,00565$, mesmo utilizando diferentes valores CFL do esquema RK. A Figura 3.8(a) dá outro exemplo dessa independência: ela mostra o coeficiente de pressão $C_{p}$ ao longo do aerofólio obtido pela combinação Ordem2-Malha1-CFL=4,0 e pela combinação Ordem2-Malha1-CFL=1,0. A diferença entre ambas soluções estacionárias não é maior do que $10^{-12}$ (Figura 3.8(c)). Similarmente, a Figura 3.8(b) mostra o $C_{p}$ ao longo do aerofólio obtido pela combinação Ordem3-Malha3-CFL $=3,5$ e pela combinação Ordem3-Malha3-CFL $=0,875$. Aqui, a variação no coeficiente de pressão $C_{p}$ devida ao CFL é de magnitude $10^{-11}$ (Figura 3.8(d)).

Por outro lado, o aumento do número CFL permite otimizar os tempos de CPU. As colunas "Iterações" e "Tempo de CPU" 6 das Tabelas 3.11 e 3.12 apresentam, respectivamente, o número de iterações e o tempo necessários para alcançar a solução estacionária. Percebe-se que, dada uma ordem do método VF e dada uma malha, o número de iterações diminui ao aumentar o número CFL. Por exemplo, o número de iterações que resulta da combinação Ordem2-Malha1-CFL=4,0 é 5747, ou seja, um 24, 71\% do número de iterações da combinação Ordem2-Malha1-CFL=1,0. Esta queda no número de iterações também é observada no tempo de CPU. E mais ainda, o tempo de CPU teórico é diretamente proporcional ao número de iterações (vide equação (3.20), no caso subsônico e $\alpha=0^{\circ}$ ). Portanto,

$$
\text { Tempo de CPU teórico (\%) = No. de Iterações (\%), }
$$

\footnotetext{
${ }^{6} \mathrm{O}$ tempo de CPU inclui, ademais do tempo do processo iterativo, o tempo pre-processo iterativo. O pre-processo iterativo demora, na maioria dos testes desta subseção, menos de $2 \mathrm{~s}$. Esses tempos são quase insignificantes quando comparados com os tempos do processo iterativo.
} 
onde o símbolo (\%) indica quantidades relativas às que resultam com o CFL mais baixo. Assim, a coluna "Iterações (\%)" das Tabelas 3.11 e 3.12 mostra também o tempo de CPU teórico (\%). E comparando esta coluna com a coluna "Tempo de CPU (\%)" verifica-se, como no caso subsônico e $\alpha=0^{\circ}$, que o tempo teórico é diferente ao tempo medido ${ }^{7}$. A Tabela 3.13 mostra o quociente Tempo de CPU medido (\%) sobre Tempo de CPU teórico (\%) para alguns testes desta subseção. Essa razão varia entre $1-0,16$ e $1+0,16$. 


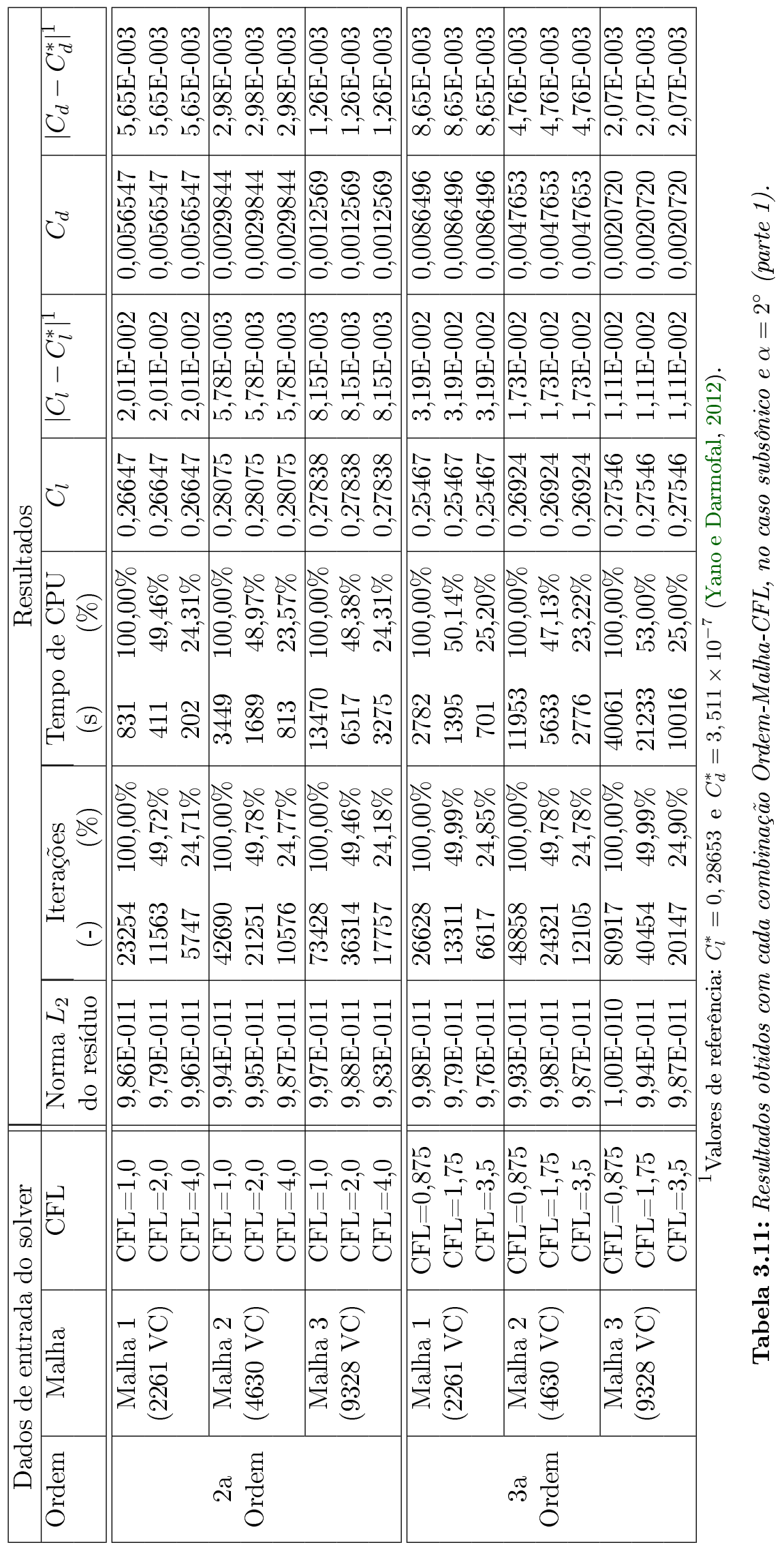




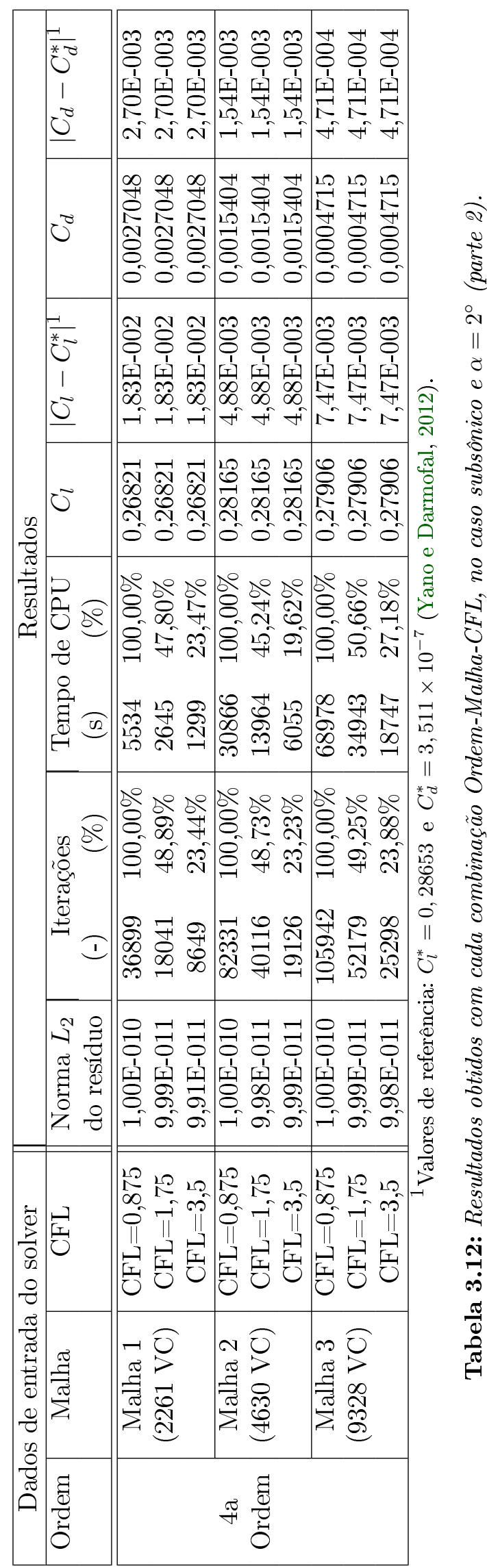




$$
\frac{k K}{k B}
$$




\begin{tabular}{|lccc|}
\hline Combinação & $\begin{array}{c}\text { Tempo de } \\
\text { CPU teórico } \\
(\%)\end{array}$ & $\begin{array}{c}\text { Tempo de } \\
\text { CPU medido } \\
(\%)\end{array}$ & $\begin{array}{c}\text { Tempo de CPU medido (\%) } \\
\text { Tempo de CPU teórico (\%) }\end{array}$ \\
\hline \hline Ordem3-Malha3-CFL $=1,75$ & $49,99 \%$ & $53,00 \%$ & 1,06 \\
Ordem4-Malha2-CFL $=3,5$ & $23,23 \%$ & $19,62 \%$ & 0,84 \\
Ordem4-Malha3-CFL $=3,5$ & $23,88 \%$ & $27,18 \%$ & 1,14 \\
\hline
\end{tabular}

Tabela 3.13: Exemplos da razão $\frac{\text { Tempo de } C P U \text { medido (\%) }}{\text { Tempo de } C P U \text { teórico (\%) }}$, no caso subsônico e $\alpha=2^{\circ}$.

\section{Coeficientes $C_{l}$ e $C_{d}$}

O autor do presente trabalho não encontra, na literatura, o valor exato do coeficiente de sustentação $\left(C_{l}\right)$ para este caso subsônico e $\alpha=2^{\circ}$. Já, o coeficiente de arrasto $\left(C_{d}\right)$ sim é conhecido: ele deveria ser nulo porque este escoamento subsônico é irrotacional (Jameson e Mavriplis, 1985). Yano e Darmofal (2012) simulam este caso subsônico utilizando o método Galerkin Descontínuo com polinômios de grau 3, e considerando um domínio quadrado $2 R \times 2 R \operatorname{com} R=10^{4} c$. Eles escolhem este amplo domínio após um estudo da sensibilidade do arrasto à localização do far-field (Seção 3.5). Assim, os coeficientes $C_{l}$ e $C_{d}$ reportados por esses pesquisadores são

$$
\begin{aligned}
& C_{l}^{*}=0,28653 \\
& C_{d}^{*}=3,511 \times 10^{-7} .
\end{aligned}
$$

Esta solução de referência serve para calcular o erro do presente trabalho (vide colunas " $\left|C_{l}-C_{l}^{*}\right|$ " e " $\left|C_{d}-C_{d}^{*}\right|$ " das Tabelas 3.11 e 3.12). Percebe-se que o valor de referência $C_{d}^{*}<<C_{d}$ (do presente trabalho); portanto o erro do arrasto é aproximadamente igual ao próprio arrasto (se calcular o erro utilizando o valor teórico, o erro do arrasto seria precisamente o arrasto). As Figuras 3.9(a) e 3.9(c) mostram, respectivamente, os erros de sustentação e de arrasto que resultam para cada combinação Ordem-Malha ${ }^{8}$. Estas figuras dão indícios da convergência (em malha) de cada ordem do método VF. Isto é, o erro deveria decrescer se continuar aumentando o número de volumes de controle das malhas. Em relação ao $C_{l}$, observa-se que a 2 a e 4 a ordem apresentam o mesmo nível de precisão e a convergência (em malha) apresenta flutuações. Em relação ao $C_{d}$, todas as ordens do método VF estão convergindo (em malha) sem oscilações e a 4a ordem apresenta os resultados mais precisos. Nos dois coeficientes, observa-se que a 3a ordem tem os erros mais altos. Isto é devido, principalmente, a uma deficiente recuperação da pressão no bordo de fuga (Figura 3.10). Nesta região, o polinômio de grau 2 não se ajusta tão bem (quanto os polinômios de grau impar) à anti-simetria da velocidade vertical $v$ do fluido. Nejat e Ollivier-Gooch (2008) reportam este problema da 3 a ordem ao simular um caso subsônico similar $\left(M_{\infty}=0,63\right.$ e ângulo $\left.\alpha=2^{\circ}\right)$ utilizando o mesmo esquema de VF do presente trabalho.

Ao aplicar métodos de alta e de baixa-ordem para este caso subsônico e $\alpha=2^{\circ}$, Andren et al. (2011) encontram que as discretizações de alta-ordem não são tão eficientes quando resultam num erro de arrasto maior do que $10^{-4}$; o favoritismo sobre os métodos de baixa-ordem é mais claro ao procurar maior precisão. Os testes do presente trabalho caem no primeiro caso, mesmo assim, analisa-se a eficiência das ordens do método VF. As Figuras 3.9(b) e 3.9(d) apresentam o erro de sustentação e o erro de arrasto versus o tempo de $\mathrm{CPU}^{9}$. Elas dão indícios de que a 4a ordem ainda não supera a eficiência da 2 a ordem.

Vale destacar também que o erro, na simulação deste caso subsônico, depende do tamanho do domínio (assim como da ordem e da malha). De fato, as condições de fronteira (far-field) tem um efeito mais significativo na solução, do que no caso subsônico e $\alpha=0^{\circ}$ (vide Seção 3.5). Fazer um

\footnotetext{
${ }^{8}$ Lembre-se que, dada uma ordem do método VF e uma malha computacional, obtem-se uma solução estacionária independente do número CFL do esquema RK.

${ }^{9}$ Esses tempos de CPU são os ótimos, isto é, são calculados com o CFL máximo para cada ordem do método VF: $\mathrm{CFL}=4,0$ para o método de $2 \mathrm{a}$ ordem e $\mathrm{CFL}=3,5$ para os métodos de alta-ordem.
} 
estudo completo da precisão e da eficiência do método VF não é um objetivo deste trabalho. E sim, diminuir os tempos de CPU para o conjunto de malhas deste trabalho (Capítulo 5). A Figura 3.11 apresenta o campo de pressão ao redor do aerofólio NACA0012 obtido com a Malha 3 (9328 VC) e três ordens do método VF. A pressão atinge o máximo perto do bordo de ataque, logo a pressão cai ao longo do aerofólio (na superfície superior a pressão atinge o mínimo) e, no bordo de fuga, a pressão aumenta novamente. É nesta região que as três ordens apresentam diferenças mas são quase imperceptíveis.

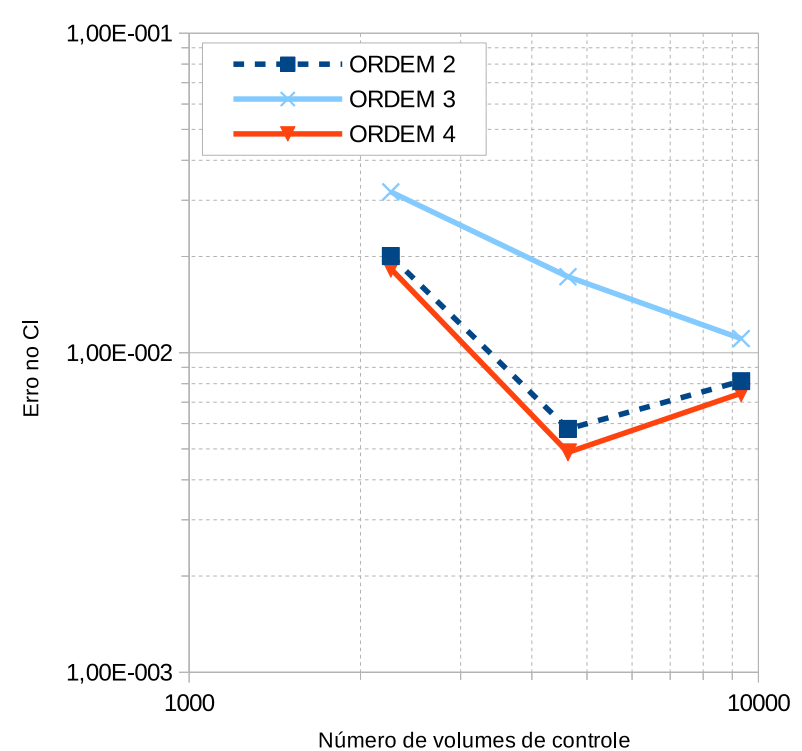

(a)

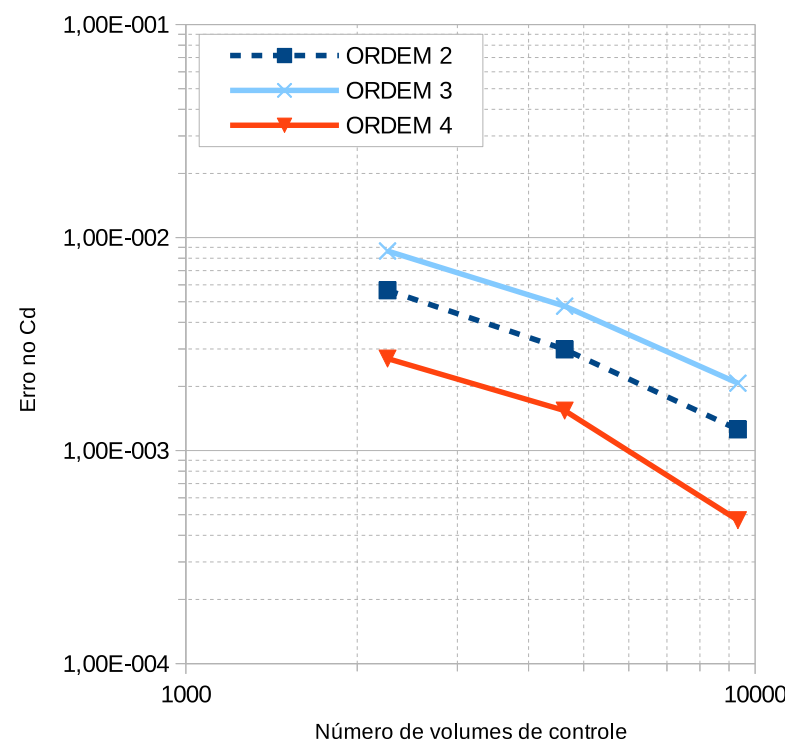

(c)

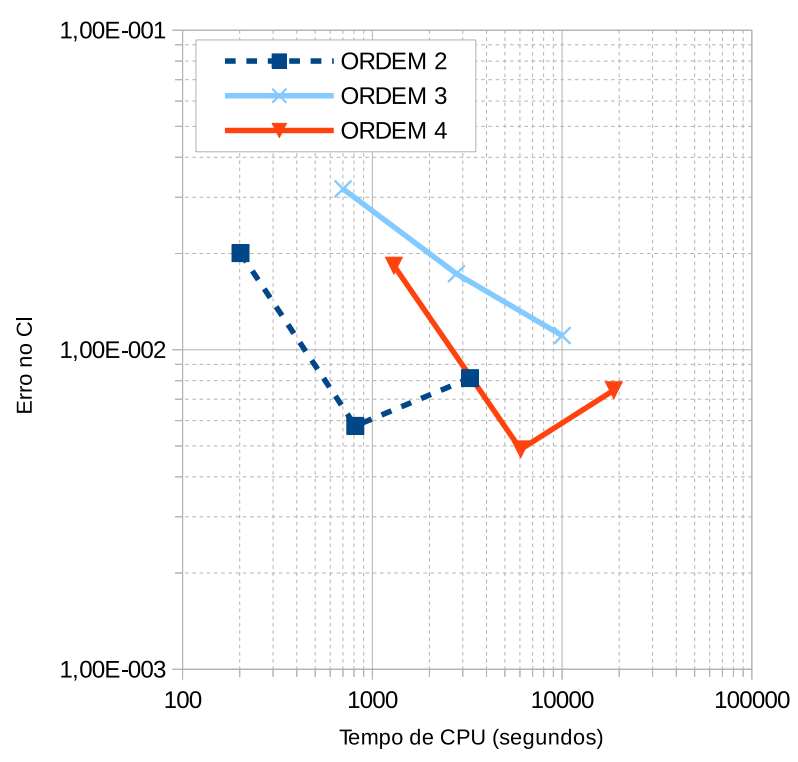

(b)

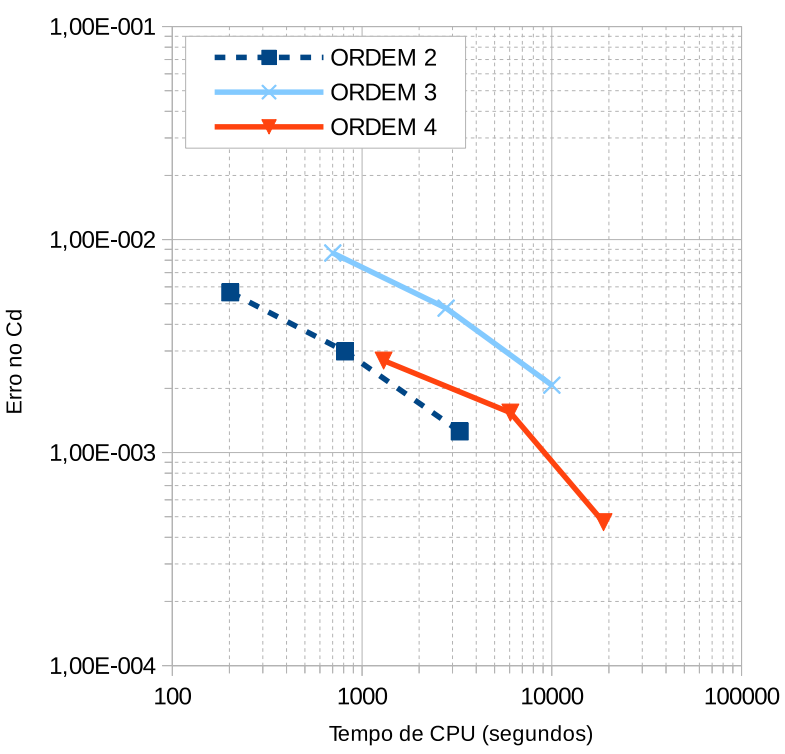

(d)

Figura 3.9: Erros nos coeficientes de sustentação $\left(C_{l}\right)$ e de arrasto $\left(C_{d}\right)$, no caso subsônico e $\alpha=2^{\circ}$. 


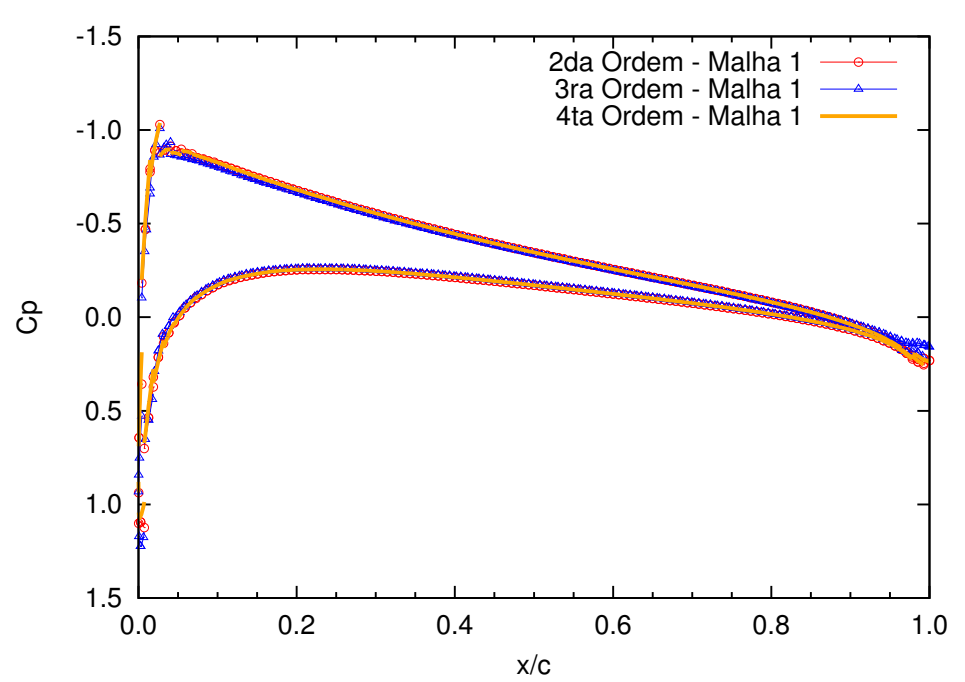

(a) Malha 1 (2261 VC).

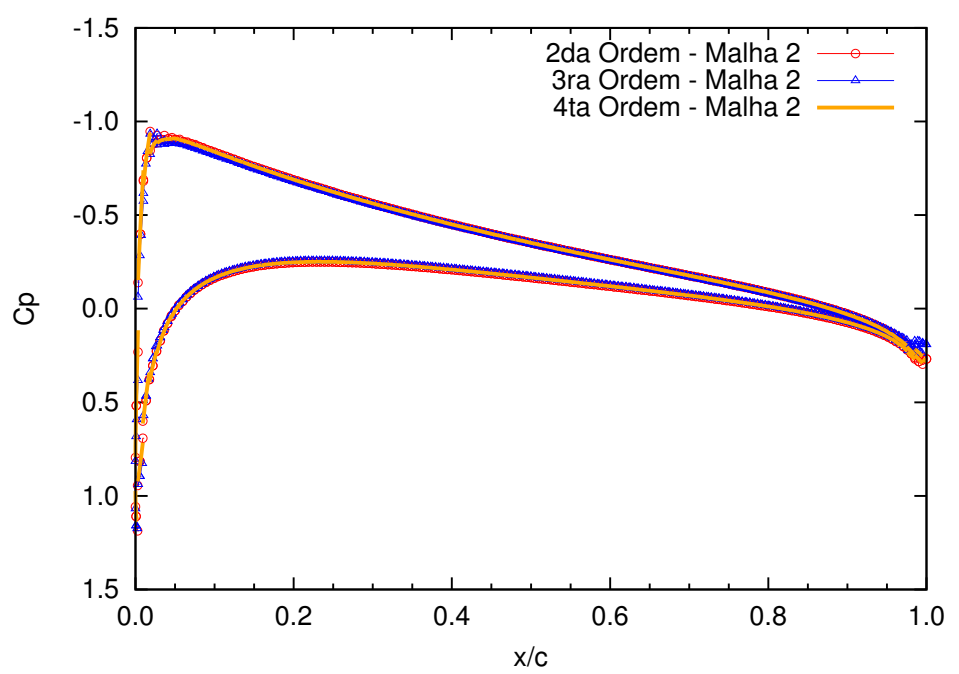

(c) Malha 2 (4630 VC).

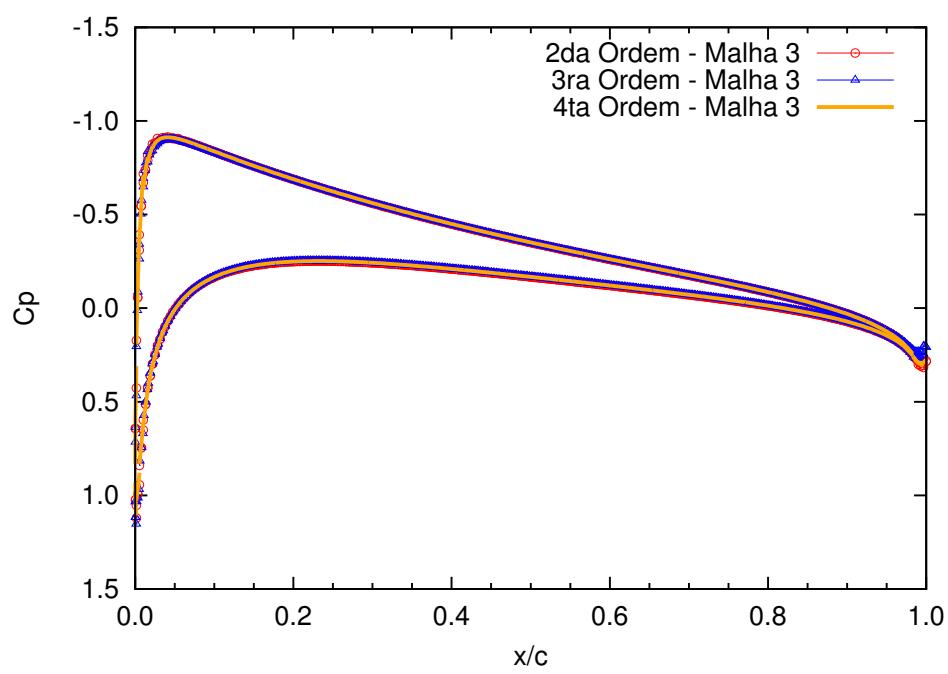

(e) Malha 3 (9328 VC).

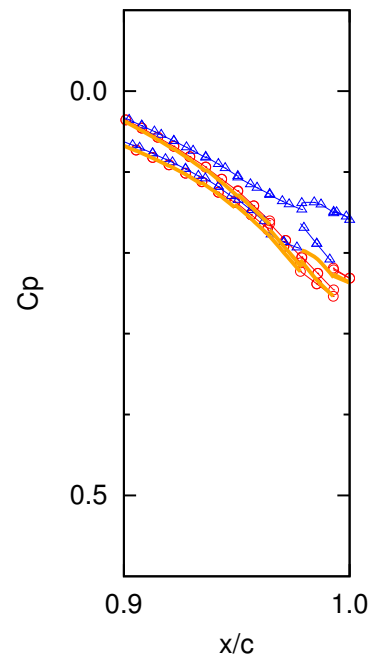

(b) Zoom no bordo de fuga.

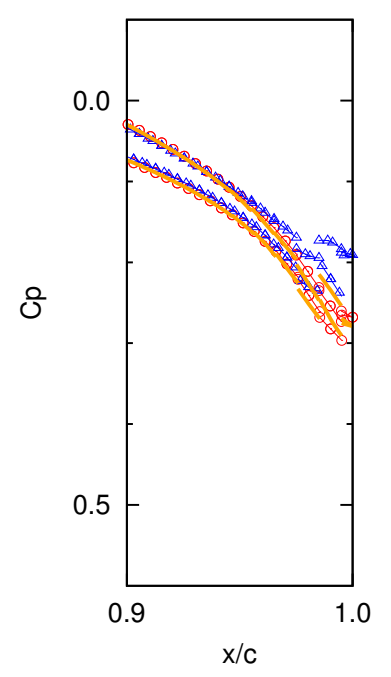

(d) Zoom no bordo de fuga.

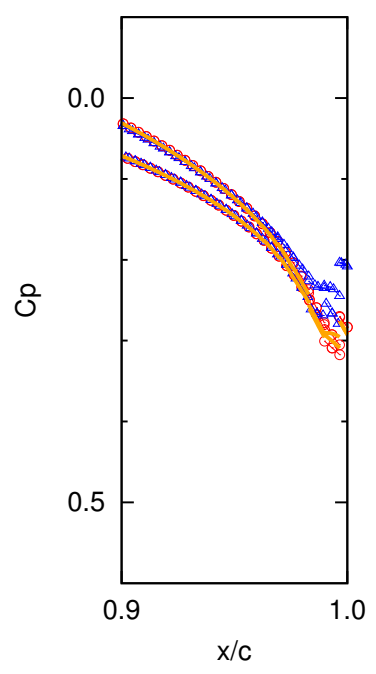

(f) Zoom no bordo de fuga.

Figura 3.10: Coeficiente de pressão $C_{p}$ ao longo do aerofólio, no caso subsônico e $\alpha=2^{\circ}$. 


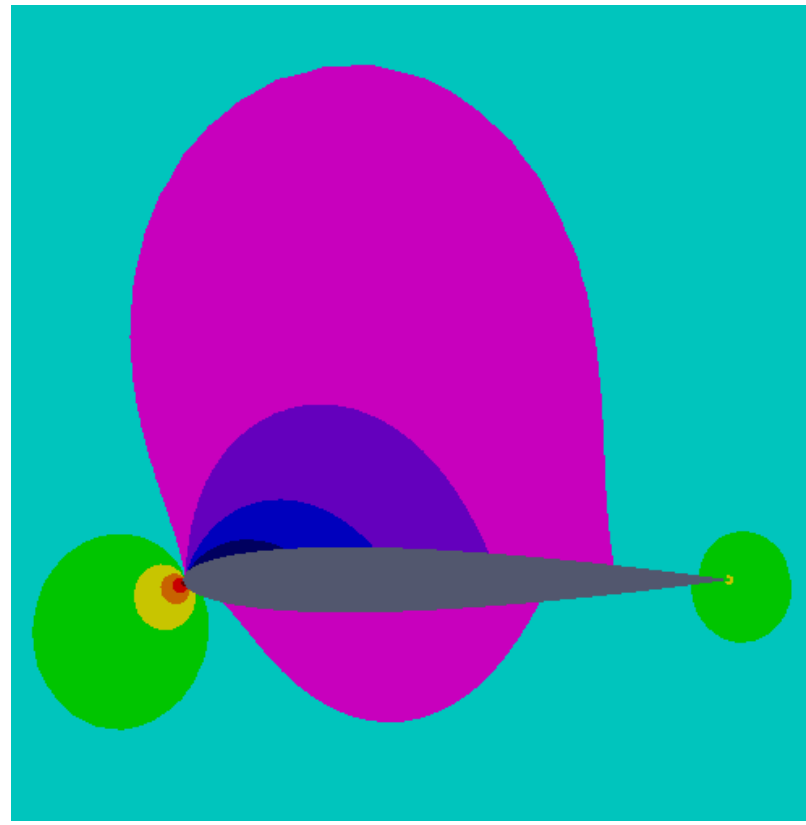

(a) 2a Ordem, Malha 3 (9328 VC).

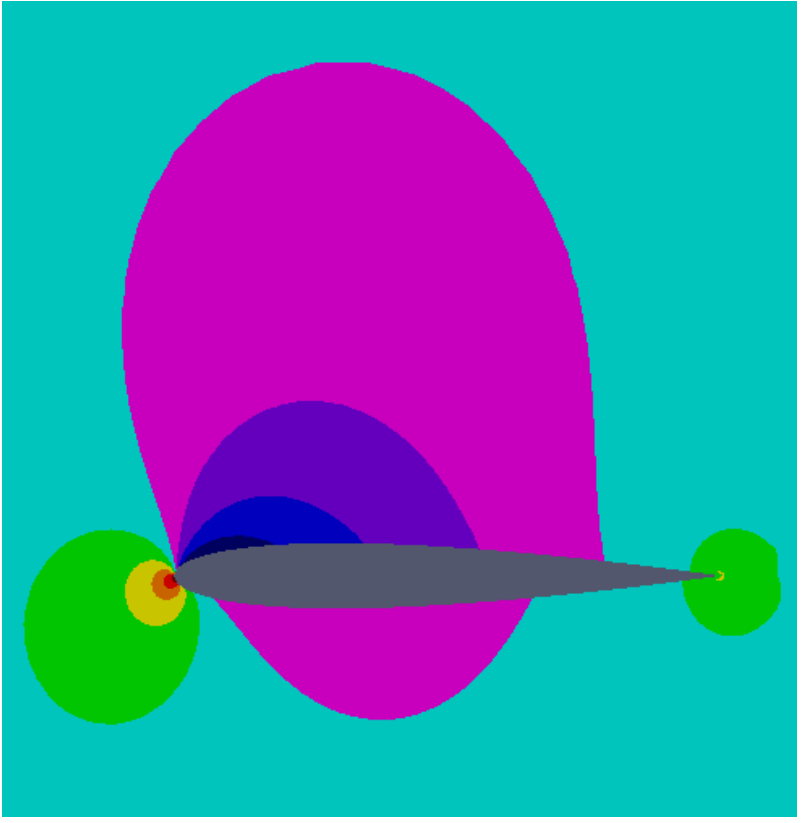

(b) 3a Ordem, Malha 3 (9328 VC).

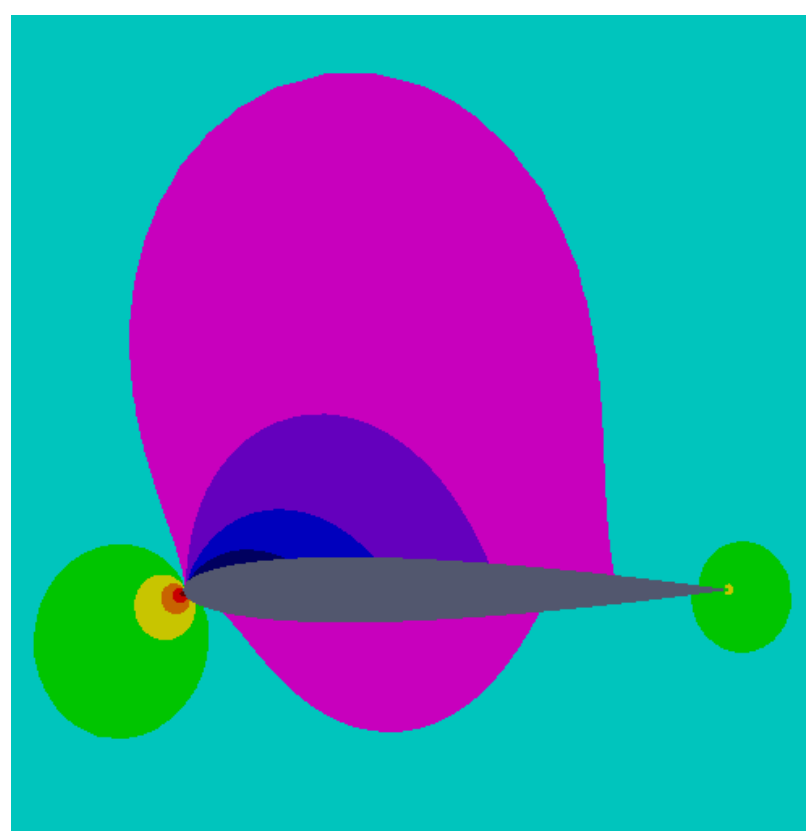

(c) 4a Ordem, Malha 3 (9328 VC).

\section{Pressāo (N/m2)}

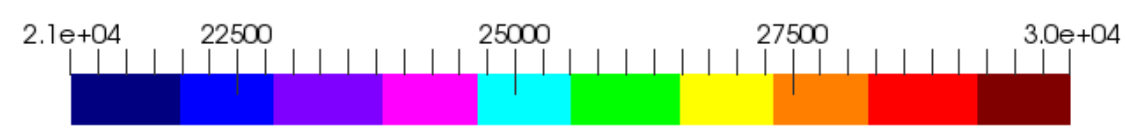

Figura 3.11: Pressão do escoamento $P\left(N / m^{2}\right)$, no caso subsônico e $\alpha=2^{\circ}$. 
3.8.3 NACA 0012 Transônico, $M_{\infty}=0,8, \alpha=1,25^{\circ}$

Este caso refere-se ao escoamento invíscido e estacionário ao redor do aerofólio NACA 0012 sob as condições mostradas na Tabela $3.14^{10}$. Em condições de corrente livre, a velocidade do ar forma um ângulo $\left(\alpha=1,25^{\circ}\right)$ com a horizontal, o número Mach do ar é 0,8 , a pressão estática é de $25000 \mathrm{~N} / \mathrm{m}^{2}$ e a temperatura estática é de $233 \mathrm{~K}$. Com esses dados encontra-se a pressão total e a temperatura total de corrente livre (Anderson, 2001): $P_{\text {total }, \infty}=38108,5 \mathrm{~N} / \mathrm{m}^{2}$ e $T_{\text {total }, \infty}=262,824$ K. Estes valores são necessários para especificar a condição de entrada subsônica (Seção 3.5). A condição de parede é imposta na superfície do aerofólio porque ali a velocidade do ar (invíscido) é tangencial à superfície.

\begin{tabular}{ccc|}
$\alpha$ & $=$ & $1,25^{\circ}$ \\
$M_{\infty}$ & $=$ & 0,8 \\
$P_{\infty}$ & $=$ & $25000 \mathrm{~N} / \mathrm{m}^{2}$ \\
$T_{\infty}$ & $=$ & $233 \mathrm{~K}$
\end{tabular}

Tabela 3.14: Condições de corrente livre, no caso transônico.

A equação (3.19) é a expressão analítica para a superfície do NACA0012 com comprimento de corda $c$ igual a $1 \mathrm{~m}$. O domínio de interesse é a região em volta do NACA0012 e que está limitada por uma circunferência de raio $50 c$ centrada no ponto $0,3 c$ da corda do aerofólio. Este domínio é o mesmo do caso subsônico e $\alpha=2^{\circ}$. Além disso, neste caso transônico, adotam-se as mesmas malhas computacionais. As características dessas malhas estão apresentadas na Tabela 3.15. A Figura 3.12 mostra o zoom das malhas numa vizinhança do aerofólio. O código VF-RK consegue ler o arquivo da malha computacional selecionada e dar início a um teste. Nos testes desta subseção são consideradas as mesmas condições iniciais e o mesmo critério de parada. A condição inicial utilizada é a condição de corrente livre: Impõe-se os valores da Tabela 3.14 em cada VC. O critério de parada está descrito na Seção 3.2: O processo iterativo é interrompido quando a norma $L_{2}$ do resíduo converge a $10^{-10}$.

\footnotetext{
${ }^{10}$ Este caso corresponde ao Caso-Teste 1 do AGARD Fluid Dynamics Panel (1985). Simulações mais recentes deste caso são reportados por Vassberg e Jameson (2010) e Yano e Darmofal (2012)
} 


\begin{tabular}{|c|c|c|}
\hline Malha & No. de VC na superfície do aerofólio & No. total de VC \\
\hline \hline Malha 1 & 142 & 2261 \\
Malha 2 & 204 & 4630 \\
Malha 3 & 296 & 9328 \\
\hline
\end{tabular}

Tabela 3.15: Características das malhas computacionais para o caso transônico.

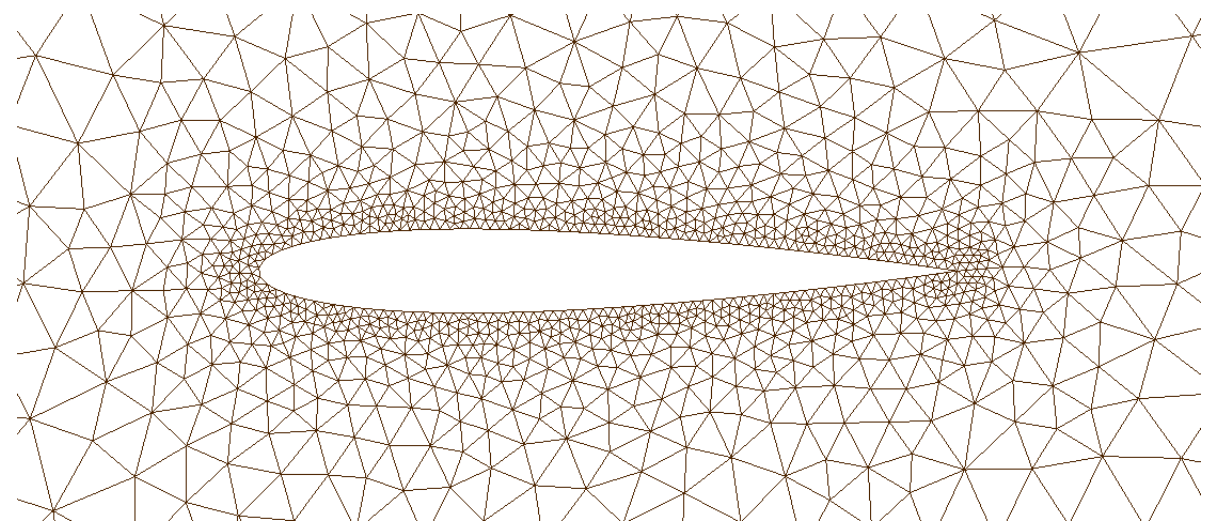

(a) Malha 1 (142 vértices na superfície do aerofólio).

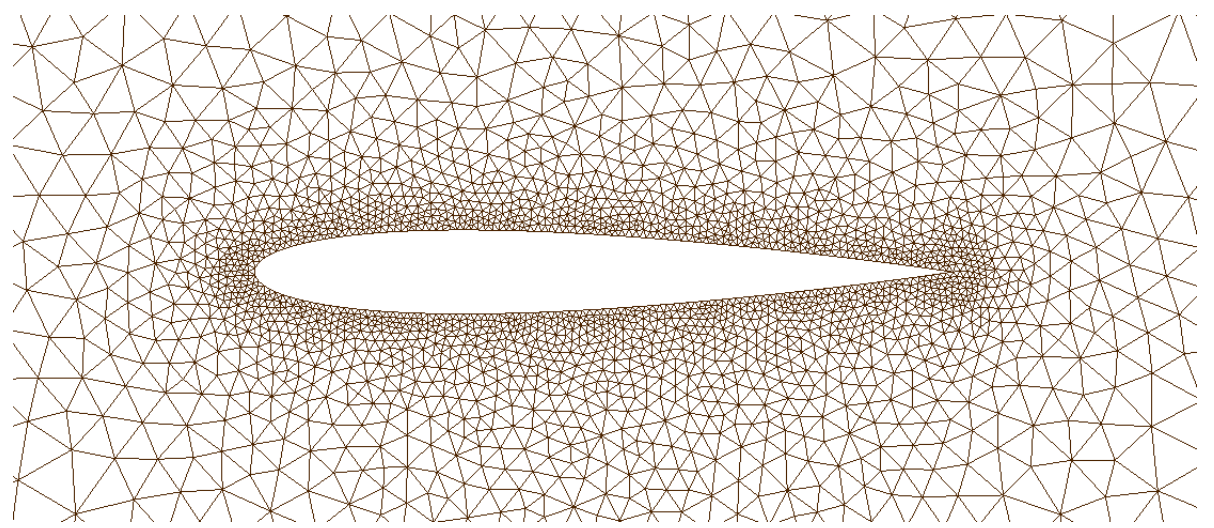

(b) Malha 2 (204 vértices na superfície do aerofólio).

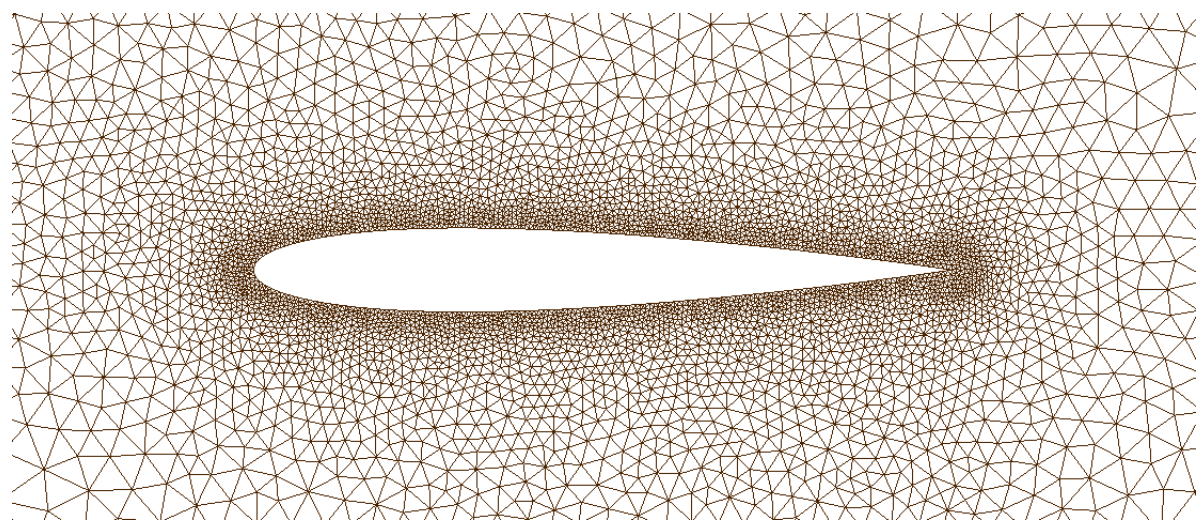

(c) Malha 3 (296 vértices na superfície do aerofólio).

Figura 3.12: Malhas computacionais para o caso transônico. 


\section{Busca experimental do CFL máximo}

De maneira análoga aos casos subsônicos, procura-se o CFL máximo para cada ordem do método VF. Apesar de utilizar a mesma discretização espacial e temporal, os resultados desta busca são diferentes aos obtidos nos casos subsônicos. A Tabela 3.16 mostra que o método de VF de 2a ordem combina bem (consegue-se convergência) com valores de CFL menores ou iguais a 4,0. Já o método de VF de 4a ordem se ajusta a valores de CFL menores ou iguais a 3,0. O método de VF de 3a ordem é especial e será comentado ao final do parágrafo. Vale destacar que a busca desses valores máximos de CFL foi empírica (utilizou-se o código). Os testes convergentes da Tabela 3.16 se dão para todas as malhas da Tabela 3.15. Ora, os testes não convergentes são peculiares e merecem ser detalhados. Com 2a ordem e $\mathrm{CFL}=4,5$ não se consegue convergência com as Malhas 1 e 2, e sim com a Malha 3 (a malha mais fina). Mas, para uniformizar, considera-se que a 2a ordem combina bem com números CFL menores ou iguais a 4,0. Com 4a ordem e $\mathrm{CFL}=3,5$ não se consegue convergência com as Malhas 2 e 3, e sim com a Malha 1 (a malha mais grossa). Mas, para uniformizar, considerase que a 4 a ordem combina bem com números CFL menores ou iguais a 3,0. Por fim, ao combinar a 3a ordem com diversos valores de CFL (maiores e iguais a 0,5 ) não se obtêm convergência. Se ocorrer convergência, seria com valores de CFL menores a 0,5 . Ainda nesse caso, o esquema seria lento. Por esse motivo, apenas se estudam os esquemas de VF de ordem 2 e 4, neste caso transônico.

\begin{tabular}{|c|cccc|}
\hline Ordem & $\mathrm{CFL}=3,0$ & $\mathrm{CFL}=3,5$ & $\mathrm{CFL}=4,0$ & $\mathrm{CFL}=4,5$ \\
\hline \hline 2a Ordem & converge & converge & converge & não converge \\
3a Ordem & não converge & não converge & não converge & não converge \\
4a Ordem & converge & não converge & não converge & não converge \\
\hline
\end{tabular}

Tabela 3.16: Busca do CFL máximo para cada ordem do método de VF, no caso transônico.

\section{Influência do CFL nos testes}

A Tabela 3.17 mostra os resultados dos testes para este caso transônico. Consideram-se, assim como nos casos subsônicos, combinações Ordem-Malha-CFL (coluna "Dados de entrada do solver" da Tabela anterior). Observa-se que todos os testes resultam em soluções numéricas estacionárias, a partir das quais são calculados os coeficientes de sustentação e de arrasto. E, da mesma maneira que nos casos subsônicos, comprova-se que o aumento do número CFL não diminui (nem aumenta) a precisão da solução estacionária: dada uma ordem e uma malha, os valores de $C_{l}$ e $C_{d}$ são independentes do número CFL do esquema RK. Essa independência também se verifica no coeficiente de pressão $C_{p}$ ao longo do aerofólio (Figura 3.13): cada combinação de 2a Ordem-Malha 1 resulta em valores $C_{p}$ cuja diferença (devida ao CFL) não é maior do que $10^{-12}$ (Figura 3.13(c)); similarmente, cada combinação de 4a Ordem-Malha 3 resulta em $C_{p}$ 's cuja diferença (devida ao CFL) máxima é de $4 \times 10^{-11}$ (Figura 3.13(d)).

Por outro lado, o aumento do número CFL permite otimizar os tempos de CPU. As colunas "Iterações" e "Tempo de CPU" ${ }^{11}$ da Tabela 3.17 apresentam, respectivamente, o número de iterações e o tempo necessários para alcançar a solução estacionária. Percebe-se que, dada uma ordem do método VF e dada uma malha, o número de iterações diminui ao aumentar o número CFL. Esta queda no número de iterações também é observada no tempo de CPU. E lembrando que, o tempo de CPU teórico é diretamente proporcional ao número de iterações (vide equação (3.20), no caso subsônico e $\alpha=0^{\circ}$ ), tem-se que

$$
\text { Tempo de CPU teórico (\%) = No. de Iterações (\%), }
$$

onde o símbolo (\%) indica quantidades relativas às que resultam com o CFL mais baixo. Assim, a

\footnotetext{
${ }^{11} \mathrm{O}$ tempo de CPU inclui, ademais do tempo do processo iterativo, o tempo pre-processo iterativo. O pre-processo iterativo demora, nos testes desta subseção, 1 s no máximo. Esses tempos são quase insignificantes quando comparados com os tempos do processo iterativo.
} 
coluna "Iterações (\%)" da Tabela 3.17 mostra também o tempo de CPU teórico (\%). E comparando esta coluna com a coluna "Tempo de CPU (\%)" verifica-se, como nos casos subsônicos, que o tempo teórico é diferente ao tempo medido ${ }^{12}$. A Tabela 3.18 mostra o quociente Tempo de CPU medido (\%) sobre Tempo de CPU teórico (\%) para alguns testes desta subseção. Essa razão varia entre $1-0,16$ e $1+0,16$.

\footnotetext{
${ }^{12}$ Vide Apêndice A
} 


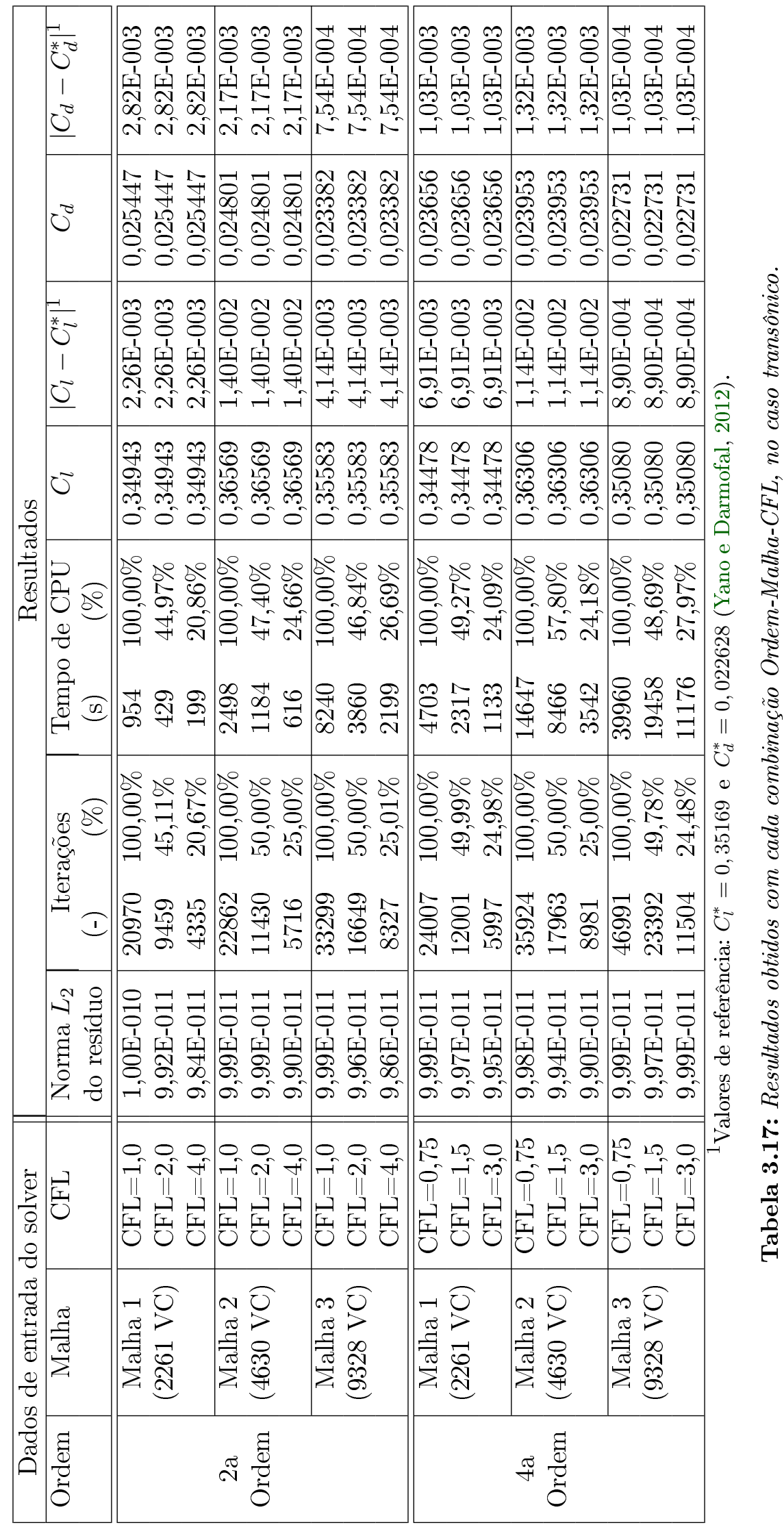



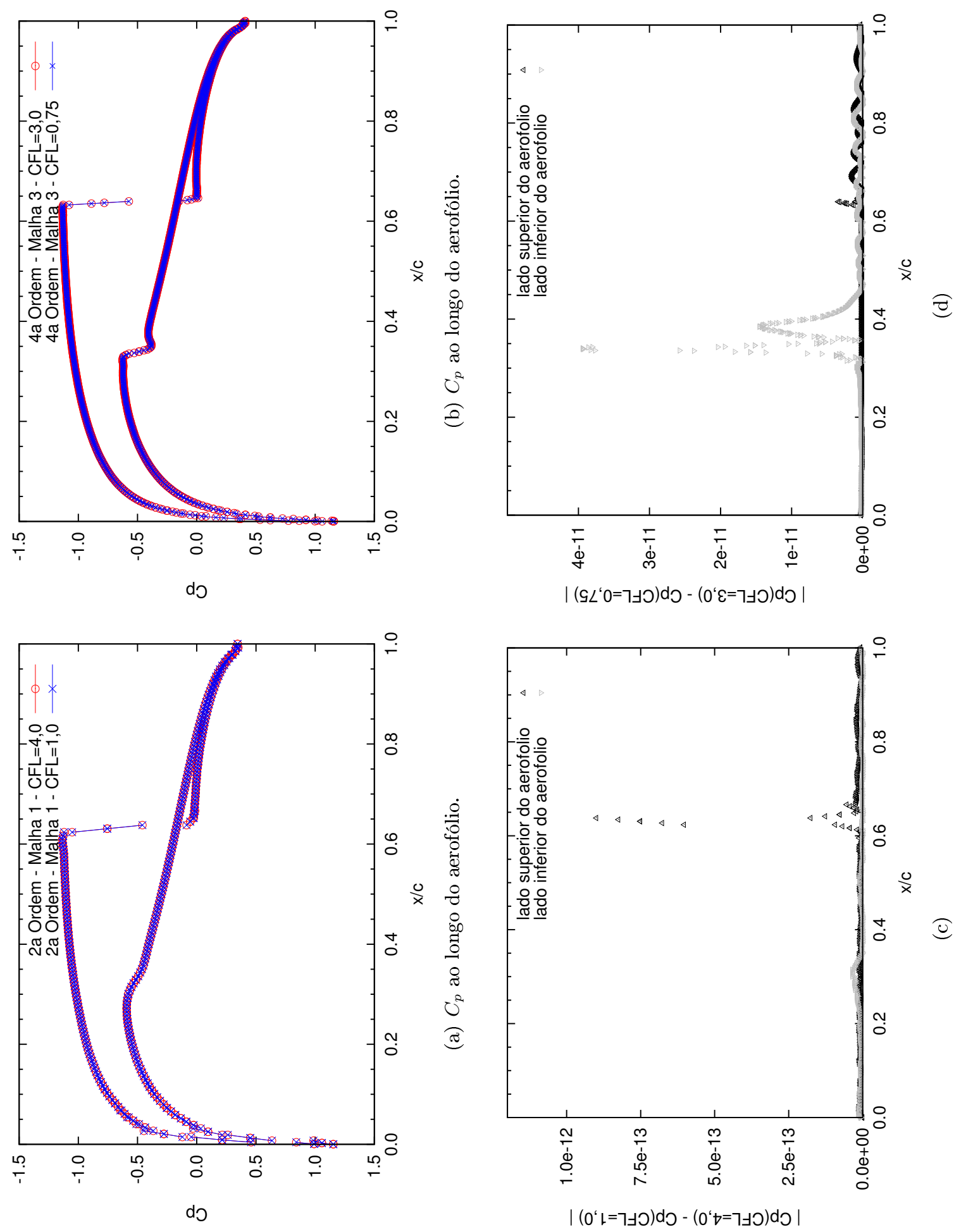

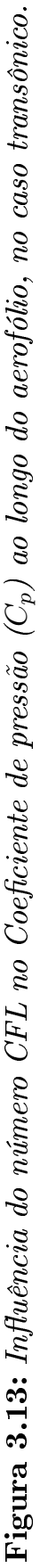




\begin{tabular}{|lccc|}
\hline Combinação & $\begin{array}{c}\text { Tempo de } \\
\text { CPU teórico } \\
(\%)\end{array}$ & $\begin{array}{c}\text { Tempo de } \\
\text { CPU medido } \\
(\%)\end{array}$ & $\begin{array}{c}\text { Tempo de CPU medido (\%) } \\
\text { Tempo de CPU teórico (\%) }\end{array}$ \\
\hline \hline Ordem2-Malha3-CFL $=2,0$ & $50,00 \%$ & $46,84 \%$ & 0,94 \\
Ordem4-Malha2-CFL $=1,5$ & $50,00 \%$ & $57,80 \%$ & 1,16 \\
Ordem4-Malha3-CFL $=3,0$ & $24,48 \%$ & $27,97 \%$ & 1,14 \\
\hline
\end{tabular}

Tabela 3.18: Exemplos da razão $\frac{\text { Tempo de } C P U \text { medido (\%) }}{\text { Tempo de } C P U \text { teórico (\%) }}$ no caso transônico.

\section{Coeficientes $C_{l}$ e $C_{d}$}

O autor do presente trabalho não encontra, na literatura, os valores exatos dos coeficientes de sustentação $\left(C_{l}\right)$ e de arrasto $\left(C_{d}\right)$ para este caso transônico. Yano e Darmofal (2012) simulam este caso transônico utilizando o método Galerkin Descontínuo com polinômios de grau 2, e considerando um domínio quadrado $2 R \times 2 R \operatorname{com} R=10^{4} c$. Assim, os coeficientes $C_{l}$ e $C_{d}$ reportados por esses pesquisadores são

$$
\begin{aligned}
& C_{l}^{*}=0,35169 \\
& C_{d}^{*}=0,022628 .
\end{aligned}
$$

Esta solução de referência serve para calcular o erro do presente trabalho (vide colunas " $\left|C_{l}-C_{l}^{*}\right|$ " e " $\left|C_{d}-C_{d}^{*}\right|$ " da Tabela 3.17). Dado que a solução de referência está baseada num domínio maior, os erros incluem o efeito do tamanho do domínio (vide Seção 3.5). As Figuras 3.14(a) e 3.14(c) mostram, respectivamente, os erros de sustentação e de arrasto que resultam para cada combinação Ordem-Malha ${ }^{13}$. Em relação ao arrasto $C_{d}$, as ordens do método VF estão convergindo (em malha). E no caso da sustentação $C_{l}$, observa-se uma convergência (em malha) com oscilações; este comportamento é observado também nos trabalhos de Vassberg e Jameson (2010) e Yano e Darmofal (2012), sobretudo nas simulações com as malhas mais grossas. No presente trabalho, observa-se que as oscilações na convergência do coeficiente $C_{l}$ são causadas, principalmente, pela diferença na localização do choque sobre a superfície superior do aerofólio. A Figura 3.15 revela o efeito do refinamento da malha (mantendo fixa a ordem do método VF) na localização do choque. Vale lembrar que os vértices da Malha 1 não necessariamente fazem parte dos vértices da Malha 2. O mesmo acontece com a Malha 2 em relação à Malha 3.

A seguir, estudam-se os coeficientes $C_{l}$ e $C_{d}$ obtidos com a Malha $2(4630 \mathrm{VC})$ e os valores obtidos em outras pesquisas com malhas e domínios equivalentes (Tabela 3.19). Ollivier-Gooch (1995) utiliza o método de VF de 2 a ordem sobre uma malha quadrada de $100 c$ por lado e 4156 VC. Esta simulação é, em termos de ordem, malha e tamanho do domínio, comparável à combinação 2a Ordem-Malha 2 (4630 VC). Essas duas simulações conseguem resultados próximos. Porém, a proximidade com o resultado de Ollivier-Gooch (1995) é maior ao utilizar a combinação 4a ordemMalha 2. Isto poderia explicar-se pelo fato de que Ollivier-Gooch (1995) utiliza um refinamento maior na região de ambos os choques: da superfície superior e inferior do aerofólio. Uma das simulações reportadas pelo AGARD Fluid Dynamics Panel (1985) utiliza uma malha estruturada de raio 50 c que possui 192 pontos sobre o aerofólio, o que é comparável com a Malha 2 (Fig. 3.12). Porém, os valores reportados estão ainda mais distantes dos obtidos no presente trabalho porque, no AGARD Fluid Dynamics Panel (1985), a condição de fronteira far-field inclui o efeito de um ponto-vórtice (para diminuir o erro devido ao tamanho do domínio). Perceba-se que, a simulação do AGARD Fluid Dynamics Panel (1985) consegue resultados mais próximos aos valores de referência $C_{l}^{*}$ e $C_{d}^{*}$ do que o presente trabalho.

Para o conjunto de malhas do presente trabalho, há indícios de que a 4a ordem não supera a

\footnotetext{
${ }^{13}$ Lembre-se que, dada uma ordem do método VF e uma malha computacional, obtem-se uma solução estacionária independente do número CFL do esquema RK.
} 


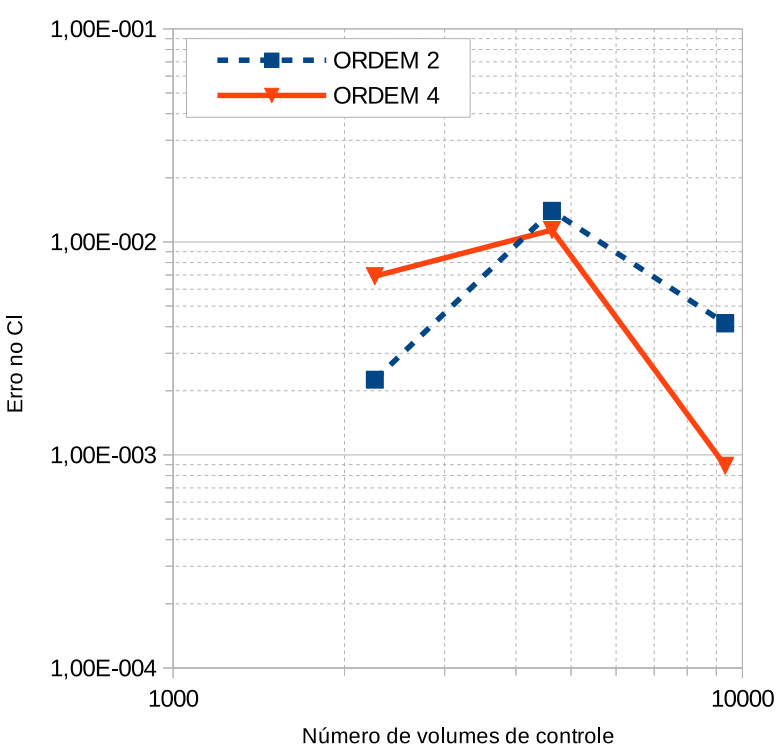

(a)

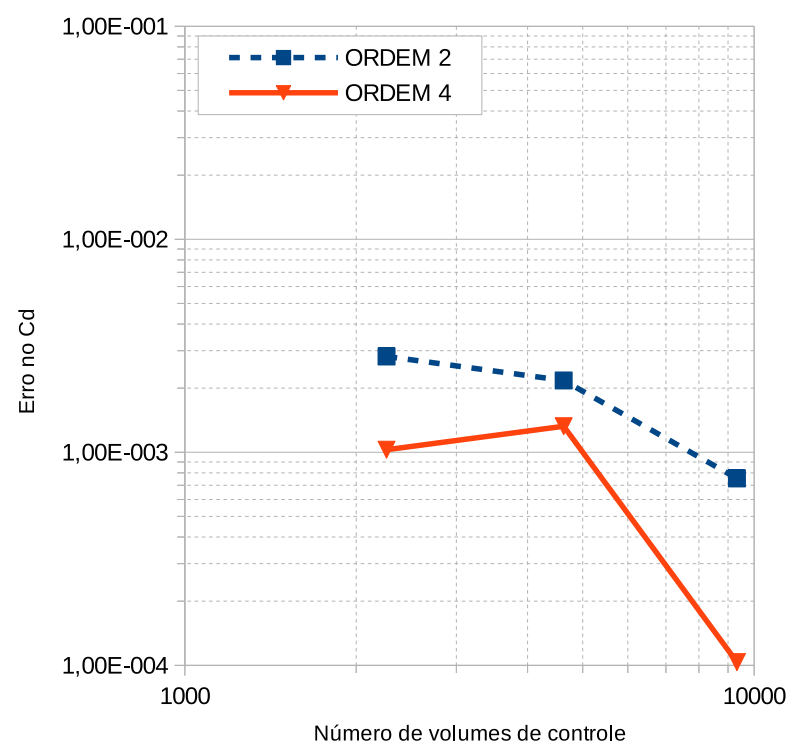

(c)

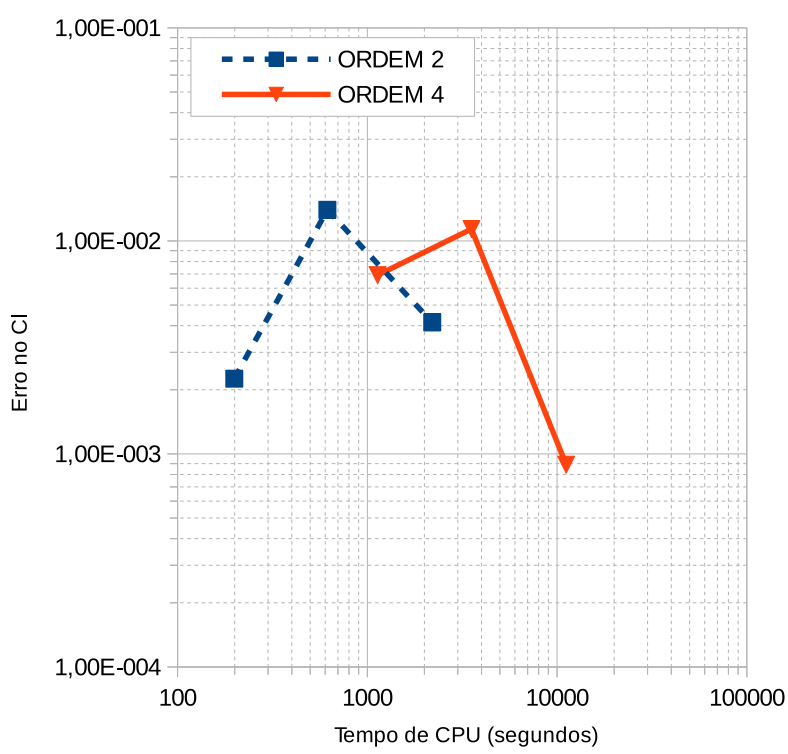

(b)

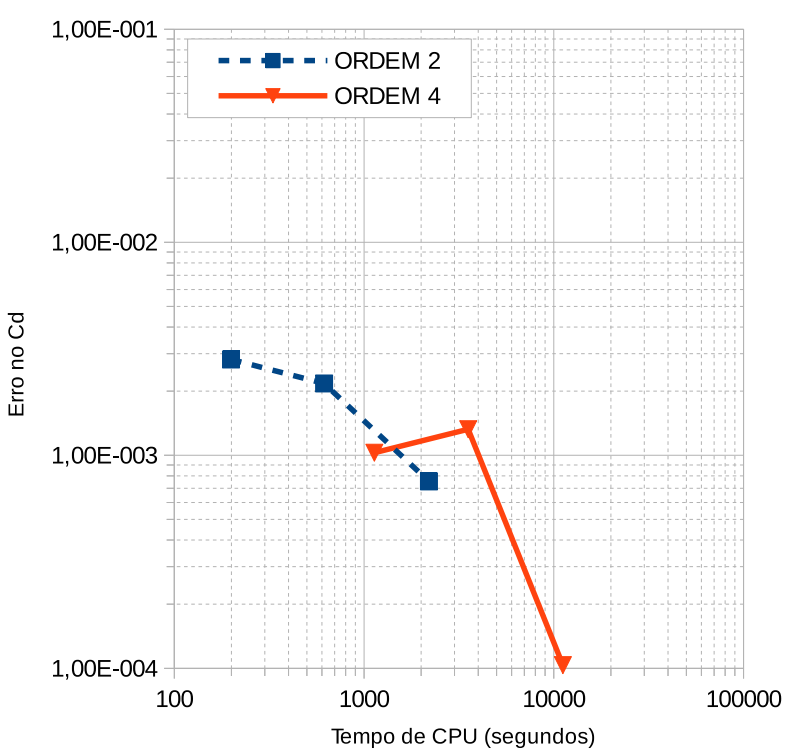

(d)

Figura 3.14: Erros nos coeficientes de sustentação $\left(C_{l}\right)$ e de arrasto $\left(C_{d}\right)$, no caso transônico.

Presente trabalho - 2a Ordem, 4630 VC

\begin{tabular}{lll}
$C_{l}$ & & $C_{d}$ \\
\cline { 1 - 1 } 0,36569 & & 0,024801 \\
0,36306 & & 0,023953 \\
0,361 & & 0,0227 \\
0,3474 & & 0,0221
\end{tabular}

Presente trabalho - 4a Ordem, 4630 VC

Ollivier-Gooch (1995) - 2a Ordem, 4156 VC

0,3474

malha estruturada $(192 \times 39)$, com ponto-vórtice

Tabela 3.19: Comparação dos coeficientes de sustentação $C_{l}$ e de arrasto $C_{d}$ obtidos no caso transônico.

eficiência da 2a ordem (vide Figuras 3.14(b) e 3.14(d) ${ }^{14}$ ). Uma conclusão confiável precisaria da análise do tamanho do domínio assim como de um maior número de malhas. Este tipo de estudo

\footnotetext{
${ }^{14}$ Nessas figuras, os tempos de CPU são os ótimos, isto é, são calculados com o CFL máximo para cada ordem do método VF: $\mathrm{CFL}=4,0$ para o método de 2 a ordem e $\mathrm{CFL}=3,0$ para o método de $4 \mathrm{a}$ ordem.
} 


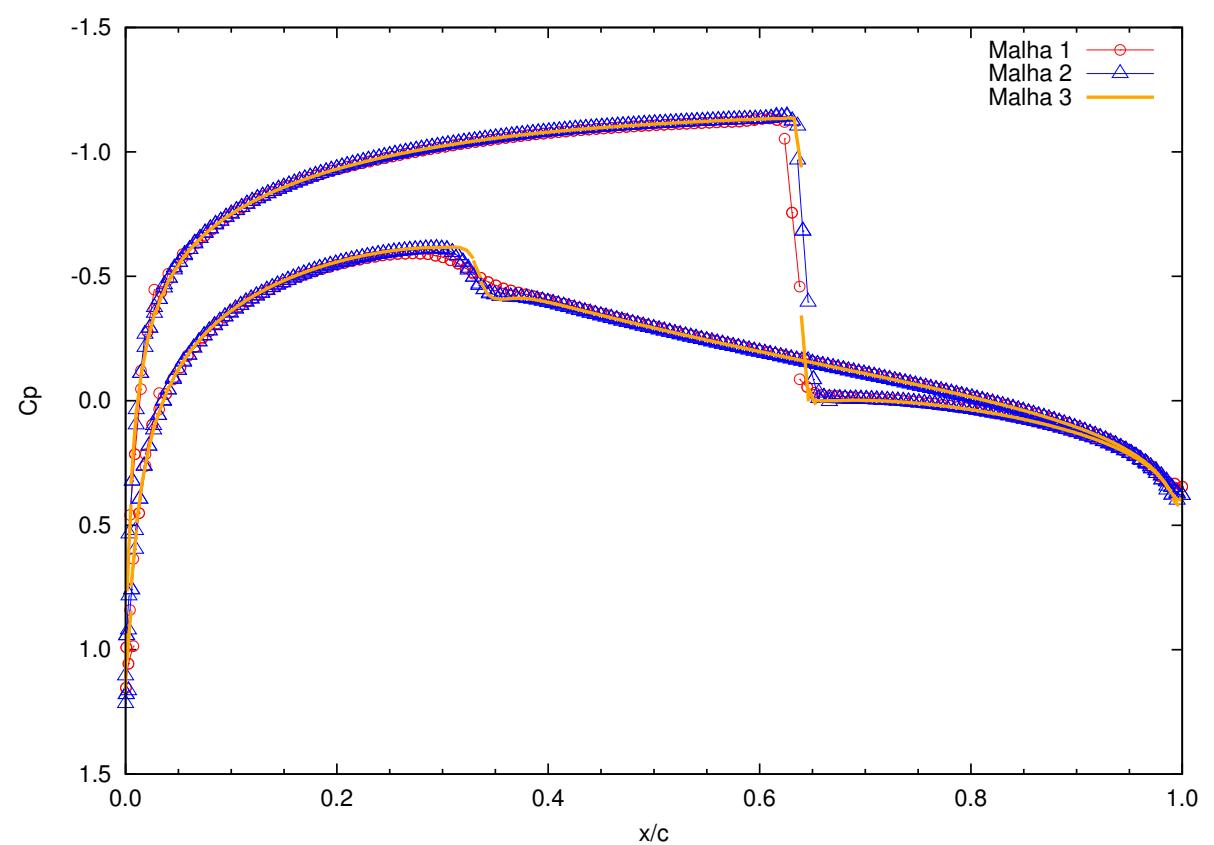

(a) 2a Ordem.

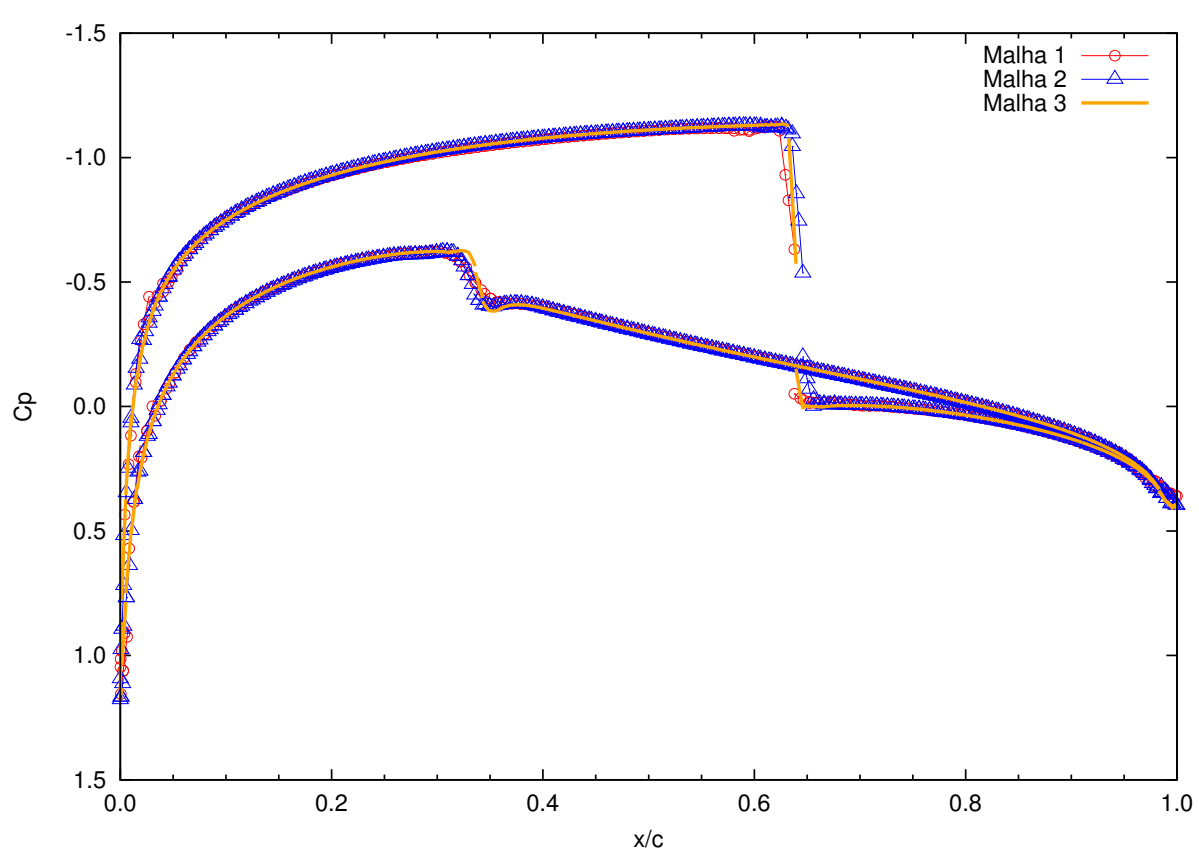

(c) 4a Ordem.

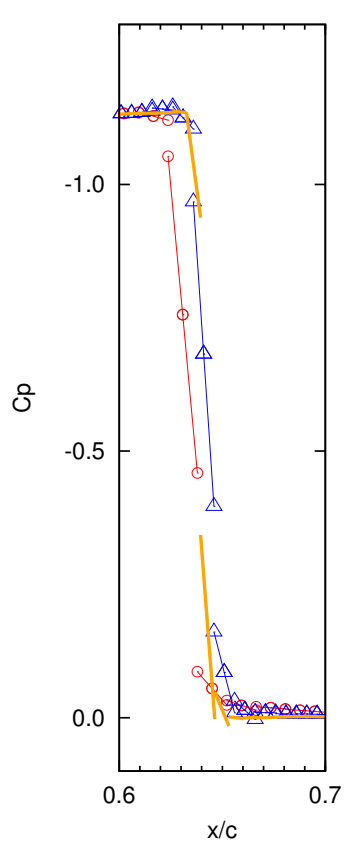

(b) 2a Ordem (choque).

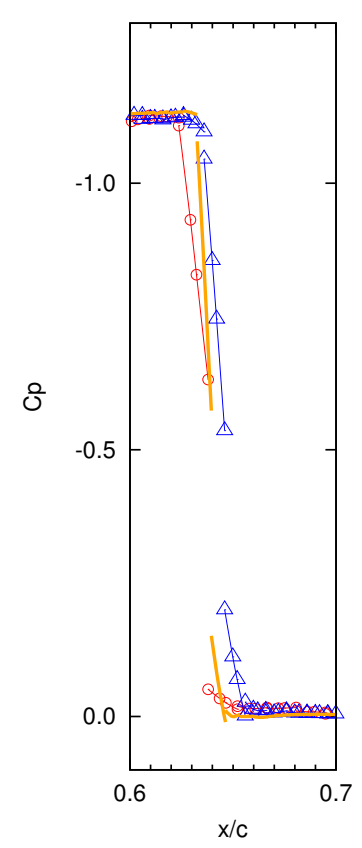

(d) 4a Ordem (choque).

Figura 3.15: Coeficiente de pressão $C_{p}$ ao longo do aerofólio, no caso transônico.

sim é feito pelo Yano e Darmofal (2012) e Balan et al. (2012b). Esses pesquisadores concluem que a alta-ordem é tão eficiente quanto a baixa-ordem, mesmo utilizando um refinamento adaptativo nas malhas. Yano e Darmofal (2012) comparam o custo computacional deste caso transônico com o caso subsônico e $\alpha=2^{\circ}$. Eles observam que o custo aumenta não só pelo tratamento dos choques, mas também pela queda na velocidade de convergência residual. 


\section{Campos de pressão e do número de Mach}

A Figura 3.16 apresenta o campo de pressão ${ }^{15}$ ao redor do aerofólio NACA0012 obtido com algumas combinações Ordem-Malha. O AGARD Fluid Dynamics Panel (1985) reporta, assim como o presente trabalho, a existência de dois choques (descontinuidades) de pressão, um para cada lado do aerofólio. Observa-se que o choque na superfície inferior do aerofólio obtido pela combinação 2a Ordem-Malha 1 é mais difuso do que o obtido pelas outras combinações. O benefício na resolução desse choque pela alta-ordem é evidente. Também obtem-se melhor nitidez do choque inferior ao aumentar o número de VC. Os campos de pressão das combinações 2a Ordem-Malha 3 e 4a OrdemMalha 3 são bastante parecidos. As diferenças podem ser percebidas ao observar o coeficiente $C_{p}$ ao longo do aerofólio (Figura 3.15). Esta figura também revela a boa performance do limitador no controle das oscilações da solução próxima a um choque: a curva do $C_{p}$ está de acordo com aquela apresentada por Michalak e Ollivier-Gooch (2008) e Michalak e Ollivier-Gooch (2009). A Figura 3.17 mostra que o limitador de pressão $\widehat{\Phi}_{i}$ é ativado intensamente no pré- e pós-choque (sobretudo no choque do lado superior do aerofólio); e permanece inativo $\left(\widehat{\Phi}_{i}=1\right)$ nas regiões onde a solução da pressão é suave.

De maneira análoga, é ilustrado o campo do número de Mach (Fig. 3.18). Esta figura é comparável à apresentada pelo AGARD Fluid Dynamics Panel (1985), Nejat (2007) e Vassberg e Jameson (2010): ela ilustra a região supersônica antes do choque na superfície superior do aerofólio, e também duas regiões de estagnação: no bordo de ataque e de fuga. Percebe-se que as características do número de Mach ao redor do bordo de fuga são peculiares e são explicadas a seguir. Os dois choques presentes neste caso transônico são de diferente intensidade: os saltos da pressão total (Anderson, 2001) através desses choques são diferentes. Assim, a pressão total difere no bordo de fuga (a pressão total de um ponto próximo à superfície superior é diferente ao valor de um ponto próximo à superfície inferior); e dado que a pressão estática deve coincidir, tem-se que as velocidades devem diferir. Ou seja, o bordo de fuga é um ponto gerador de uma superfície de deslizamento (Pulliam e Barton, 1985). A resolução desta descontinuidade é um dos objetivos do refinamento adaptativo de malha (Yano e Darmofal, 2012).

\subsection{Conclusão}

Simulando problemas aerodinâmicos canônicos - vide p. ex. AGARD Fluid Dynamics Panel (1985), Ollivier-Gooch (1995) e Vassberg e Jameson (2010) -, demonstra-se que o código VF-RK produz soluções das equações de Euler; os resultados (coeficientes de sustentação $C_{l}$ e de arrasto $C_{d}$, curvas do coeficiente de pressão $C_{p}$, e campos de pressão e do número de Mach ao redor do aerofólio) são comparáveis aos reportados na literatura. Quando os valores exatos dos coeficientes $C_{l}$ e $C_{d}$ são desconhecidos, calcula-se o erro usando os coeficientes apresentados por Yano e Darmofal (2012); eles, no entanto, consideram um domínio físico maior e portanto, o erro calculado inclui o efeito do tamanho do domínio. Numa futura pesquisa será estudada a solução como função do raio do domínio; essa pesquisa consistirá do cálculo dos coeficientes $h$-independentes (i.e. convergentes em malha) para cada raio do estudo. Sem essa análise, ainda não é possível dar conclusões sobre a eficiência das ordens do método VF; porém, na literatura (Andren et al., 2011) (Yano e Darmofal , 2012) (Balan et al., 2012b), há sim estudos completos da eficiência: nos casos subsônicos, a altaordem consegue ser mais eficiente do que a baixa-ordem, já no caso transônico, não há muita diferença. Nos próximos capítulos, incorpora-se o método p-multigrid para diminuir os tempos de CPU da 4 a ordem.

Vale lembrar que, neste Capítulo 3, comprova-se que o aumento do número CFL (dentro da região de estabilidade) não modifica o valor da solução estacionária; o aumento do CFL é importante sim para encontrar os tempos ótimos de CPU. Além disso, esta variação do CFL permite calcular o

\footnotetext{
${ }^{15}$ A visualização é feita pelo ParaView 4.3 .1 utilizando os valores nos vértices; os valores no resto do triângulo são calculadas por interpolação dos valores nos três vértices. Portanto, a visualização nas células mais grossas, p. ex. aquelas afastadas do aerofólio, deve ser interpretada com precaução.
} 


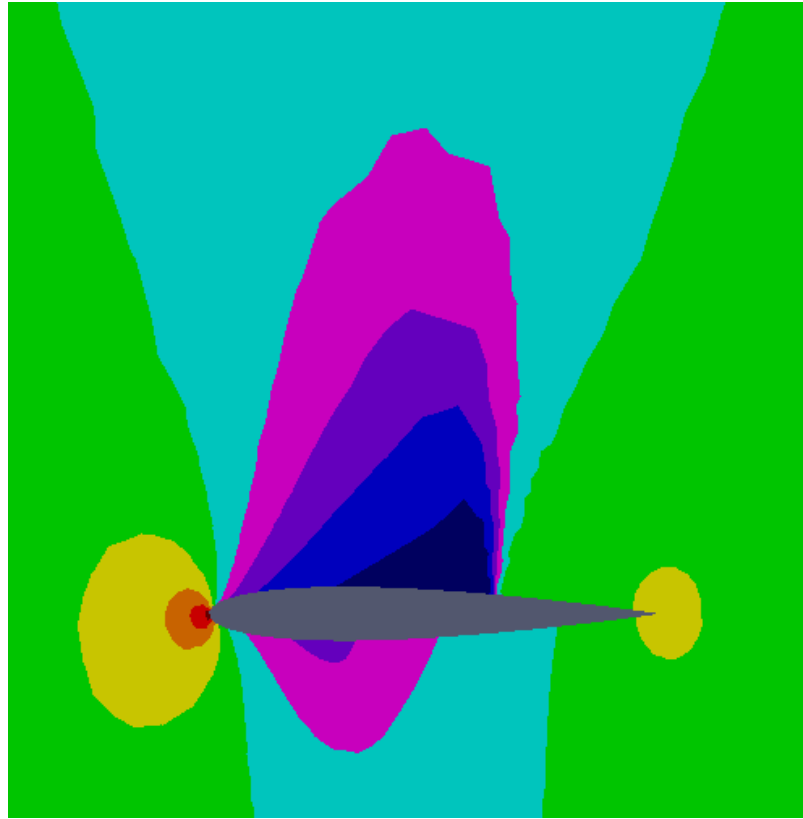

(a) 2a Ordem, Malha 1 (2261 VC).

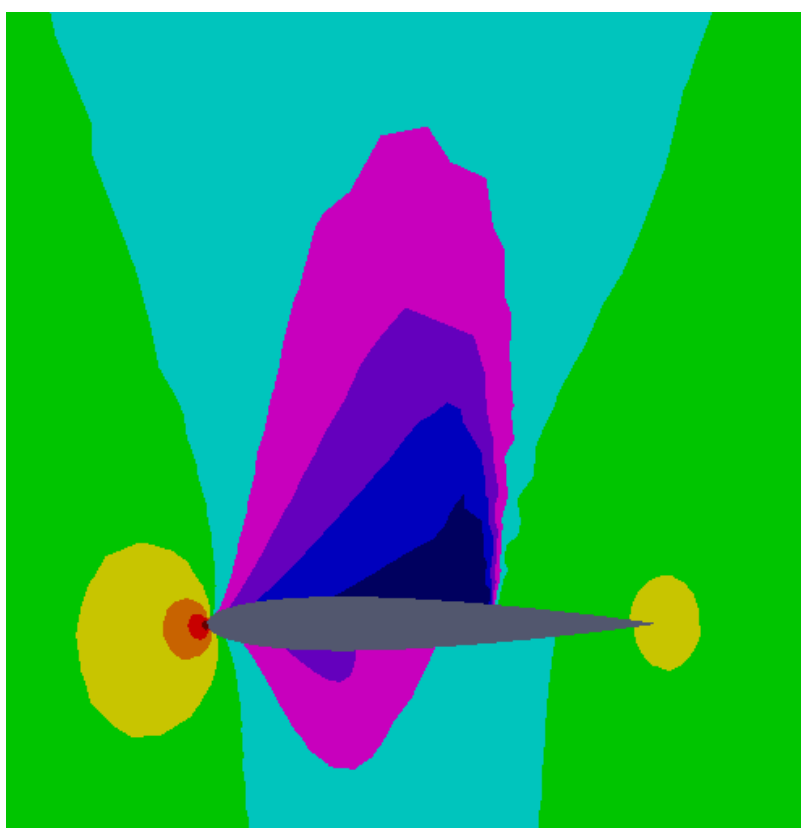

(c) 4a Ordem, Malha 1 (2261 VC).

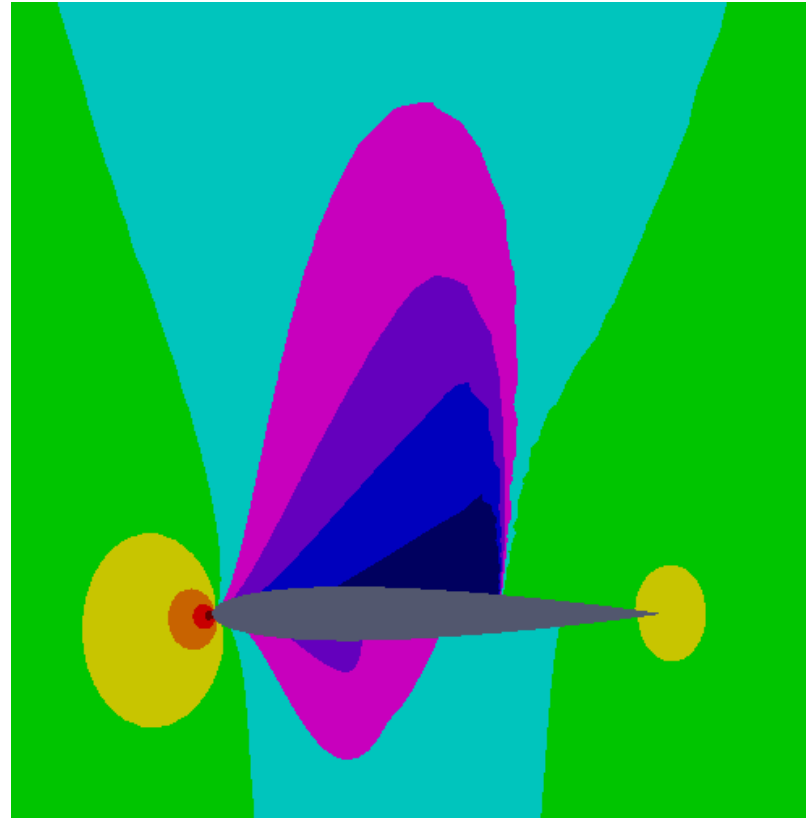

(b) 2a Ordem, Malha 3 (9328 VC).

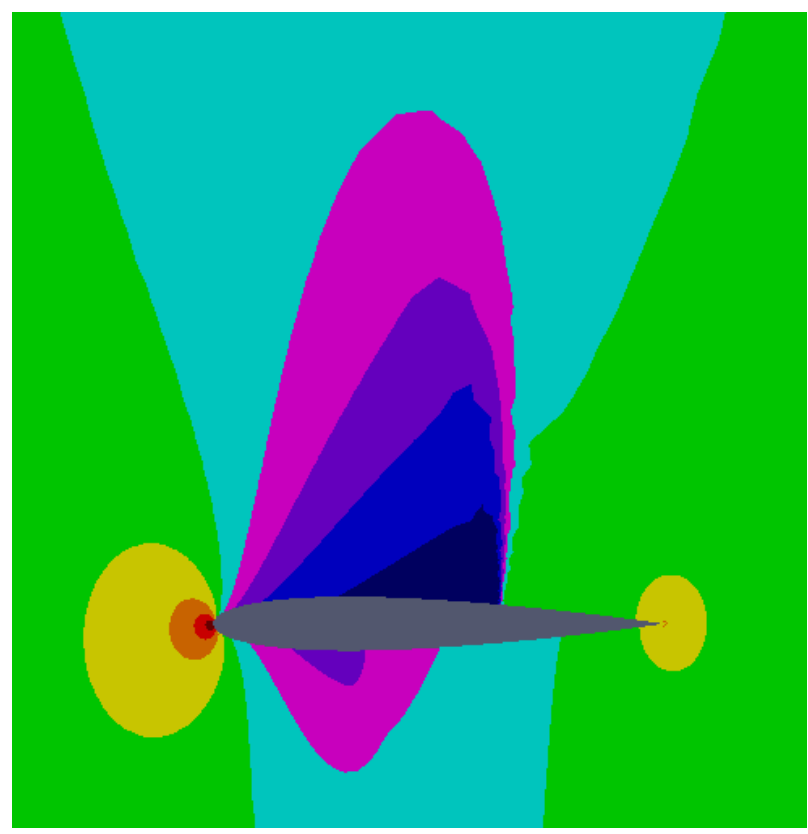

(d) 4a Ordem, Malha 3 (9328 VC).

Pressão $(\mathrm{N} / \mathrm{m} 2)$

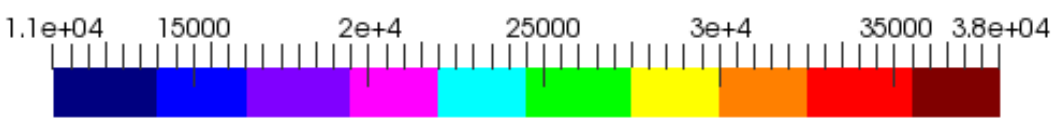

Figura 3.16: Pressão do escoamento $P\left(N / m^{2}\right)$, no caso transônico.

quociente Tempo de CPU medido (\%) sobre Tempo de CPU teórico (\%), onde o símbolo (\%) indica quantidades relativas às que resultam com um CFL baixo; o tempo de CPU medido é o tempo de processamento de um teste (tempo de CPU teórico) mais o tempo que a CPU gasta em outros processos, na E/S, etc. Para os testes da Seção 3.8, o quociente mencionado varia entre 1-0,16 e $1+0,16$; estes valores são úteis na estimativa de uma cota para os quocientes desse tipo do Capítulo 5 (vide Apêndice A). 


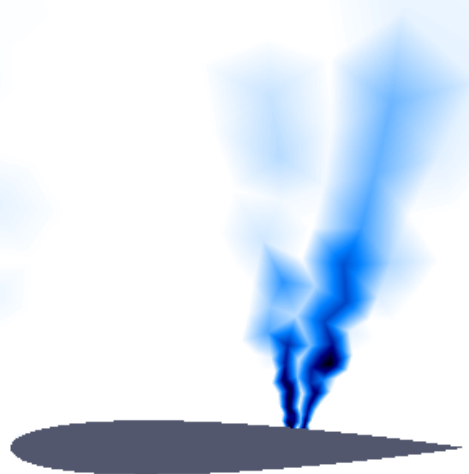

(a) 2a Ordem, Malha 1 (2261 VC).

(c) 4a Ordem, Malha 1 (2261 VC).

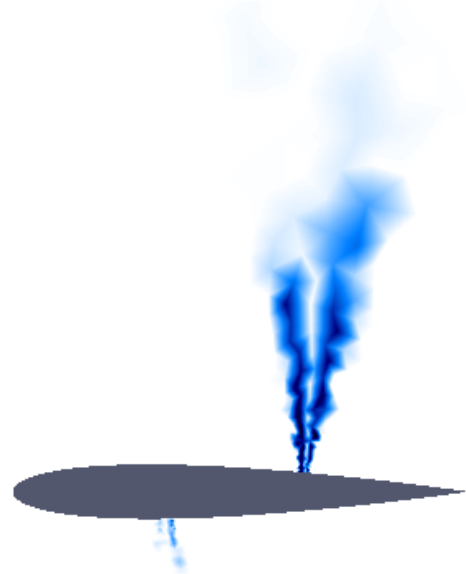

(b) 2a Ordem, Malha 3 (9328 VC).

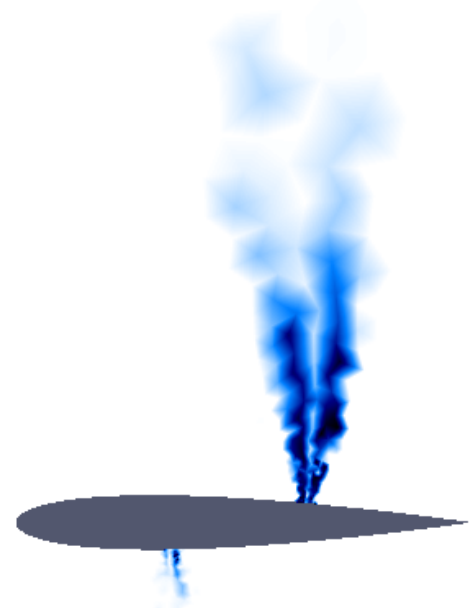

(d) 4a Ordem, Malha 3 (9328 VC).

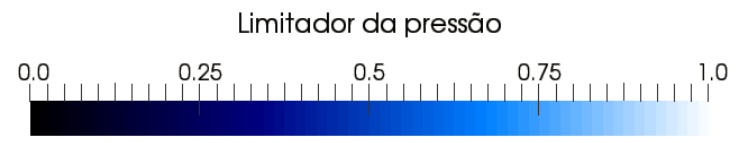

Figura 3.17: Limitador da pressão $\widehat{\Phi}_{i}$ para cada célula $\Omega_{i}$, no caso transônico. Eles são ativados $\left(\widehat{\Phi}_{i}<1\right)$, principalmente, quando são esperados extremos locais. 


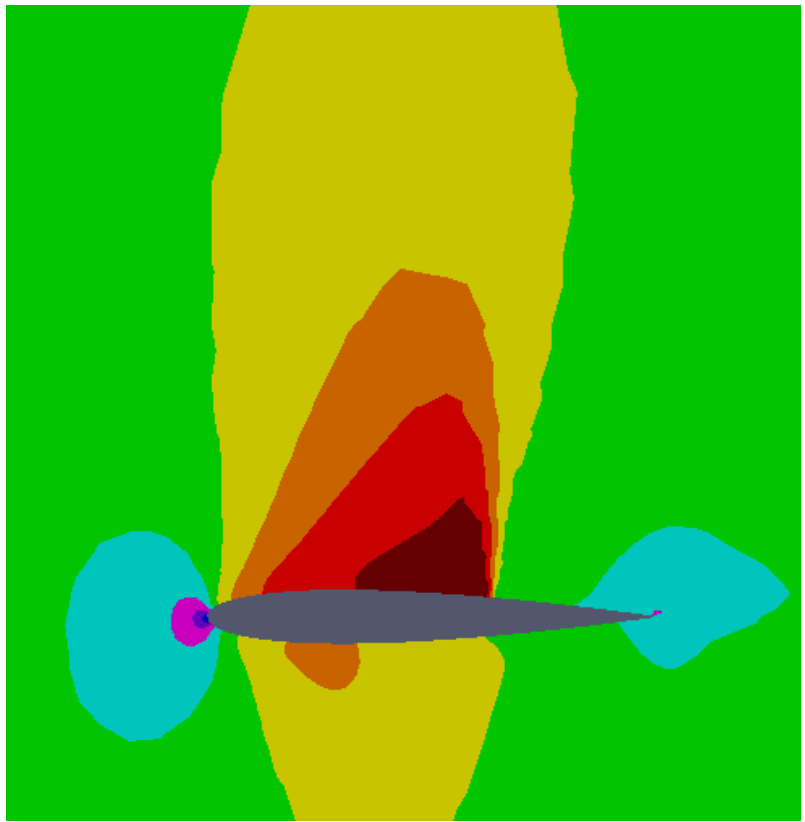

(a) 2a Ordem, Malha 1 (2261 VC).

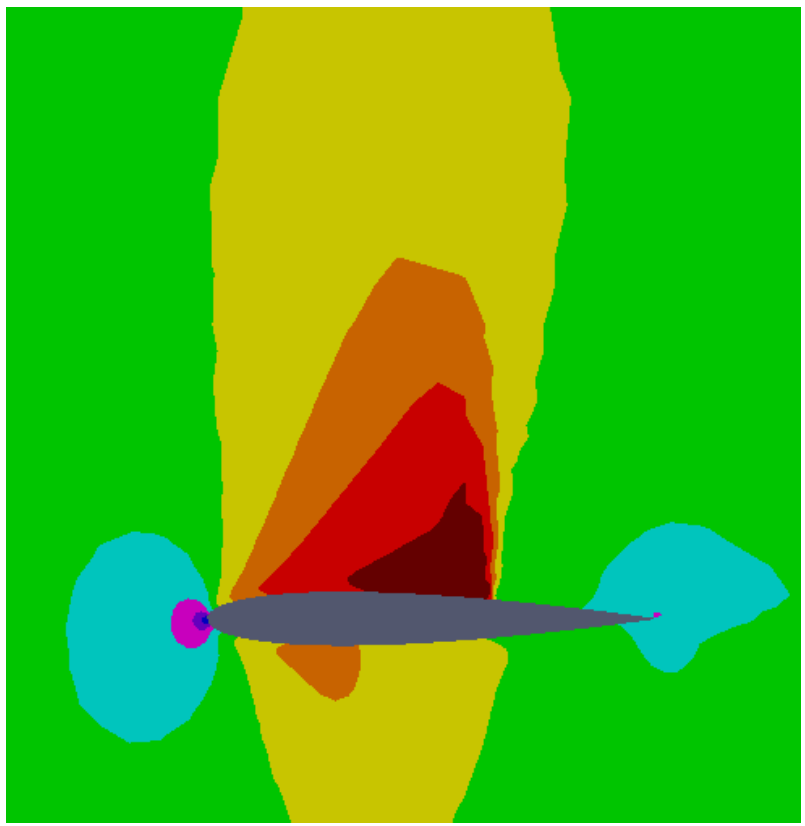

(c) 4a Ordem, Malha 1 (2261 VC).

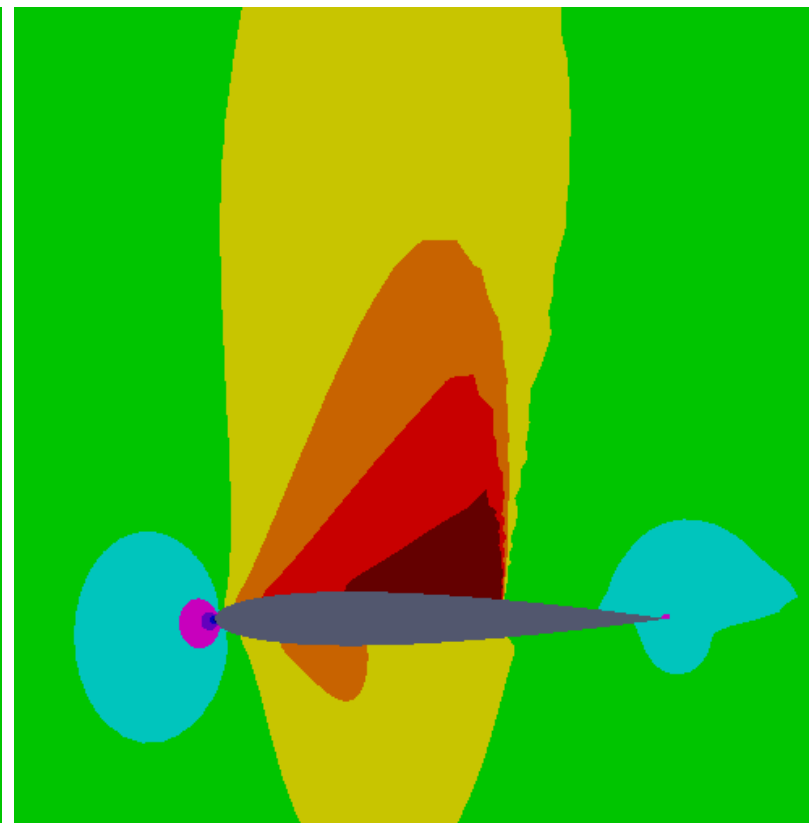

(b) 2a Ordem, Malha 3 (9328 VC).

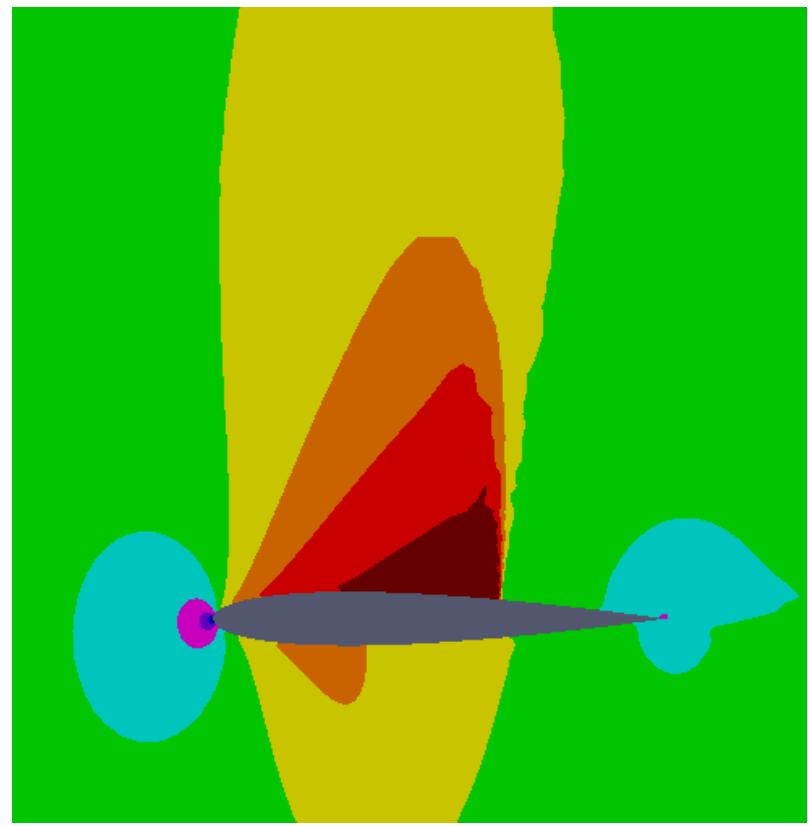

(d) 4a Ordem, Malha 3 (9328 VC).

Mach

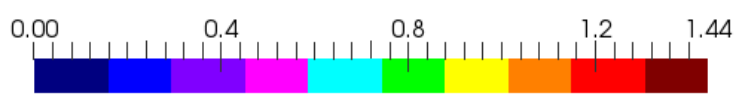

Figura 3.18: Número de Mach do escoamento, no caso transônico. 


\section{Capítulo 4}

\section{Método p-Multigrid para Volumes Finitos de Alta-Ordem}

Este capítulo começa apresentando o método de Diferença Espectral, que é uma discretização espacial de alta-ordem. Esta apresentação é breve porém suficiente para estudar, posteriormente, ao acelerador p-multigrid explícito desenvolvido no contexto da Diferença Espectral. O capítulo finaliza com a adaptação deste p-multigrid explícito ao âmbito do método VF de alta-ordem.

\subsection{Método de Diferença Espectral}

O método de Diferença Espectral está baseado na forma diferencial das equações de movimento do fluido,

$$
\frac{\partial \mathbf{U}}{\partial t}+\frac{\partial \mathbf{F}}{\partial x}+\frac{\partial \mathbf{G}}{\partial y}=0
$$

onde, no caso das equações de Euler 2D (Chorin e Marsden, 2000) (Toro, 2009),

$$
\mathbf{U} \equiv\left[\begin{array}{c}
\rho \\
\rho u \\
\rho v \\
E
\end{array}\right] \quad \mathbf{F} \equiv\left[\begin{array}{c}
\rho u \\
\rho u^{2}+P \\
\rho u v \\
u(E+P)
\end{array}\right] \quad \mathbf{G} \equiv\left[\begin{array}{c}
\rho v \\
\rho u v \\
\rho v^{2}+P \\
v(E+P)
\end{array}\right]
$$

ora, as equações de Euler 2D podem ser re-escritas assim:

$$
\frac{\partial \mathbf{U}}{\partial t}=-\nabla \cdot \overrightarrow{\mathbf{F}}
$$

onde

$$
\overrightarrow{\mathbf{F}}=\mathbf{F} \vec{i}+\mathbf{G} \vec{j}
$$

O método de Diferença Espectral permite aproximar as equações de Euler (4.3) por um sistema de EDOs do tipo

$$
\frac{d \mathbf{U}_{j, i}}{d t}=-\mathbf{R}_{j, i}(\mathbf{U})
$$

A notação utilizada nessas EDOs é dada a seguir. Para cada célula $i$, denota-se os pontos de solução ${ }^{1}$ e os pontos de fluxo por $r_{j, i}$ e $r_{k, i}$, respectivamente (vide Figura 4.1). $\mathbf{U}_{j, i}(t)$, solução dessas EDOs, é uma aproximação de $\mathbf{U}\left(r_{j, i}, t\right)$, solução das equações de Euler nos pontos de solução $r_{j, i}$. Os seguintes passos resumem o processo de definição do resíduo $\mathbf{R}_{j, i}(\mathbf{U})$ (Liu et al., 2006) (Wang et al., 2007) (Liang et al., 2009a):

\footnotetext{
${ }^{1}$ Tradução do termo em inglês solution points ou do, também utilizado, termo unknown points.
} 


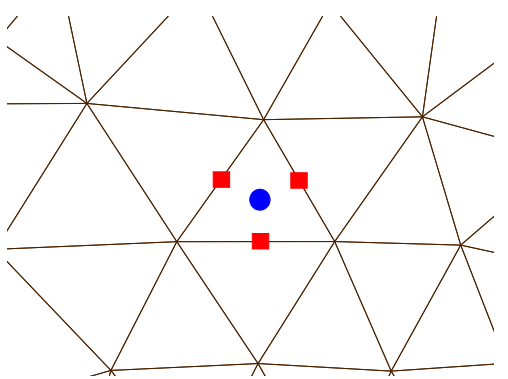

(a) 1a Ordem.

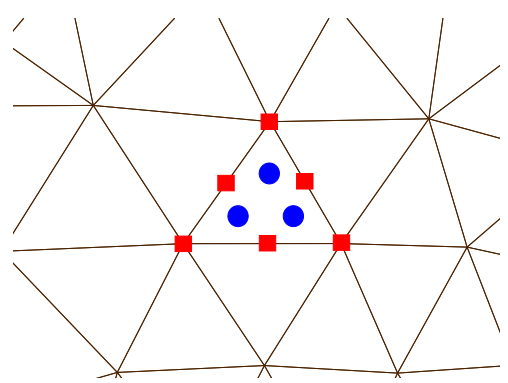

(b) 2 a Ordem.

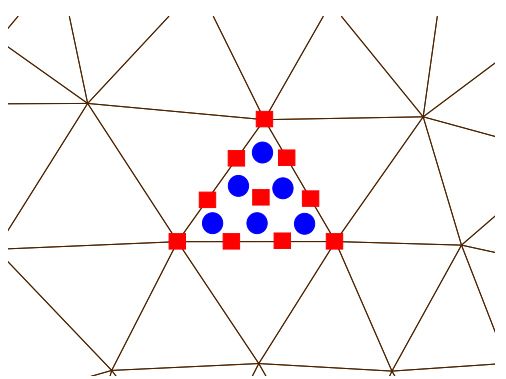

(c) 3 a Ordem.

Figura 4.1: Pontos de solução $r_{j, i}(\bullet)$ e pontos de fluxo $r_{k, i}(\mathbf{\square})$ da célula i triangular.

Passo 1: A partir das estimativas $\mathbf{U}_{j, i}$, constrói-se um polinômio de ordem $p$ em cada célula $i$ :

$$
\mathbf{U}_{i}(r) \equiv \sum_{j=1}^{N_{p}} L_{j, i}(r) \mathbf{U}_{j, i},
$$

onde $N_{p}$ é o número de pontos de solução requeridos para essa ordem polinomial e $L_{j, i}$ são funções base polinomiais de tipo Lagrange. Como resultado, $\mathbf{U}_{i}$ é contínuo dentro do elemento célula, e descontínuo nas interfaces do elemento.

Passo 2: Com o polinômio avaliado num ponto de fluxo $\left(\mathbf{U}_{i}\left(r_{k, i}\right)\right)$, pode-se calcular o fluxo nesse ponto (equação (4.4)). Mas, em $r_{k, i}$, o fluxo não está unicamente determinado e portanto, é utilizado um solver de Riemann unidimensional (como aquele de Rusanov (1961) ou de Roe (1981)) para obter uma única componente normal do fluxo. Isto último é feito nos pontos de fluxo sobre as faces do triângulo, já nos pontos de fluxo sobre vértices, é utilizado um tratamento especial porque eles estão associados a duas faces por cada célula (Wang et al. , 2007). Em resumo, um único fluxo $\overrightarrow{\mathbf{F}}_{k, i}$ é determinado para cada ponto de fluxo.

Passo 3: Constrói-se um polinômio de ordem $p+1$, em cada célula $i$ :

$$
\overrightarrow{\mathbf{F}}_{i}(r) \equiv \sum_{k=1}^{N_{p+1}} M_{k, i}(r) \overrightarrow{\mathbf{F}}_{k, i},
$$

onde $M_{k, i}$ formam um conjunto de funções base definidas unicamente pela localização dos pontos de fluxo. Também, encontra-se a divergência de $\overrightarrow{\mathbf{F}}_{i}(r)$,

$$
\nabla \bullet \overrightarrow{\mathbf{F}}_{i}(r)=\sum_{k=1}^{N_{p+1}} \nabla M_{k, i}(r) \bullet \overrightarrow{\mathbf{F}}_{k, i}
$$

e avalia-se num ponto de solução $\left(\nabla \bullet \overrightarrow{\mathbf{F}}_{i}\left(r_{j, i}\right)\right)$.

Passo 4: Por fim, define-se o resíduo em cada ponto de solução $r_{j, i}$ como

$$
\mathbf{R}_{j, i}(\mathbf{U}) \equiv \nabla \bullet \overrightarrow{\mathbf{F}}_{i}\left(r_{j, i}\right)
$$

onde $\mathbf{U}$, argumento do resíduo, representa o conjunto de todas as soluções aproximadas; ou seja, não basta a solução aproximada $\mathbf{U}_{j, i}$ para definir o resíduo no ponto de solução $r_{j, i}$.

Para resolver as equações de Euler semi-discretizadas (4.5), utiliza-se algum esquema de integração de tempo (explícito ou implícito). A seguir, apresenta-se o esquema explícito RK-SSP de 3 
estágios (Shu, 1988) com resíduo de Diferença Espectral:

$$
\begin{aligned}
\mathbf{U}_{i}^{(1)} & =\mathbf{U}_{i}^{n}-\Delta t \mathbf{R}_{i}\left(\mathbf{U}^{n}\right) \\
\mathbf{U}_{i}^{(2)} & =\frac{3}{4} \mathbf{U}_{i}^{n}+\frac{1}{4}\left[\mathbf{U}_{i}^{(1)}-\Delta t \mathbf{R}_{i}\left(\mathbf{U}^{(1)}\right)\right] \\
\mathbf{U}_{i}^{n+1} & =\frac{1}{3} \mathbf{U}_{i}^{n}+\frac{2}{3}\left[\mathbf{U}_{i}^{(2)}-\Delta t \mathbf{R}_{i}\left(\mathbf{U}^{(2)}\right)\right]
\end{aligned}
$$

onde

$$
\mathbf{U}_{i}^{\square} \equiv\left[\begin{array}{c}
\mathbf{U}_{1, i}^{\square} \\
\ldots \\
\mathbf{U}_{N_{p}, i}^{\square}
\end{array}\right] \quad \mathbf{R}_{i}\left(\mathbf{U}^{\square}\right) \equiv\left[\begin{array}{c}
\mathbf{R}_{1, i}\left(\mathbf{U}^{\square}\right) \\
\ldots \\
\mathbf{R}_{N_{p}, i}\left(\mathbf{U}^{\square}\right)
\end{array}\right] .
$$

\section{2 p-Multigrid Explícito para o Método de Diferença Espectral}

Se todas as iterações (ou passos), como aquela apresentada em (4.10), considerarem a mesma ordem polinomial na discretização, é de esperar que as soluções mantenham uma precisão dessa ordem. Com a finalidade de acelerar o processo iterativo, o método p-multigrid calcula uma solução de alta-ordem utilizando iterações no nível polinomial de alta e de baixa-ordem. No nível de baixaordem, o resíduo é modificado para aproximá-lo a um resíduo de alta-ordem. Além disso, o pmultigrid requer que o esquema de avanço no tempo ${ }^{2}$ (chamado no contexto multigrid de smoother) seja eficiente em amortecer os erros de alta frequência. Com isto, no nível de alta-ordem, o campo de erro tem suas altas frequências removidas e, as baixas frequências que sobraram são removidas no nível de baixa-ordem porque essas baixas frequências atuam como altas frequências neste nível (Liang et al., 2009b).

Nesta seção, estuda-se o p-multigrid explícito apresentado por Liang et al. (2009b) no contexto do método de Diferença Espectral, mais especificamente, o p-multigrid com smoother RK-SSP. Vale destacar que, naquele artigo, também é implementado o smoother implícito Gauss-Seidel simétrico LU. O estudo começa lembrando que o resíduo nos pontos de solução, $\mathbf{R}_{i}\left(\mathbf{U}^{\square}\right)$, depende da ordem $p$ da discretização; por isso, coloca-se a letra $p$ na notação, ou seja, $\mathbf{R}_{i}^{p}\left(\mathbf{U}^{\square}\right)$. Analogamente, se a solução $\mathbf{U}_{i}^{\square}$ está sendo calculada no nível de ordem $p$, utiliza-se a notação $\mathbf{U}_{i}^{p, \square}$.

Na busca de uma solução de alta-ordem, o p-multigrid utiliza iterações no nível polinomial de alta-ordem e no nível de ordens inferiores. A seguir, as iterações em cada nível polinomial são descritas denotando o nível de alta-ordem por $p$ e os níveis de ordens inferiores por $p-1, p-2$, etc.

- no nível $p$, cada iteração é o passo descrito em (4.10), ou seja,

$$
\begin{aligned}
\mathbf{U}_{i}^{p,(1)} & =\mathbf{U}_{i}^{p, n}-\Delta t \mathbf{R}_{i}^{p}\left(\mathbf{U}^{p, n}\right) \\
\mathbf{U}_{i}^{p,(2)} & =\frac{3}{4} \mathbf{U}_{i}^{p, n}+\frac{1}{4}\left[\mathbf{U}_{i}^{p,(1)}-\Delta t \mathbf{R}_{i}^{p}\left(\mathbf{U}^{p,(1)}\right)\right] \\
\mathbf{U}_{i}^{p, n+1} & =\frac{1}{3} \mathbf{U}_{i}^{p, n}+\frac{2}{3}\left[\mathbf{U}_{i}^{p,(2)}-\Delta t \mathbf{R}_{i}^{p}\left(\mathbf{U}^{p,(2)}\right)\right]
\end{aligned}
$$

- no nível $p-1$, cada iteração também é executada como em (4.10), mas o resíduo utilizado deve ser o resíduo modificado $\mathbf{R}_{i}^{p-1}\left(\mathbf{U}^{\square}\right)-\mathbf{r h s}_{i}^{p-1}$. Ou seja, uma iteração é o seguinte passo:

$$
\begin{aligned}
\mathbf{U}_{i}^{p-1,(1)} & =\mathbf{U}_{i}^{p-1, n}-\Delta t\left(\mathbf{R}_{i}^{p-1}\left(\mathbf{U}^{p-1, n}\right)-\mathbf{r h s} s_{i}^{p-1}\right) \\
\mathbf{U}_{i}^{p-1,(2)} & =\frac{3}{4} \mathbf{U}_{i}^{p-1, n}+\frac{1}{4}\left[\mathbf{U}_{i}^{p-1,(1)}-\Delta t\left(\mathbf{R}_{i}^{p-1}\left(\mathbf{U}^{p-1,(1)}\right)-\mathbf{r h s}_{i}^{p-1}\right)\right] \\
\mathbf{U}_{i}^{p-1, n+1} & =\frac{1}{3} \mathbf{U}_{i}^{p-1, n}+\frac{2}{3}\left[\mathbf{U}_{i}^{p-1,(2)}-\Delta t\left(\mathbf{R}_{i}^{p-1}\left(\mathbf{U}^{p-1,(2)}\right)-\mathbf{r h s}_{i}^{p-1}\right)\right]
\end{aligned}
$$

\footnotetext{
${ }^{2} \mathrm{Na}$ resolução de problemas estacionários, utiliza-se o termo esquemas de relaxação.
} 


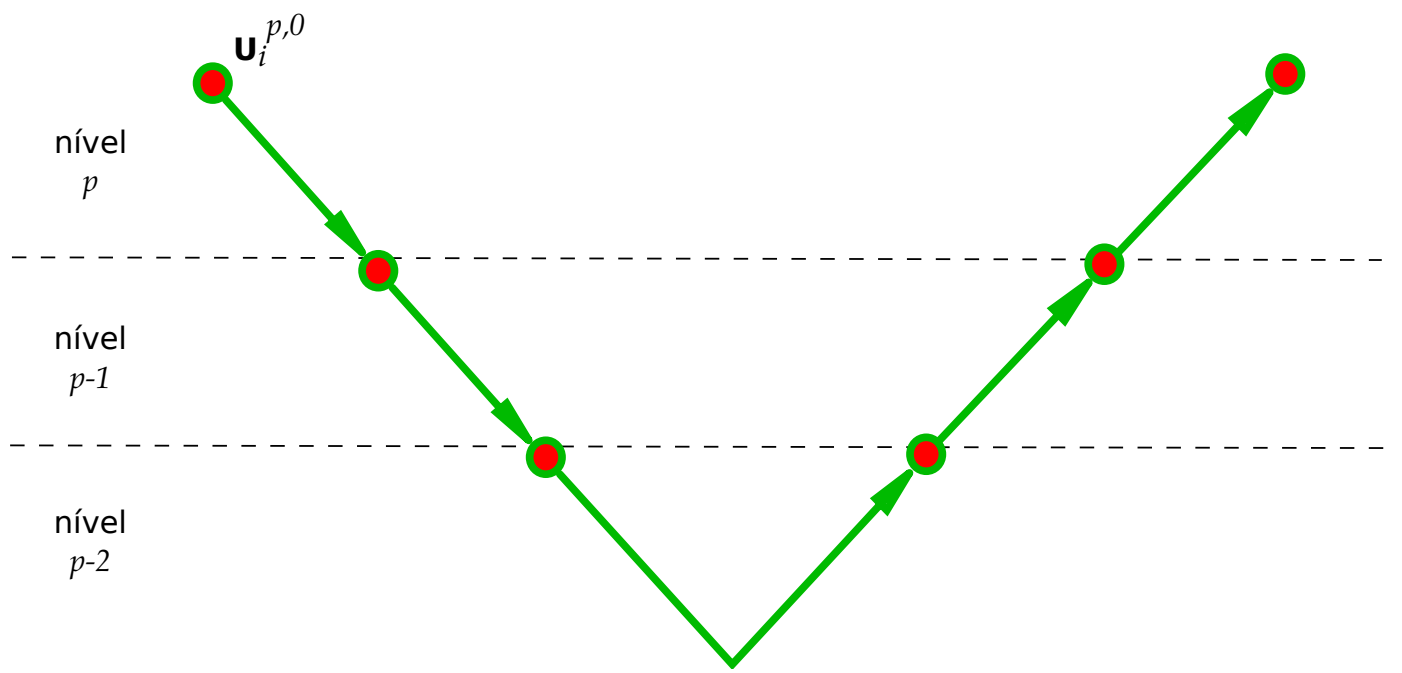

Figura 4.2: Percurso das iterações (passos) do smoother RK-SSP pelos niveis polinomiais $p, p-1$ e $p-2$. Em particular, esta figura representa um Vciclo de três níveis.

- no nível $p-2$, de maneira análoga ao nível $p-1$, utiliza-se um resíduo modificado, $\mathbf{R}_{i}^{p-2}\left(\mathbf{U}^{\square}\right)$ $\mathbf{r h s}_{i}^{p-2}$. Logo, cada iteração fica assim:

$$
\begin{aligned}
\mathbf{U}_{i}^{p-2,(1)} & =\mathbf{U}_{i}^{p-2, n}-\Delta t\left(\mathbf{R}_{i}^{p-2}\left(\mathbf{U}^{p-2, n}\right)-\mathbf{r h s}_{i}^{p-2}\right) \\
\mathbf{U}_{i}^{p-2,(2)} & =\frac{3}{4} \mathbf{U}_{i}^{p-2, n}+\frac{1}{4}\left[\mathbf{U}_{i}^{p-2,(1)}-\Delta t\left(\mathbf{R}_{i}^{p-2}\left(\mathbf{U}^{p-2,(1)}\right)-\mathbf{r h s}_{i}^{p-2}\right)\right] \\
\mathbf{U}_{i}^{p-2, n+1} & =\frac{1}{3} \mathbf{U}_{i}^{p-2, n}+\frac{2}{3}\left[\mathbf{U}_{i}^{p-2,(2)}-\Delta t\left(\mathbf{R}_{i}^{p-2}\left(\mathbf{U}^{p-2,(2)}\right)-\mathbf{r h s}_{i}^{p-2}\right)\right]
\end{aligned}
$$

As iterações em níveis inferiores tem o mesmo formato. O rhs é definido ao final desta seção, na ilustração de um esquema p-multigrid particular. O esquema mais básico do método p-multigrid é o chamado ciclo em $V$, ou Vciclo. Ele recebe este nome em virtude da trajetória que percorre entre os diferentes níveis polinomiais (vide Figura 4.2).

No contexto da Diferença Espectral, o método p-multigrid requer de operadores de restrição $\left(I_{p \downarrow p-1}, I_{p-1 \downarrow p-2}\right)$ e de prolongação $\left(I_{p-2 \uparrow p-1}, I_{p-1 \uparrow p}\right)$ para a comunicação entre diferentes níveis polinomiais. A restrição consiste em mover soluções e resíduos nos pontos de solução desde um espaço de ordem polinomial superior a outro de ordem polinomial inferior (vide Figura 4.1). A prolongação se refere ao procedimento no qual a diferença de duas soluções ${ }^{3}$ no nível inferior é redistribuído como diferença de duas soluções no nível superior.

Finalmente, apresentam-se os passos para atualizar a solução $\mathbf{U}_{i}^{p, 0}$, percorrendo um Vciclo de três níveis polinomiais: $p, p-1$ e $p-2$. A Figura 4.3 exibe este Vciclo.

Passo 1: Dado $\mathbf{U}_{i}^{p, 0}$, aplicam-se algumas iterações no nível $p$ (4.12) até conseguir uma solução mais atualizada, p. ex. $\mathbf{U}_{i}^{p, A}$.

Passo 2: Restringe-se a última solução, $\mathbf{U}_{i}^{p, A}$, a um nível inferior: $\mathbf{U}_{i}^{p-1, A} \equiv I_{p \downarrow p-1}\left(\mathbf{U}_{i}^{p, A}\right)$.

Passo 3: Define-se, no nível mais alto, o seguinte parâmetro: $\mathbf{d}_{i}^{p} \equiv-\mathbf{R}_{i}^{p}\left(\mathbf{U}^{p, A}\right)$.

Passo 4: Define-se o rhs das iterações no nível $p-1$ (4.13): $\mathbf{r h s}_{i}^{p-1} \equiv \mathbf{R}_{i}^{p-1}\left(\mathbf{U}^{p-1, A}\right)+I_{p \downarrow p-1}\left(\mathbf{d}_{i}^{p}\right)$. Note-se que o rhs depende apenas das soluções no "instante" $A$.

\footnotetext{
${ }^{3}$ Mais especificamente, é a diferença entre uma solução da n-ésima iteração e uma da m-ésima iteração. No trabalho de Liang et al. (2009b), utiliza-se o termo correção em vez de diferença porque, na resolução de problemas estacionários, a diferença é, de fato, uma correção.
} 


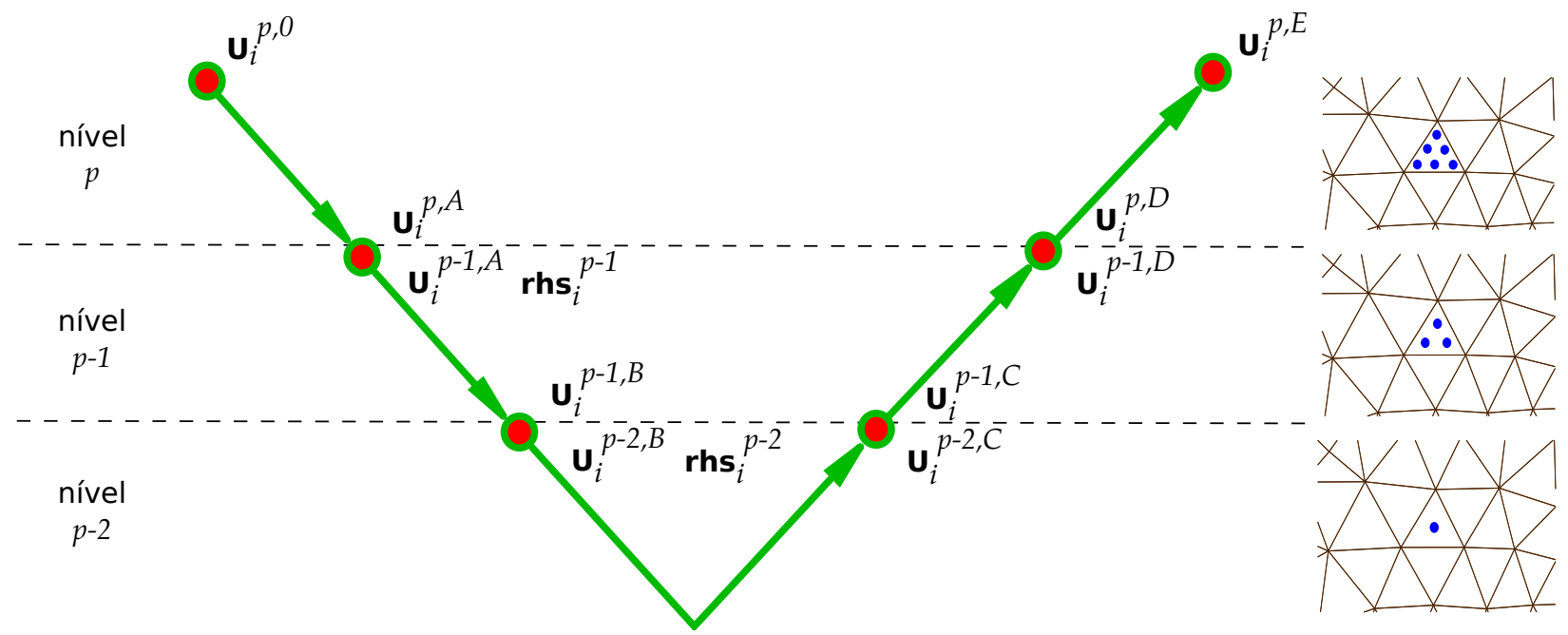

Figura 4.3: Vciclo de três niveis no contexto do método de Diferença Espectral.

Passo 5: A partir de $\mathbf{U}_{i}^{p-1, A}$, aplicam-se algumas iterações no nível $p-1$ (4.13) até conseguir uma solução mais atualizada, p. ex. $\mathbf{U}_{i}^{p-1, B}$. Observe-se que o rhs permanece congelado em todas essas iterações; note-se também que, no primeiro estágio da primeira iteração neste nível, o resíduo modificado pode ser substituído por $-I_{p \downarrow p-1}\left(\mathbf{d}_{i}^{p}\right)$.

Passo 6: Restringe-se a última solução, $\mathbf{U}_{i}^{p-1, B}$, ao nível $p-2: \mathbf{U}_{i}^{p-2, B} \equiv I_{p-1 \downarrow p-2}\left(\mathbf{U}_{i}^{p-1, B}\right)$.

Passo 7: Define-se, no nível intermédio, o seguinte parâmetro: $\mathbf{d}_{i}^{p-1} \equiv-\left(\mathbf{R}_{i}^{p-1}\left(\mathbf{U}^{p-1, B}\right)-\mathbf{r h s} \mathbf{s}_{i}^{p-1}\right)$.

Passo 8: Define-se o rhs das iterações no nível $p-2(4.14): \mathbf{r h s}_{i}^{p-2} \equiv \mathbf{R}_{i}^{p-2}\left(\mathbf{U}^{p-2, B}\right)+I_{p-1 \downarrow p-2}\left(\mathbf{d}_{i}^{p-1}\right)$. Note-se que este rhs depende das soluções nos "instantes" $B$ e $A$.

Passo 9: A partir de $\mathbf{U}_{i}^{p-2, B}$, aplicam-se algumas iterações no nível $p-2$ (4.14) até conseguir uma solução mais atualizada, p. ex. $\mathbf{U}_{i}^{p-2, C}$. Observe-se que o rhs permanece congelado em todas essas iterações; note-se também que, no primeiro estágio da primeira iteração neste nível, o resíduo modificado pode ser substituído por $-I_{p-1 \downarrow p-2}\left(\mathbf{d}_{i}^{p-1}\right)$.

Passo 10: Atualiza-se a última solução calculada no nível intermédio $\left(\mathbf{U}_{i}^{p-1, B}\right)$ : $\mathbf{U}_{i}^{p-1, C} \equiv \mathbf{U}_{i}^{p-1, B}+I_{p-2 \uparrow p-1}\left(\mathbf{U}_{i}^{p-2, C}-\mathbf{U}_{i}^{p-2, B}\right)$.

Note-se que há uma prolongação de uma diferença de soluções, e para essa diferença é utilizado o valor restrito calculado no Passo 6.

Passo 11: A partir de $\mathbf{U}_{i}^{p-1, C}$, aplicam-se algumas iterações no nível $p-1$ (4.13) até conseguir uma solução mais atualizada, p. ex. $\mathbf{U}_{i}^{p-1, D}$. Vale destacar que o rhs neste nível continua sendo o mesmo definido no Passo 4.

Passo 12: Atualiza-se a última solução calculada no nível mais alto $\left(\mathbf{U}_{i}^{p, A}\right)$ : $\mathbf{U}_{i}^{p, D} \equiv \mathbf{U}_{i}^{p, A}+I_{p-1 \uparrow p}\left(\mathbf{U}_{i}^{p-1, D}-\mathbf{U}_{i}^{p-1, A}\right)$.

Note-se que há uma prolongação de uma diferença de soluções, e para essa diferença é utilizado o valor restrito calculado no Passo 2.

Passo 13: Por fim, a partir de $\mathbf{U}_{i}^{p, D}$, aplicam-se algumas iterações no nível $p$ (4.12) até conseguir uma solução mais atualizada, p. ex. $\mathbf{U}_{i}^{p, E}$.

Assim, a solução $\mathbf{U}_{i}^{p, 0}$ é atualizada para $\mathbf{U}_{i}^{p, E}$ e esta serve como dado inicial para um próximo Vciclo; ou seja, estes ciclos podem ser repetidos até atingir algum critério de parada. 
Ao executar os Passos 6-11 mais uma vez, é formado um Wciclo de três níveis. Ora, se estes passos são removidos, o esquema formado é o clássico Vciclo de dois níveis.

\subsection{Adaptação ao Método de Volumes Finitos}

Nesta seção, adapta-se o p-multigrid apresentado na Seção 4.2 ao contexto do método VF. O smoother a considerar é o esquema RK de van Leer et al. (1989) descrito em (3.9). Vale lembrar que a notação $R_{i}^{p}\left(\bar{U}^{\square}\right)$ refere-se ao resíduo no volume de controle $\Omega_{i}$ calculado com a discretização VF de ordem $p$; e que a notação $\bar{U}_{i}^{\square}$ refere-se à solução média no volume de controle $\Omega_{i}$. Percebe-se que esta solução média, em contraposição com a solução $\mathbf{U}_{i}^{\square}$ na Diferença Espectral, não inclui graus de liberdade adicionais como os pontos de solução.

Como todo p-multigrid, o proposto nesta seção calcula uma solução de alta-ordem utilizando iterações no nível polinomial de alta-ordem e no nível de ordens inferiores. A seguir, as iterações em cada nível polinomial são descritas denotando o nível de alta-ordem por $p$ e os níveis de ordens inferiores por $p-1, p-2$, etc.

- no nível $p$, cada iteração é o passo descrito em (3.9), ou seja,

$$
\begin{aligned}
\bar{U}_{i}^{(0)} & =\bar{U}_{i}^{n} \\
\bar{U}_{i}^{(k)} & =\bar{U}_{i}^{(0)}-\alpha_{k} \Delta t R_{i}^{p}\left(\bar{U}^{(k-1)}\right), k=1, . ., 5 \\
\bar{U}_{i}^{n+1} & =\bar{U}_{i}^{(5)}
\end{aligned}
$$

- no nível $p-1$, cada iteração também é executada como em (3.9), mas o resíduo utilizado deve ser o resíduo modificado $R_{i}^{p-1}\left(\bar{U}^{\square}\right)-r h s_{i}^{p-1}$. Ou seja, uma iteração é o seguinte passo:

$$
\begin{aligned}
\bar{U}_{i}^{(0)} & =\bar{U}_{i}^{n} \\
\bar{U}_{i}^{(k)} & =\bar{U}_{i}^{(0)}-\alpha_{k} \Delta t\left[R_{i}^{p-1}\left(\bar{U}^{(k-1)}\right)-r h s_{i}^{p-1}\right], k=1, . ., 5 \\
\bar{U}_{i}^{n+1} & =\bar{U}_{i}^{(5)}
\end{aligned}
$$

- no nível $p-2$, de maneira análoga ao nível $p-1$, utiliza-se um resíduo modificado, $R_{i}^{p-2}\left(\bar{U}^{\square}\right)$ $r h s_{i}^{p-2}$. Logo, cada iteração fica assim:

$$
\begin{aligned}
\bar{U}_{i}^{(0)} & =\bar{U}_{i}^{n} \\
\bar{U}_{i}^{(k)} & =\bar{U}_{i}^{(0)}-\alpha_{k} \Delta t\left[R_{i}^{p-2}\left(\bar{U}^{(k-1)}\right)-r h s_{i}^{p-2}\right], k=1, . ., 5 \\
\bar{U}_{i}^{n+1} & =\bar{U}_{i}^{(5)}
\end{aligned}
$$

Os resíduos modificados considerados nos níveis $p-1$ e $p-2$ são aproximações de um resíduo de alta-ordem. Uma maior análise dos resíduos modificados é dada no final desta seção.

Vale lembrar que, no contexto da Diferença Espectral, os pontos de solução mudam ao trocar de nível polinomial (vide Figura 4.3). Por isso, na hora de descer de um nível $p$ para um nível $p-1$, o p-multigrid para Diferença Espectral precisa trazer a solução $\mathbf{U}_{i}^{p, n}$ nos pontos de solução do nível $p$ para os pontos de solução do nível $p-1$, via uma operação de restrição. Sem pontos de solução nos volumes de controle, o p-multigrid proposto não necessita esta restrição: a solução $\bar{U}_{i}^{n}$ no nível $p$ é diretamente utilizada no nível $p-1$. E na subida, a solução $\bar{U}_{i}^{m}$ no nível $p-1$ também é diretamente usada no nível $p$. O p-multigrid para Diferença Espectral precisa, nesta subida, a prolongação descrita na Seção 4.2.

A seguir, apresentam-se os passos para atualizar a solução $\bar{U}_{i}^{0}$, percorrendo um Vciclo de três níveis polinomiais: $p, p-1$ e $p-2$. A Figura 4.4 exibe este Vciclo proposto. 


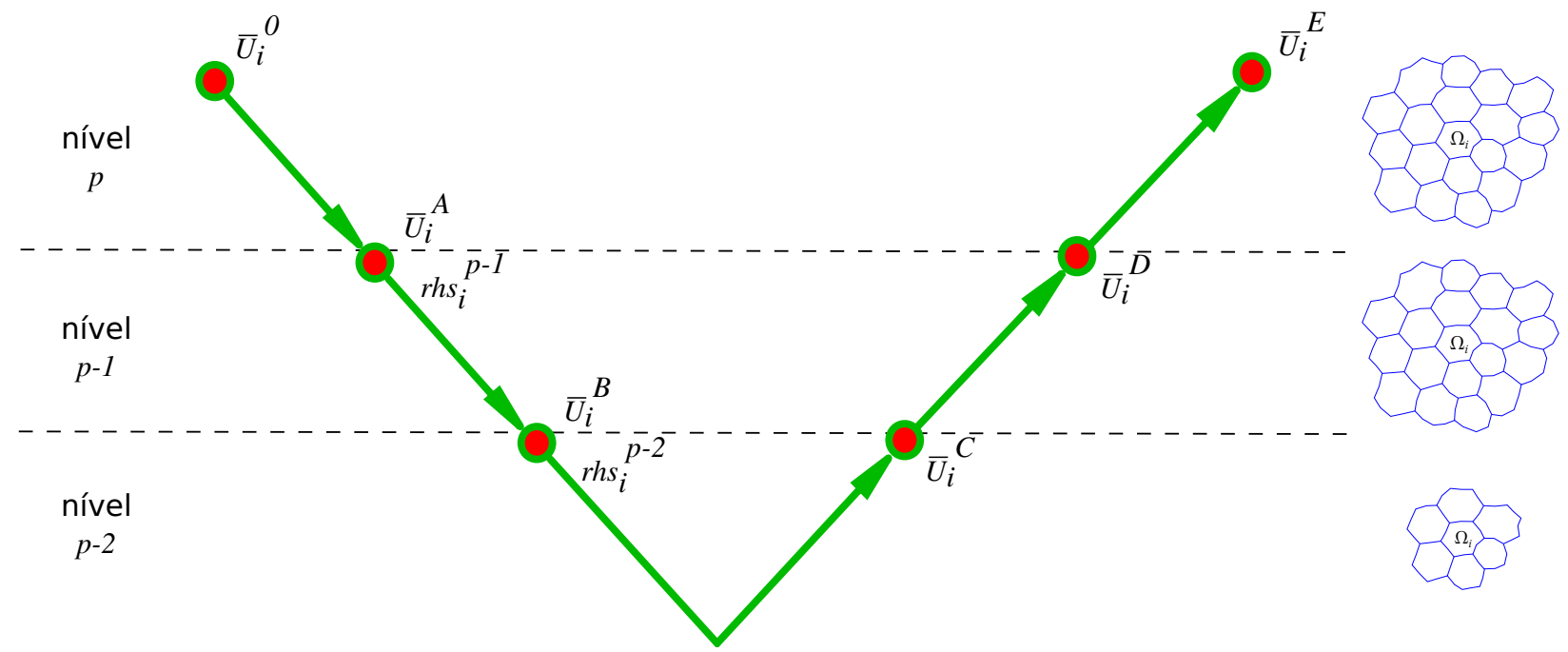

Figura 4.4: Vciclo de três níveis no contexto do método de Volumes Finitos.

Passo 1: Dado $\bar{U}_{i}^{0}$, aplicam-se algumas iterações no nível $p$ (4.15) até conseguir uma solução mais atualizada, p. ex. $\bar{U}_{i}^{A}$.

Passo 2: Define-se o $r h s$ das iterações no nível $p-1$ (4.16): $r h s_{i}^{p-1} \equiv R_{i}^{p-1}\left(\bar{U}^{A}\right)-R_{i}^{p}\left(\bar{U}^{A}\right)$. Note-se que o rhs depende apenas da solução no "instante" $A$.

Passo 3: A partir de $\bar{U}_{i}^{A}$, aplicam-se algumas iterações no nível $p-1$ (4.16) até conseguir uma solução mais atualizada, p. ex. $\bar{U}_{i}^{B}$. Observe-se que o $r h s$ permanece congelado em todas essas iterações; note-se também que, no primeiro estágio da primeira iteração neste nível, o resíduo modificado pode ser substituído por $R_{i}^{p}\left(\bar{U}^{A}\right)$.

Passo 4: Define-se o $r h s$ das iterações no nível $p-2$ (4.17): $r h s_{i}^{p-2} \equiv R_{i}^{p-2}\left(\bar{U}^{B}\right)-R_{i}^{p-1}\left(\bar{U}^{B}\right)+$ $r h s_{i}^{p-1}$. Note-se que este $r h s$ depende das soluções nos "instantes" $B$ e $A$.

Passo 5: A partir de $\bar{U}_{i}^{B}$, aplicam-se algumas iterações no nível $p-2$ (4.17) até conseguir uma solução mais atualizada, p. ex. $\bar{U}_{i}^{C}$. Observe-se que o $r h s$ permanece congelado em todas essas iterações; note-se também que, no primeiro estágio da primeira iteração neste nível, o resíduo modificado pode ser substituído por $R_{i}^{p-1}\left(\bar{U}^{B}\right)-r h s_{i}^{p-1}$.

Passo 6: A partir de $\bar{U}_{i}^{C}$, aplicam-se algumas iterações no nível $p-1$ (4.16) até conseguir uma solução mais atualizada, p. ex. $\bar{U}_{i}^{D}$. Vale destacar que o rhs neste nível continua sendo o mesmo definido no Passo 2.

Passo 7: Por fim, a partir de $\bar{U}_{i}^{D}$, aplicam-se algumas iterações no nível $p$ (4.15) até conseguir uma solução mais atualizada, p. ex. $\bar{U}_{i}^{E}$.

Assim, a solução $\bar{U}_{i}^{0}$ é atualizada para $\bar{U}_{i}^{E}$ e esta serve como dado inicial para um próximo Vciclo. Para formar um Wciclo de três níveis, basta executar uma vez mais os Passos 4, 5 e 6; e sem eles é formado o Vciclo clássico.

Finalmente, é dada uma observação do Vciclo de três níveis proposto. Para qualquer iteração (ou estágio), denotada por $\square$, tem-se que

$$
R_{i}^{p}\left(\bar{U}^{\square}\right)=R_{i}^{p-1}\left(\bar{U}^{\square}\right)-\left[R_{i}^{p-1}\left(\bar{U}^{\square}\right)-R_{i}^{p}\left(\bar{U}^{\square}\right)\right] ;
$$


ora, das iterações no nível $p-1$ (4.16) e da definição do $r h s$ do Passo 2 acima, tem-se que

$$
\begin{aligned}
\begin{array}{r}
\text { Resíduo modificado } \\
\text { no nível } p-1
\end{array} & R_{i}^{p-1}\left(\bar{U}^{\square}\right)-r h s_{i}^{p-1} \\
& =R_{i}^{p-1}\left(\bar{U}^{\square}\right)-\left[R_{i}^{p-1}\left(\bar{U}^{A}\right)-R_{i}^{p}\left(\bar{U}^{A}\right)\right] .
\end{aligned}
$$

Portanto, o resíduo modificado para as iterações no nível $p-1$ se aproxima ao resíduo de alta-ordem à medida que o parâmetro $r h s_{i}^{p-1}$ se aproxime da diferença $R_{i}^{p-1}\left(\bar{U}^{\square}\right)-R_{i}^{p}\left(\bar{U}^{\square}\right)$. Fazendo uma análise similar, observa-se que o resíduo modificado para as iterações no nível $p-2(4.17)$ se aproxima ao resíduo de alta-ordem (ordem $p$ ) conforme o parâmetro $r h s_{i}^{p-2}$ se aproxime de $R_{i}^{p-2}\left(\bar{U}^{\square}\right)-R_{i}^{p-1}\left(\bar{U}^{\square}\right)+r h s_{i}^{p-1}$, e rhs $i_{i}^{p-1}$ se aproxime de $R_{i}^{p-1}\left(\bar{U}^{\square}\right)-R_{i}^{p}\left(\bar{U}^{\square}\right)$.

\subsection{Conclusão}

Demonstra-se que é possível aplicar um esquema p-multigrid ao método estudado nos Capítulos 2 e 3, isto é, o método VF de alta-ordem com avanço RK. A natureza não compacta do método VF permite que o p-multigrid transfira diretamente a solução para diferentes níveis polinomiais. Já, o método de Diferença Espectral (DE) de natureza compacta implica que o p-multigrid precise de operadores de restrição e prolongação nesta transferência. Mesmo assim, no âmbito DE, Liang et al. (2009b) reportam que o p-multigrid acelera a simulação do escoamento subsônico ao redor do NACA0012 sem sustentação: o p-multigrid explícito requer aproximadamente $13 \%$ do tempo de CPU da combinação DE-RK explícito (sem p-multigrid). No próximo capítulo, se verifica que, resolvendo problemas estacionários, o p-multigrid proposto também é um acelerador e não contamina a precisão de alta-ordem do método VF. 


\section{Capítulo 5}

\section{Resultados}

Neste capítulo, a performance do método p-multigrid proposto é comparada com aquela do método VF de 4a ordem com avanço RK, em termos de precisão e de tempo de CPU, principalmente. O código pMG, desenvolvido a partir do p-multigrid proposto (Seção 4.3), resolve os problemas estacionários de advecção-difusão no canal retangular e no segmento anular (Seção 2.6), assim como os três regimes de escoamento ao redor do aerofólio NACA0012 (Seção 3.8). Vale destacar que são procuradas soluções de 4a ordem. Nesse sentido, utilizam-se Vciclos de 3 níveis o4-o3-o2-o3-o4 (isto é, a sequencia de níveis é 4a, 3a, 2a, 3a e 4a ordem). Excepcionalmente, o problema do escoamento transônico é resolvido com Vciclos o4-o2-o4 e o4-o2-o1-o2-o4, sempre procurando soluções de 4a ordem. Os resultados do p-multigrid (solver pMG) são comparados com aqueles do método VF de 4a ordem com avanço RK (solver VF-RK). Para fazer uma comparação justa consideram-se, para cada problema estacionário, as mesmas malhas computacionais, assim como o mesmo chute inicial, o mesmo critério de parada e o mesmo computador.

\subsection{Advecção-difusão no canal retangular}

Os dados da física deste problema e as malhas computacionais estão descritos na Seção 2.6.2. Seis esquemas p-multigrid são considerados na resolução deste problema (Tabela 5.1). O processo iterativo de três desses esquemas consiste de apenas Vciclos o4-o3-o2-o3-o4. Aqui é importante explicar que a sequencia 1-1-2-1-1 indica o número de iterações no nível de 4a, 3a, 2a, 3a e 4a ordem, respectivamente, por cada ciclo. Os Vciclos 1-1-4-1-1 e 1-1-8-1-1 seguem essa interpretação. Os últimos três esquemas da Tabela 5.1 são full multigrid. Mais especificamente, o processo iterativo começa com 2 a ordem até que a norma $L_{2}$ do resíduo seja $2 \times 10^{-2}$; logo o processo continua com Vciclos 1-2-2 (o3-o2-o3) até que o resíduo seja $5 \times 10^{-3}$; e depois o processo continua com os Vciclos de 3 níveis indicados.

\begin{tabular}{ll}
\hline Acrônimo & Definição \\
\hline MG 1-1-2-1-1 & apenas Vciclos 1-1-2-1-1 (o4-o3-o2-o3-o4) \\
MG 1-1-4-1-1 & apenas Vciclos 1-1-4-1-1 (o4-o3-o2-o3-o4) \\
MG 1-1-8-1-1 & apenas Vciclos 1-1-8-1-1 (o4-o3-o2-o3-o4) \\
Full MG 1-1-2-1-1 & 2a ordem + Vciclos 1-2-2 (o3-o2-o3) + Vciclos 1-1-2-1-1 (o4-o3-o2-o3-o4) \\
Full MG 1-1-4-1-1 & 2a ordem + Vciclos 1-2-2 (o3-o2-o3) + Vciclos 1-1-4-1-1 (o4-o3-o2-o3-o4) \\
Full MG 1-1-8-1-1 & 2a ordem + Vciclos 1-2-2 (o3-o2-o3) + Vciclos 1-1-8-1-1 (o4-o3-o2-o3-o4) \\
\hline
\end{tabular}

Tabela 5.1: Acrônimos dos esquemas p-multigrid utilizados no caso advecção-difusão no canal retangular.

Vale lembrar que, no processo iterativo, é utilizado o passo local de tempo (Seção 4.3). Neste caso de advecção-difusão, ele é calculado com $\mathrm{CFL}=1,0$, que é o mesmo número CFL utilizado na Seção 2.6.2. 


\begin{tabular}{|c|c|c|c|c|}
\hline & 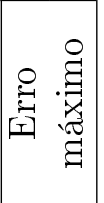 & 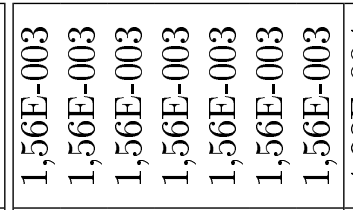 & 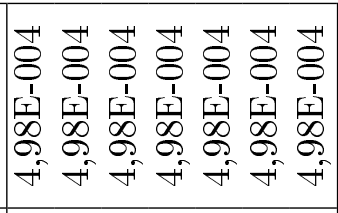 & 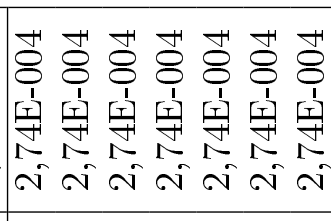 \\
\hline & 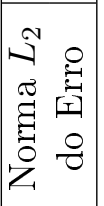 & 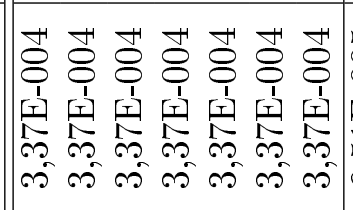 & 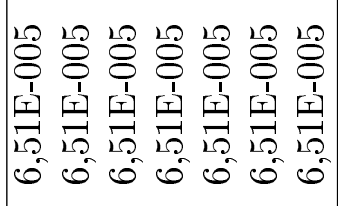 & 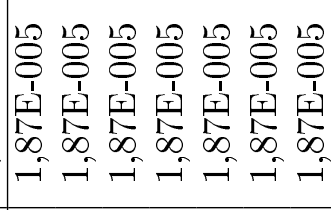 \\
\hline & 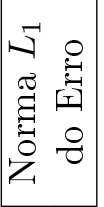 & 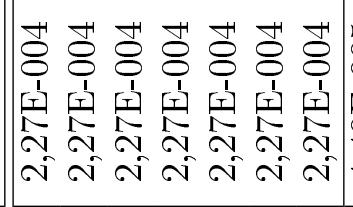 & 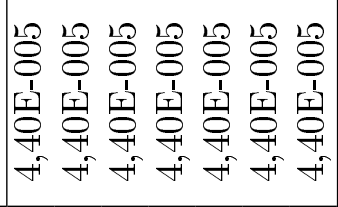 & 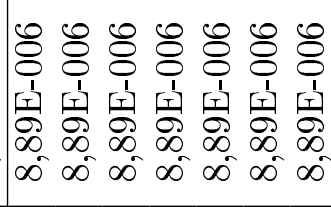 \\
\hline & 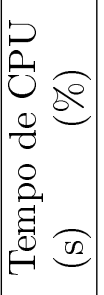 & 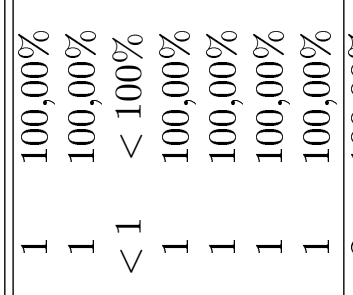 & 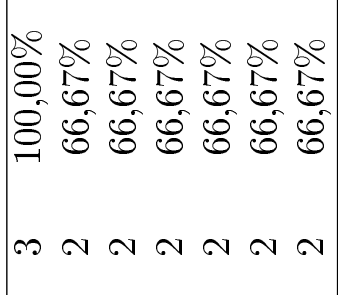 & 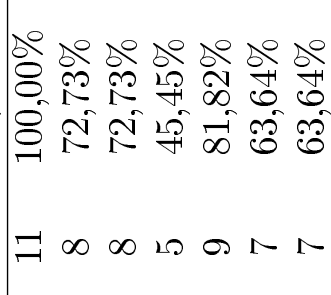 \\
\hline & 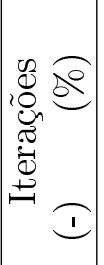 & 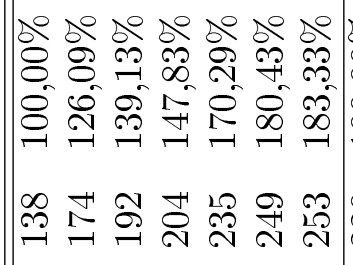 & 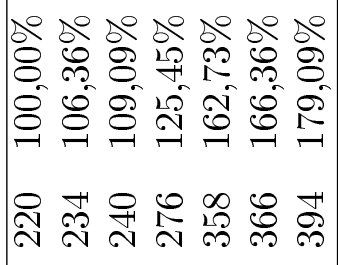 & 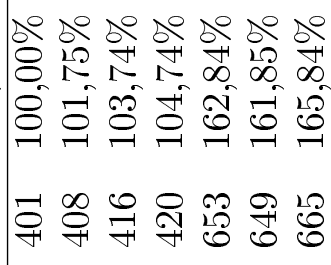 \\
\hline & 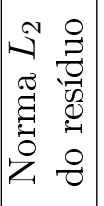 & 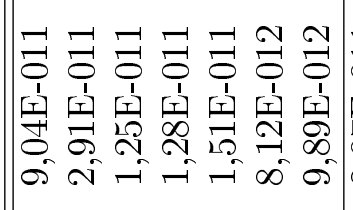 & 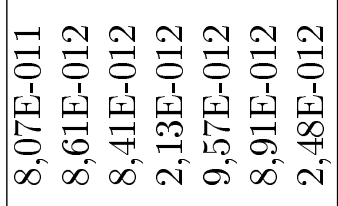 & 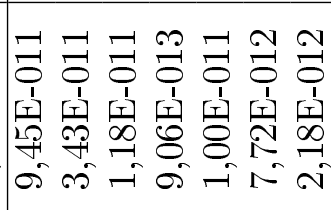 \\
\hline 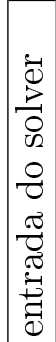 & 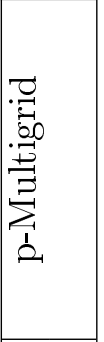 & 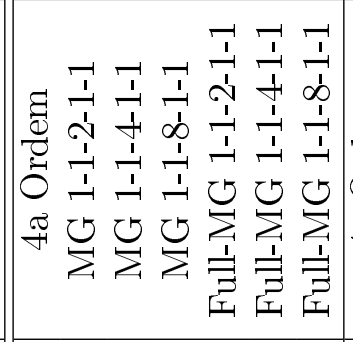 & 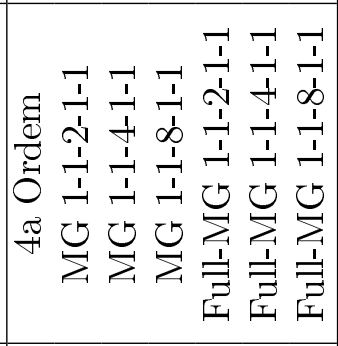 & 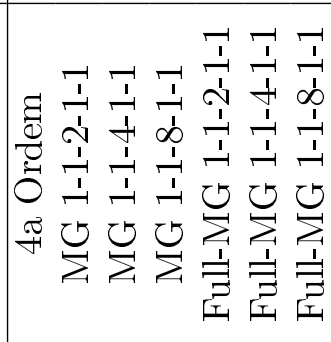 \\
\hline 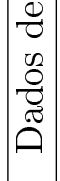 & & 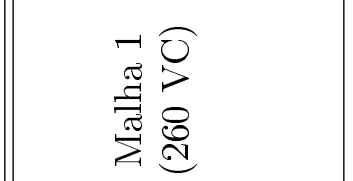 & 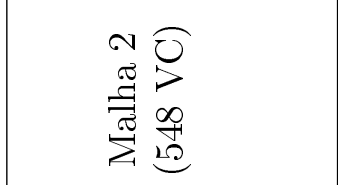 & $\frac{\infty}{\stackrel{\overbrace{}}{\mathcal{G}}}$ \\
\hline
\end{tabular}




\begin{tabular}{|c|c|c|c|c|}
\hline & 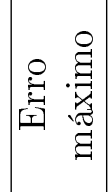 & 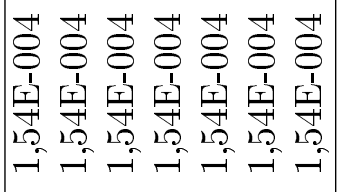 & 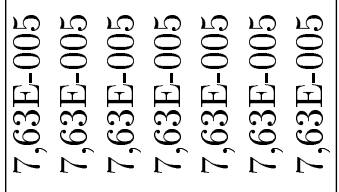 & 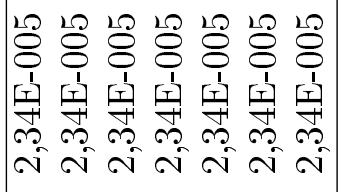 \\
\hline & 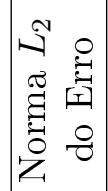 & 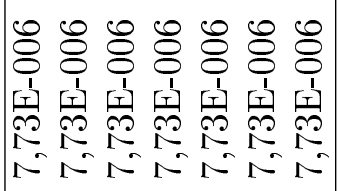 & 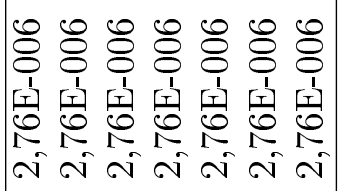 & 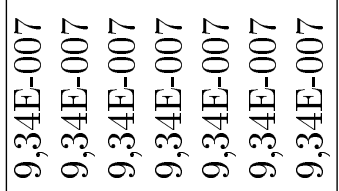 \\
\hline & 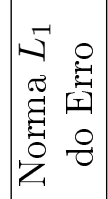 & 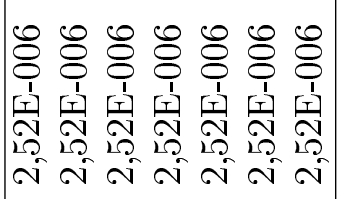 & 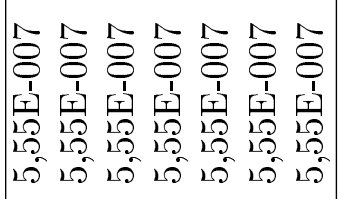 & 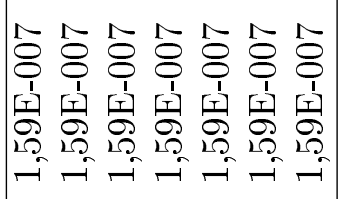 \\
\hline & 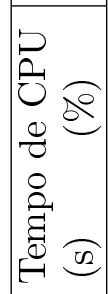 & 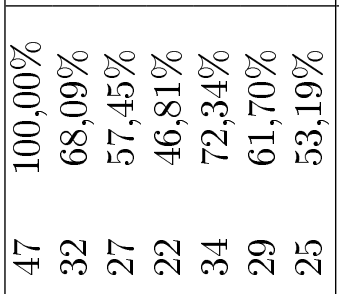 & 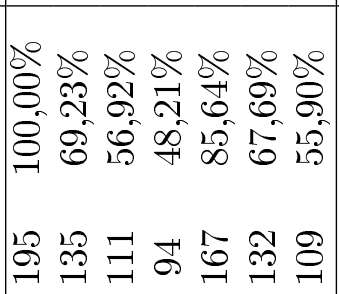 & 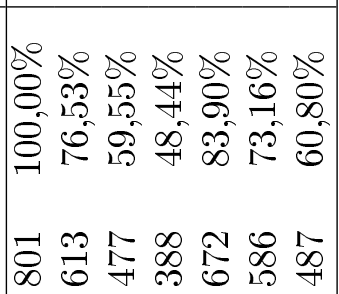 \\
\hline & 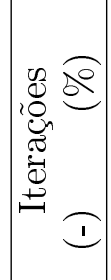 & 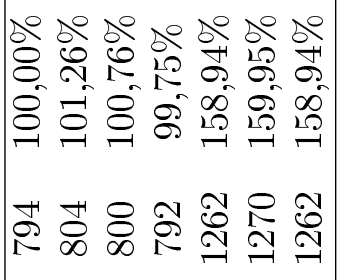 & 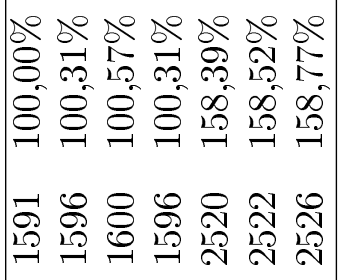 & 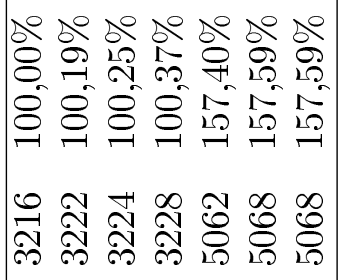 \\
\hline & 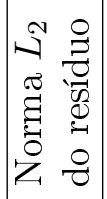 & 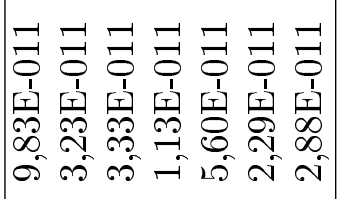 & 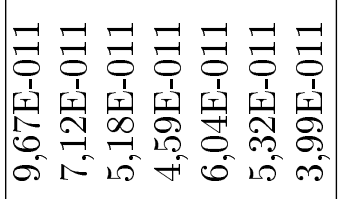 & 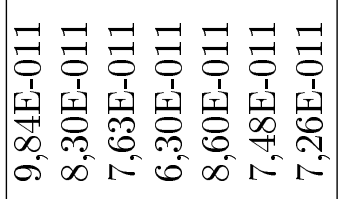 \\
\hline 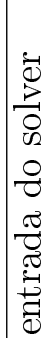 & 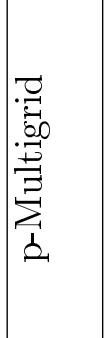 & 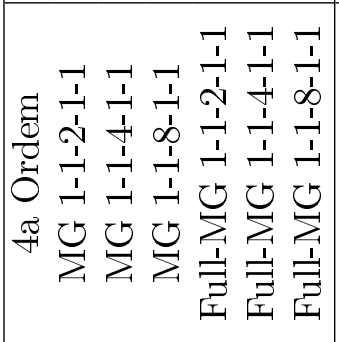 & 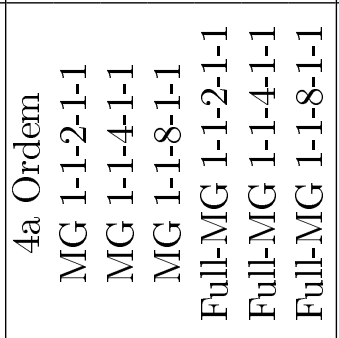 & 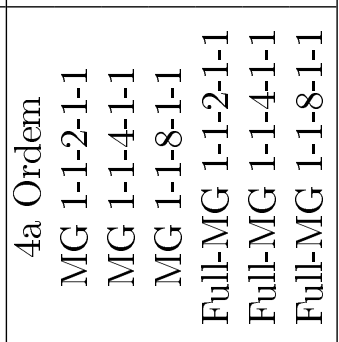 \\
\hline 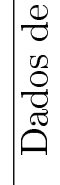 & 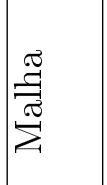 & 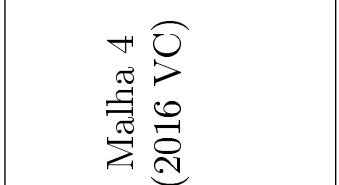 & 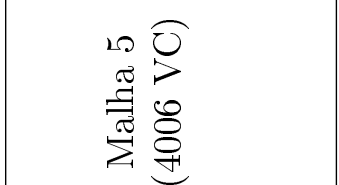 & 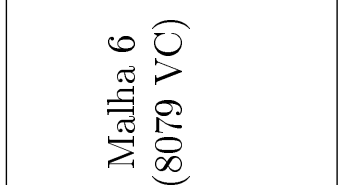 \\
\hline
\end{tabular}


Cada combinação Malha-p-Multigrid resulta numa solução deste problema (Tabelas 5.2 e 5.3). Nestas tabelas, também são incluídos os resultados com 4 a ordem ${ }^{1}$. As colunas "Norma $L_{1}$ do Erro", "Norma $L_{2}$ do Erro" e "Erro máximo" mostram uma característica importante: dada uma malha, não há variação entre as soluções obtidas pelos esquemas p-multigrid e pela 4a ordem. Por exemplo, a combinação Malha 1 com 4a Ordem resulta numa solução com erro médio de $2,27 \times 10^{-4}$, erro em norma $L_{2}$ de $3,37 \times 10^{-4}$ e erro máximo de $1.56 \times 10^{-3}$; estas são as mesmas medidas do erro obtido pela combinação Malha 1 com quaisquer dos esquemas p-multigrid. Em resumo, a precisão oferecida pelos esquemas p-multigrid é a mesma oferecida pelo método VF de 4a ordem com avanço RK (Figura 5.1(a)).

Mais ainda, os esquemas p-multigrid considerados atingem a solução num tempo de CPU menor do que o método VF de 4a ordem. A Figura 5.1(b) ilustra o bom desempenho de dois esquemas p-multigrid: MG 1-1-8-1-1 e Full-MG 1-1-8-1-1. A coluna "Tempo de CPU" das Tabelas 5.2 e 5.3 dá uma informação mais completa: ela mostra os tempos (em segundos) para todos os esquemas p-multigrid, assim como a razão (em porcentagem) entres esses tempos e o tempo da 4a ordem. Dessas tabelas, observa-se que o tempo associado ao esquema MG 1-1-8-1-1 oscila entre $45 \%$ e $48 \%$ do tempo da 4 a ordem ${ }^{2}$. Já o esquema Full-MG 1-1-8-1-1 resulta em tempos relativos de $53 \%$ até $64 \%$.

Embora os esquemas p-multigrid conseguem soluções rápidas, eles não conseguem diminuir o número de iterações do processo iterativo que resulta com 4a ordem (vide coluna "Iterações" das tabelas acima mencionadas). O número de iterações (\%) e o tempo de CPU (\%) que resultam da combinação Malha 3 com esquemas p-multigrid são mostrados na Figura 5.2(a). Observe-se que o número de iterações associados aos esquemas MG 1-1-2-1-1, MG 1-1-4-1-1 e MG 1-1-8-11 é aproximadamente igual ao número de iterações da 4a ordem. Já os esquemas full multigrid necessitam, aproximadamente, $60 \%$ mais iterações do que a 4a ordem precisa. Resultados análogos são obtidos ao considerar a Malha 6, envés da Malha 3 (Figura 5.2(b)).

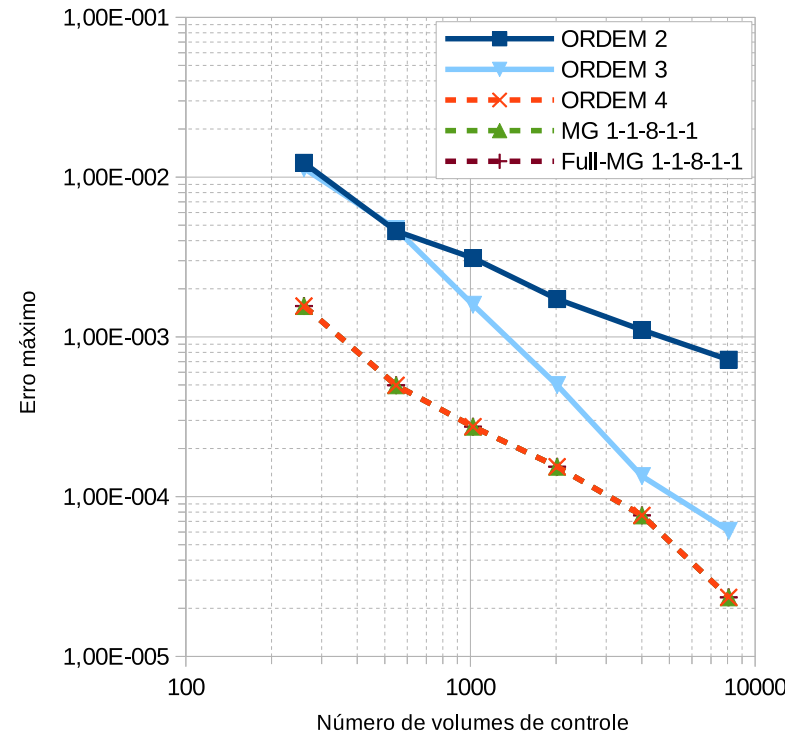

(a)

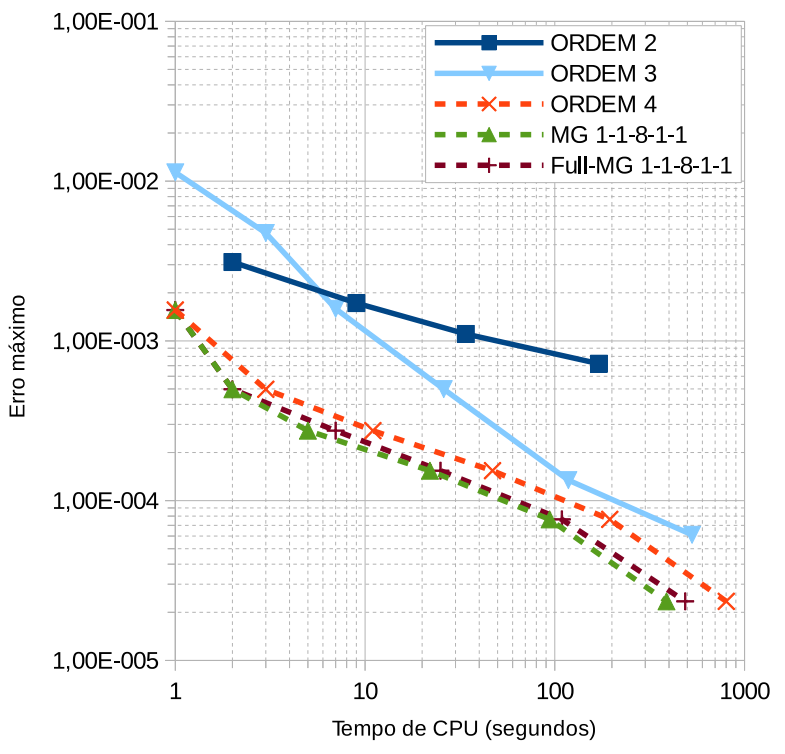

(b)

Figura 5.1: Erro máximo versus Número de VC e Tempo de CPU, no caso advecção-difusão no canal retangular. As combinações 2a Ordem-Malha 1 e 2a Ordem-Malha 2 levam um tempo de CPU menor a $1 \mathrm{~s}$ e não são mostrados em (b).

\footnotetext{
${ }^{1}$ São os resultados obtidos pelo método de VF de 4a ordem com avanço RK (Seção 2.6.2).

${ }^{2}$ Os tempos são medidos pela função GNU C difftime que não mede tempos menores do que 1s. Então, a faixa de tempos de CPU (\%) mencionada não considera os resultados com as Malhas 1 e 2 porque os tempos para estas malhas são comparáveis a $1 \mathrm{~s}$.
} 


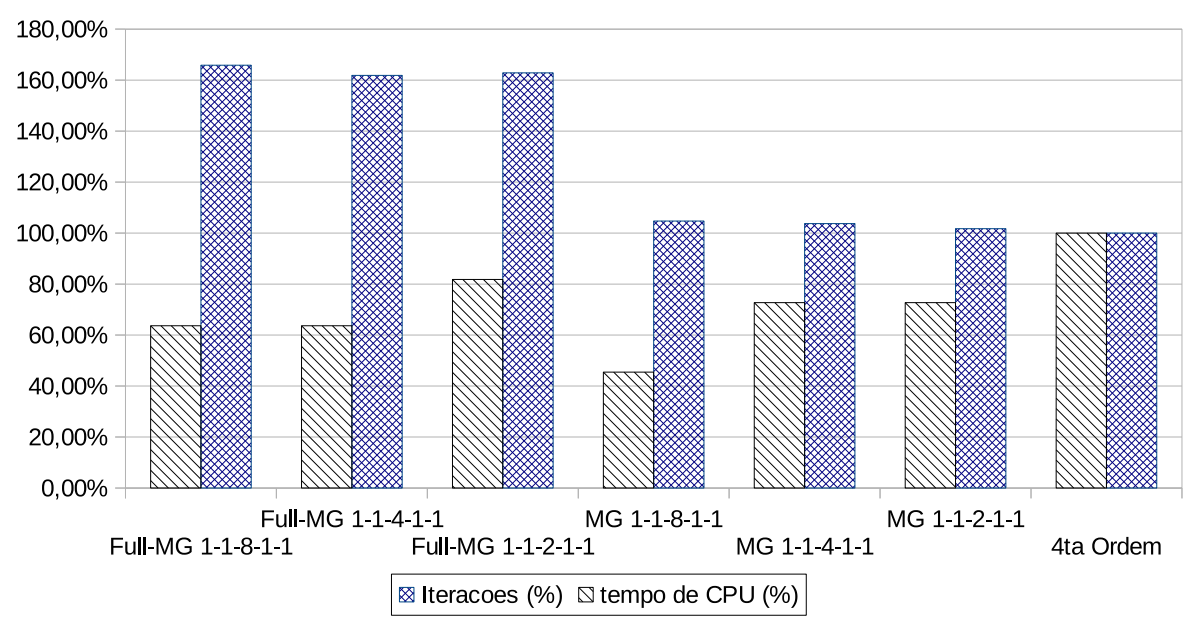

(a) Malha $3(1021 \mathrm{VC})$.

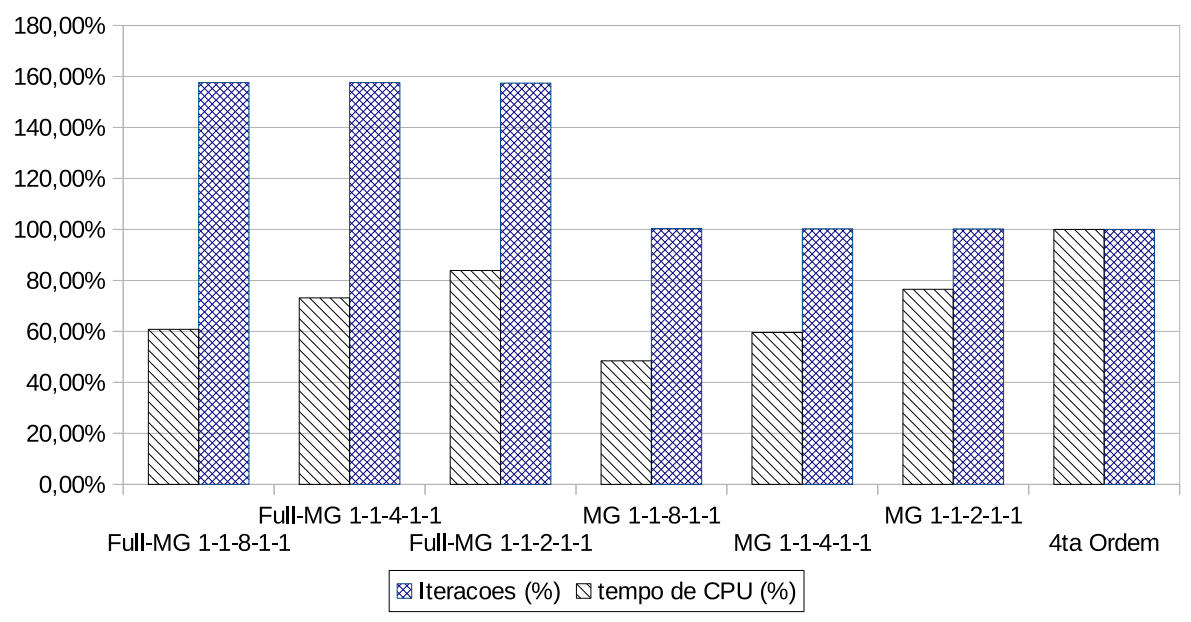

(b) Malha $6(8079 \mathrm{VC})$.

Figura 5.2: Número de Iterações (\%) e Tempo de CPU (\%) consumido nos testes com p-multigrid, no caso advecção-difusão no canal retangular.

Assim, em termos do número de iterações e do tempo de CPU, o esquema MG 1-1-8-1-1 apresenta as maiores vantagens. A Figura 5.3(a) mostra que este esquema p-multigrid consegue diminuir o resíduo da mesma maneira que o método VF de 2a e 4a ordem, em termos do número de iterações. Já em termos do tempo de CPU (Figura 5.3(b)), a convergência residual é mais rápida do que a 4a ordem porque 8 de cada 12 iterações são feitas no nível de 2a ordem. O esquema Full-MG 1-1-8-1-1 tem uma história de convergência interessante e diferente à aquela da 2a e 4a ordem (Figura 5.4). Quando o resíduo alcança uma norma $L_{2}$ de 0,0001, observa-se uma dificuldade para o esquema pmultigrid diminuir o resíduo. Este período corresponde aos primeiros ciclos V 1-1-8-1-1, que procura uma solução de 4a ordem. Nesta fase, a condição de fronteira Dirichlet na entrada do canal está sendo, pela primeira vez, considerada com precisão de 4a ordem. Isto implica uma diferença que deve ser transportada pelo escoamento até a saída do canal e, na opinião do autor do presente trabalho, seria um dos fatores da demora na convergência residual. 


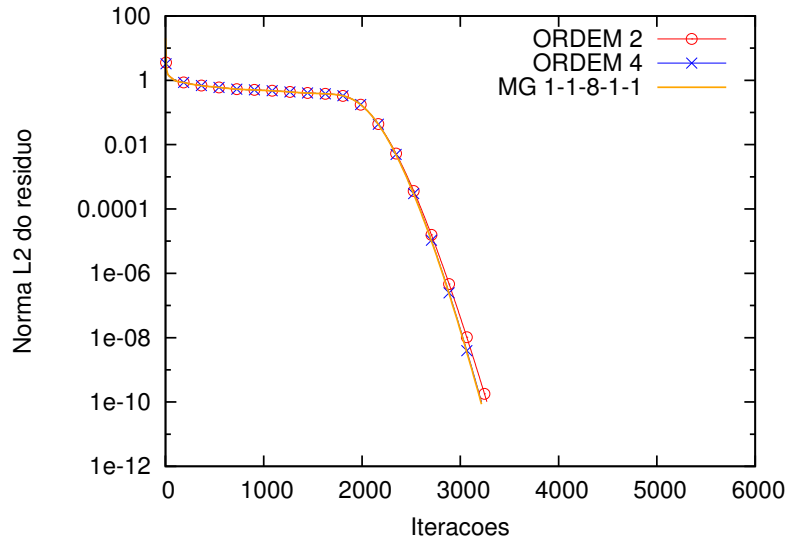

(a)

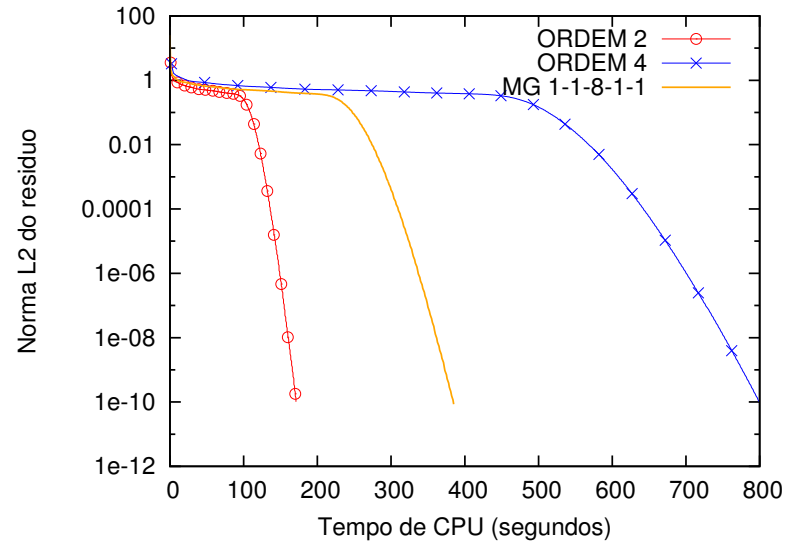

(b)

Figura 5.3: Comparação do esquema p-multigrid MG 1-1-8-1-1 com duas ordens do método VF, utilizando a Malha 6 (8079 VC), no caso advecção-difusão no canal retangular.

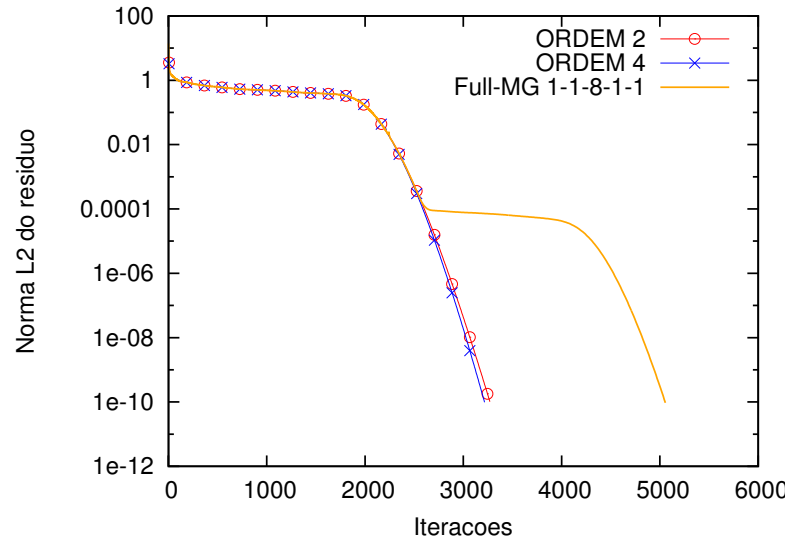

(a)

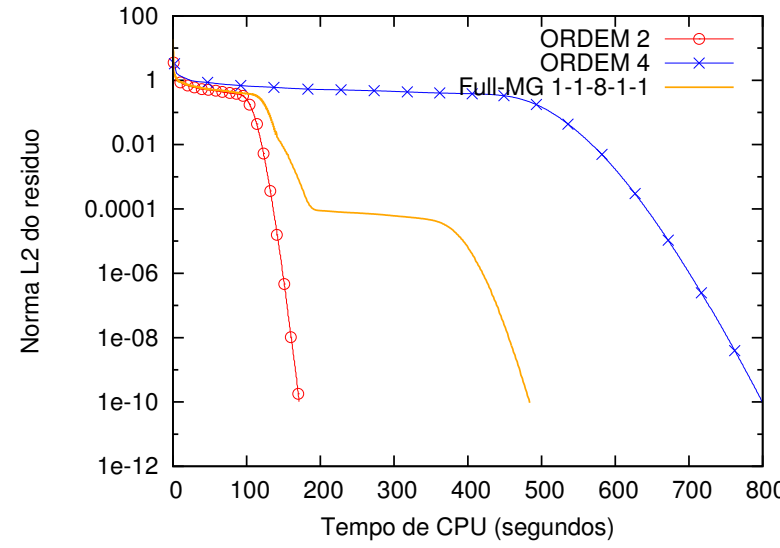

(b)

Figura 5.4: Comparação do esquema p-multigrid Full-MG 1-1-8-1-1 com duas ordens do método VF, utilizando a Malha 6 (8079 VC), no caso advecção-difusão no canal retangular. 


\subsection{Advecção-difusão no segmento anular}

Os dados da física deste problema e as malhas computacionais estão descritos na Seção 2.6.3. Os seis esquemas p-multigrid descritos na Tabela 5.1 são considerados na resolução deste problema. Para uma comparação justa com o método VF de 4a ordem, é utilizado o número CFL da Seção 2.6.3 $(\mathrm{CFL}=1,0)$.

As Tabelas 5.4 e 5.5 mostram os resultados das combinações Malha-p-Multigrid, assim como os resultados com 4 a ordem ${ }^{3}$. A performance dos esquemas p-multigrid é análoga à apresentada no caso do canal retangular (Seção 5.1): dada uma malha, não há variação entre as soluções obtidas pelos esquemas p-multigrid e pela 4a ordem (vide Figura 5.5(a)); há sim um ganho nos tempos de CPU (Figura 5.5(b)), o tempo associado ao esquema MG 1-1-8-1-1 oscila entre $47 \%$ e $48 \%$ do tempo de 4 a ordem ${ }^{4}$, e o esquema Full-MG 1-1-8-1-1 resulta em tempos relativos de $48 \%$ até $51 \%$.

As diferenças entre os esquemas MG e Full-MG, observadas no caso do canal retangular, também aparecem neste caso. Primeiro, o número de iterações associados aos esquemas MG 1-1-2-1-1, MG 1-1-4-1-1 e MG 1-1-8-1-1 é aproximadamente igual ao número de iterações da 4a ordem; ora, os esquemas full multigrid necessitam, aproximadamente, $40 \%$ mais iterações do que a 4a ordem precisa (vide Figura 5.6). Segundo, o esquema MG 1-1-8-1-1 consegue diminuir o resíduo por cada iteração, da mesma maneira que o método VF de 2a e 4a ordem (Figura 5.7); já o esquema Full-MG 1-1-8-1-1 reduz esta taxa de convergência quando o resíduo alcança uma norma $L_{2}$ de 0,0001 (Figura 5.8). Esta desaceleração seria motivada pela mesma razão mencionada no caso do canal retangular: nesta fase do processo iterativo, a condição de Dirichlet na entrada do domínio está sendo, pela primeira vez, considerada com precisão de 4a ordem; isto implica uma diferença que influi no resíduo até que ela saia do domínio, transportada pelo escoamento.

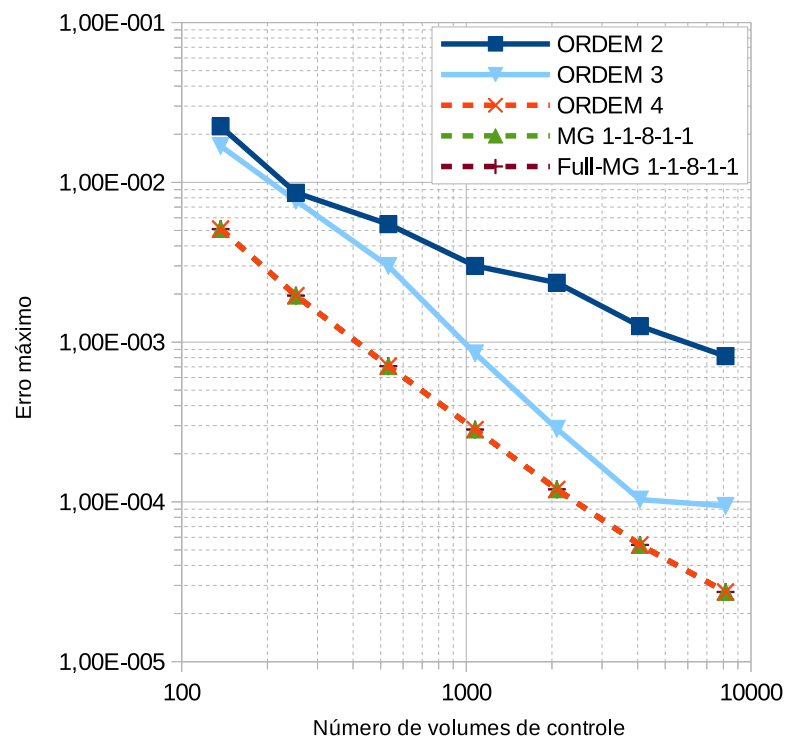

(a)

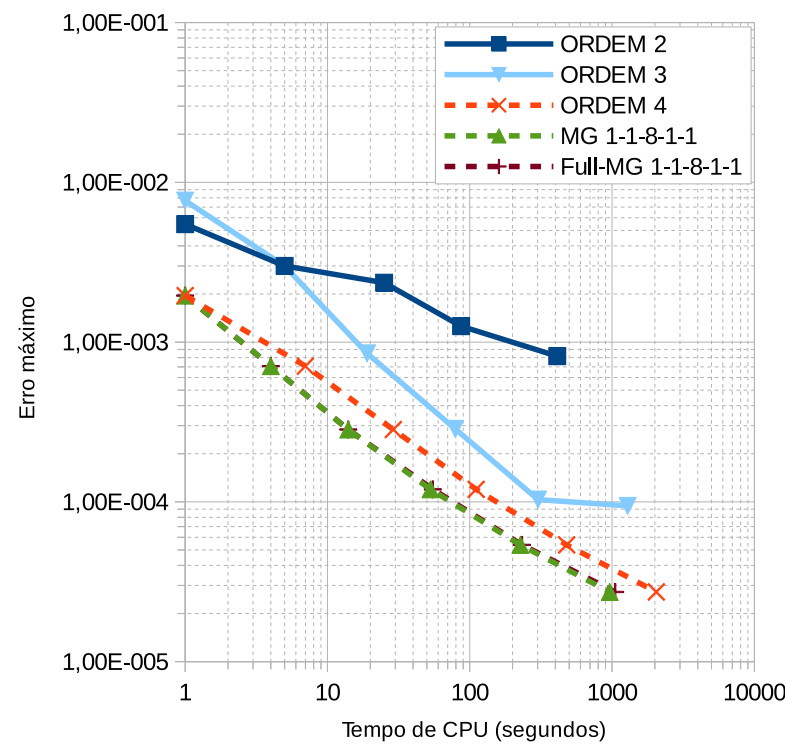

(b)

Figura 5.5: Erro máximo versus Número de VC e Tempo de CPU, no caso advecção-difusão no segmento anular. As combinações com a Malha 1 e a combinação 2 a Ordem-Malha 2 levam um tempo de CPU menor a 1 s e não são mostrados em (b).

\footnotetext{
${ }^{3}$ São os resultados obtidos pelo método de VF de 4a ordem com avanço RK (Seção 2.6.3).

${ }^{4}$ Vide nota de rodapé 2 deste capítulo. A faixa de tempos de CPU (\%) mencionada aqui não considera os resultados com as Malhas 1,2 e 3 .
} 


\begin{tabular}{|c|c|c|c|c|c|}
\hline & 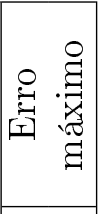 & 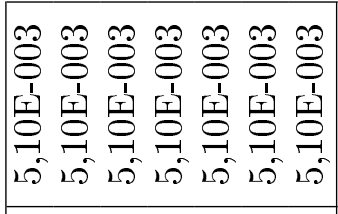 & 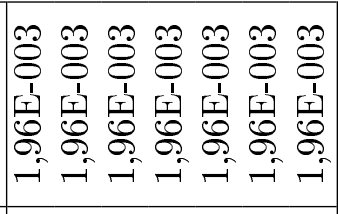 & 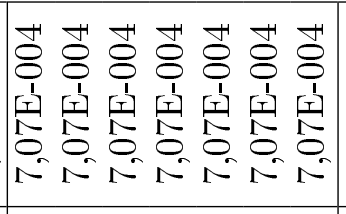 & 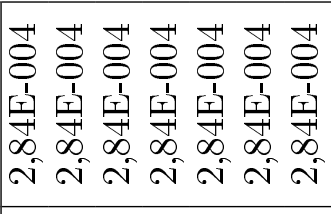 \\
\hline & 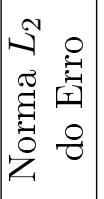 & 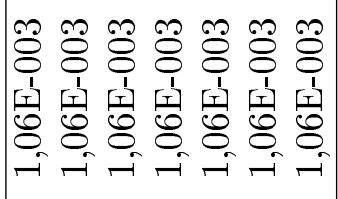 & 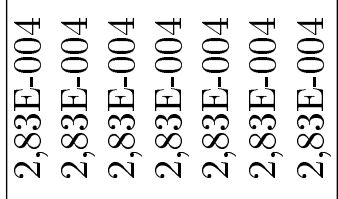 & 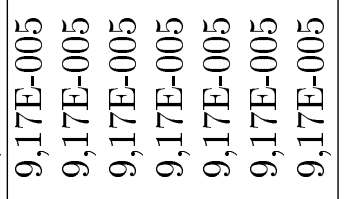 & 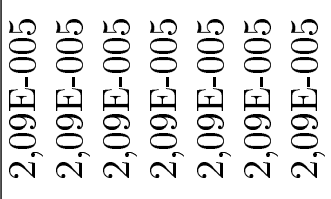 \\
\hline & 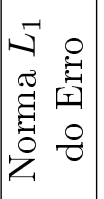 & 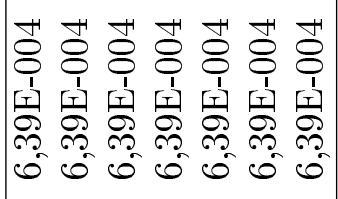 & 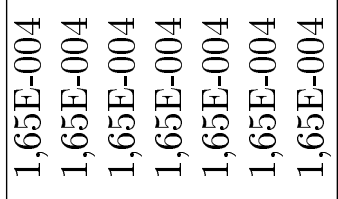 & 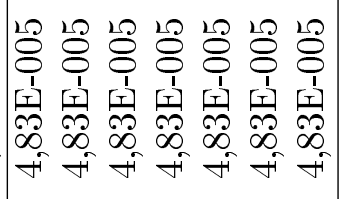 & 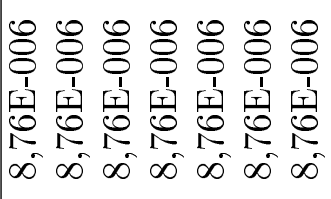 \\
\hline & 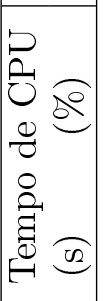 & 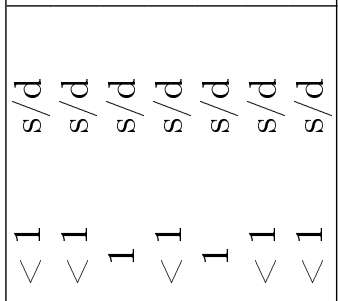 & 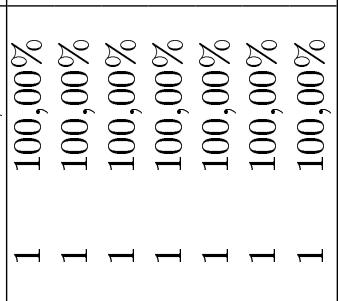 & 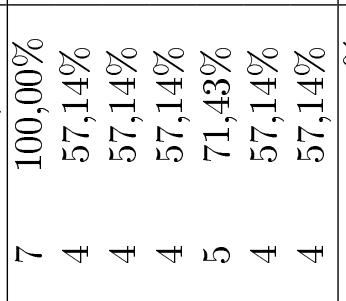 & 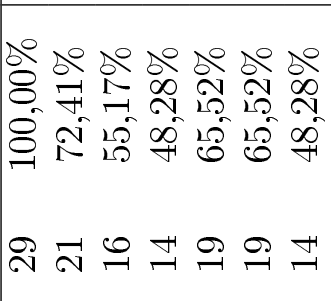 \\
\hline & 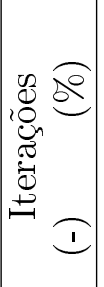 & 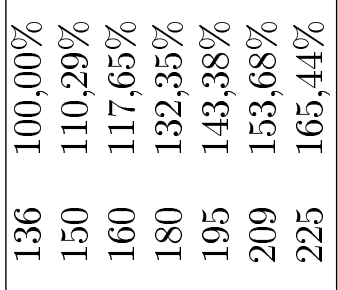 & 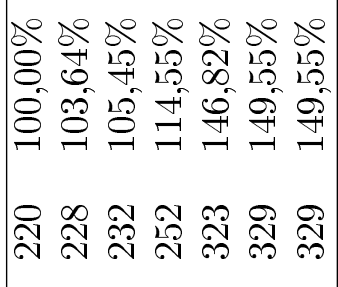 & 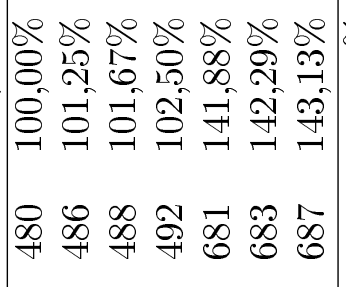 & 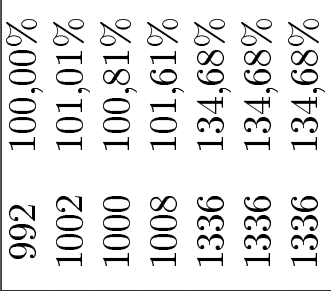 \\
\hline & 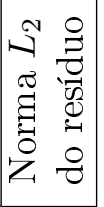 & 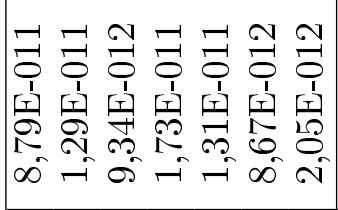 & 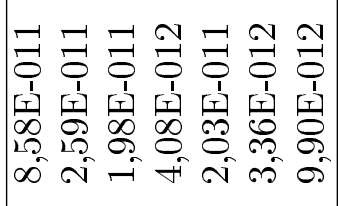 & 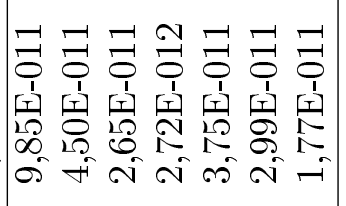 & 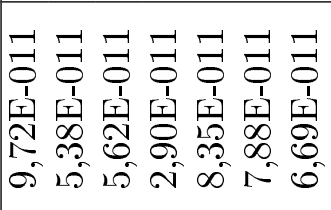 \\
\hline 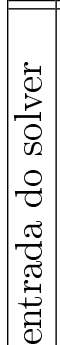 & . & 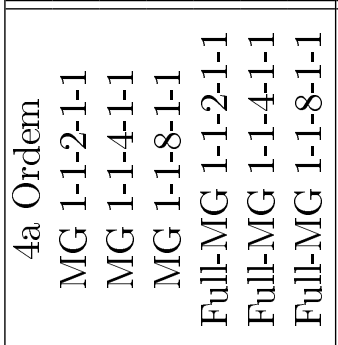 & 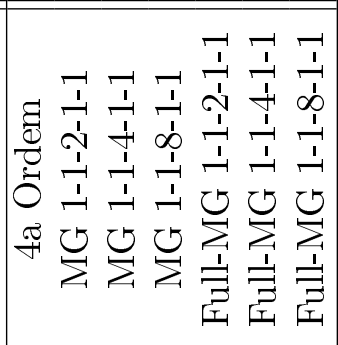 & 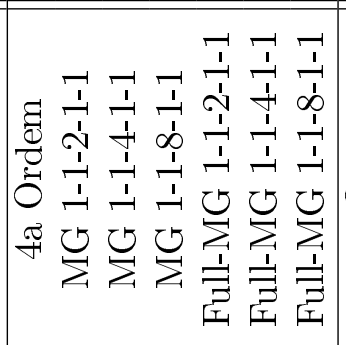 & 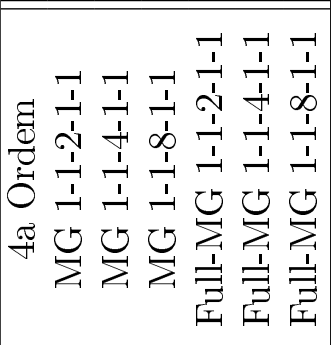 \\
\hline$\underset{\nabla}{ }$ & 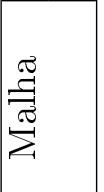 & 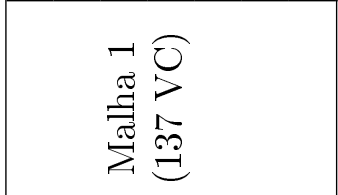 & 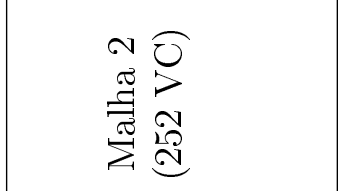 & 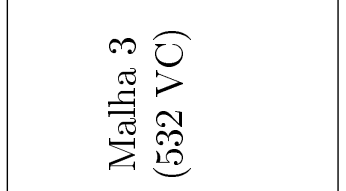 & 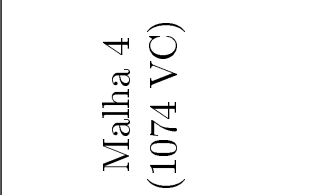 \\
\hline
\end{tabular}




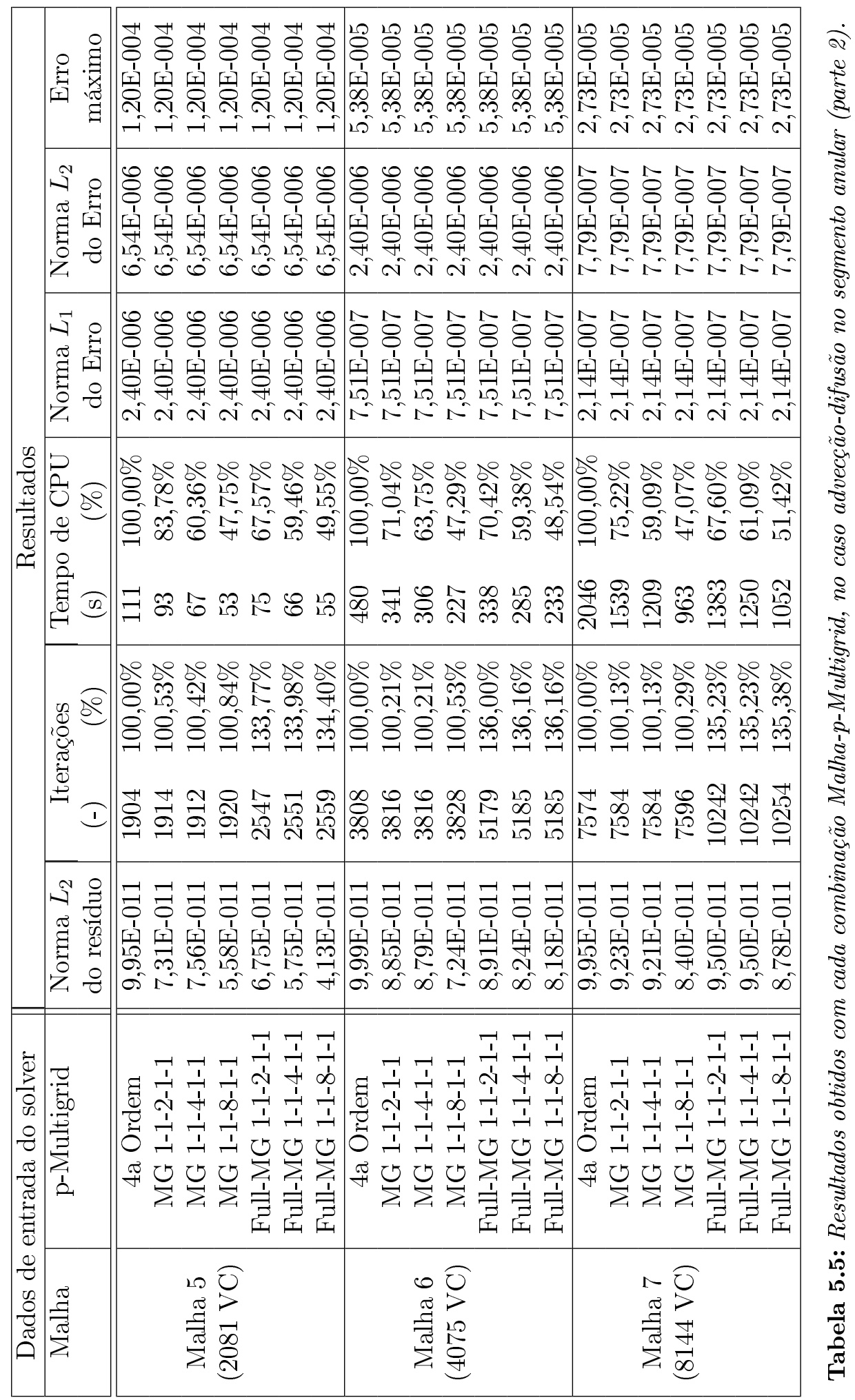




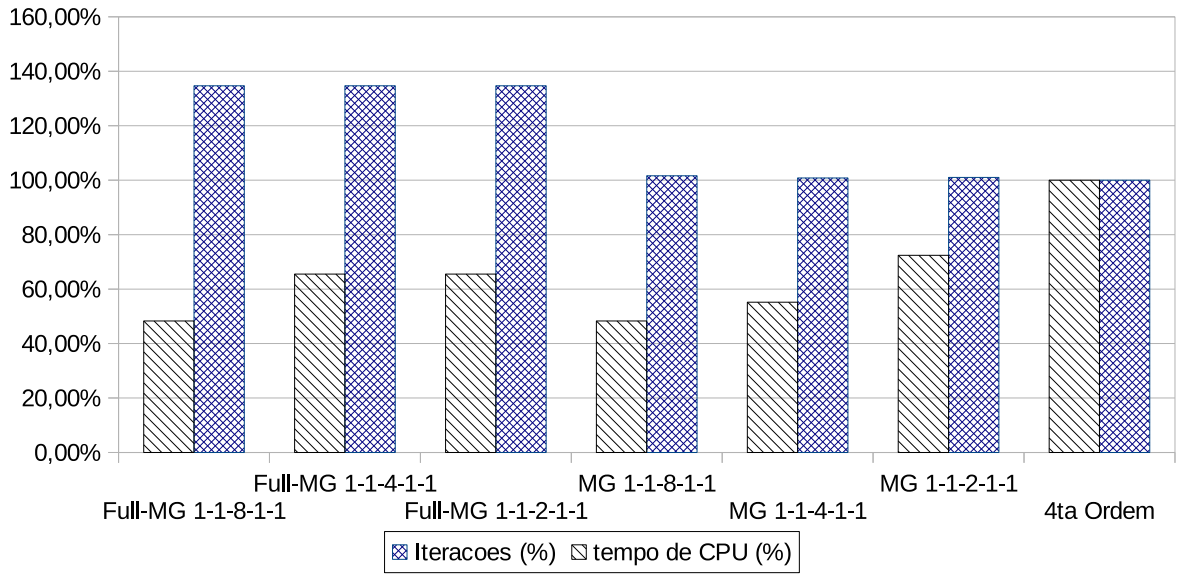

(a) Malha $4(1074 \mathrm{VC})$.

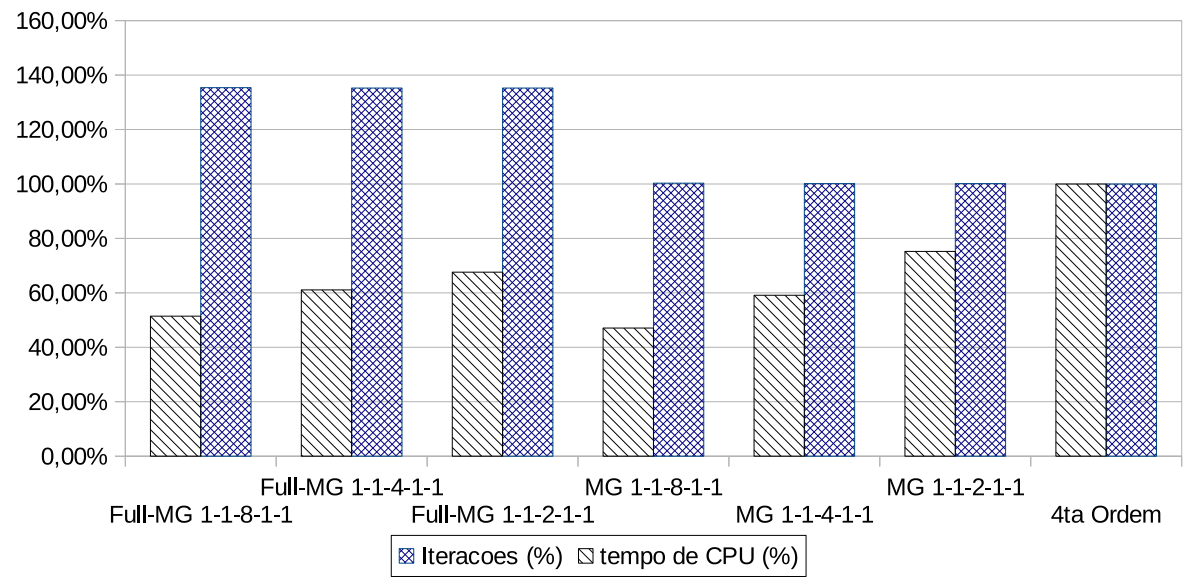

(b) Malha 7 (8144 VC).

Figura 5.6: Número de Iterações (\%) e Tempo de CPU (\%) consumido nos testes com p-multigrid, no caso advecção-difusão no segmento anular. 


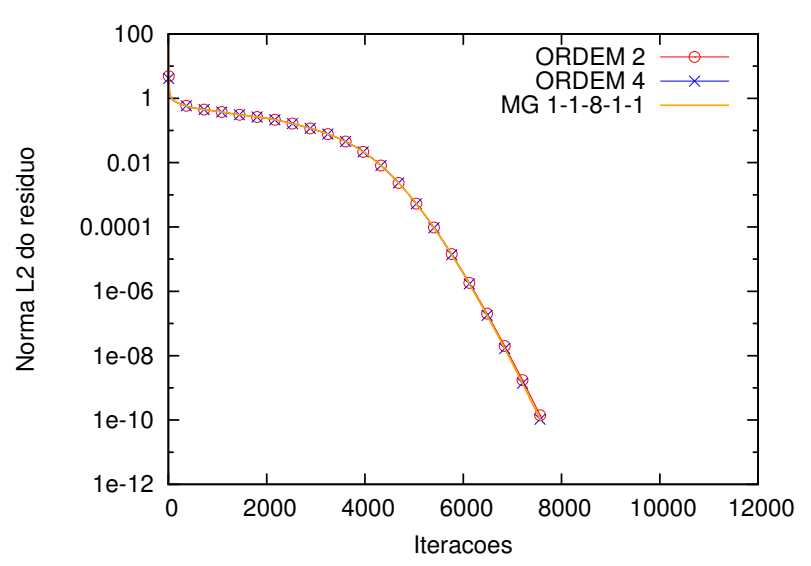

(a)

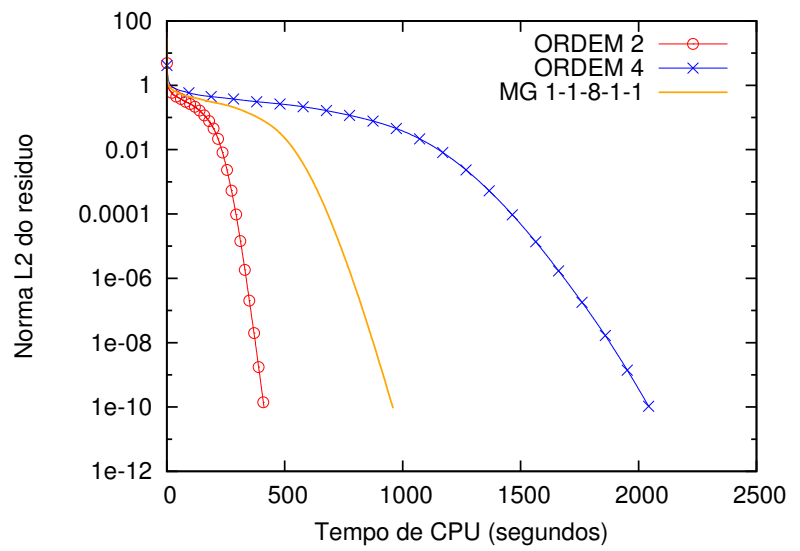

(b)

Figura 5.7: Comparação do esquema p-multigrid MG 1-1-8-1-1 com duas ordens do método VF, utilizando a Malha 7 (8144 VC), no caso advecção-difusão no segmento anular.

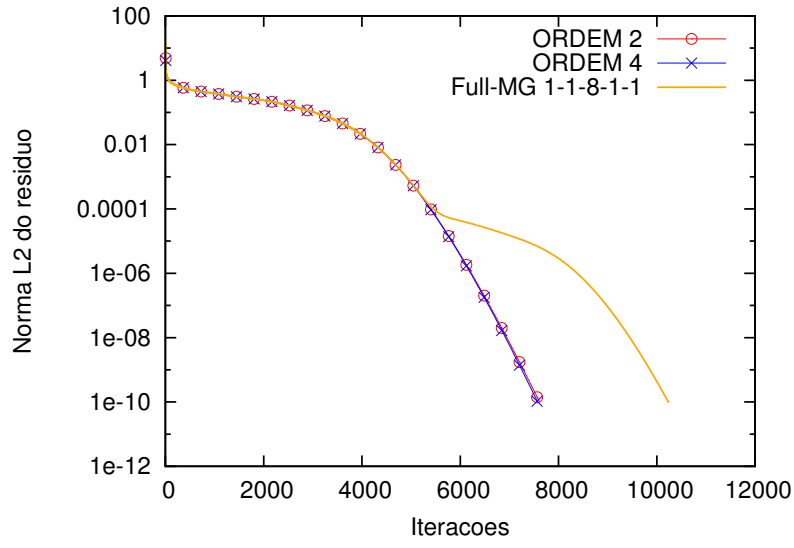

(a)

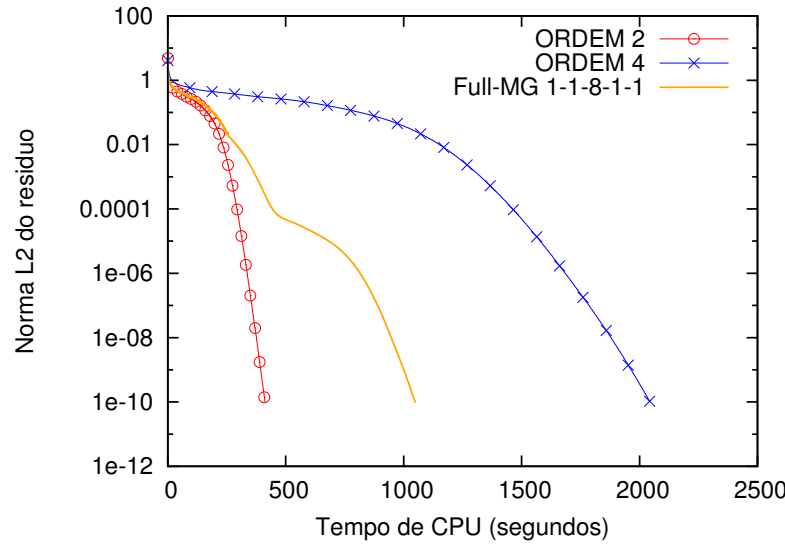

(b)

Figura 5.8: Comparação do esquema p-multigrid Full-MG 1-1-8-1-1 com duas ordens do método VF, utilizando a Malha 7 (8144 VC), no caso advecção-difusão no segmento anular. 


\subsection{NACA 0012 Subsônico, $M_{\infty}=0,4, \alpha=0^{\circ}$}

Os dados deste problema, como as condições de corrente livre e as malhas computacionais, estão descritos na Seção 3.8.1. Liang et al. (2009b) e Premasuthan et al. (2009) simulam este caso subsônico utilizando esquemas full multigrid; e no presente trabalho também consideram-se esse tipo de esquemas. A Tabela 5.6 apresenta o acrônimo e a definição de cada esquema full multigrid utilizado neste caso subsônico. O processo iterativo começa com 2 a ordem até que a norma $L_{2}$ do resíduo seja $2 \times 10^{-2}$; logo o processo continua com Vciclos 1-2-2 (o3-o2-o3) até que o resíduo seja $5 \times 10^{-3}$; e depois o processo continua com os Vciclos de 3 níveis indicados.

\begin{tabular}{ll}
\hline Acrônimo & Definição \\
\hline $1-1-2-1-1$ & 2a ordem + Vciclos 1-2-2 (o3-o2-o3) + Vciclos 1-1-2-1-1 (o4-o3-o2-o3-o4) \\
$1-1-4-1-1$ & 2a ordem + Vciclos 1-2-2 (o3-o2-o3) + Vciclos 1-1-4-1-1 (o4-o3-o2-o3-o4) \\
$1-1-6-1-1$ & 2a ordem + Vciclos 1-2-2 (o3-o2-o3) + Vciclos 1-1-6-1-1 (o4-o3-o2-o3-o4) \\
$1-1-8-1-1$ & 2a ordem + Vciclos 1-2-2 (o3-o2-o3) + Vciclos 1-1-8-1-1 (o4-o3-o2-o3-o4) \\
\hline
\end{tabular}

Tabela 5.6: Acrônimos dos esquemas p-multigrid utilizados no caso subsônico e $\alpha=0^{\circ}$.

Considera-se um único número $\mathrm{CFL}$ ao longo do processo iterativo: $\mathrm{CFL}=2,5$; este valor é igual ao CFL máximo para o método VF de 4a ordem (Seção 3.8.1).

A Tabela 5.7 mostra os resultados das combinações Malha-p-Multigrid, assim como os resultados com 4a ordem ${ }^{5}$. Das colunas " $C_{l}$ " e " $C_{d}$ " verifica-se que, dada uma malha, não há variação entre as soluções obtidas pelos esquemas p-multigrid e pela 4a ordem; ou seja, ambos os métodos oferecem a mesma precisão (Figuras 5.9(a) e 5.9(c)). As Figuras 5.9(b) e 5.9(d) ilustram o bom desempenho de dois esquemas p-multigrid: 1-1-4-1-1 e 1-1-8-1-1. Este último é o mais eficiente: o tempo de CPU associado a esse esquema oscila entre $24 \%$ e $32 \%$ do tempo requerido pela 4 a ordem (vide coluna "Tempo de CPU" da Tabela 5.7). Fazendo apenas uma simples comparação, vale ressaltar que, no contexto do método de Diferença Espectral, Liang et al. (2009b) conseguem um tempo de CPU (\%) de $13 \%$ aproximadamente, utilizando um outro smoother explícito; no presente trabalho, ainda é possível aprimorar os esquemas apresentados.

A coluna "Iterações" da Tabela 5.7 mostra que, em contraste com o caso de advecção-difusão, os esquemas p-multigrid sim conseguem diminuir o número de iterações do processo iterativo que resulta com 4a ordem. O esquema 1-1-8-1-1 apresenta as maiores vantagens: o número de iterações associado a esse esquema oscila entre $56 \%$ e $68 \%$ do número de iterações da 4a ordem. A Figura 5.10 é plotada a partir das colunas "Iterações (\%)" e "Tempo de CPU (\%)" da Tabela 5.7. Ela ilustra a redução do número de iterações (e do tempo de CPU) para todos os esquemas p-multigrid considerados neste trabalho; isto indica que tais esquemas são, de fato, p-multigrid: o nível polinomial de baixa-ordem amortece rapidamente os erros de alta frequência.

A Figura 5.11 mostra a história da convergência residual em termos do número de iterações e do tempo de CPU associada ao esquema 1-1-8-1-1 e a duas ordens do método VF ${ }^{6}$. As características do esquema full multigrid são evidentes: ele começa no nível de 2a ordem e, após umas 2400 iterações, utilizam-se Vciclos 1-2-2 para procurar uma solução de 3a ordem; isto resulta num salto do resíduo, de $2 \times 10^{-2}$ para 10. Um salto similar acontece ao trocar para Vciclos 1-1-8-1-1. Vale destacar que esta figura corresponde à Malha 1 e que, utilizando esta grade, a convergência é atingida com $56 \%$ do número de iterações da 4 a ordem, e num tempo de CPU de $24 \%$ do tempo da 4 a ordem. A Figura 5.12 é análoga mas corresponde à Malha 3 (mais fina). O desempenho do esquema 1-1-8-1-1 cai levemente: as porcentagens anteriores mudam para $68 \%$ (número de iterações) e $32 \%$ (tempo de CPU).

\footnotetext{
${ }^{5}$ Os resultados da 4a ordem correspondem aos apresentados na Seção 3.8.1, com o CFL máximo $(\mathrm{CFL}=2,5)$ do avanço RK.

${ }^{6}$ Os resultados da 2a ordem correspondem aos apresentados na Seção 3.8.1, com o CFL máximo $(\mathrm{CFL}=3,0)$ do avanço RK.
} 


\begin{tabular}{|c|c|c|c|c|}
\hline & 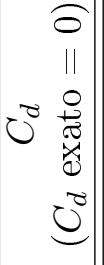 & 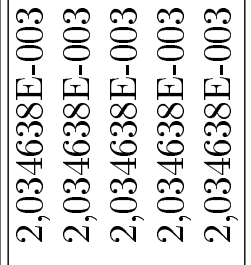 & 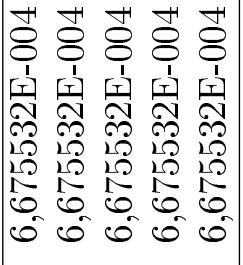 & 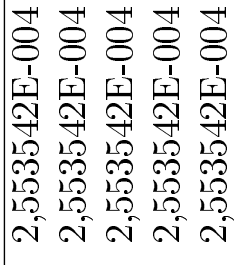 \\
\hline & 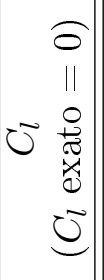 & 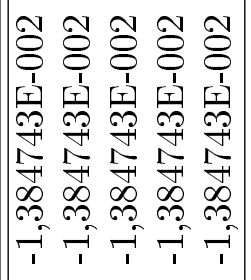 & 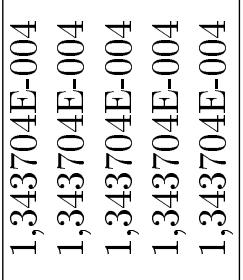 & 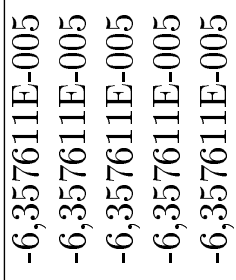 \\
\hline 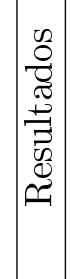 & 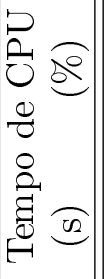 & 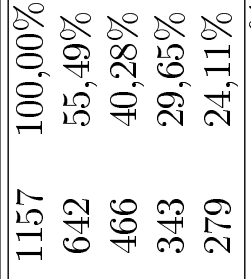 & 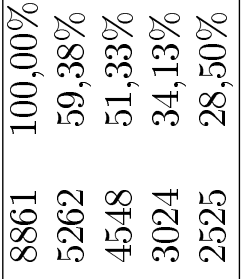 & 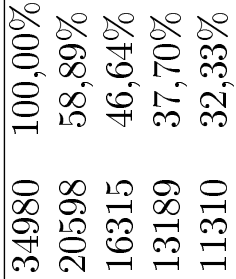 \\
\hline & 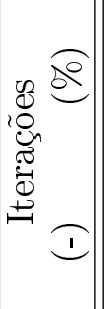 & 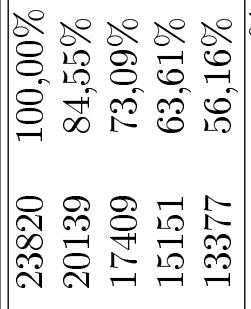 & 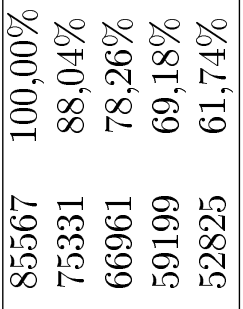 & 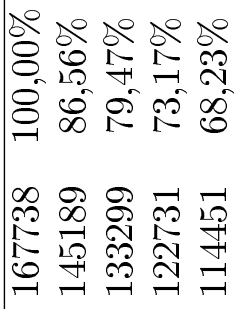 \\
\hline & 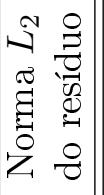 & 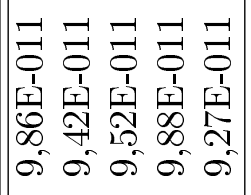 & 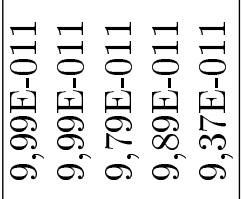 & 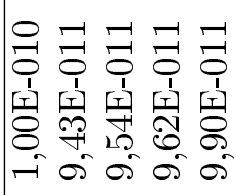 \\
\hline 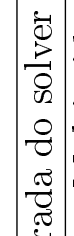 & 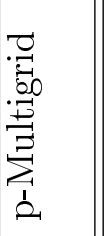 & 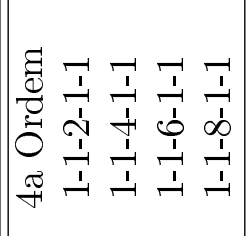 & 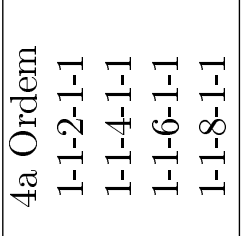 & 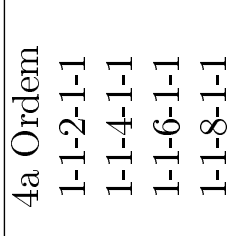 \\
\hline 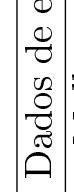 & $\frac{\sqrt[\pi]{\Xi}}{\frac{\pi}{2}}$ & 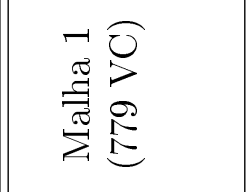 & 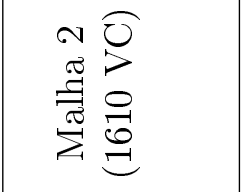 & 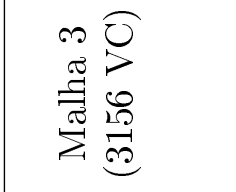 \\
\hline
\end{tabular}




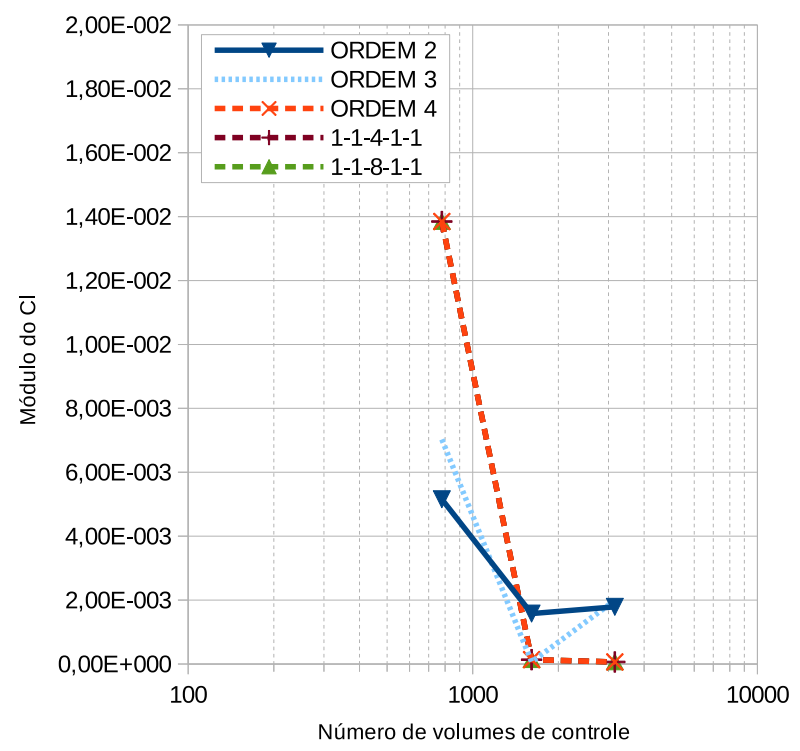

(a)

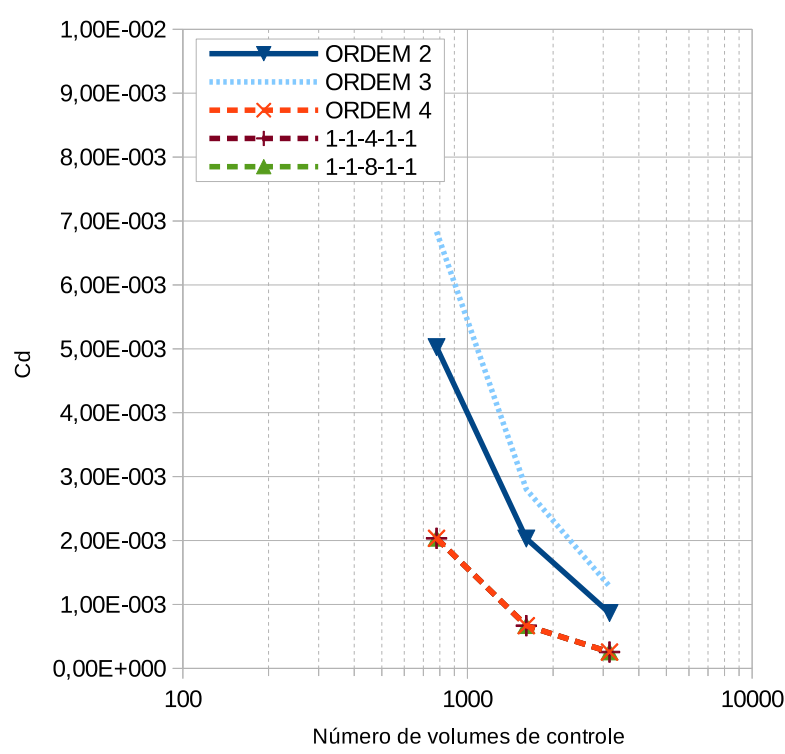

(c)

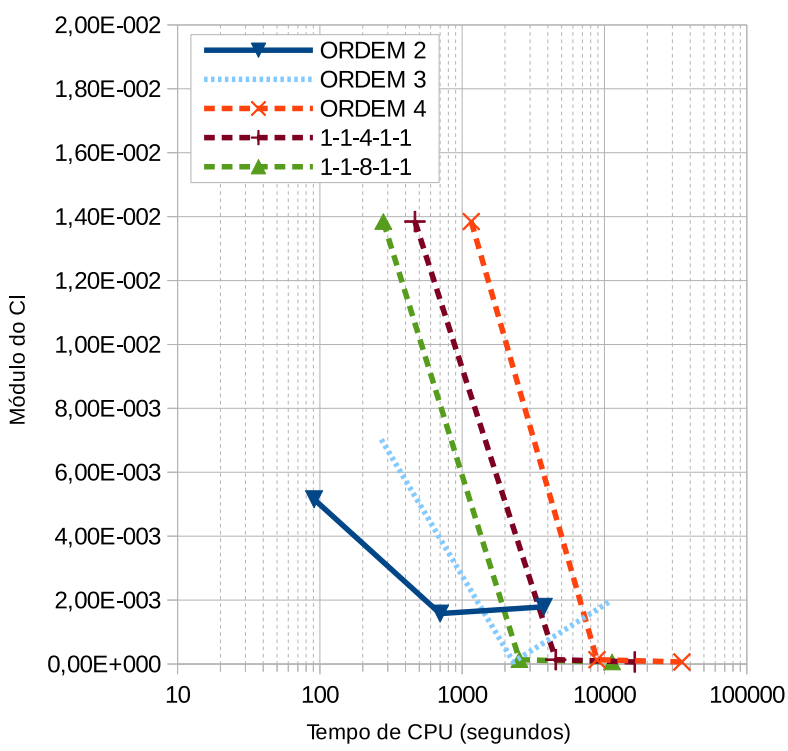

(b)

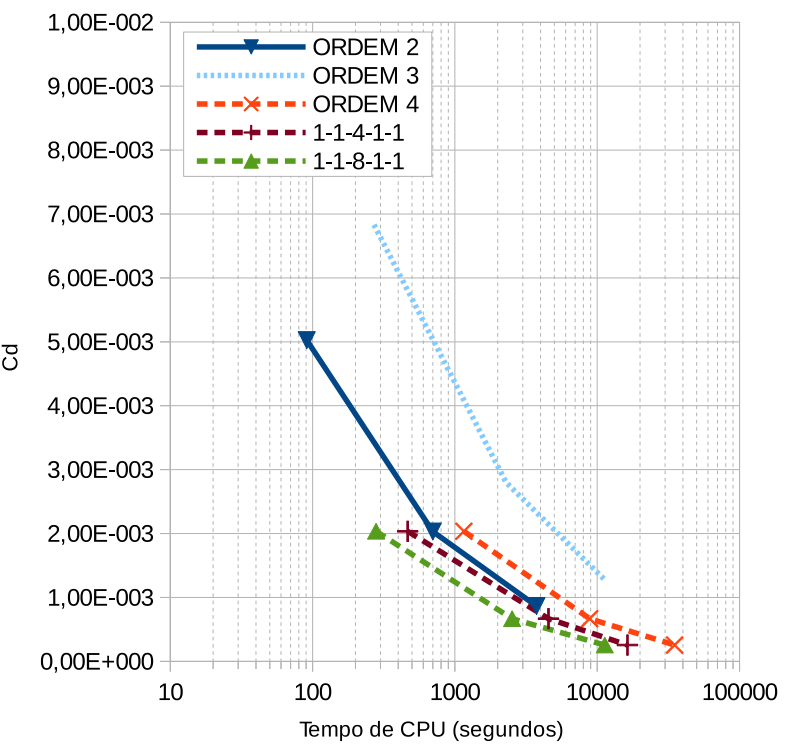

(d)

Figura 5.9: Coeficientes de sustentação $\left(C_{l}\right)$ e de arrasto $\left(C_{d}\right)$, no caso subsônico e $\alpha=0^{\circ}$. 


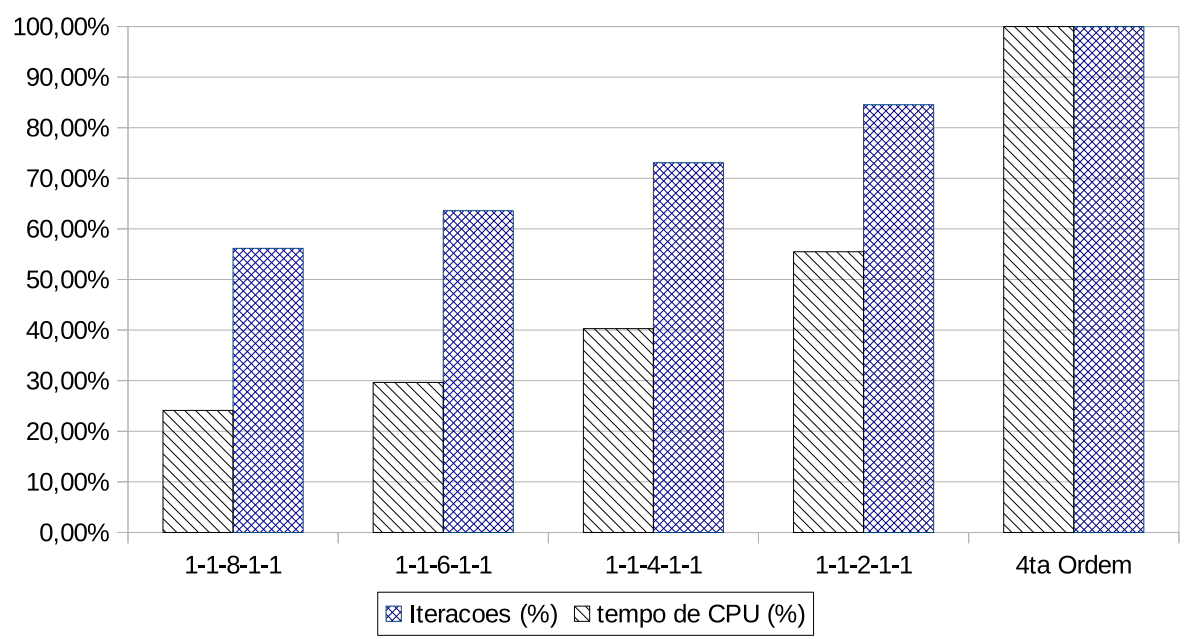

(a) Malha 1 (779 VC).

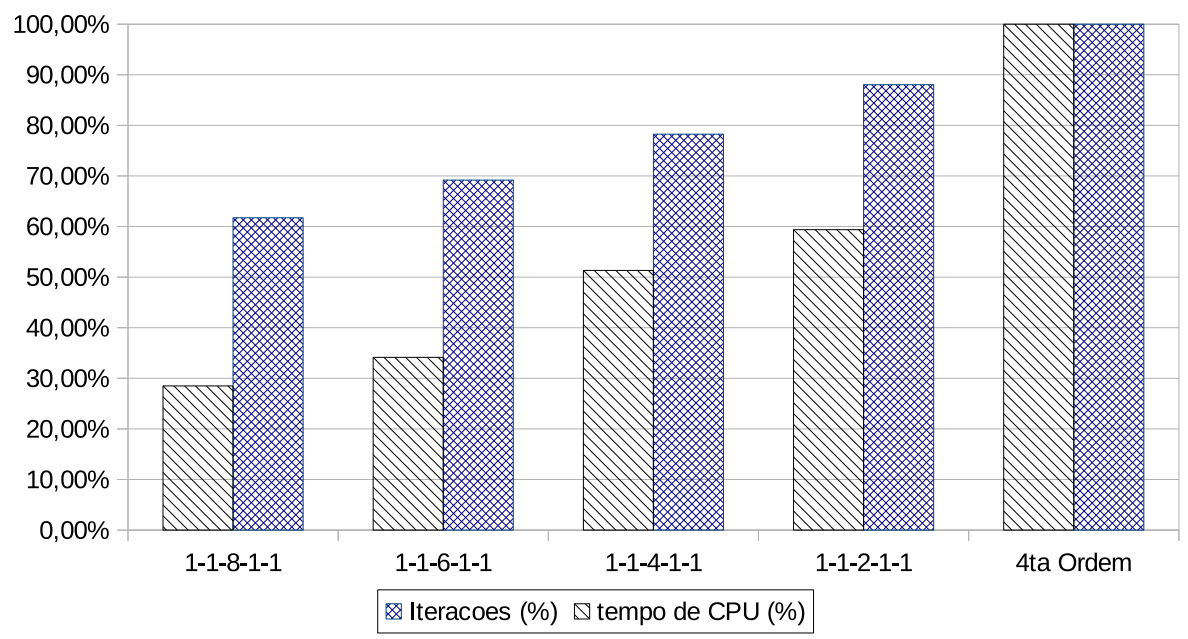

(b) Malha $2(1610 \mathrm{VC})$.

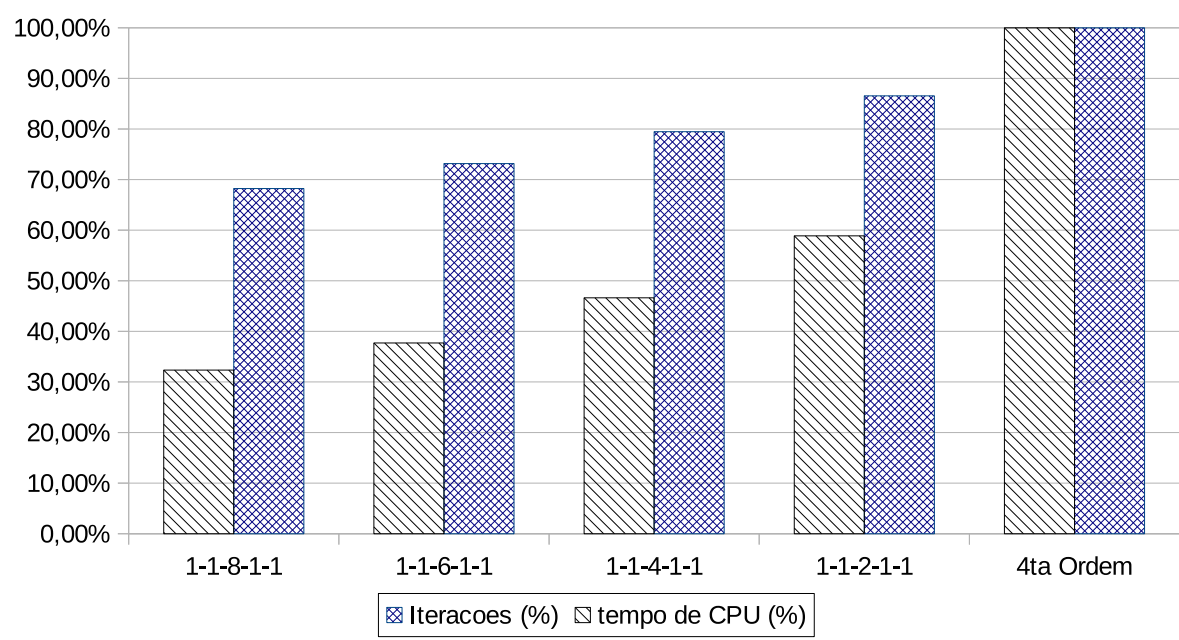

(c) Malha $3(3156 \mathrm{VC})$.

Figura 5.10: Número de Iterações (\%) e Tempo de CPU (\%) consumido nos testes com p-multigrid, no caso subsônico e $\alpha=0^{\circ}$. 


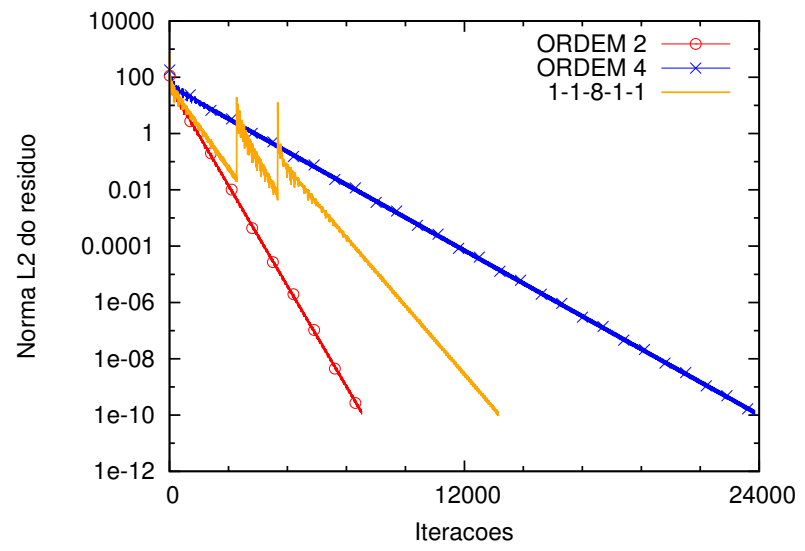

(a)

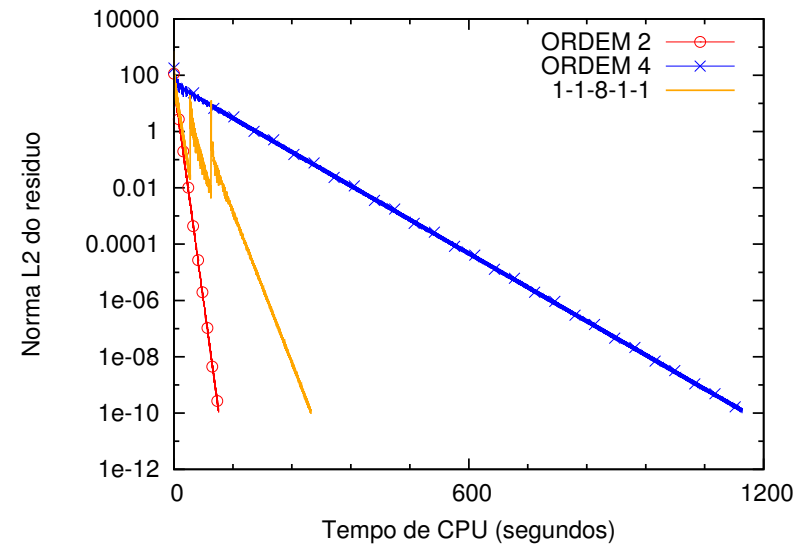

(b)

Figura 5.11: Comparação do esquema p-multigrid 1-1-8-1-1 com duas ordens do método VF, utilizando a Malha 1 (77rg VC), no caso subsônico e $\alpha=0^{\circ}$.

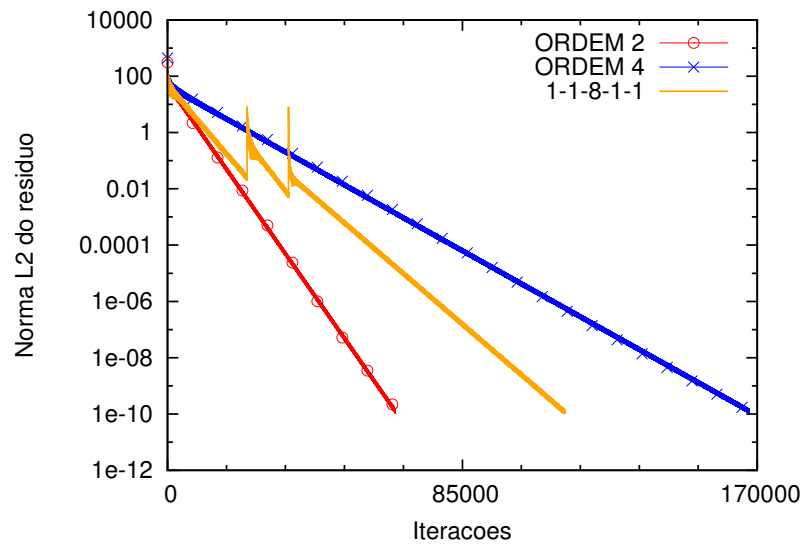

(a)

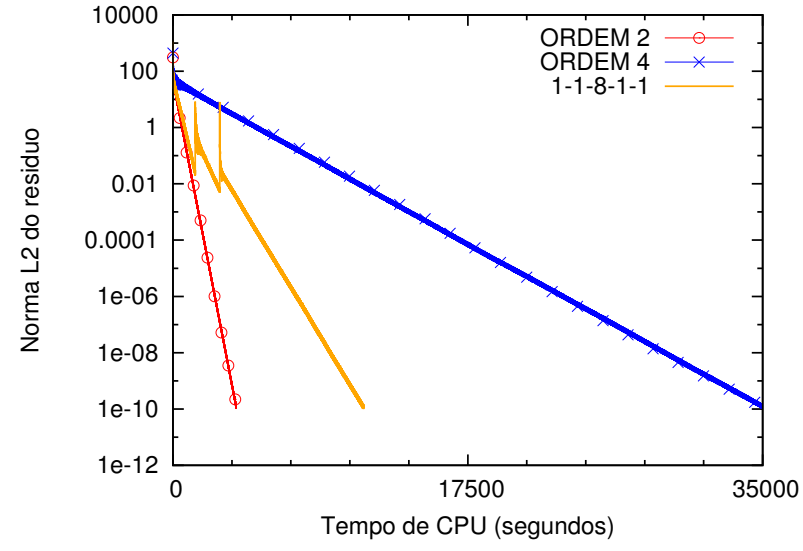

(b)

Figura 5.12: Comparação do esquema p-multigrid 1-1-8-1-1 com duas ordens do método VF, utilizando a Malha 3 (3156 VC), no caso subsônico e $\alpha=0^{\circ}$. 


\subsection{NACA 0012 Subsônico, $M_{\infty}=0,5, \alpha=2^{\circ}$}

As condições de corrente livre deste problema, assim como as malhas computacionais utilizadas, estão descritas na Seção 3.8.2. De maneira análoga ao caso subsônico e $\alpha=0^{\circ}$, são considerados os quatro esquemas full multigrid da Tabela 5.6 e um único CFL ao longo do processo iterativo. Neste caso, o número CFL é 3,5 que é igual ao CFL máximo para o método VF de 4a ordem (Seção 3.8.2).

A Tabela 5.8 mostra os resultados das combinações Malha-p-Multigrid, assim como os resultados com 4 a ordem ${ }^{7}$. Essa tabela e a Figura 5.13 mostram que os esquemas p-multigrid oferecem a mesma precisão que a 4a ordem, num tempo de CPU menor. O tempo de CPU associado ao esquema 1-18-1-1 oscila entre $37 \%$ e $45 \%$ do tempo requerido pela 4a ordem (vide coluna "Tempo de CPU" da Tabela 5.8).

Da Figura 5.14, observa-se que os esquemas p-multigrid, em geral, requerem menos iterações do que a 4 a ordem para chegar na solução estacionária. No entanto, ao comparar esta figura com a Figura 5.10 (do caso subsônico e $\alpha=0^{\circ}$ ), nota-se uma queda no desempenho em termos do número de iterações. A Figura 5.15 mostra a história da convergência residual em termos do número de iterações e do tempo de CPU associada ao esquema 1-1-8-1-1 e a duas ordens do método VF ${ }^{8}$. Esta figura corresponde à Malha 1 e, a Figura 5.16, à Malha 3. É evidente a redução no tempo de CPU, em relação ao método VF de 4a ordem; contudo, a diminuição do número de iterações não é tão intensa (compare-se com o caso subsônico e $\alpha=0^{\circ}$ ). Nesse sentido, um aprimoramento dos esquemas p-multigrid apresentados incluirá, numa futura pesquisa, uma variação do número CFL porque isto permite iterar na região de estabilidade onde os erros de altas frequências sejam eficazmente amortecidos. Nessa pesquisa, também pode ser incluída, se for o caso, uma mudança de smoother.

\footnotetext{
${ }^{7}$ Os resultados da 4a ordem correspondem aos apresentados na Seção 3.8.2, com o CFL máximo $(\mathrm{CFL}=3,5)$ do avanço RK.

${ }^{8}$ Os resultados da 2a ordem correspondem aos apresentados na Seção 3.8.2, com o CFL máximo $(\mathrm{CFL}=4,0)$ do avanço RK.
} 


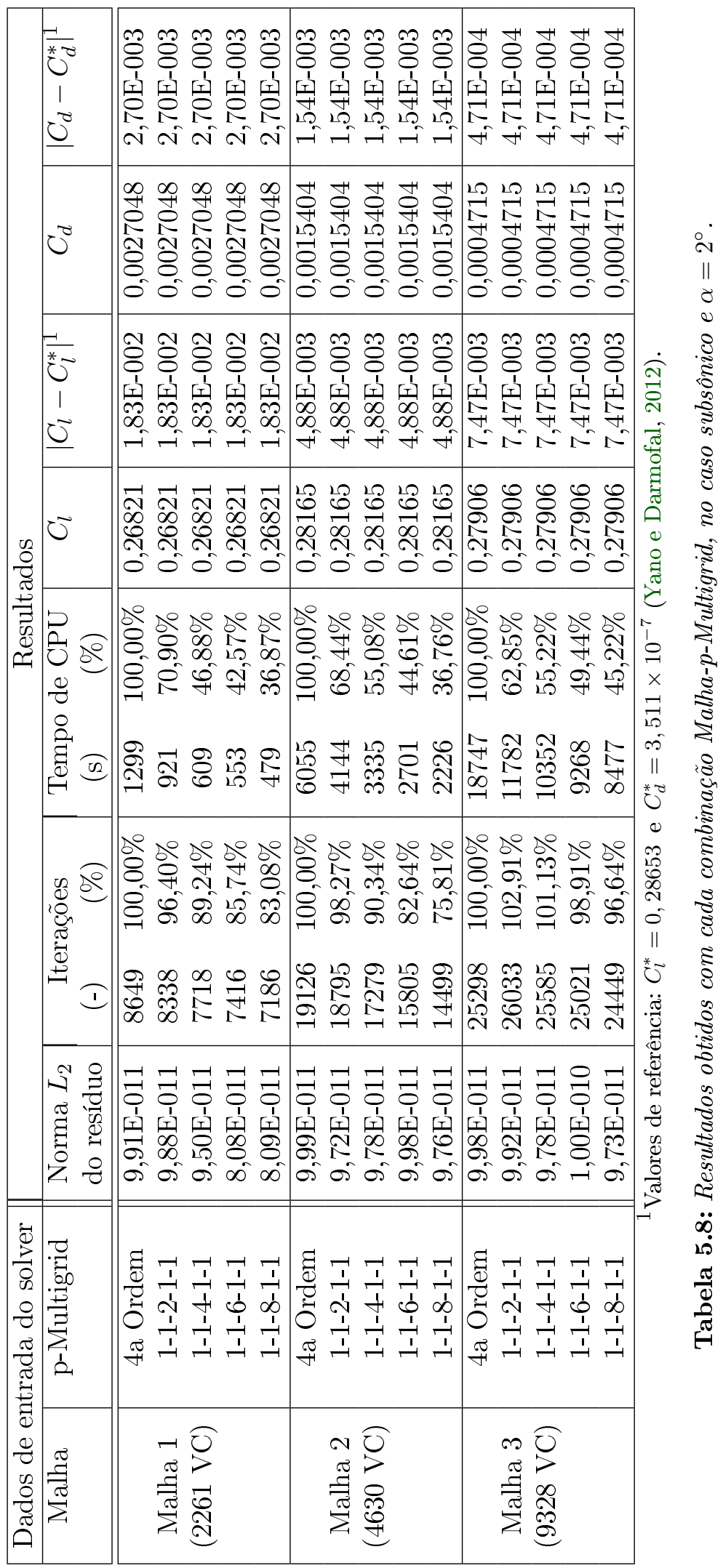




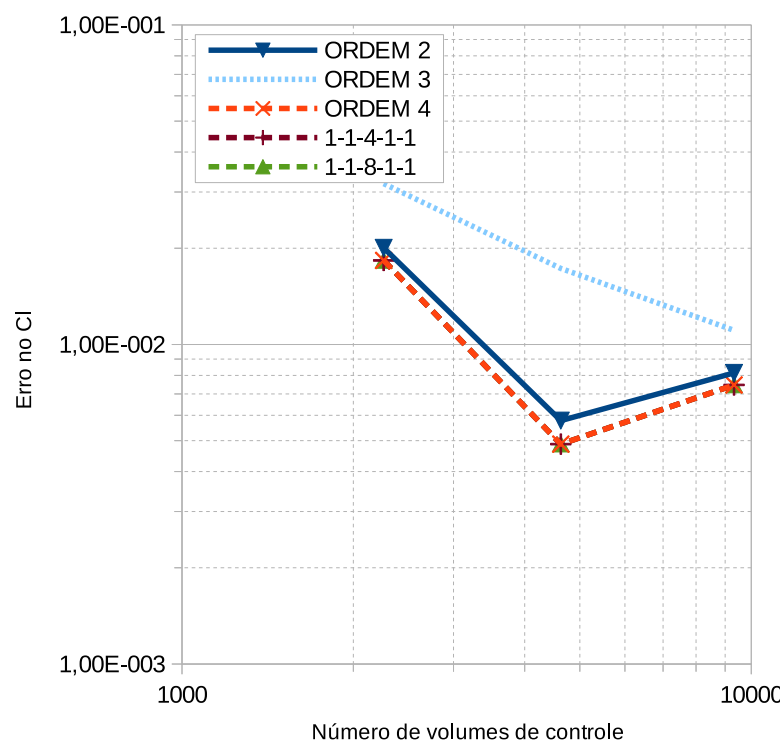

(a)

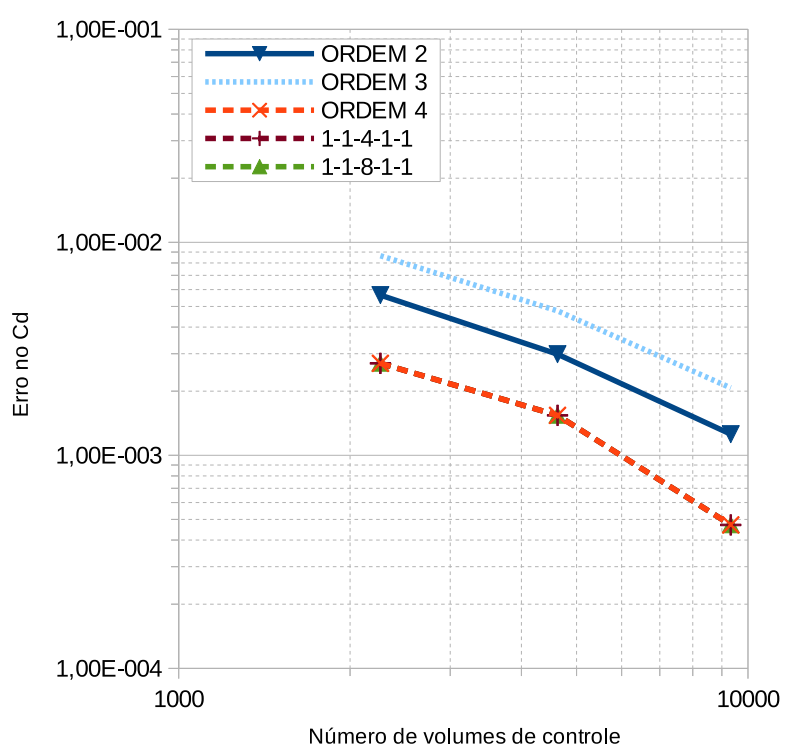

(c)

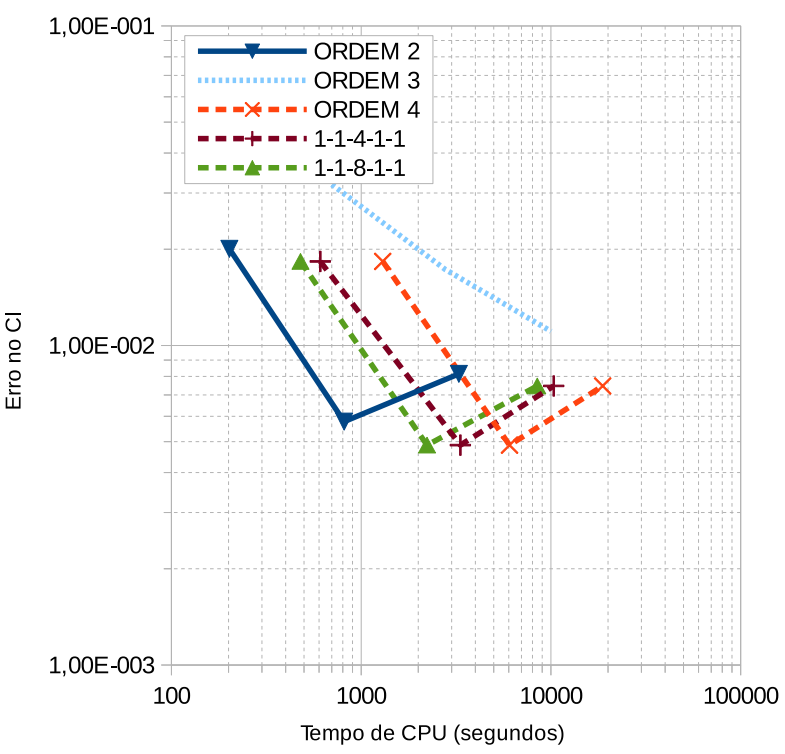

(b)

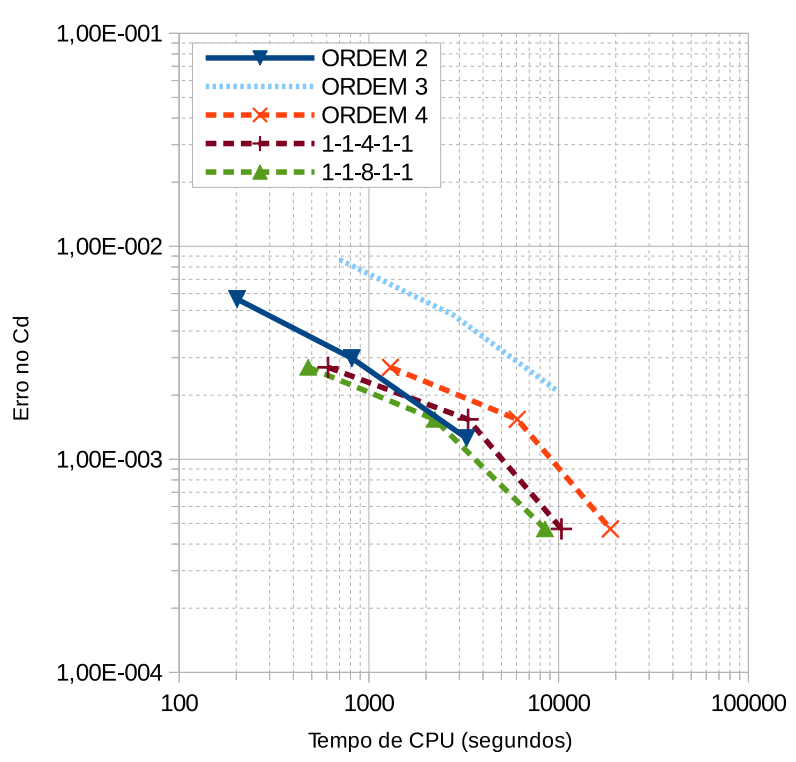

(d)

Figura 5.13: Erros nos coeficientes de sustentação $\left(C_{l}\right)$ e de arrasto $\left(C_{d}\right)$, no caso subsônico e $\alpha=2^{\circ}$. 


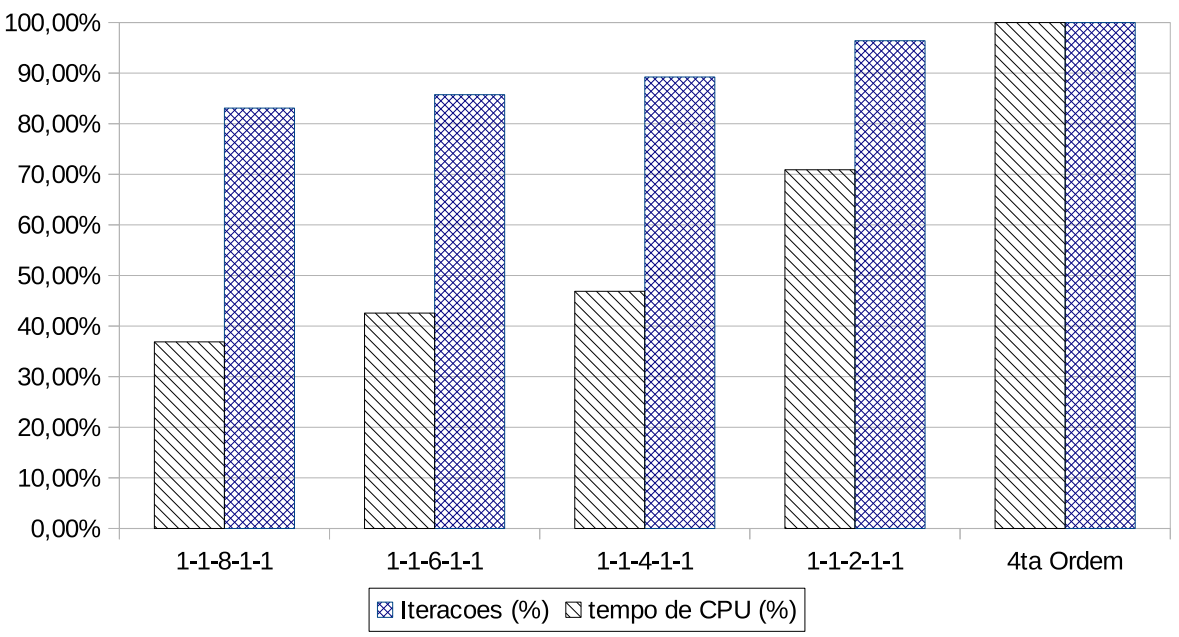

(a) Malha 1 (2261 VC).

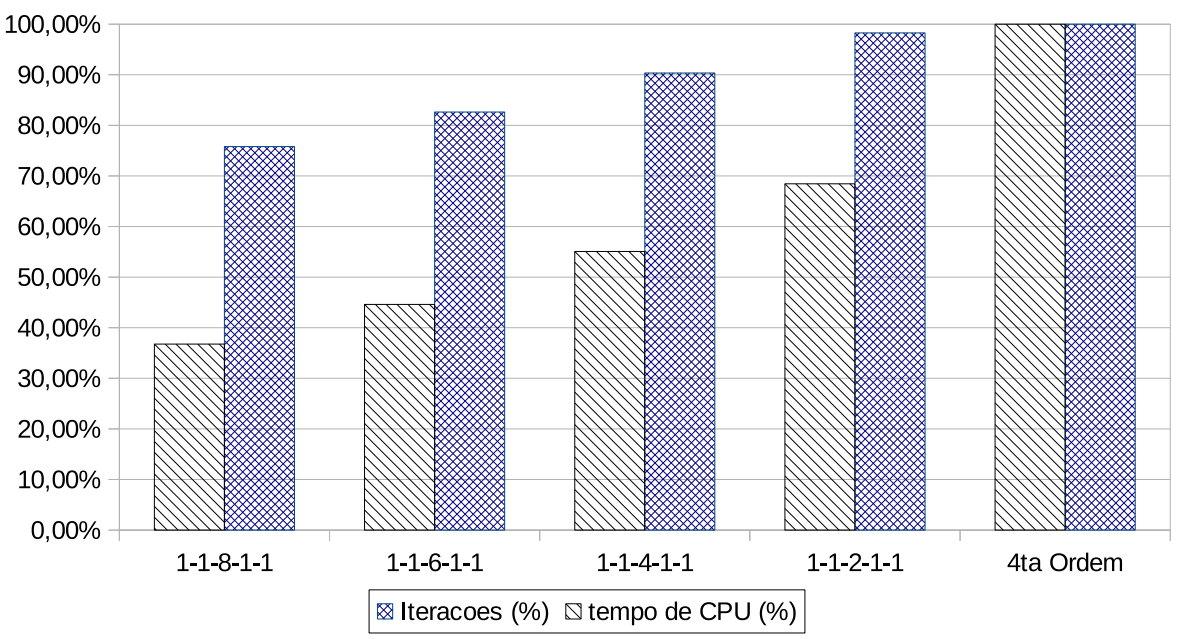

(b) Malha 2 (4630 VC).

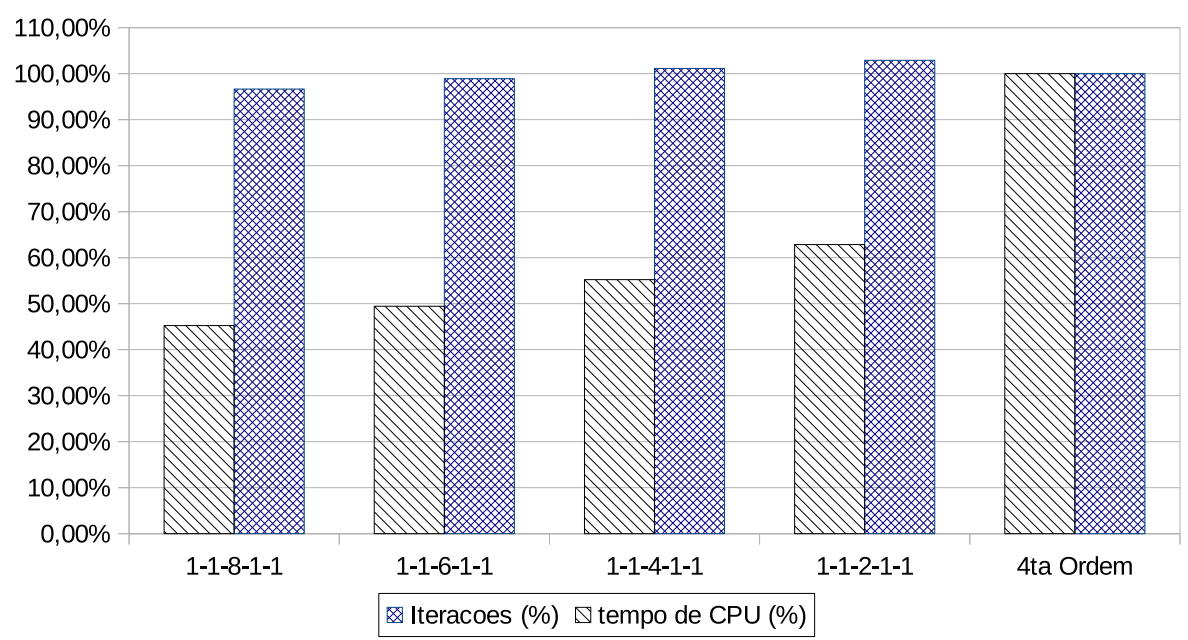

(c) Malha 3 (9328 VC).

Figura 5.14: Número de Iterações (\%) e Tempo de CPU (\%) consumido nos testes com p-multigrid, no caso subsônico e $\alpha=2^{\circ}$. 


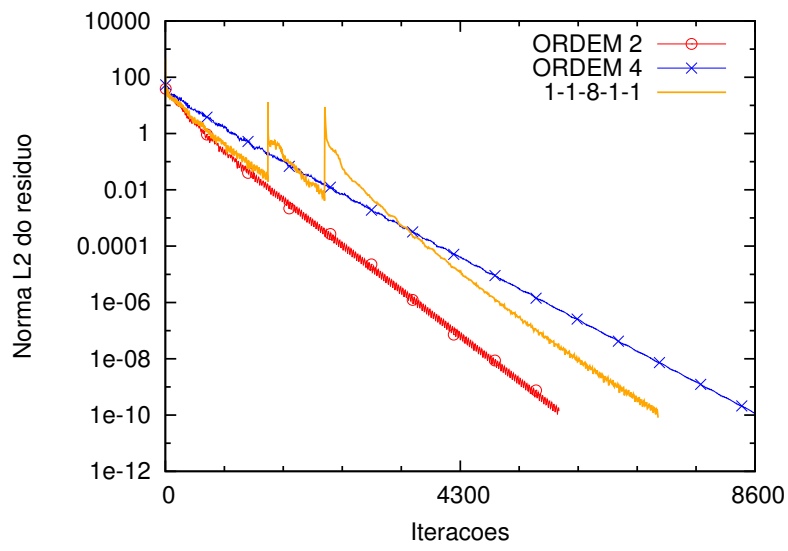

(a)

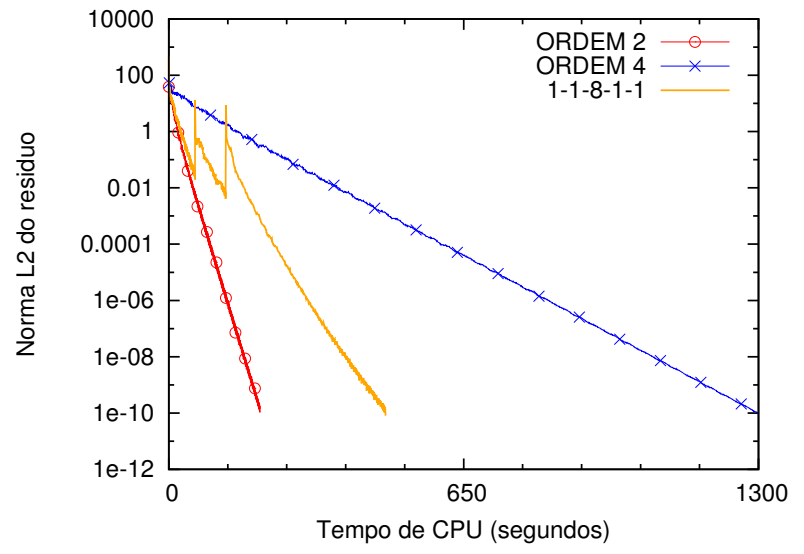

(b)

Figura 5.15: Comparação do esquema p-multigrid 1-1-8-1-1 com duas ordens do método VF, utilizando a Malha 1 (2261 VC), no caso subsônico e $\alpha=2^{\circ}$.

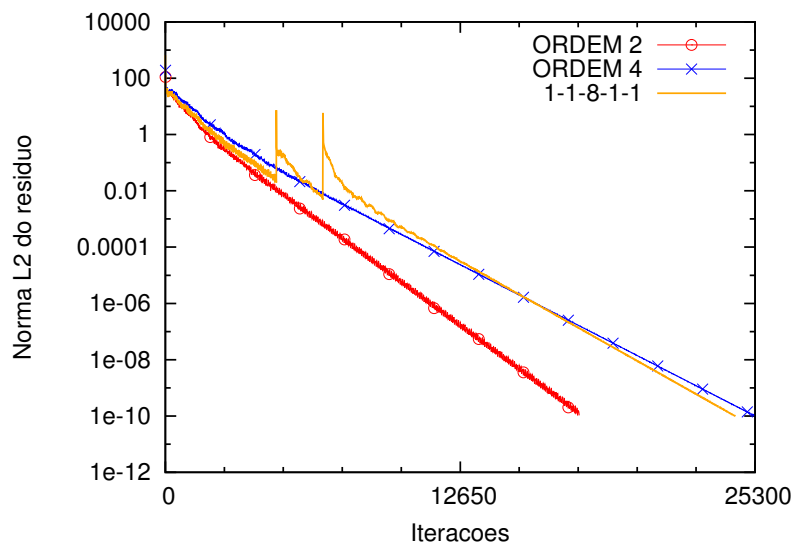

(a)

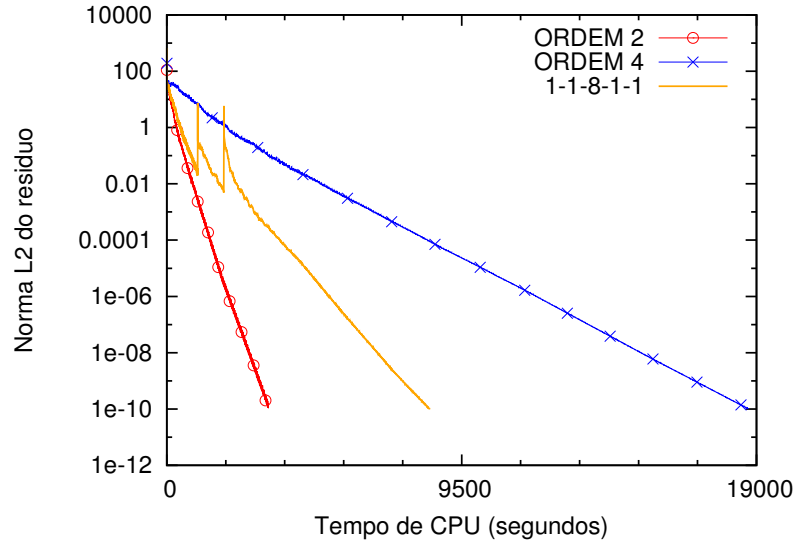

(b)

Figura 5.16: Comparação do esquema p-multigrid 1-1-8-1-1 com duas ordens do método VF, utilizando a Malha 3 (9328 VC), no caso subsônico e $\alpha=2^{\circ}$. 


\subsection{NACA 0012 Transônico, $M_{\infty}=0,8, \alpha=1,25^{\circ}$}

As condições de corrente livre deste problema, assim como as malhas computacionais utilizadas, estão descritas na Seção 3.8.3. A Tabela 5.9 apresenta o acrônimo e a definição de cada esquema full multigrid utilizado neste caso transônico. Nos três primeiros, o processo iterativo começa com 2a ordem até que a norma $L_{2}$ do resíduo seja $2 \times 10^{-2}$, e o processo acaba com os Vciclos de 2 níveis o4-o2-o4 indicados; nestes três esquemas, é considerado um único CFL ao longo do processo: $\mathrm{CFL}=3,0$ (este valor é igual ao CFL máximo para o método VF de 4a ordem, Seção 3.8.3). Ora, o processo iterativo dos três últimos esquemas começa com 1a ordem até que a norma $L_{2}$ do resíduo seja $5 \times 10^{-2}$, logo o processo continua com Vciclos 1-2-2 (o2-o1-o2) até que o resíduo seja $2 \times 10^{-2}$, e acaba com os Vciclos de 3 níveis o4-o2-o1-o2-o4 indicados; para a segunda e a terceira etapa deste processo iterativo, também é considerado o número $\mathrm{CFL}=3,0$ constante, no entanto, para a primeira etapa considera-se o valor de $\mathrm{CFL}=1,0{ }^{9}$.

\begin{tabular}{ll}
\hline Acrônimo & Definição \\
\hline $1-1-1$ & 2a ordem + Vciclos 1-1-1 (o4-o2-o4) \\
$1-2-1$ & 2a ordem + Vciclos 1-2-1 (o4-o2-o4) \\
$1-3-1$ & 2a ordem + Vciclos 1-3-1 (o4-o2-o4) \\
$1-1-1-1-1$ & 1a ordem + Vciclos 1-2-2 (o2-o1-o2) + Vciclos 1-1-1-1-1 (o4-o2-o1-o2-o4) \\
$1-1-2-1-1$ & 1a ordem + Vciclos 1-2-2 (o2-o1-o2) + Vciclos 1-1-2-1-1 (o4-o2-o1-o2-o4) \\
$1-1-3-1-1$ & 1a ordem + Vciclos 1-2-2 (o2-o1-o2) + Vciclos 1-1-3-1-1 (o4-o2-o1-o2-o4) \\
\hline
\end{tabular}

Tabela 5.9: Acrônimos dos esquemas p-multigrid utilizados no caso transônico.

A Tabela 5.10 mostra os resultados das combinações Malha-p-Multigrid, assim como os resultados com 4 a ordem ${ }^{10}$. A relação dos esquemas p-multigrid com a 4 a ordem, em termos de precisão e tempo de CPU, é análoga à apresentada nos casos subsônicos: os esquemas p-multigrid são mais eficientes do que a $4 \mathrm{a}$ ordem (Figura 5.17). O tempo de CPU associado ao esquema 1-1-3-1-1 oscila entre $38 \%$ e $44 \%$ do tempo requerido pela 4 a ordem (vide coluna "Tempo de CPU" da Tabela 5.10).

Neste caso transônico, em contraste com os casos subsônicos, os esquemas p-multigrid necessitam mais iterações do que a 4 a ordem precisa: a Figura 5.18 mostra que o número de iterações dos esquemas de 2 níveis o4-o2-o4 é aproximadamente $10 \%$ maior ao número de iterações requerido pela 4a ordem, e similarmente, mostra que os esquemas de 3 níveis o4-o2-o1-o2-o4 precisam de $29 \%$ a $47 \%$ mais iterações. A Figura $5.19^{11}$ descreve a convergência residual do esquema 1-3-1 e ajuda na análise do aumento das iterações nos esquemas de 2 níveis. Primeiro, percebe-se que o salto do resíduo (de $2 \times 10^{-2}$ para 10) do esquema 1-3-1 retarda a convergência de tal maneira que não é possível superar a performance da 4 a ordem, em termos de número de iterações. Segundo, note-se que, a taxa de convergência do esquema p-multigrid é similar àquela da 4a ordem. Para acelerar a convergência desses esquemas p-multigrid, serão considerados, numa futura pesquisa, outros valores do CFL (é necessário entrar na região de estabilidade onde os erros de alta frequência sejam rapidamente amortecidos).

\footnotetext{
${ }^{9}$ No presente trabalho, está faltando ainda um estudo da combinação do método VF de 1a ordem com diferentes valores de CFL. Por isso, os esquemas full multigrid, que começam procurando uma solução de 1a ordem, consideram um CFL relativamente baixo $(\mathrm{CFL}=1,0)$ na primeira etapa, e depois continuam com o $\mathrm{CFL}=3,0$.

${ }^{10}$ Os resultados da 4a ordem correspondem aos apresentados na Seção 3.8.3, com o CFL máximo $(\mathrm{CFL}=3,0)$ do avanço RK.

${ }^{11}$ Os resultados da 2a ordem correspondem aos apresentados na Seção 3.8.3, com o CFL máximo $(\mathrm{CFL}=4,0)$ do avanço RK.
} 


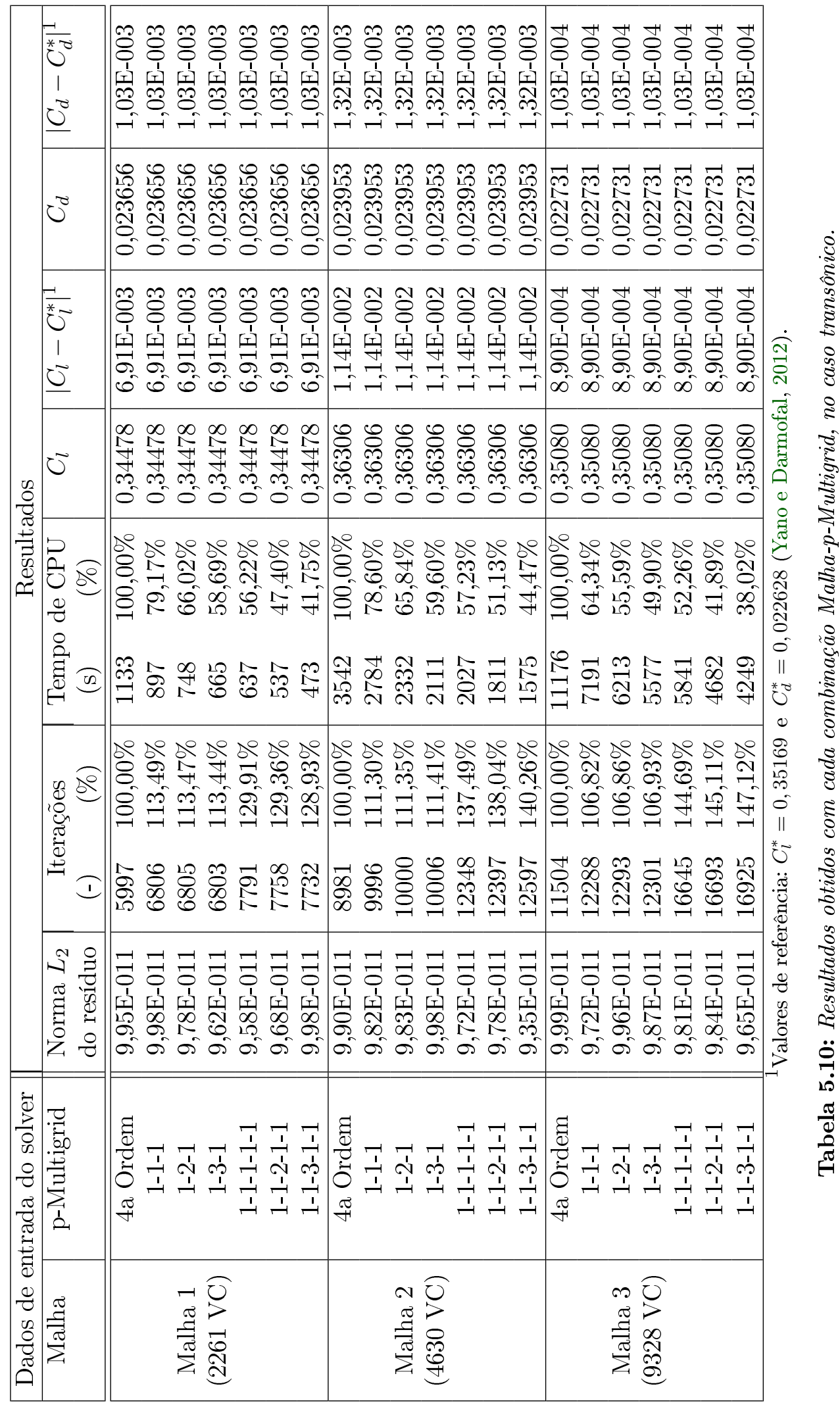




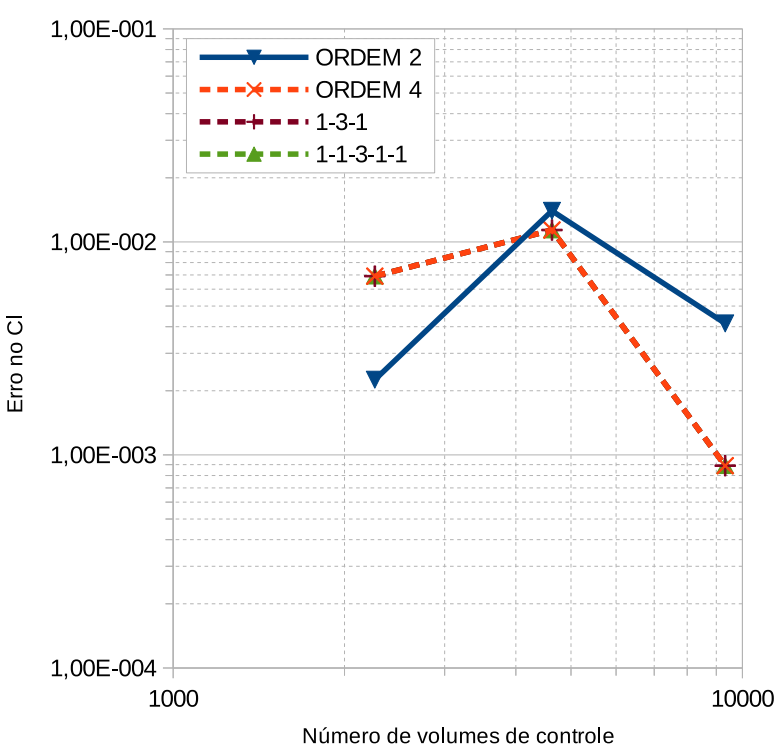

(a)

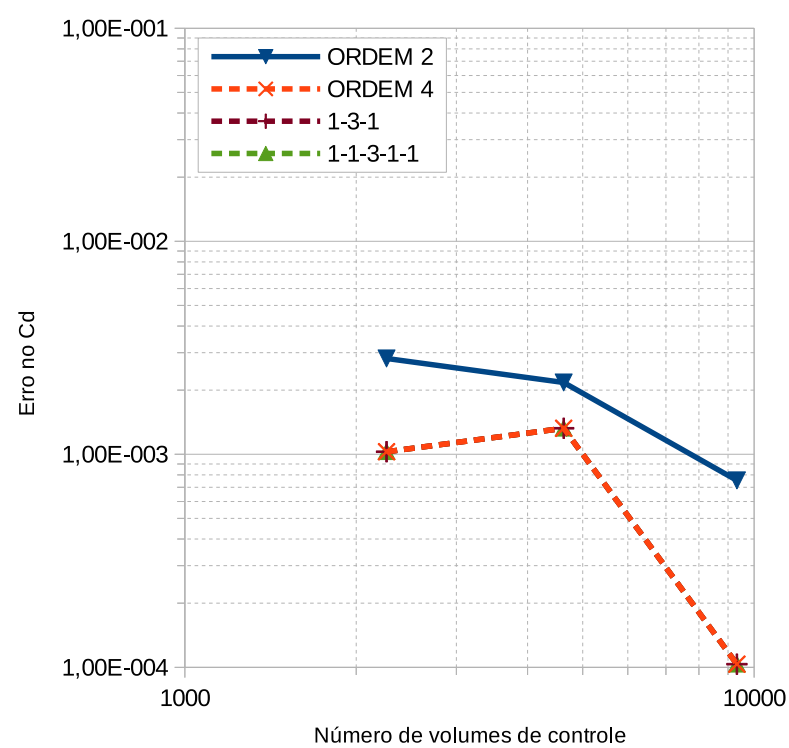

(c)

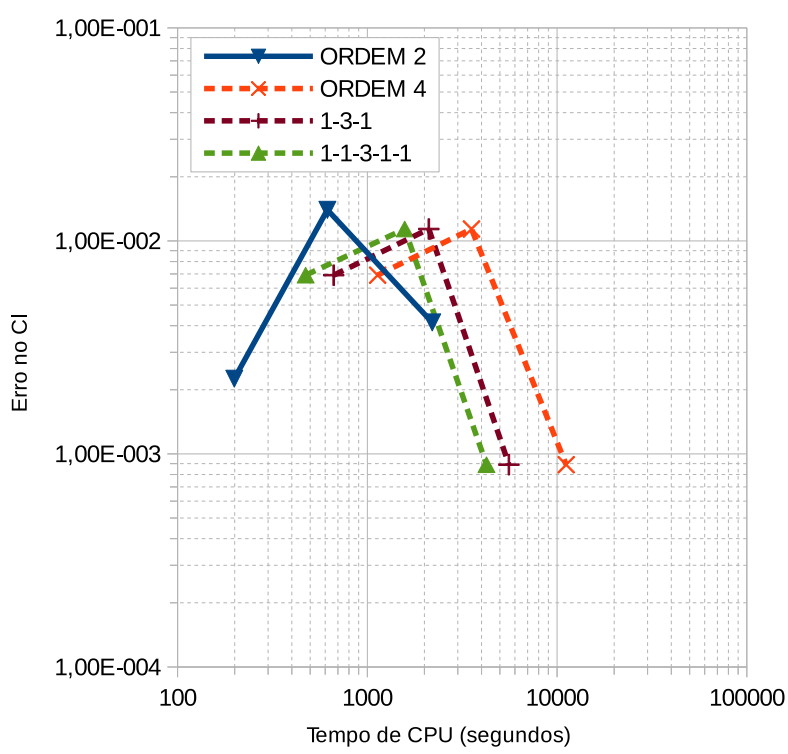

(b)

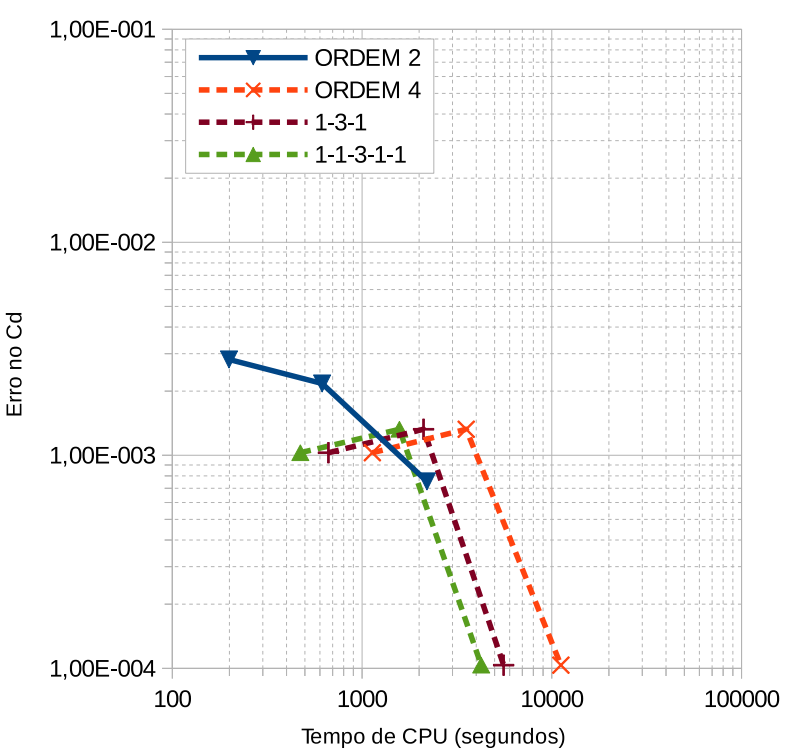

(d)

Figura 5.17: Erros nos coeficientes de sustentação $\left(C_{l}\right)$ e de arrasto $\left(C_{d}\right)$, no caso transônico.

Agora, a Figura 5.20 descreve a convergência residual do esquema 1-1-3-1-1, que utiliza o nível de 1a ordem. Esta figura identifica alguns momentos do processo iterativo onde a convergência, em termos do número de iterações, é demorada. O primeiro momento é a primeira etapa destes esquemas full multigrid, quando é procurada uma solução de 1a ordem com um CFL relativamente baixo $(\mathrm{CFL}=1,0){ }^{12}$. Outra retardação acontece nos dois saltos do resíduo. Estas desvantagens deverão ser superadas numa futura pesquisa, assim como testar Vciclos com um maior número de iterações no nível de 1a ordem (p. ex. 1-1-9-1-1). Essa futura pesquisa, também pode incluir a variação do CFL (como dito no parágrafo anterior) e, se for o caso, uma mudança de smoother.

Finalmente, as Figuras 5.21 e 5.22 apresentam os campos de pressão e do Mach, respectivamente. Dada uma malha, o esquema p-multigrid 1-1-3-1-1 e o método VF de 4a ordem oferecem a mesma resolução, isto é, as diferenças são indistinguíveis.

\footnotetext{
${ }^{12}$ Vide notá de rodapé 9 deste capítulo.
} 


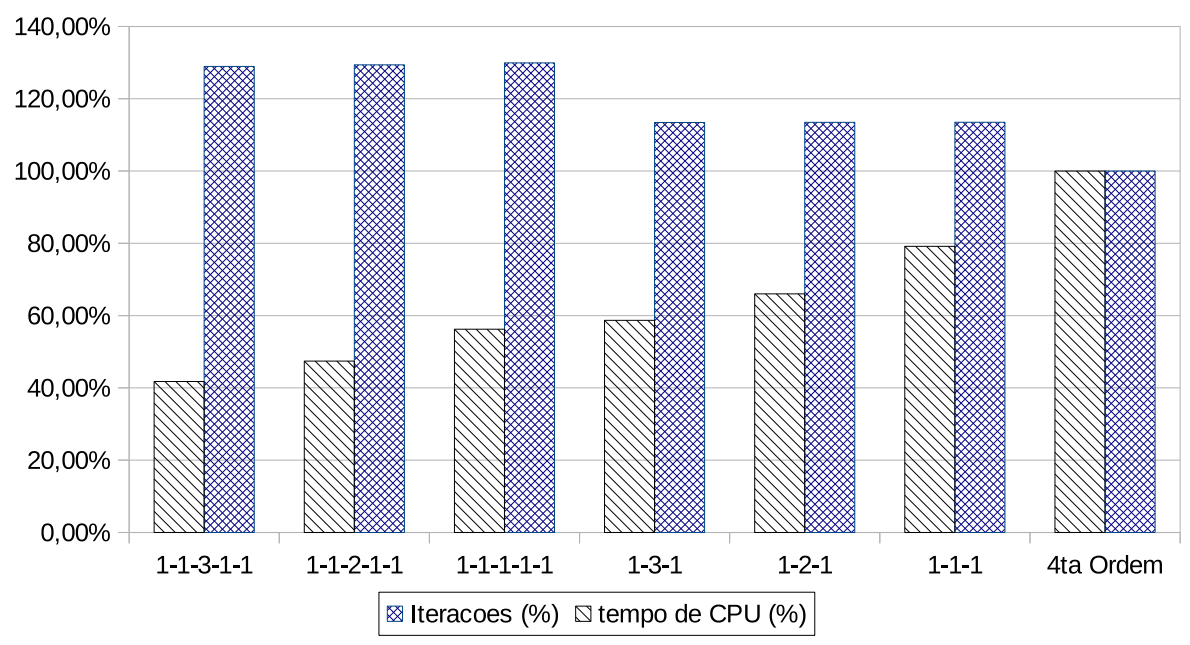

(a) Malha $1(2261 \mathrm{VC})$.

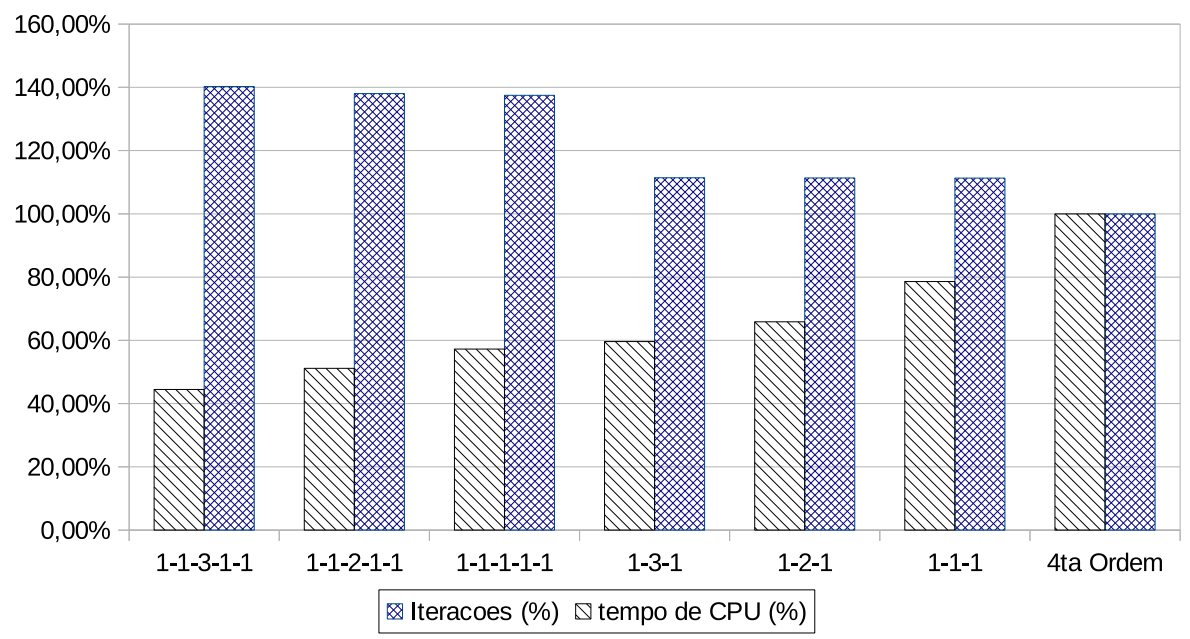

(b) Malha $2(4630 \mathrm{VC})$.

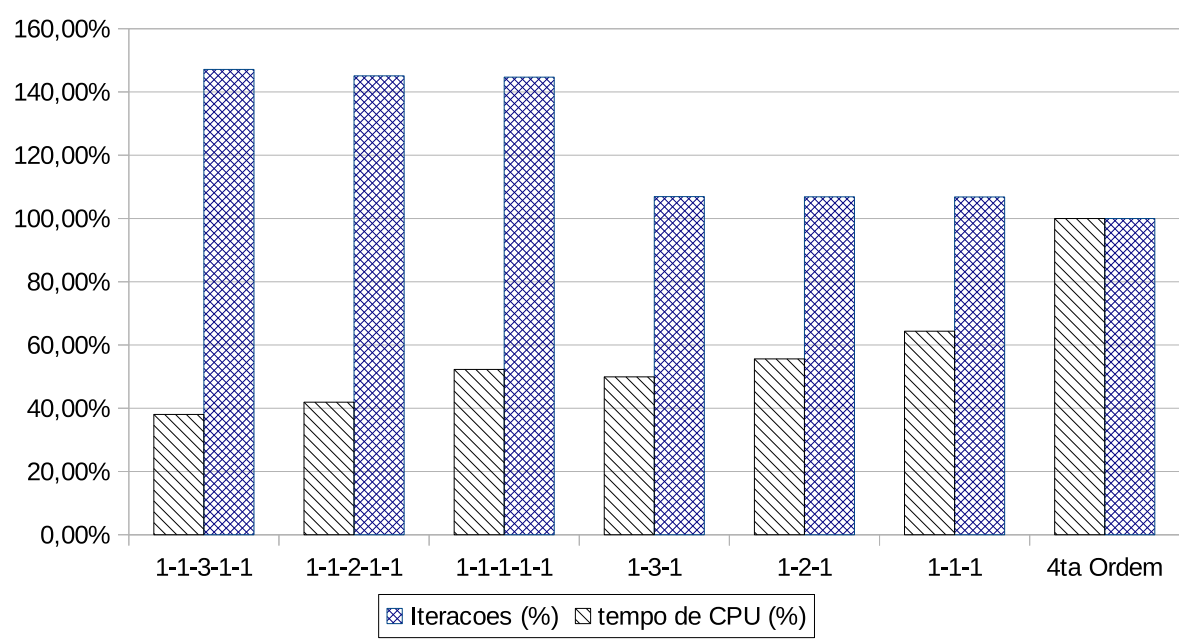

(c) Malha $3(9328 \mathrm{VC})$.

Figura 5.18: Número de Iterações (\%) e Tempo de CPU (\%) consumido nos testes com p-multigrid, no caso transônico. 


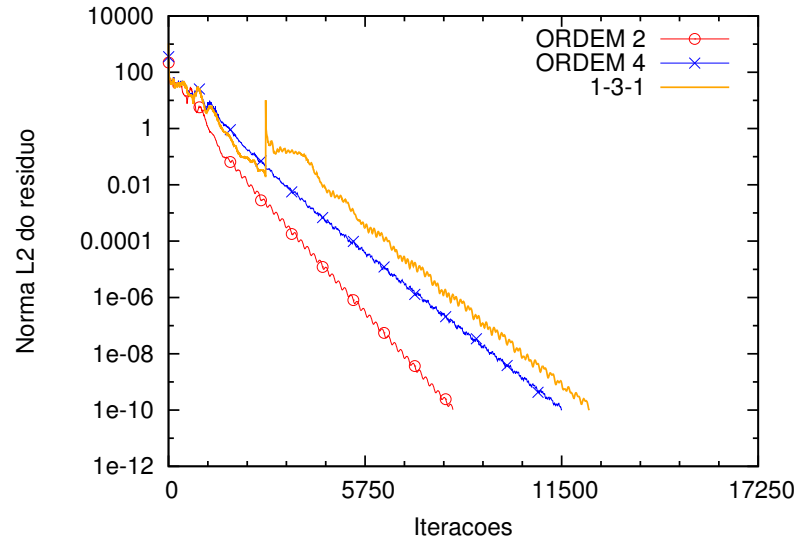

(a)

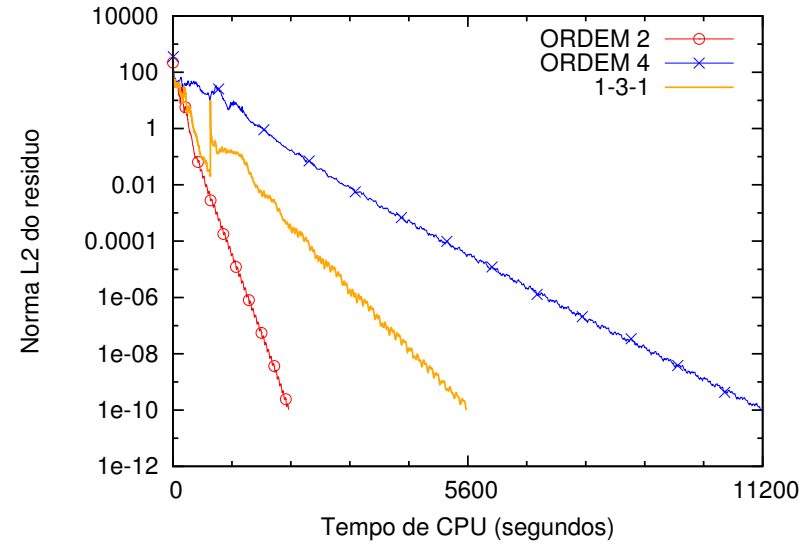

(b)

Figura 5.19: Comparação do esquema p-multigrid 1-3-1 com duas ordens do método VF, utilizando a Malha 3 (9328 VC), no caso transônico.

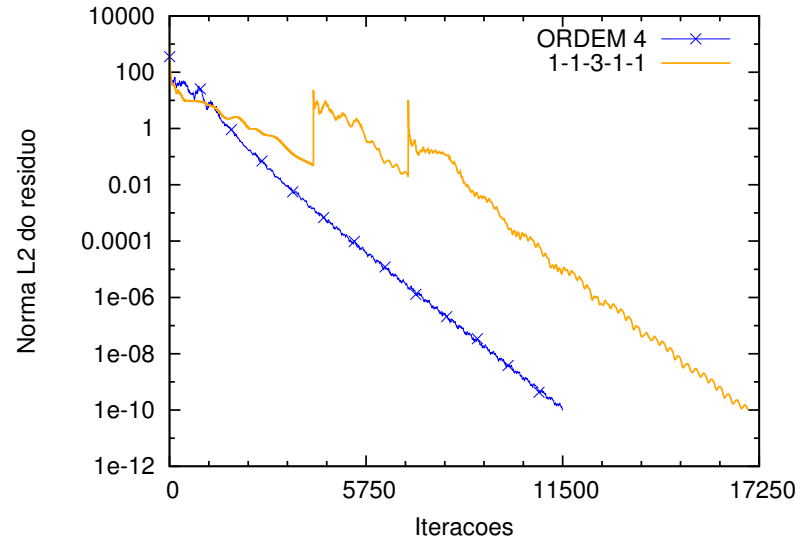

(a)

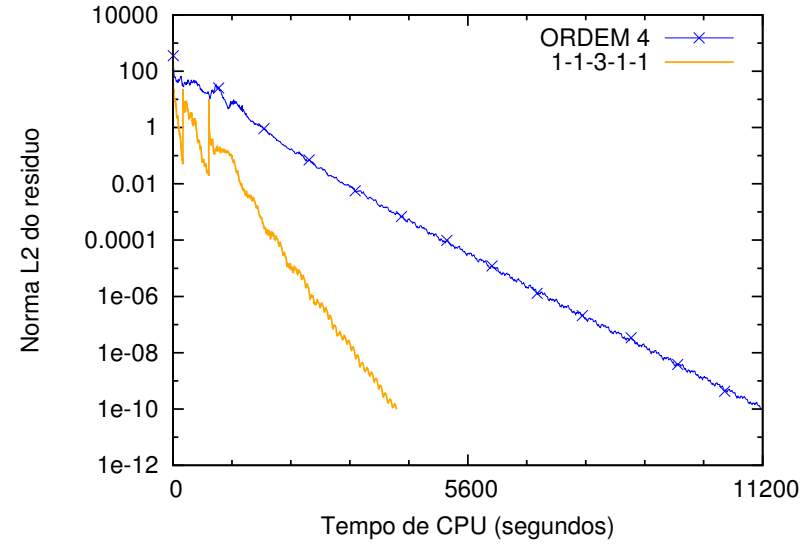

(b)

Figura 5.20: Comparação do esquema p-multigrid 1-1-3-1-1 com a 4a ordem do método VF, utilizando a Malha 3 (9328 VC), no caso transônico. 


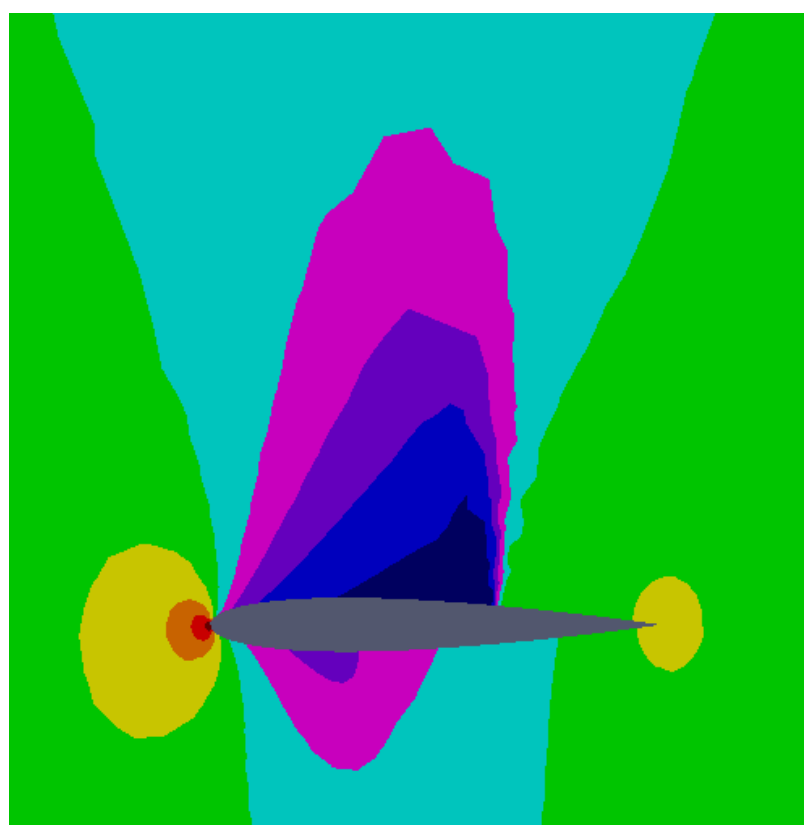

(a) Malha 1 (2261 VC), p-Multigrid 1-1-3-1-1.

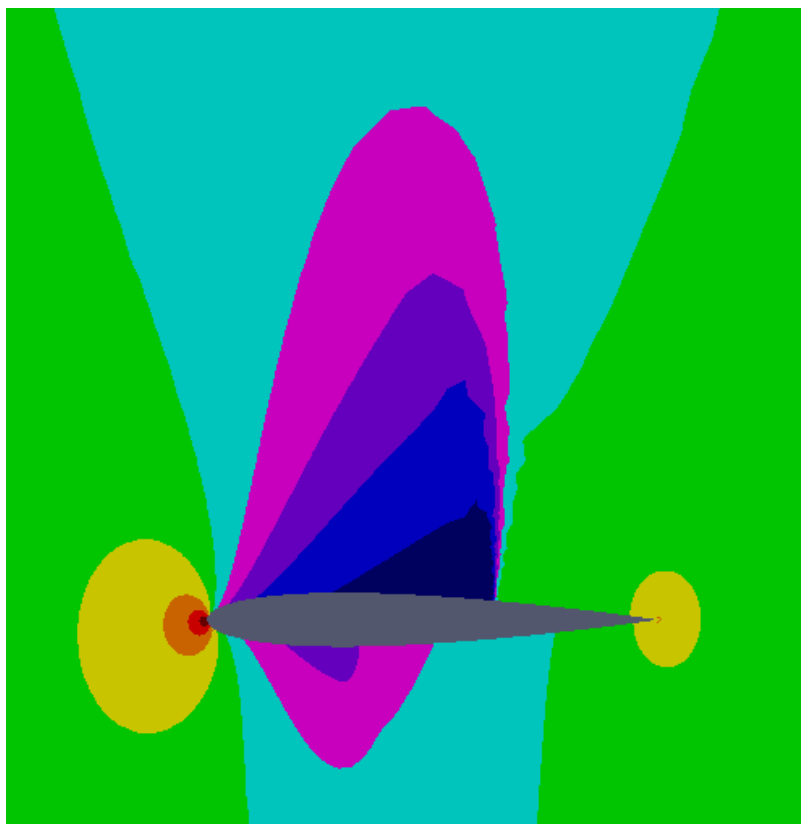

(c) Malha 3 (9328 VC), p-Multigrid 1-1-3-1-1.

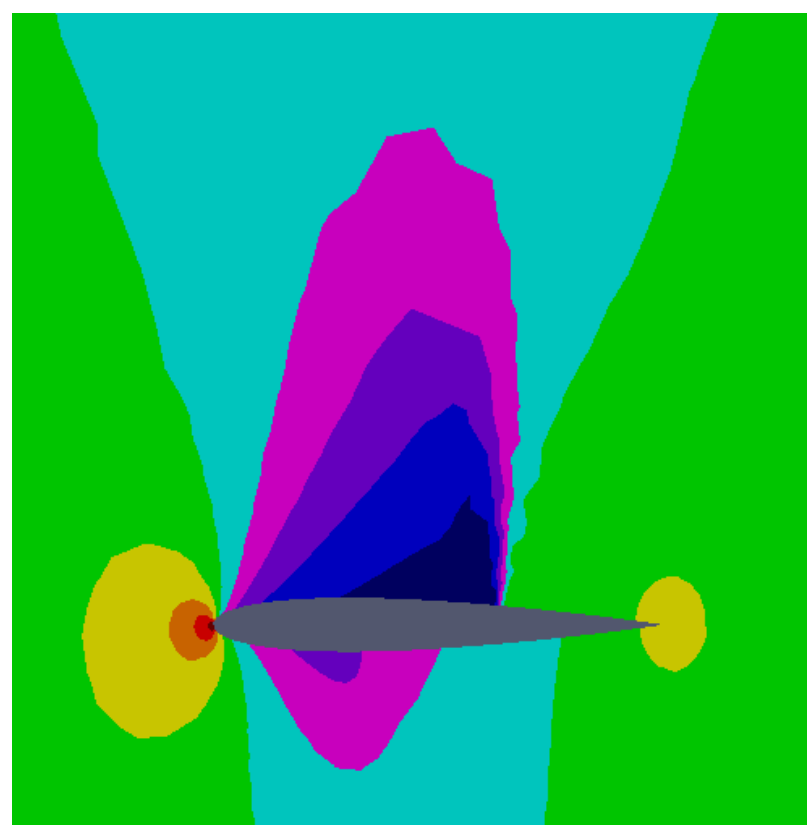

(b) Malha 1 (2261 VC), 4a. Ordem.

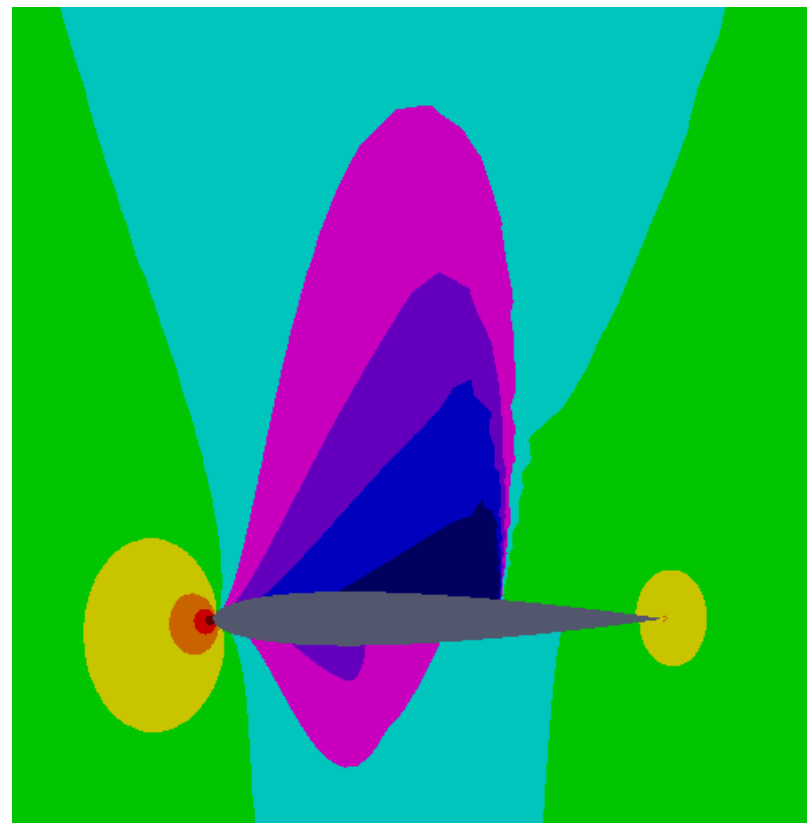

(d) Malha 3 (9328 VC), 4a. Ordem.

\section{Pressão $(\mathrm{N} / \mathrm{m} 2)$}

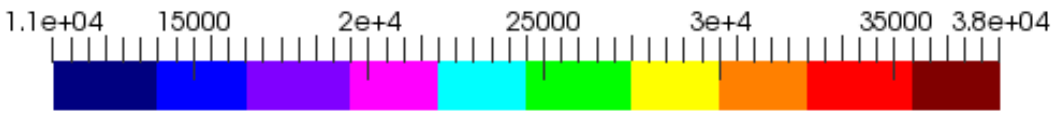

Figura 5.21: Pressão do escoamento $P\left(N / m^{2}\right)$, no caso transônico. 


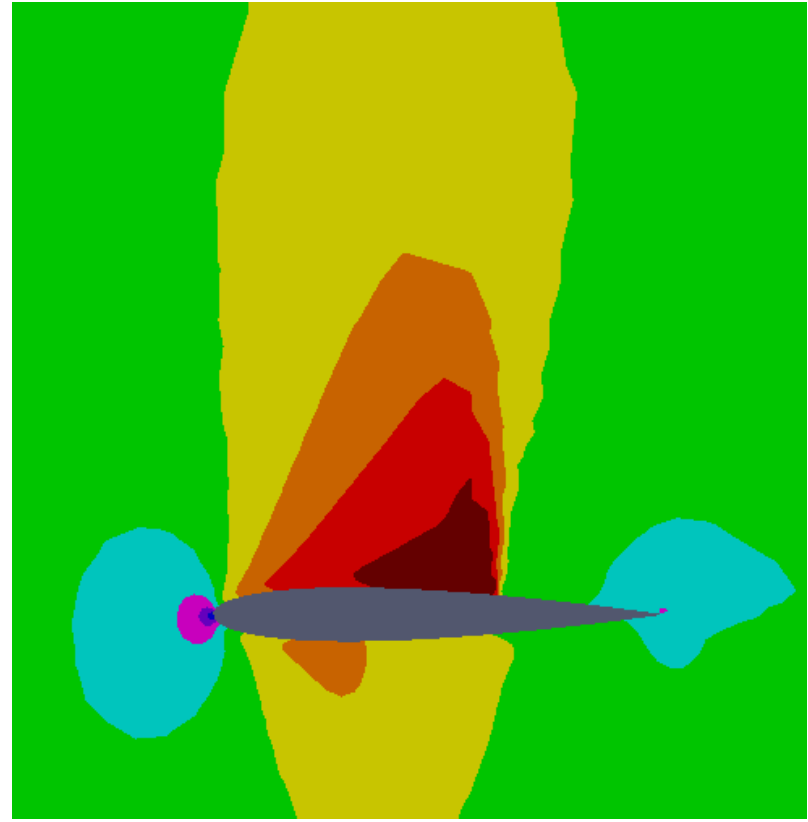

(a) Malha 1 (2261 VC), p-Multigrid 1-1-3-1-1.

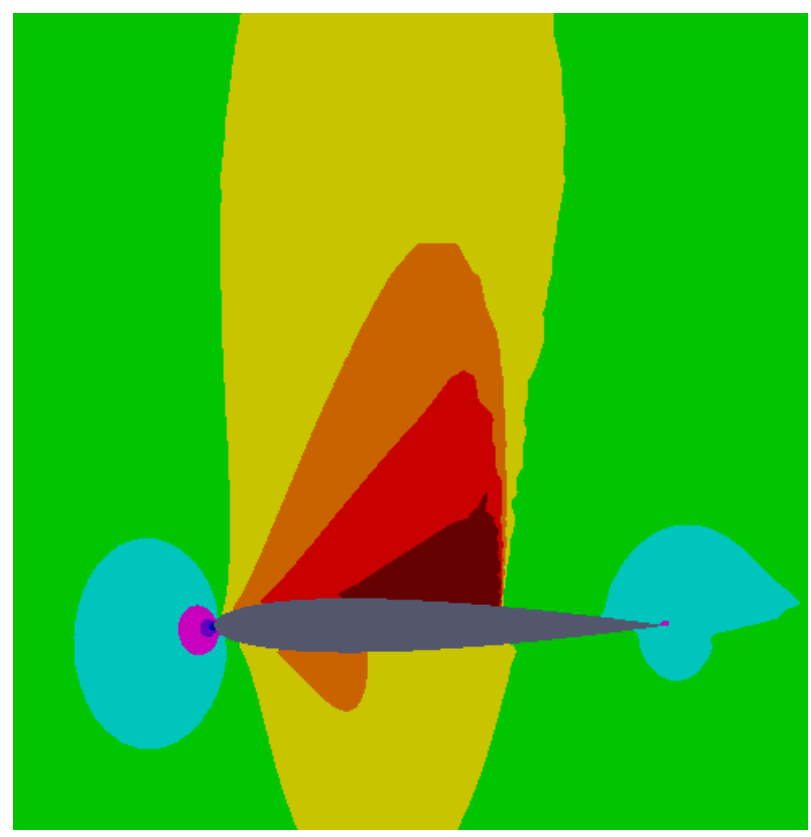

(c) Malha 3 (9328 VC), p-Multigrid 1-1-3-1-1.

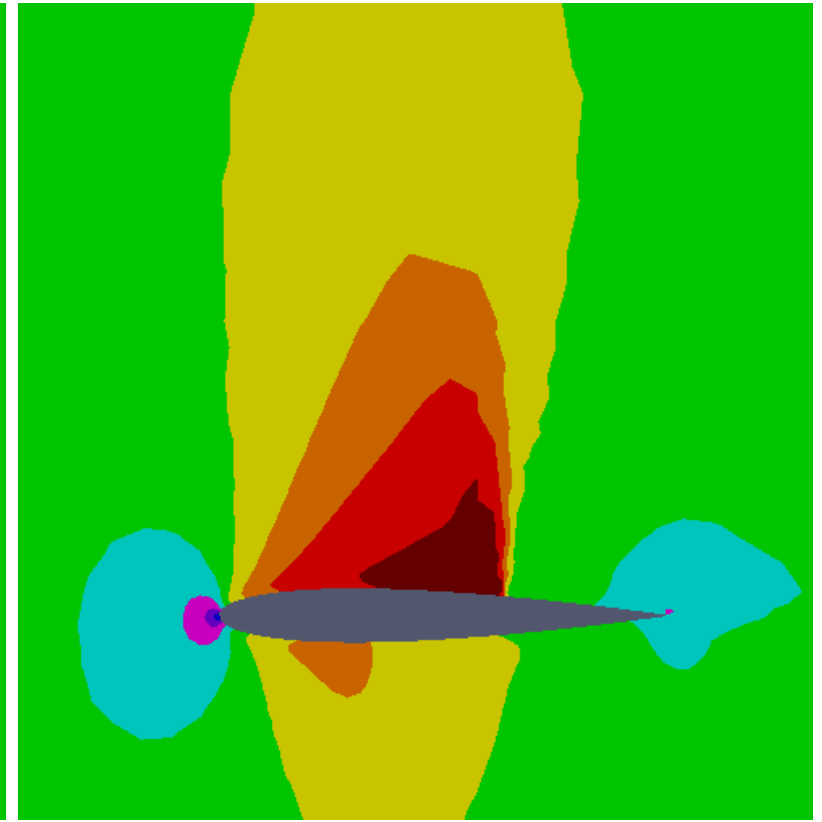

(b) Malha 1 (2261 VC), 4a. Ordem.

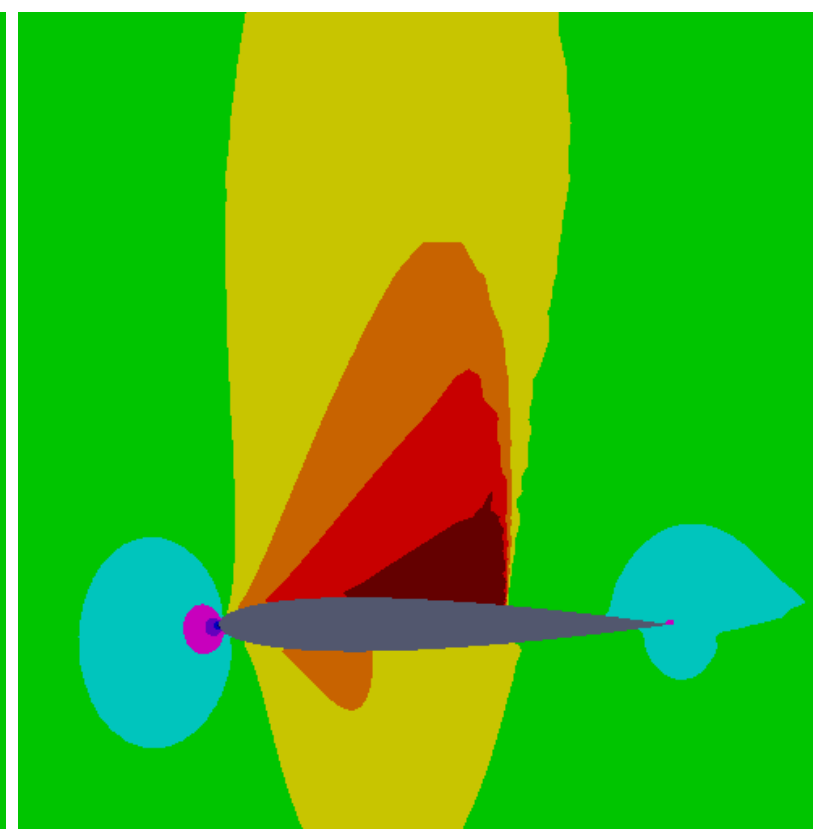

(d) Malha 3 (9328 VC), 4a. Ordem.

Mach

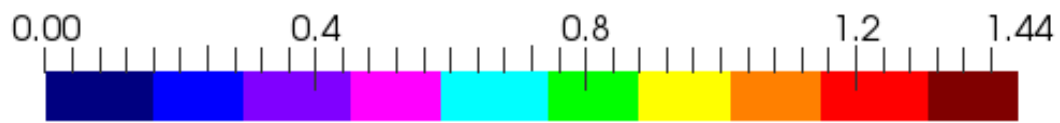

Figura 5.22: Número de Mach do escoamento, no caso transônico. 


\section{Capítulo 6}

\section{Conclusões e Futuros Trabalhos}

\subsection{Conclusões}

Nos Capítulos 2 e 3, desenvolve-se o solver VF-RK, baseado na combinação do método VF de alta-ordem do Michalak (2009) com o avanço RK do van Leer et al. (1989). O solver é capaz de resolver as equações de advecção-difusão e de Euler para problemas estacionários conhecidos na literatura. No Capítulo 4, estuda-se o p-multigrid desenvolvido por Liang et al. (2009b), no contexto da discretização espacial de Diferença Espectral. O método p-multigrid acelera o processo iterativo comutando níveis polinomiais de alta e de baixa-ordem. Essa ideia é adaptada, agora, ao contexto dos Volumes Finitos. O método p-multigrid proposto é relativamente mais simples porque, em contraposição com o p-multigrid para Diferença Espectral, não precisa de operadores de restrição e prolongação para a comunicação entre diferentes níveis. Por fim, no Capítulo 5, implementa-se o solver pMG, baseado no p-multigrid proposto, para resolver os problemas estacionários considerados nos Capítulos 2 e 3, e comparar com os resultados do método VF de 4a ordem (mais especificamente, com os resultados do solver VF-RK com 4a ordem e CFL máximo). O smoother do p-multigrid é o esquema Runge-Kutta, também utilizado no código VF-RK; consideram-se diferentes Vciclos procurando sempre soluções de $4 \mathrm{a}$ ordem. Os resultados indicam que o método p-multigrid proposto é mais eficiente que o método de Volumes Finitos de 4a ordem (sem p-multigrid), isto é, os dois métodos oferecem a mesma precisão mas o primeiro pode levar menos de $50 \%$ do tempo de CPU do segundo.

A Tabela 6.1 mostra o tempo de CPU (\%) e o número de iterações (\%) de alguns testes com pmultigrid. Por exemplo, no caso NACA 0012 transônico, encontra-se que o tempo de CPU associado a um teste com p-multigrid é $38 \%$ do tempo requerido pela 4 a ordem. Vale destacar que o tempo de CPU inclui o tempo que a CPU, se requerida, gasta em outros processos, na $\mathrm{E} / \mathrm{S}$, etc. Ao desconsiderar esses tempos de espera, as porcentagens podem variar por um fator de até 1,20 (vide Apêndice A); assim, no exemplo anterior, o tempo de CPU teórico pode oscilar entre $32 \%$ e $46 \%$. Com isto, percebe-se que o método p-multigrid oferece soluções mais rápidas do que a 4a ordem, em todos os casos. Em relação ao número de iterações (\%), a vantagem do p-multigrid proposto é clara no caso NACA 0012 subsônico e $\alpha=0^{\circ}$ : se consegue diminuir o número de iterações que resulta com a 4a ordem; o nível polinomial de baixa-ordem dos Vciclos amortece rapidamente os erros de alta frequência. No outro caso subsônico, também há redução mas é menos intensa; já nos outros casos, ainda não se consegue diminuir o número de iterações (será necessária, numa futura pesquisa, uma maior análise do p-multigrid).

\subsection{Sugestões para Pesquisas Futuras}

\section{Primeiras sugestões}

No presente trabalho, algumas mudanças podem ser feitas para tentar reduzir o número de iterações. Primeiro, os esquemas full-multigrid consideram umas etapas prévias aos Vciclos de 3 níveis; 


\begin{tabular}{|c|c|c|}
\hline \multirow[b]{2}{*}{$\begin{array}{l}\text { Caso } \\
\text { combinação Malha-p-Multigrid }\end{array}$} & \multicolumn{2}{|c|}{ Resultados } \\
\hline & $\begin{array}{c}\text { Tempo de CPU } \\
(\%)\end{array}$ & $\begin{array}{c}\text { Iterações } \\
(\%)\end{array}$ \\
\hline Advecção-difusão no canal retangular & & \\
\hline $\begin{array}{l}\text { malha mais fina com MG 1-1-8-1-1 } \\
\text { Advecção-difusão no segmento anular }\end{array}$ & $48 \%$ & $100 \%$ \\
\hline malha mais fina com MG 1-1-8-1-1 & $47 \%$ & $100 \%$ \\
\hline $\begin{array}{l}\text { NACA 0012 Subsonico, } M_{\infty}=0,4, \alpha=0^{\circ} \\
\text { malha mais fina com full-multigrid } 1-1-8-1-1\end{array}$ & $32 \%$ & $68 \%$ \\
\hline $\begin{array}{l}\text { NACA 0012 Subsônico, } M_{\infty}=0,5, \alpha=2^{\circ} \\
\text { malha mais fina com full-multigrid } 1-1-8-1-1 \\
\text { NACA } 0012 \text { Transônico, } M_{\infty}=0,8, \alpha=1,25^{\circ}\end{array}$ & $45 \%$ & $97 \%$ \\
\hline malha mais fina com full-multigrid 1-1-3-1-1 (o4-o2-o1-o2-o4) & $38 \%$ & $147 \%$ \\
\hline
\end{tabular}

Tabela 6.1: Resultados de alguns testes com p-multigrid. O símbolo (\%) indica quantidades relativas às que resultam com o método VF de 4 a ordem (sem p-multigrid).

este precondicionamento está retardando a convergência (vide p. ex. a Figura 5.20(a)) e, portanto, deve ser modificado ou, se for o caso, desconsiderado do processo iterativo. Segundo, os Vciclos são considerados neste trabalho apenas para testar o p-multigrid; então, poderia-se estudar Vciclos mais longos, ou seja, com mais iterações no nível de baixa-ordem, porque este nível deveria amortecer os erros de alta frequência otimizando assim a convergência. Esta propriedade de amortecimento, vai depender, entre outras coisas, do número CFL; um estudo experimental do CFL, então, seria uma outra mudança que poderia reduzir o número de iterações.

Vale destacar uma diferença que se observa entre o caso NACA 0012 subsônico e $\alpha=0^{\circ}$ e os outros casos. Naquele, consegue-se diminuir o número de iterações, e a convergência (em termos das iterações) da 2 a ordem é quase dois vezes mais rápida do que a convergência da 4a ordem; nos outros casos, a 2a ordem é quase tão rápida quanto a 4a ordem e, coincidentemente, o método p-multigrid não consegue reduzir as iterações. Haveria que pensar se o p-multigrid proposto (com smoother RK de van Leer et al. (1989)) pode ser aprimorado (p. ex. variando o CFL) ou não.

\section{Smoother RK do tipo SSP}

Esquemas Runge-Kutta do tipo SSP (Strong Stability Preserving) preservam as propriedades de estabilidade forte da combinação da discretização espacial com o método de Euler explícito (para a discretização do tempo). Este método de Euler é de primera ordem e, apartir dele, procurase esquemas de alta-ordem no tempo que preservem sua estabilidade forte. Evidencias numéricas mostram que oscilações poderiam ocorrer ao utilizar esquemas de integração de tempo de altaordem não SSP (Gottlieb e Shu, 1998) (Gottlieb et al., 2001). Shu (1988) e Shu e Osher (1988) apresentam esquemas RK-SSP de 2a e 3a ordem; e Spiteri e Ruuth (2002) apresentam um esquema RK-SSP de 4a ordem de precisão.

No artigo do Liang et al. (2009b), são utilizados esquemas RK-SSP como smoother do método p-multigrid explícito no contexto da Diferença Espectral; esse tipo de esquemas poderia substituir o smoother de van Leer et al. (1989) (utilizado no presente trabalho). Esquemas RK-SSP também demonstram ser eficientes nos problemas não estacionários (Premasuthan et al., 2009) e também poderiam ser considerados no caso não estacionário da Subseção 2.6.1.

\section{Métodos implícitos}

Esquemas implícitos são uma alternativa no avanço do tempo. Ollivier-Gooch e Michalak (2011) e Michalak (2009) combinam um solver linear Newton-Krylov (mais especificamente, o GMRES de Saad e Schultz (1986)) com o método VF de alta-ordem, na resolução de problemas de escoamento 
invíscido e viscoso. A decomposição ILU (LU incompleta) do Jacobiano é utilizada como precondicionador e usam uma busca-línea para adaptar o passo local de tempo. Este esquema GMRES precondicionado poderia ser considerado, no futuro, como smoother implícito de um p-multigrid.

No contexto do método Galerkin Descontínuo, Fidkowski et al. (2005) aplicam um p-multigrid implícito na resolução das equações de Navier-Stokes (NACA 0012 sem sustentação) e conseguem reduzir significativamente o tempo de CPU requerido pelo método sem p-multigrid. Analogamente, no âmbito da Diferença Espectral, Liang et al. (2009b) aceleram a resolução do caso invíscido NACA 0012 sem sustentação: o p-multigrid implícito requer aproximadamente 1\% do tempo de CPU da combinação DE-RK explícito (sem p-multigrid). E para diminuir o armazenamento na memória, Liang et al. (2009b) também propõem esquemas p-multigrid com smoothers misturados, isto é, um smoother explícito nos níveis de alta-ordem e outro, implícito, nos níveis inferiores.

\section{Novos esquemas de integração do tempo}

No contexto do método Galerkin Descontínuo, Gassner et al. (2011) propõem um esquema RK explícito com passo local de tempo mas que preserva a precisão temporal na resolução de problemas não estacionários (equações de advecção e de Euler). Cada célula da malha pode trabalhar com seu próprio passo de tempo ótimo, dado pela restrição de estabilidade local.

Também no contexto do método Galerkin Descontínuo, Persson (2011) propõe um esquema híbrido implícito-explícito na resolução de problemas de turbulência modelados por Large Eddy Simulation. O algoritmo implícito é utilizado nas regiões "duras" stiff (devido à geometria ou à física) enquanto um esquema explícito é usado nas demais regiões.

No futuro, também será interessante uma adaptação desses esquemas ao ambiente de VF.

\section{Paralelização}

Métodos compactos (por exemplo GD e DE) implicam numa mínima quantidade de comunicação de dados em computadores paralelos que incluem clusters CPU e GPU (Graphics Processing Unit). Klockner et al. (2009) sugerem que a minimização da comunicação é fundamental para alcançar o melhor desempenho numa placa GPU com milhares de cores de computador. Michalak e Ollivier-Gooch (2004) descrevem os passos necessários para adaptar um solver VF de alta-ordem genérico, não estruturado, para uma arquitetura paralela; eles resolvem um problema escalar (condução de calor) num cluster CPU de 24 processadores. Uma futura pesquisa poderia incluir a análise do método VF (não compacto) paralelizado na resolução das equações de Euler; a comunicação dos coeficientes da reconstrução será crítica no desempenho do solver.

\subsection{Consideração Final}

O estudo realizado indica que é possível alcançar alta-ordem com um desempenho diferenciado utilizando uma infraestrutura convencional de geração de malha (malha de baixa-ordem) com algum suporte do solver de alta-ordem para o tratamento de fronteiras curvas. Apesar do deslocamento da comunidade acadêmica para a direção do Galerkin Descontínuo, ainda existe potencial a ser explorado em Volumes Finitos. Essa transição aparenta ser mais natural para a indústria que depende de solvers comerciais. 


\section{Apêndice A}

\section{Tempo de CPU (\%)}

\section{A.1 Definições relacionadas ao Tempo de CPU}

- O tempo de CPU medido, ou simplesmente tempo de CPU, é obtido no presente trabalho pela função GNU C difftime que mede a diferença entre o tempo calendário do início e do fim de um teste. Assim, o tempo de CPU medido inclui tempos de espera: a CPU pode ser requerida pela E/S ou por outros processos (Loosemore et al., 2015).

- O tempo de CPU teórico não inclui esses tempos de espera, é unicamente o tempo de processamento do teste. Neste trabalho, não é obtido esse tempo teórico; para isso, poderia ser útil a função GNU C clock (Loosemore et al., 2015).

- O tempo de CPU medido (\%), ou simplesmente tempo de CPU (\%), é a razão (em porcentagem) entre o tempo de CPU medido para um teste e o tempo medido para um outro teste. Na Seção 3.8, calculam-se esses porcentagens para comparar dois testes associados a diferentes CFL. No Capítulo 5, calculam-se os tempos de CPU (\%) para comparar um teste com p-multigrid com um teste sem p-multigrid.

- O tempo de CPU teórico (\%), é a razão (em porcentagem) entre o tempo de CPU teórico para um teste e o tempo teórico para um outro teste. Na Seção 3.8, estuda-se a influência do CFL; o tempo de CPU teórico (\%) é estimado pelo quociente entre o número de iterações obtido com um CFL e o número de iterações para outro CFL. No Capítulo 5, compara-se o método com p-multigrid e o método sem p-multigrid; o tempo de CPU teórico (\%) não é calculado, mas pode ser estimado utilizando o tempo de CPU medido (\%) e o número $\Delta$ proposto neste apêndice.

\section{A.2 Objetivo do Apêndice}

Escolher um número $\Delta \geqslant 0$ tal que, para cada teste com p-multigrid do Capítulo 5,

$$
\frac{\text { tempo de CPU medido (\%) }}{\text { tempo de CPU teórico (\%) }} \in\left[\frac{1}{1+\Delta}, 1+\Delta\right] \text {. }
$$

Vale lembrar que, no Capítulo 5, o símbolo (\%) indica quantidades relativas às que resultam com o teste sem p-multigrid. Lembre-se também que os valores do tempo de CPU medido (\%) já são conhecidos (Capítulo 5) e que, junto com o número $\Delta$, dão uma estimativa do tempo de CPU teórico (\%) dos testes com p-multigrid.

\section{A.3 Número $\Delta$}

Para começar com a escolha do $\Delta$, enuncia-se a seguinte proposição: 
Proposição 1. Seja $\varepsilon \geqslant 0$ e sejam $q_{1}, q_{2} \in[1,1+\varepsilon]$. Então, $\frac{q_{1}}{q_{2}} \in\left[\frac{1}{1+\varepsilon}, 1+\varepsilon\right]$.

A seguir, verifica-se o seguinte:

Proposição 2. Existe um $\varepsilon \geqslant 0,1905$ tal que, para cada teste do presente trabalho,

$$
\frac{\text { tempo de CPU medido }}{\text { tempo de CPU teórico }} \in[1,1+\varepsilon] \text {. }
$$

Demonstração. Vale destacar que, para cada teste, o tempo de CPU medido refere-se ao reportado no presente trabalho e o tempo de CPU teórico é desconhecido. Sendo finito o número desses testes, existe um valor máximo para os quocientes $\frac{\text { tempo de CPU medido }}{\text { tempo de CPU teórico }}$ esse valor máximo pode ser escrito com $1+\varepsilon$. O valor mínimo desses quocientes é 1 pois o tempo de CPU medido inclui, ademais do tempo de processamento, o tempo de espera.

Agora, verifica-se que $\varepsilon$ não pode ser menor do que 0,1905 . Para isso, são utilizados os quocientes $\frac{\text { tempo de CPU medido (\%) }}{\text { tempo de CPU teórico (\%) }}$ calculados na Seção 3.8; lembre-se que, nessa seção,

$$
\frac{\text { tempo de CPU medido }(\%)}{\text { tempo de CPU teórico }(\%)}=\frac{\left(\frac{\text { tempo de CPU medido - CFL alto }}{\text { tempo de CPU medido - CFL baixo }}\right)}{\left(\frac{\text { tempo de CPU teórico - CFL alto }}{\text { tempo de CPU teórico - CFL baixo }}\right)},
$$

ou seja,

$$
\frac{\text { tempo de CPU medido }(\%)}{\text { tempo de CPU teórico (\%) }}=\frac{\left(\frac{\text { tempo de CPU medido - CFL alto }}{\text { tempo de CPU teórico - CFL alto }}\right)}{\left(\frac{\text { tempo de CPU medido - CFL baixo }}{\text { tempo de CPU teórico - CFL baixo }}\right)} \text {. }
$$

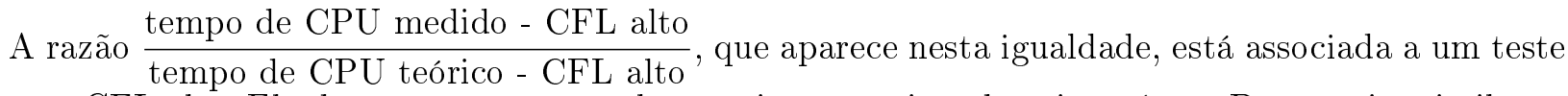
com CFL alto. Ela deve ser menor ao valor máximo mencionado acima, $1+\varepsilon$. De maneira similar, a razão $\frac{\text { tempo de CPU medido - CFL baixo }}{\text { tempo de CPU teórico - CFL baixo }}$ associada ao teste com CFL baixo, pertence ao intervalo $[1,1+\varepsilon]$. Logo, pela Proposição 1 e pela igualdade (A.2),

$$
\frac{1}{1+\varepsilon} \leqslant \frac{\text { tempo de CPU medido }(\%)}{\text { tempo de CPU teórico }(\%)} \leqslant 1+\varepsilon .
$$

Ora, o mínimo e o máximo dos quocientes $\frac{\text { tempo de CPU medido }(\%)}{\text { tempo de CPU teórico }(\%)}$ calculados na Seção 3.8 são, respectivamente, $1-0,16$ e $1+0,16$. Logo,

$$
\begin{aligned}
\frac{1}{1+\varepsilon} & \leqslant 1-0,16 \mathrm{e} \\
1+0,16 & \leqslant 1+\varepsilon .
\end{aligned}
$$

Resolvendo ambas inequações tem-se que $\varepsilon \geqslant 0,1905$.

Percebe-se que a cota superior $1+\varepsilon$, para os quocientes $\frac{\text { tempo de CPU medido }}{\text { tempo de CPU teórico }}$, segue sendo desconhecida, mas encontrá-la não é o objetivo deste apêndice. A seguinte proposição trata dos quocientes que sim precisam ser acotados.

Proposição 3. Existe um $\varepsilon \geqslant 0,1905$ tal que, para cada par de testes do presente trabalho,

$$
\frac{\text { tempo de CPU medido (\%) }}{\text { tempo de CPU teórico (\%) }} \in\left[\frac{1}{1+\varepsilon}, 1+\varepsilon\right] \text {. }
$$


Demonstração. Esta proposição é uma consequência das duas proposições anteriores. Seja $\varepsilon$ o mesmo da Proposição 2. Ora, para dois testes quaisquer, teste A e teste B, do presente trabalho tem-se que

$$
\frac{\text { tempo de CPU medido }(\%)}{\text { tempo de CPU teórico }(\%)}=\frac{\left(\frac{\text { tempo de CPU medido }- \text { teste A }}{\text { tempo de CPU medido - teste B }}\right)}{\left(\frac{\text { tempo de CPU teórico - teste A }}{\text { tempo de CPU teórico - teste B }}\right)},
$$

ou seja,

$$
\frac{\text { tempo de CPU medido }(\%)}{\text { tempo de CPU teórico }(\%)}=\frac{\left(\frac{\text { tempo de CPU medido }- \text { teste } \mathrm{A}}{\text { tempo de CPU teórico - teste A }}\right)}{\left(\frac{\text { tempo de CPU medido }- \text { teste B }}{\text { tempo de CPU teórico - teste B }}\right)} \text {. }
$$

Os quocientes $\frac{\text { tempo de CPU medido }}{\text { tempo de CPU teórico }}$, do lado direito desta igualdade, pertencem ao intervalo $[1,1+\varepsilon], \operatorname{com} \varepsilon \geqslant 0,1905$. Logo, pela Proposição 1 obtem-se o desejado.

Observe-se que os quocientes $\frac{\text { tempo de CPU medido (\%) }}{\text { tempo de CPU teórico (\%) }}$ calculados na Seção 3.8 pertencem ao intervalo $\left[\frac{1}{1+0,1905}, 1+0,1905\right]$; de fato, o mínimo desses quocientes é $1-0,16$ (que é igual à $\frac{1}{1+0,1905}$ ) e o máximo é $1+0,16$ (menor do que $\left.1+0,1905\right)$. Esse intervalo é um bom candidato para conter os quocientes desconhecidos do Capítulo 5; a seguir, enunciam-se algumas razões que motivam essa afirmação:

- Todos os testes do presente trabalho foram executados pelo mesmo computador. Vale destacar ainda que, durante o desenvolvimento de todo o trabalho, o computador rodava, simultaneamente e sem parar, um código de uma outra pesquisa; portanto, poderia-se dizer que o uso da CPU era aproximadamente o mesmo.

- O solver pMG (utilizado no Capítulo 5) foi escrito a partir do solver VF-RK (Seção 3.8). Ambos códigos utilizam a linguagem $\mathrm{C}$ e os mesmos parámetros, como leitura/escritura de dados, alocação de memória, etc.

O máximo (e o mínimo) dos quocientes desconhecidos do Capítulo 5 pode ser estimado, formalmente, utilizando alguma inferência estatística (Meyer, 1970); nesse caso, a amostra é representativa: 48 é o número de quocientes desse tipo calculados na Seção 3.8 e a quantidade de quocientes desconhecidos do Capítulo 5 (testes do NACA 0012) chega a 42. Então, espera-se que o intervalo $\left[\frac{1}{1+0,1905}, 1+0,1905\right]$ seja útil para acotar uma quantidade razoável dos quocientes do Capítulo 5. À luz desta observação e da Proposição 3, escolhe-se $\Delta=0,20$. Assim, estima-se que, para cada teste com p-multigrid do Capítulo 5,

$$
\frac{\text { tempo de CPU medido }(\%)}{\text { tempo de CPU teórico }(\%)} \in\left[\frac{1}{1+\Delta}, 1+\Delta\right] \text {. }
$$

\section{A.4 Recurso computacional utilizado}

Todos os testes reportados no presente trabalho foram realizados numa CPU Intel(R) Xeon(R) X5690 de 24 cores e $3.47 \mathrm{GHz}$, com 64Gb de memória RAM DIMM e $1333 \mathrm{MHz}$, e com sistema operacional Linux. Esta máquina (chamada de Guepardo00) está localizada no Laboratório de Matemática Aplicada do IME-USP. 
APÊNDICE A 


\section{Referências Bibliográficas}

AGARD Fluid Dynamics Panel (1985) AGARD Fluid Dynamics Panel. Test Cases for Inviscid Flow Field Methods. AGARD Advisory Report AR-211. Citado na pág. 69, 75, 76, 78

Ahmad e Boybeyi (2005) N. Ahmad e Z. Boybeyi. Advection-diffusion equation on unstructured adaptive grids. Em NOAA/EPA Golden Jubilee Symposium on Air Quality Modeling and Its Applications. Citado na pág. 9

Anderson (2001) J. D. Anderson. Fundamentals of Aerodynamics. McGraw-Hill Series in Aeronautical and Aerospace Engineering, 3rd ed. Citado na pág. 48, 58, 69, 78

Andren et al. (2011) J. Andren, H. Gao, M. Yano, D. L. Darmofal, C. Ollivier-Gooch e Z. J. Wang. A comparison of higher-order methods on a set of canonical aerodynamics applications. AIAA paper, 3230. Citado na pág. 56, 58, 65, 78

Balan et al. (2012a) A. Balan, G. May e J. Schöberl. A stable high-order spectral difference method for hyperbolic conservation laws on triangular elements. J. Comput. Phys., 231:23592375. Citado na pág. 3

Balan et al. (2012b) A. Balan, G. May, J. Schütz e M. Woopen. C1.3 flow over the NACA0012 airfoil, inviscid and viscous, subsonic and transonic. Em First international workshop on highorder CFD methods. Citado na pág. 77,78

Barth e Frederickson (1990) T. J. Barth e P. O. Frederickson. Higher order solution of the Euler equations on unstructured grids using quadratic reconstruction. AIAA, Paper 90-0013. Citado na pág. iii, v, 2, 10

Blazek (2001) J. Blazek. Computational Fluid Dynamics: Principles and Applications. Elsevier, 1st ed. Citado na pág. 9, 43, 44, 45

Burden e Faires (2004) R. L. Burden e J. D. Faires. Numerical Analysis. Brooks Cole, 8th ed. Citado na pág. 19, 24, 32

Canuto et al. (2006) C. Canuto, M. Y. Hussaini, A. Quarteroni e T. A. Zang. Spectral methods: Fundamentals in single domains. Springer. Citado na pág. 1

Chorin e Marsden (2000) A. J. Chorin e J. E. Marsden. A Mathematical Introduction to Fluid Mechanics. Springer, 3rd ed. Citado na pág. 41, 83

Cockburn et al. (2000) B. Cockburn, G. E. Karniadakis e C. W. Shu. Discontinuous Galerkin methods: Theory, computation and applications. Springer. Citado na pág. 3

Fidkowski e Darmofal (2011) K. J. Fidkowski e D. L. Darmofal. Review of output-based error estimation and mesh adaptation in computational fluid dynamics. American Institute of Aeronautics and Astronautics Journal, Vol. 49 No. 4:673-694. Citado na pág. 3

Fidkowski et al. (2005) K. J. Fidkowski, T. A. Oliver, J. Lu e D. L. Darmofal. p-Multigrid solution of high-order discontinuous Galerkin discretizations of the compressible Navier-Stokes equations. Journal of Computational Physics, Vol. 207:92-113. Citado na pág. 4, 5, 45, 121 
Galassi et al. (2015) M. Galassi, J. Davies, J. Theiler, B. Gough, G. Jungman, P. Alken, M. Booth, F. Rossi e R. Ulerich. GNU Scientific Library Reference Manual, Novembro 2015. Edition 2.1, for GSL Version 2.1. Citado na pág. 10, 14

Gassner et al. (2011) G. J. Gassner, F. Hindenlang e C.-D. Munz. A Runge-Kutta based discontinuous Galerkin method with time accurate local time stepping. Em Adaptive High-order Methods in Computational Fluid Dynamics, páginas 95-118. Editado por Z. J. Wang (World Scientific Publishing). Citado na pág. 121

Geuzaine e Remacle (2009) C. Geuzaine e J.-F. Remacle. Gmsh: a three-dimensional finite element mesh generator with built-in pre- and post-processing facilities. International Journal for Numerical Methods in Engineering, Vol. 79, Issue 11:1309-1331. Citado na pág. 18, 23, 31, 48, 58

Golub e van Loan (1996) G. H. Golub e C. F. van Loan. Matrix Computations. Johns Hopkins University Press, 3rd ed. Citado na pág. 10, 18

Gottlieb e Shu (1998) S. Gottlieb e C. W. Shu. Total variation diminishing runge-kutta schemes. Math. Compu., 67 No. 221:73-85. Citado na pág. 120

Gottlieb et al. (2001) S. Gottlieb, C. W. Shu e E. Tadmor. Strong stability preserving high-order time discretization methods. SIAM Review, 43:89-112. Citado na pág. 120

Ii et al. (2005) S. Ii, M. Shimuta e F. Xiao. A 4th-order and single-cell-based advection scheme on unstructured grids using multi-moments. Computer Physics Communications, Vol. 173:17-33. Citado na pág. 9, 16, 39

Jameson e Mavriplis (1985) A. Jameson e D. Mavriplis. Finite volume solution of the twodimensional Euler equations on a regular triangular mesh. AIAA, Paper 85-0435. Citado na pág. 56,65

Jameson et al. (1981) A. Jameson, W. Schmidt e E. Turkel. Numerical solution of the Euler equations by finite volume methods using Runge-Kutta time stepping schemes. AIAA, Paper No. 81-1259. Citado na pág. 18, 21

Klockner et al. (2009) A. Klockner, T. Warburton, J. Bridge e J. S. Hesthaven. Nodal discontinuous Galerkin methods on graphics processors. J. Comput. Phys., 228:7863-7882. Citado na pág. 121

Kopriva e Kolias (1996) D. A. Kopriva e J. H. Kolias. A conservative staggered-grid Chebyshev multidomain method for compressible flows. J. Comput. Phys., Vol. 125, No. 1:244-261. Citado na pág. 3

Leveque (2002) R. J. Leveque. Finite volume methods for hyperbolic problems. Cambridge University Press. Citado na pág. 1, 16

Liang et al. (2009a) C. Liang, A. Jameson e Z. J. Wang. Spectral difference method for compressible flow on unstructured grids with mixed elements. J. Comput. Phys., 228 No.8:2847-2858. Citado na pág. 3,83

Liang et al. (2009b) C. Liang, R. Kannan e Z. J. Wang. A p-multigrid spectral difference method with explicit and implicit smoothers on unstructured triangular grids. Comput. Fluids, 38 No.2: 254-265. Citado na pág. iii, v, 5, 47, 85, 86, 90, 102, 119, 120, 121

Liu et al. (2006) Y. Liu, M. Vinokur e Z. J. Wang. Spectral difference method for unstructured grids I: Basic formulation. J. Comput. Phys., Vol. 216, No.2:780-801. Citado na pág. 3, 83 
Loosemore et al. (2015) S. Loosemore, R. M. Stallman, R. McGrath, A. Oram e U. Drepper. The GNU C Library Reference Manual, Agosto 2015. For version 2.22. Citado na pág. 123

Lu (2005) J. Lu. An a Posteriori Error Control Framework for Adaptive Precision Optimization Using Discontinuous Galerkin Finite Element Method. Tese de Doutorado, Massachusetts Inst. of Technology, Cambridge, U. S. Citado na pág. 3

Luo et al. (2006) H. Luo, J. D. Baum e R. Lohner. A p-multigrid discontinuous Galerkin method for the Euler equations on unstructured grids. Journal of Computational Physics, Vol. 211 No. 2:767-783. Citado na pág. 4,5

Meyer (1970) P. L. Meyer. Introductory Probability and Statistical Applications. Addison Wesley, 2nd ed. Citado na pág. 125

Michalak (2009) C. Michalak. Efficient High-Order Accurate Unstructured Finite-Volume Algorithms for Viscous and Inviscid Compressible Flows. Tese de Doutorado, Dept. of Mechanical Engineering, Univ. of British Columbia, Canada. Citado na pág. iii, v, 2, 5, 8, 10, 12, 16, 42, 44, 45, $46,47,119,120$

Michalak e Ollivier-Gooch (2004) C. Michalak e C. F. Ollivier-Gooch. Parallelization of a highorder-accurate unstructured mesh finite volume solver. Em Proceedings of the Twelfth Annual Conference of the Computational Fluid Dynamics Society of Canada. CFD Society of Canada. Citado na pág. 121

Michalak e Ollivier-Gooch (2008) C. Michalak e C. F. Ollivier-Gooch. Limiters for unstructured higher-order accurate solutions of the Euler equations. AIAA, 2008-776. Citado na pág. 46, 47, 78

Michalak e Ollivier-Gooch (2009) C. Michalak e C. F. Ollivier-Gooch. Accuracy preserving limiter for the high-order accurate solution of the Euler equations. Journal of Computational Physics, Vol. 228, No. 23:8693-8711. Citado na pág. 46, 47, 78

Nastase e Mavriplis (2006) C. R. Nastase e D. J. Mavriplis. High-order discontinuous Galerkin methods using an hp-multigrid approach. Journal of Computational Physics, Vol. 213 No. 2: 330-357. Citado na pág. 4, 5

Nejat (2007) A. Nejat. A Higher-Order-Accurate Unstructured Finite Volume Newton-Krylov Algorithm for Inviscid Compressible Flows. Tese de Doutorado, Dept. of Mechanical Engineering, Univ. of British Columbia, Canada. Citado na pág. iii, v, 2, 5, 78

Nejat e Ollivier-Gooch (2008) A. Nejat e C. Ollivier-Gooch. A high-order accurate unstructured finite volume Newton-Krylov algorithm for inviscid compressible flows. Journal of Computational Physics, Vol. 227:2582-2609. Citado na pág. 65

Ollivier-Gooch e Michalak (2011) C. Ollivier-Gooch e C. Michalak. High-order finite-volume discretization of the Euler equations on unstructured meshes. Em Adaptive High-order Methods in Computational Fluid Dynamics, páginas 235-268. Editado por Z. J. Wang (World Scientific Publishing). Citado na pág. 120

Ollivier-Gooch (1995) C. F. Ollivier-Gooch. Multigrid acceleration of an upwind Euler solver on unstructured meshes. AIAA Journal, 33 No. 10:1822-1827. Citado na pág. 47, 56, 57, 75, 76, 78

Ollivier-Gooch e van Altena (2002) C. F. Ollivier-Gooch e M. van Altena. A high-orderaccurate unstructured mesh finite-volume scheme for the advection-diffusion equation. Journal of Computational Physics, Vol. 181, No. 2:729-752. Citado na pág. iii, v, xiii, xiv, 2, 8, 10, 13, 16, 22, 24, 27, 31, 32, 33, 34, 36, 39 
Ollivier-Gooch et al. (2009) C. F. Ollivier-Gooch, A. Nejat e C. Michalak. Obtaining and verifying high-order unstructured finite volume solutions to the Euler equations. AIAA Journal, Vol. 47, No. 9:2105-2120. Citado na pág. 12, 14, 15, 45

Ou et al. (2009) K. Ou, C. Liang, S. Premasuthan e A. Jameson. High-order spectral difference simulation of laminar compressible flow over two counter-rotating cylinders. AIAA Paper, 20093956. Citado na pág. 3

Persson (2011) P.-O. Persson. High-order LES simulations using implicit-explicit Runge-Kutta schemes. AIAA, Paper No. 2011-684. Citado na pág. 121

Persson e Peraire (2009) P.-O. Persson e J. Peraire. Curved mesh generation and mesh refinement using Lagrangian solid mechanics. AIAA, Paper No. 2009-949. Citado na pág. xiii, 4

Premasuthan (2010) S. Premasuthan. Towards an Efficient and Robust High Order Accurate Flow Solver for Viscous Compressible Flows. Tese de Doutorado, Dept. of Aeronautics and Astronautics, Univ. of Stanford, U. S. Citado na pág. 19, 47, 56, 57

Premasuthan et al. (2009) S. Premasuthan, C. Liang, A. Jameson e Z. J. Wang. A p-multigrid spectral difference method for viscous compressible flow using $2 \mathrm{D}$ quadrilateral meshes. AIAA, 2009-950. Citado na pág. 5, 102, 120

Pulliam e Barton (1985) T. H. Pulliam e J. T. Barton. Euler computations of AGARD Working Group 07 airfoil test cases. AIAA, 85-0018. Citado na pág. 78

Roe (1981) P. L. Roe. Approximate riemann solvers, parameter vectors, and difference schemes. Journal of Computational Physics, Vol. 43:357-372. Citado na pág. 44, 47, 84

Rusanov (1961) V. V. Rusanov. Calculation of interaction of non-steady shock waves with obstacles. J Comput Math Phys USSR, 1, No. 2:267-279. Citado na pág. 84

Saad e Schultz (1986) Y. Saad e M. H. Schultz. GMRES: A generalized minimal residual algorithm for solving nonsymmetric linear systems. SIAM J. Sci. Stat. Comp., Vol. 7 No. 3: 856-869. Citado na pág. 120

Saito (2008) O. Saito. Esquema numérico com reconstrução minimos quadrados de alta ordem em malhas não-estruturadas para a formulação euleriana do transporte de partículas. Tese de Doutorado, Instituto de Matemática e Estatística, Universidade de São Paulo, Brasil. Citado na pág. xiii, 9,17

Shu (1988) C. W. Shu. Total-variation-diminishing time discretizations. SIAM J. Sci. Stat. Comput., 9 No. 6:1073-1084. Citado na pág. 19, 39, 85, 120

Shu e Osher (1988) C. W. Shu e S. Osher. Efficient implementation of essentially non-oscillatory shock-capturing schemes. J. Comput. Phy., 77:439-471. Citado na pág. 120

Spiteri e Ruuth (2002) R. J. Spiteri e S. J. Ruuth. A new class of optimal high-order strongstability-preserving time discretization methods. SIAM J. Numer. Anal., Vol. 40:469-491. Citado na pág. $19,39,120$

Stoer e Bulirsch (2002) J. Stoer e R. Bulirsch. Introduction to Numerical Analysis. SpringerVerlag, 3rd ed. Citado na pág. 8, 14, 15, 42

Strikwerda (2004) J. C. Strikwerda. Finite difference schemes and partial differential equations. SIAM, 2nd ed. Citado na pág. 1

Toro (2009) E. Toro. Riemann Solvers and Numerical Methods for Fluid Dynamics. Springer, 3rd ed. Citado na pág. 41,83 
van Altena (1999) M. van Altena. High-order finite-volume discretisations for solving a modified advection-difussion problem on unstructured triangular meshes. Dissertação de Mestrado, Dept. Mechanical Engineering, Univ. British Columbia, Canada. Citado na pág. 13

van den Abeele et al. (2008) K. van den Abeele, C. Lacor e Z. J. Wang. On the stability and accuracy of the spectral difference method. J. Sci. Comput., 37, No. 2:162-188. Citado na pág. 3

van Leer et al. (1989) B. van Leer, C.-H. Tai e K. G. Powell. Design of optimally smoothing multi-stage schemes for the Euler equations. AIAA, Paper 89-1933. Citado na pág. 9, 16, 43, 47, 88, 119,120

Vassberg e Jameson (2010) J. C. Vassberg e A. Jameson. In pursuit of grid convergence for two-dimensional Euler solutions. Journal of Aircraft, 47 No. 4. Citado na pág. 56, 57, 69, 75, 78

Vijayan e Kallinderis (1994) P. Vijayan e Y. Kallinderis. A 3D finite-volume scheme for the Euler equations on adaptive tetrahedral grids. Journal of Computational Physics, 113:249-267. Citado na pág. 43

Vincent e Jameson (2011) P. E. Vincent e A. Jameson. Facilitating the adoption of unstructured high-order methods amongst a wider community of fluid dynamicists. Math. Model. Nat. Phenom., Vol. 6, No. 3:97-140. Citado na pág. 1, 2, 3, 4

Wang (2007) Z. J. Wang. High-order methods for the Euler and Navier-Stokes equations on unstructured grids. Prog. Aerosp. Sci., 43:1-41. Citado na pág. 2

Wang (2014) Z. J. Wang. High-order computational fluid dynamics tools for aircraft design. Phil. Trans. R. Soc. A, 372(20130318). Citado na pág. xiii, 1, 4

Wang (2015) Z. J. Wang. A perspective on high-order methods in computational fluid dynamics. Sci. China-Phys. Mech. Astron., 59(614701). doi: 10.1007/s11433-015-5706-3. Citado na pág. 1, 4, 5,14

Wang et al. (2007) Z. J. Wang, Y. Liu, G. May e A. Jameson. Spectral difference method for unstructured grids II: extension to the Euler equations. J Sci Comput., 32:45-71. Citado na pág. 83,84

Wang et al. (2013) Z. J. Wang, K. Fidkowski, R. Abgrall, F. Bassi, D. Caraeni, A. Cary, H. Deconinck, R. Hartmann, K. Hillewaert, H. T. Huynh, N. Kroll, G. May, P.-O. Persson, B. van Leer e M. Visbal. High-order CFD methods: current status and perspective. Int. J. Numer. Meth. Fluids, 72:811-845. Citado na pág. 9, 16, 43

Yano e Darmofal (2012) M. Yano e D. L. Darmofal. Case C1.3: Flow over the NACA 0012 airfoil: Subsonic inviscid, transonic inviscid, and subsonic laminar flows. Em First international workshop on high-order CFD methods. Citado na pág. 62, 63, 65, 69, 73, 75, 77, 78, 108, 113

Zienkiewicz et al. (2005) O. C. Zienkiewicz, R. L. Taylor e J. Z. Zhu. The finite element method Its basis and fundamentals. Elsevier, 6th ed. Citado na pág. 1 